\title{
Phased Retrofits in Existing Homes in Florida Phase II: Shallow Plus Retrofits
}

K. Sutherland, D. Parker, E. Martin, D. Chasar, and B. Amos

Building America Partnership for Improved Residential Construction 


\section{NOTICE}

This report was prepared as an account of work sponsored by an agency of the United States government. Neither the United States government nor any agency thereof, nor any of their employees, subcontractors, or affiliated partners makes any warranty, express or implied, or assumes any legal liability or responsibility for the accuracy, completeness, or usefulness of any information, apparatus, product, or process disclosed, or represents that its use would not infringe privately owned rights. Reference herein to any specific commercial product, process, or service by trade name, trademark, manufacturer, or otherwise does not necessarily constitute or imply its endorsement, recommendation, or favoring by the United States government or any agency thereof. The views and opinions of authors expressed herein do not necessarily state or reflect those of the United States government or any agency thereof.

This report is available at no cost from the National Renewable Energy Laboratory (NREL) at www.nrel.gov/publications.

Available electronically at SciTech Connect http:/www.osti.gov/scitech

Available for a processing fee to U.S. Department of Energy and its contractors, in paper, from:

U.S. Department of Energy

Office of Scientific and Technical Information

P.O. Box 62

Oak Ridge, TN 37831-0062

OSTI http://www.osti.gov

Phone: 865.576.8401

Fax: 865.576.5728

Email: reports@osti.gov

Available for sale to the public, in paper, from:

U.S. Department of Commerce

National Technical Information Service

5301 Shawnee Road

Alexandria, VA 22312

NTIS http://www.ntis.gov

Phone: 800.553 .6847 or 703.605 .6000

Fax: 703.605.6900

Email: orders@ntis.gov 


\title{
Phased Retrofits in Existing Homes in Florida Phase II: Shallow Plus Retrofits
}

\author{
Prepared for: \\ The National Renewable Energy Laboratory \\ On behalf of the U.S. Department of Energy's Building America Program \\ Office of Energy Efficiency and Renewable Energy \\ 15013 Denver West Parkway \\ Golden, CO 80401 \\ NREL Contract No. DE-AC36-08GO28308 \\ Prepared by: \\ K. Sutherland, D. Parker, E. Martin, D. Chasar, and B. Amos \\ Building America Partnership for Improved Residential Construction \\ 1679 Clearlake Rd. \\ Cocoa, FL 32922
}

NREL Technical Monitor: Stacey Rothgeb

Prepared under Subcontract No. KNDJ-0-40339-05

December 2016 
The work presented in this report does not represent performance of any product relative to regulated minimum efficiency requirements.

The laboratory and/or field sites used for this work are not certified rating test facilities. The conditions and methods under which products were characterized for this work differ from standard rating conditions, as described.

Because the methods and conditions differ, the reported results are not comparable to rated product performance and should only be used to estimate performance under the measured conditions. 


\section{Table of Contents}

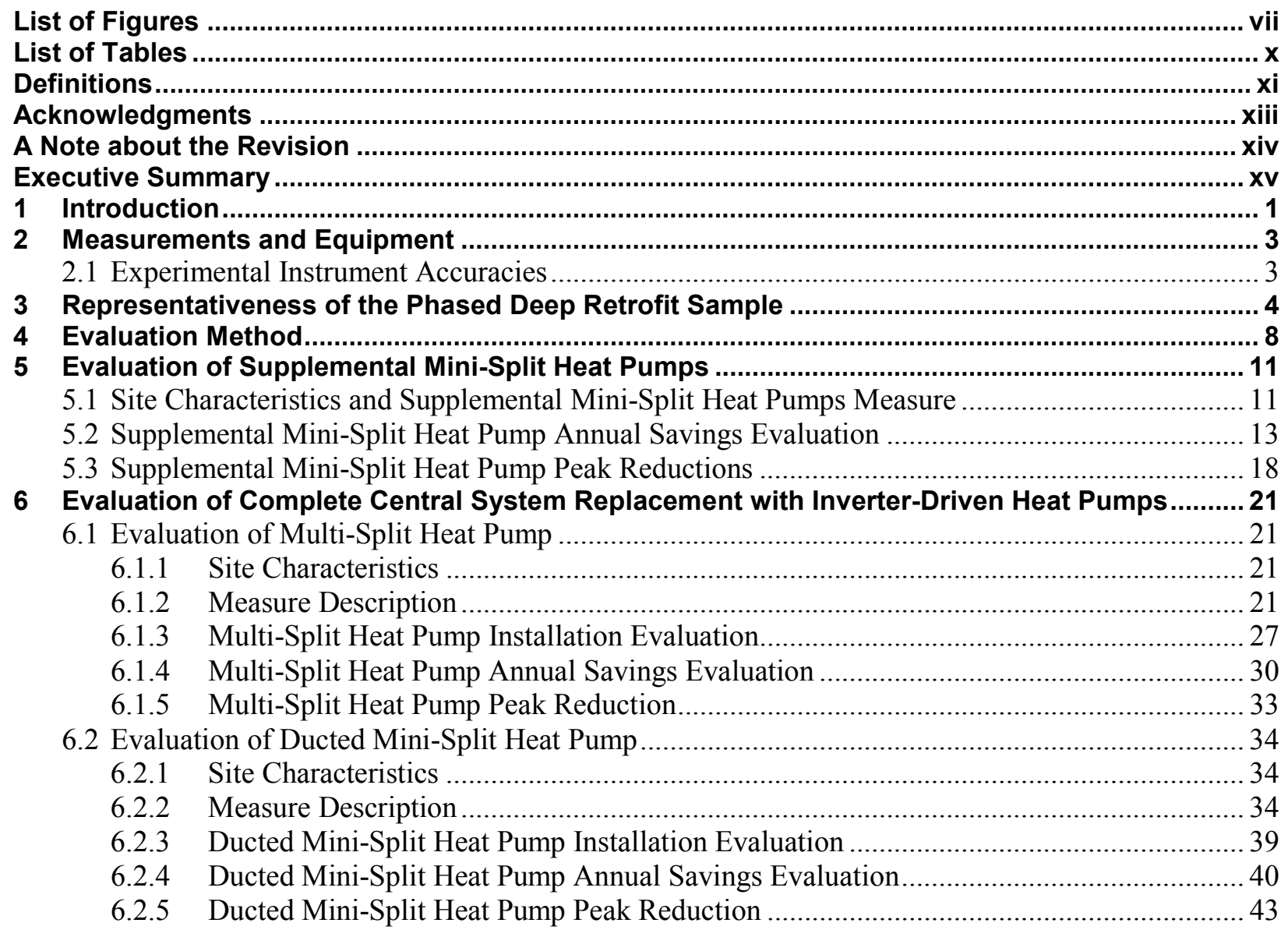

6.3 Lessons Learned from the Complete System Replacements with Inverter-Driven Heat Pumps... 43

7 Evaluation of Ducted and Space-Coupled Heat Pump Water Heaters.........................................45

7.1 Site Characteristics and Space-Coupled Heat Pump Water Heater Measure.................................. 45

7.2 Space-Coupled Heat Pump Water Heater Evaluation.................................................................. 46

7.2.1 Space-Coupled Heat Pump Water Heater Peak Reductions ............................................ 54

8 Evaluation of Exterior Insulation Finish System .....................................................................56

8.1 Characteristics and Exterior Insulation Finish System Retrofit Measure for Site 54 ................. 56

8.2 Exterior Insulation Finish System Space-Cooling Energy Evaluation ....................................... 58

8.3 Exterior Insulation Finish System Space-Heating Energy Evaluation ....................................... 61

8.4 Exterior Insulation Finish System Retrofit Savings Summary ................................................. 63

8.5 Parametric Evaluation of Factors Affecting Wall Insulation Savings in Florida Homes .............. 64

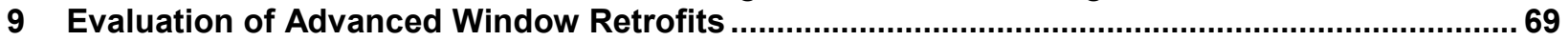

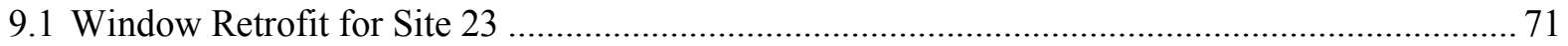

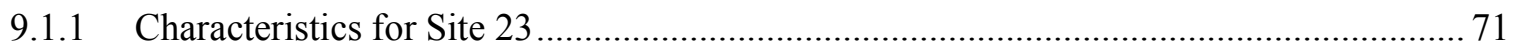

9.1.2 Window Retrofit Space-Cooling Energy Evaluation for Site 23 ................................... 72

9.1.3 Window Retrofit Space-Heating Energy Evaluation for Site 23 .................................. 74

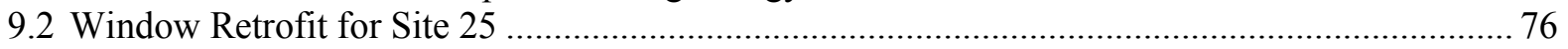

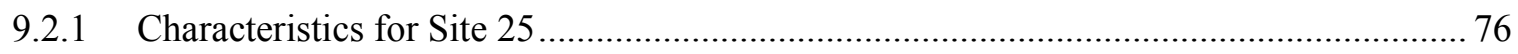

9.2.2 Window Retrofit Space-Cooling Energy Evaluation for Site 25 …............................... 77

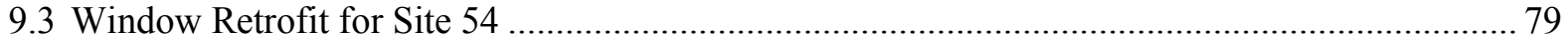

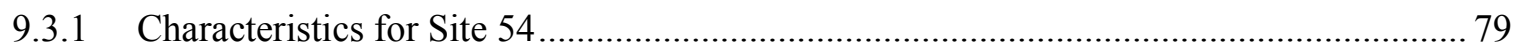

9.3.2 Window Retrofit Space-Cooling Energy Evaluation for Site 54 ..................................... 81 
9.3.3 Preliminary Exterior Insulation Finish System and Window Retrofit Space-Cooling

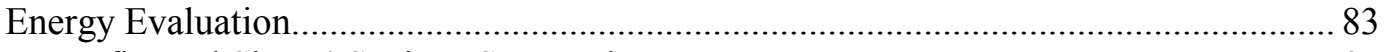

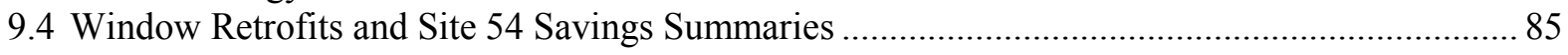

9.5 Parametric Evaluation of Factors Affecting Window Savings in Florida Homes ........................ 87

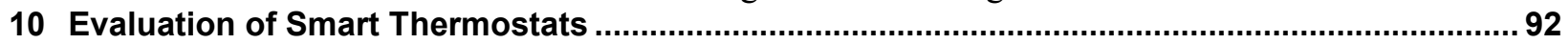

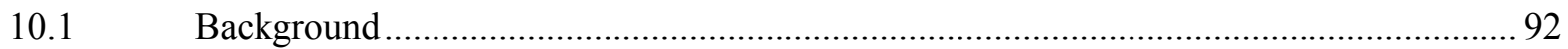

10.1.1 Unrealized Potential with Standard Programmable Thermostats ................................. 92

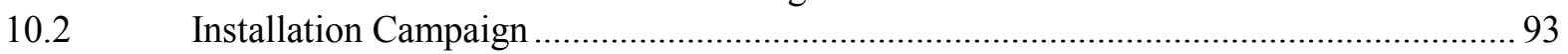

10.3 Observed Time-Related Degradation in Air-Conditioning Performance ........................ 96

$10.4 \quad$ Smart Thermostat Evaluation and Example Analysis.....................................................97

10.4.1 Visual Plot of Cooling and Heating Against Outdoor Temperature During the Length of

the Pre- and Post-Retrofit Periods and Regression Results .............................................. 99

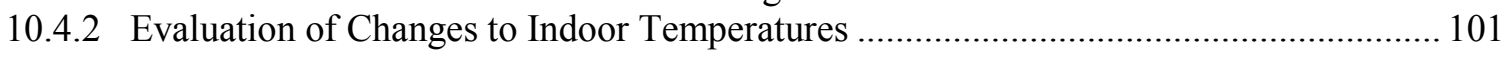

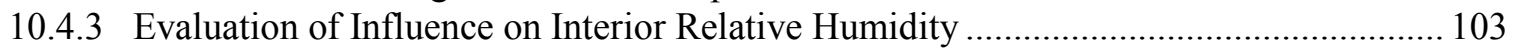

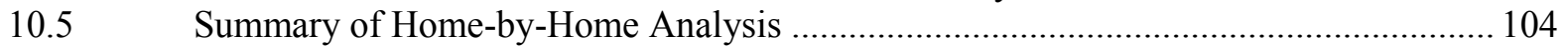

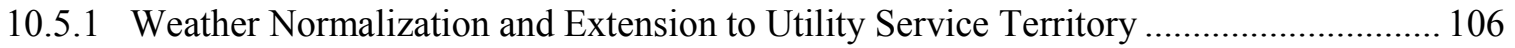

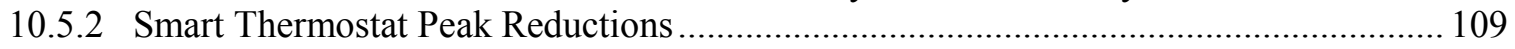

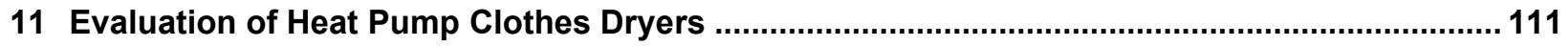

$11.1 \quad$ Heat Pump Clothes Dryer Peak Reductions …........................................................... 115

11.2 Homeowner Complaints and Acceptability Issues ...................................................... 116

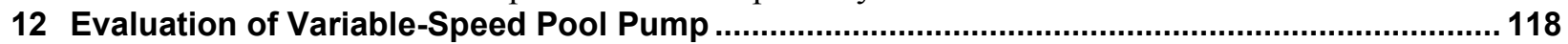

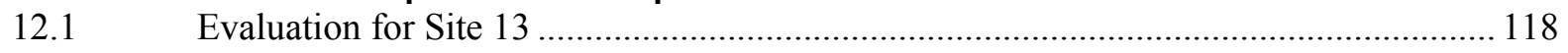

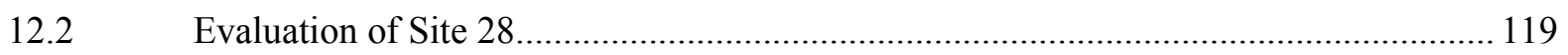

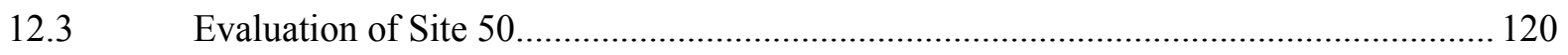

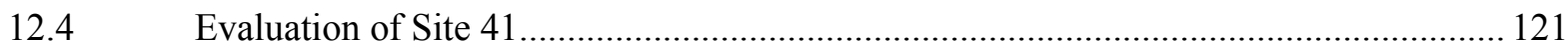

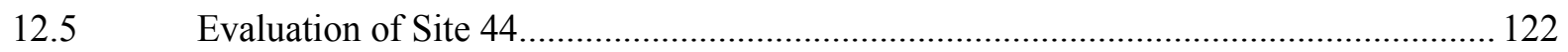

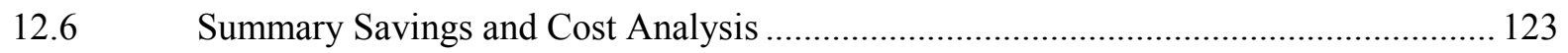

$12.7 \quad$ Variable-Speed Pool Pump Peak Reductions ............................................................... 123

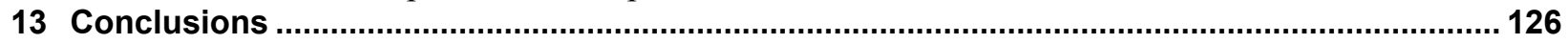

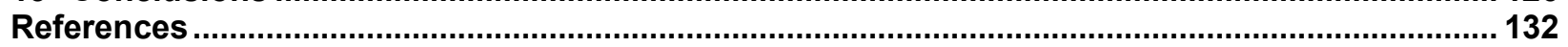

Appendix A: Estimating Florida Residential End-Uses in the PDR Sample ..................................135

Appendix B: Regressions from Analysis of Supplemental Mini-Split Heat Pump Installations ..... 142

Appendix C: Regressions from Ducted Multi-MSHPs and Single-Ducted MSHPs.......................... 143

Appendix D: Regressions from Analysis of Coupled Heat Pump Water Heaters .......................... 144

Appendix E: Regressions from Analysis of Exterior Insulation Finish Systems ..........................145

Appendix F: Regressions from Analysis of Advanced Windows ................................................. 146

Appendix G: Installed Nest Serial and Base Numbers........................................................... 147

Appendix H: Regressions from Analysis of Smart Thermostats ................................................... 148 


\section{List of Figures}

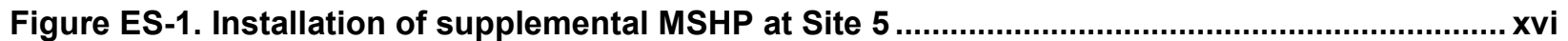
Figure ES-2. Average annual energy savings for the Phase II PDR evaluation measures .............. xxi Figure 1. Comparison of South Florida homes in FPL's service territory to PDR sample.................. 6

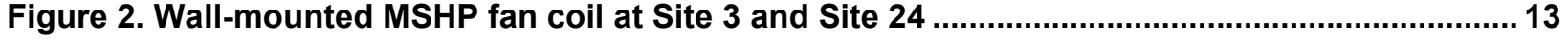

Figure 3. Time series data showing HVAC energy use by air-conditioner compressor (blue), air handling unit and strip heat (orange), and supplemental mini-split (green) for Site $60 \ldots . . . . . . .16$

Figure 4. Regression lines for measured daily cooling before and after supplemental mini-split retrofit at Site 60

Figure 5. Regression lines for measured daily space heating before and after supplemental minisplit retrofit at Site 60

Figure 6. Comparative analysis between pre- and post-retrofit demand on FPL's system peak summer day in 2014 and surrogate peak summer day in 2015

Figure 7. Comparative analysis between pre- and post-retrofit demand on FPL's system peak winter days.

Figure 8. Chosen locations for the wall-mounted fan coil (left) and the ceiling-mounted fan coil and

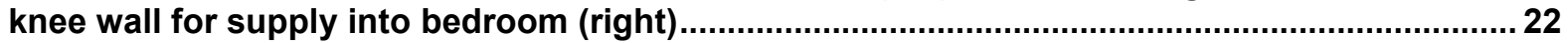

Figure 9. Condenser location, nearby electrical panel, and short exterior line set runs (left);

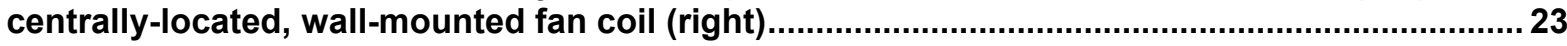

Figure 10. Design sketch of Site 11 multi-split heat pump retrofit .................................................. 23

Figure 11. Dampered collars for four supply ducts attached and sealed to fabricated junction box (left); supply register boots sealed with mastic (right).

Figure 12. Pre-retrofit attic space used for the ceiling-mounted fan coil and supply air ducting (left); penetration into attic to mount the air handling unit (right) ............................................2 25

Figure 13. Fabricated junction box installed above attic hatch (left); return plenum and mini-split fan coil installed above ceiling penetration with seams sealed (right)........................................25

Figure 14. Ceiling-mounted fan coil return grille (left); existing and new supply registers (right) .. 26

Figure 15. Line set tucked into the existing central system duct chase shelf ...................................26

Figure 16. Air barier applied to inside of return plenum .......................................................... 27

Figure 17. Average hourly temperature profile of four interior locations: bedrooms and office serviced by the ducted ceiling mount unit; dining room serviced by wall-mounted unit .......... 28

Figure 18. Hourly RH in the second bedroom pre- and post-retrofit............................................29 Figure 19. Daily average HVAC energy, indoor and outdoor conditions from May 1, 2015, through August 31, 2015, for Site 11

Figure 20. Comparative analysis between pre- and post-retrofit demand on FPL's system peak

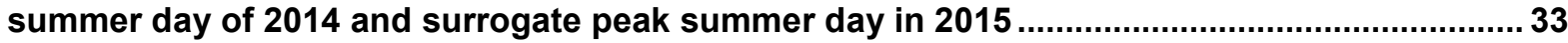

Figure 21. Ducted MSHP installation site. The arrow indicates the new fan coil location................ 34

Figure 22. Looking up at installed fan coil unit unframed (left) and framed (right) .......................... 35

Figure 23. Design sketch of Site 61 ducted MSHP ............................................................................ 36

Figure 24. Construction of living room and kitchen supply air duct (left); fabricated ducts installed and sealed with mastic (right)

Figure 25. Bedroom view showing both the MSHP and the original central system supply grilles (left); sealed wall penetrations (right)......................................................................................... 37

Figure 26. Finished ducted MSHP installation: ductwork (left and upper right) and fan coil (lower

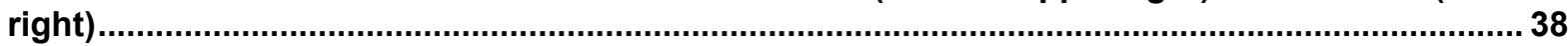

Figure 27. Pre- and post-retrofit room-by-room RH ................................................................. 40

Figure 28. Daily average HVAC energy, indoor and outdoor conditions from June 1, 2015, through

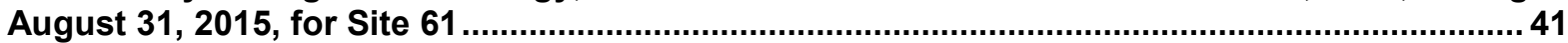

Figure 29. Comparative analysis between pre- and post-retrofit demand on FPL's system peak

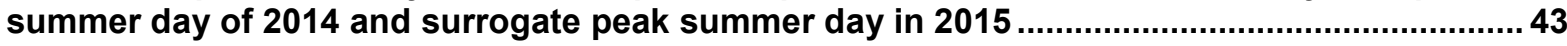

Figure 30. HPWH configurations: interior GE unit in utility room at Site 13 (left); ducted Air Generate unit at Site 5 (center); ducted A.O. Smith unit at Site 26 (right) .................................. 46

Figure 31. Parallel regression lines for Site 9 ............................................................................... 48

Figure 32. Post-retrofit composite average day's water-heating power for sites 1, 9, 13, and $26 \ldots . .48$ 
Figure 33. Cooling regression showing convergence for Site 5

Figure 34. Post-retrofit composite average day's water-heating power for sites 5, 50, 51, and 56.. 49

Figure 35. Heating regression for Site 5 ...

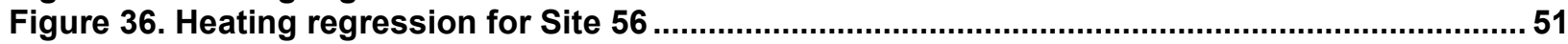

Figure 37. Y-type ducting arrangement at Site 5 allowing cold exhaust air to be diverted from the conditioned living environment

Figure 38. Comparative analysis between pre- and post-retrofit demand on FPL's system peak summer day of 2014 and surrogate peak summer day in 2015

Figure 39. Comparative analysis between pre- and post-retrofit demand on FPL's system peak winter days.

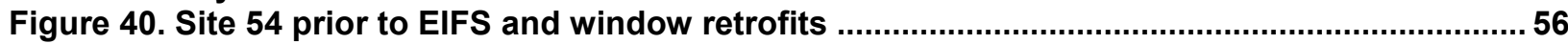

Figure 41. Attachment of 2-in. polystyrene insulation (top left), final textured coat application (top

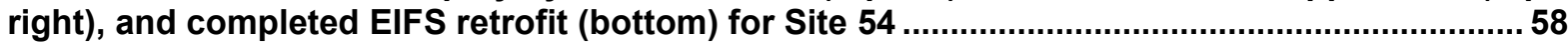

Figure 42. Regression lines for space-cooling pre- and post-EIFS retrofit for Site $54 \ldots . . \ldots \ldots \ldots \ldots . . . . .59$

Figure 43. Pre- and post-EIFS retrofit indoor and outdoor temperature profiles for cooling season observations for Site 54 .

Figure 44. Regression lines for space-heating pre- and post-EIFS retrofit for Site $54 \ldots . . \ldots \ldots \ldots \ldots . . . . . .61$

Figure 45. Pre- and post-EIFS retrofit indoor and outdoor temperature profiles for heating season observations for Site 54

Figure 46. Prototypical PDR residence rendered in BEopt with no adjacent home as at Site 54 .... 65

Figure 47. Estimated savings from standard uninsulated block walls (Point 5) compared to the addition of R-7.7 expanded polystyrene on exterior; $75^{\circ} \mathrm{F}$ set point with 1.5 times normal plug loads

Figure 48. Window retrofit for Site 23: pre-retrofit with existing single-pane, metal-framed windows (left); post-retrofit with double-pane, vinyl-frame windows (right) ...........................................72

Figure 49. Regression lines for space-cooling pre- and post-window retrofit for Site 23 ............... 73

Figure 50. Pre- and post-window retrofit indoor and outdoor temperature profiles for cooling

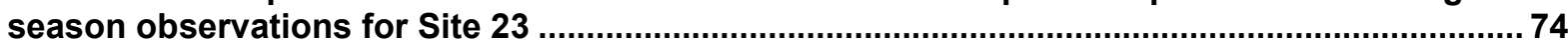

Figure 51. Regression lines for space-heating pre- and post-window retrofit for Site 23 ...............75

Figure 52. Pre- and post-retrofit indoor and outdoor temperature profiles for heating season

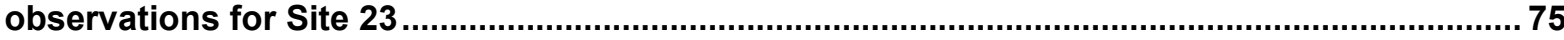

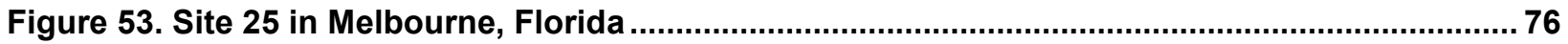

Figure 54. Regression lines for space-cooling pre- and post-window retrofit for Site 25 ...............78

Figure 55. Pre- and post-window retrofit indoor and outdoor temperature profiles for cooling

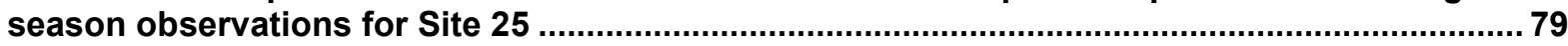

Figure 56. Site 54 after the EIFS and window retrofit ................................................................ 81

Figure 57. Regression lines for space-cooling pre- and post-window retrofit for Site 54 ............... 82

Figure 58. Pre- and post-window retrofit indoor and outdoor temperature profiles for cooling season observations for Site 54

Figure 59. Regression lines for space-cooling pre- and post-EIFS and window retrofit for Site 5484

Figure 60. Pre- and post-EIFS and window retrofit indoor and outdoor temperature profiles for cooling season observations for Site 54

Figure 61. Prototypical PDR residence rendered in BEopt with adjacent home on either side ....... 88

Figure 62. Estimated savings from single-glazed windows (Point 1) compared to double-glazed, low-e, solar-control windows, with a set point of $81^{\circ} \mathrm{F}$ and two times normal plug loads .......... 89

Figure 63. The Nest learning thermostat installed at one of the PDR sites showing the redundant temperature and humidity measurement.

Figure 64. Observed cooling efficiency related degradation at Site 22 from 2013-2014. Note the higher trend of cooling energy regressed against outdoor temperature in $2014 \ldots \ldots \ldots \ldots \ldots \ldots . . . . . . .96$

Figure 65. Cooling performance at Site 22 from 2013-2014 regressed against difference in outdoor

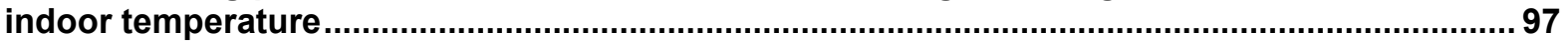

Figure 66. Existing thermostat, a Trane XT500C programmable model, at Site 28........................ 98 Figure 67. Interior temperature and local National Weather Service outdoor temperature from July 2013-July 2015 at Site 28.

Figure 68. Compressor and air handling unit power from July 2013-July 2015 for Site 28 ............ 99

Figure 69. Daily HVAC kWh during the year-long period regressed against outdoor temperature at 
Site 28. Zeros are pre-retrofit period; 1s are post. Brown triangles show air handling unit

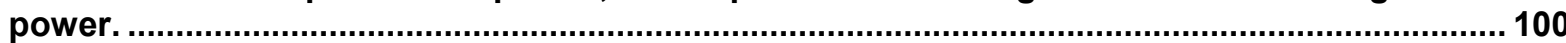

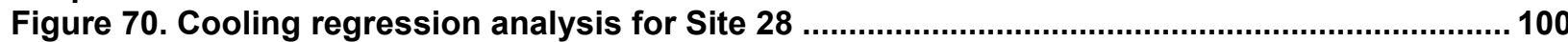

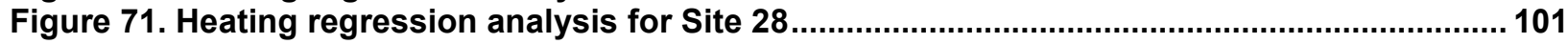

Figure 72. Pre- and post-retrofit cooling season interior temperatures regressed against outdoor

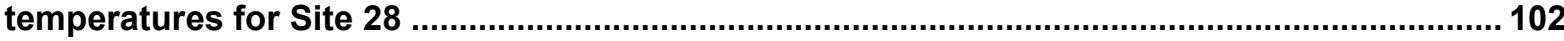

Figure 73. Pre- and post-retrofit heating season interior temperatures regressed against outdoor

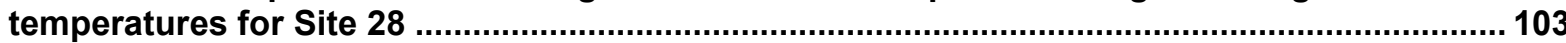

Figure 74. Installed Nest and broadband temperature and RH measurement by thermostat at Site 16

Figure 75. Pre- (green) and post-retrofit (brown) temperatures at Site 59 regressed against the daily outdoor temperature. Note the two-week period with higher set points with the Nest in the upper right.

Figure 76. Summer peak: comparative analysis between pre- and post-retrofit demand on FPL's

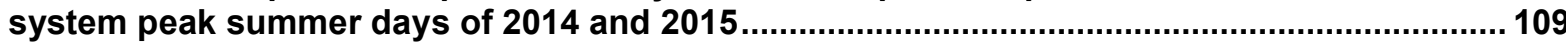

Figure 77. Winter peak: comparative analysis between pre- and post-retrofit demand on FPL's

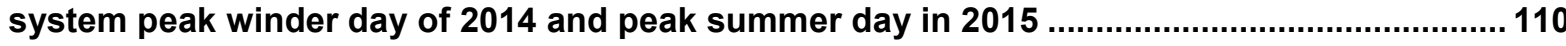

Figure 78. Energy Guide label for WFW95HED washer

Figure 79. Building America Partnership for Improved Residential Construction team member Bryan Amos awaits shipment to one of the HPCD retrofit homes in the PDR project in May 2015

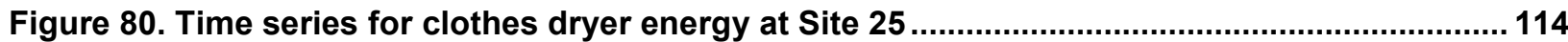

Figure 81. Comparative analysis between pre- and post-HPCD clothes drying demand ...............116

Figure 82. Laundry room dry bulb and dew point temperatures pre- and post-unvented heat pump clothes dryer installation for Site 25

Figure 83. Average time-of-day pool pump demand at Site 13 as originally found (blue) and after VSPP retrofit (green)

Figure 84. Average time-of-day pool pump demand at Site 28 as originally found (blue) and after VSPP retrofit (green)

Figure 85. Average time-of-day pool pump demand at Site $\mathbf{5 0}$ as originally found (blue) and after VSPP retrofit (green)

Figure 86. Average time-of-day pool pump demand at Site 41 as originally found (blue) and after VSPP retrofit (green)

Figure 87. Average time-of-day pool pump demand at Site 44 as originally found (blue) and after VSPP retrofit (green)

Figure 88. Summer peak: comparative analysis between pre- and post-retrofit demand on FPL's system peak summer day of 2014 and 2015.

Figure 89. Winter peak: comparative analysis between pre- and post-retrofit demand on FPL's system peak summer day of 2014 and 2015.

Figure A-1. Estimated End Uses of FPL Residential Homes (mixed): 2013 .................................139

Figure A-2. Estimated End Uses of FPL Residential Homes (non-pool homes): 2013 ................... 139

Figure A-3. Estimated End Uses of FPL Residential Homes (pools): 2013................................ 140 


\section{List of Tables}

Table ES-1. Phase II PDR Measured Evaluation Savings ..............................................................

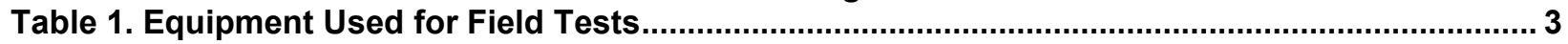

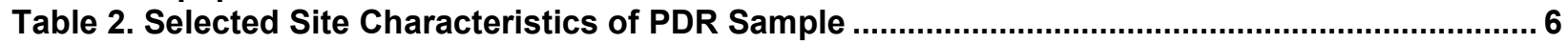

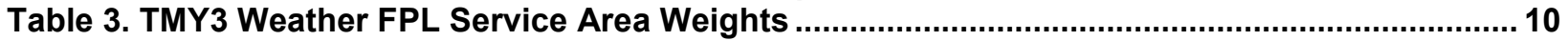

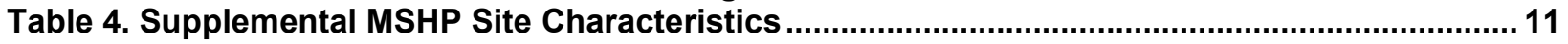

Table 5. Supplemental MSHP Site Existing HVAC Characteristics................................................. 12

Table 6. TMY3-Normalized Cooling Energy Use and Savings from the Supplemental MSHP Sites 14

Table 7. TMY3-Normalized Heating Energy Use and Savings from the Supplemental MSHP Sites. 15

Table 8. TMY3-Normalized Annual Cooling and Heating Energy Use and Savings from the

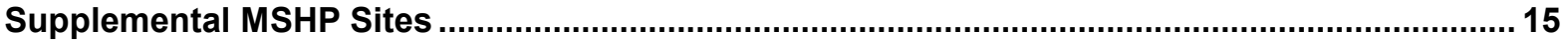

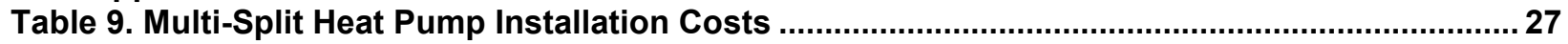

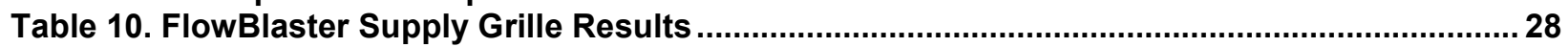

Table 11. Multi-Split Heat Pump Space-Conditioning Energy Savings .......................................... 32

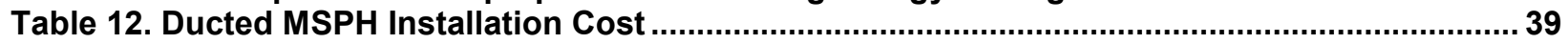

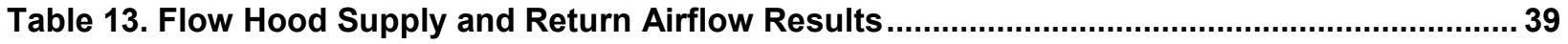

Table 14. Ducted MSHP Space-Conditioning Energy Savings........................................................ 42

Table 15. HPWH Retrofit Site Characteristics ................................................................................. 45

Table 16. Space-Coupled HPWH Installation and Commissioning Summary ...................................46

Table 17. Cooling Analysis Results for Conditioned Space-Coupled HPWH Retrofits ..................... 47

Table 18. Heating Analysis Results for Conditioned Space-Coupled HPWH Retrofits ....................50

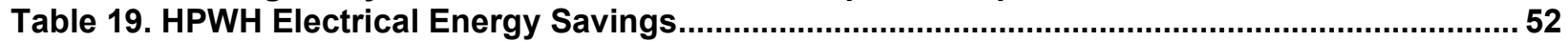

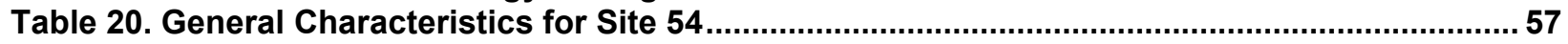

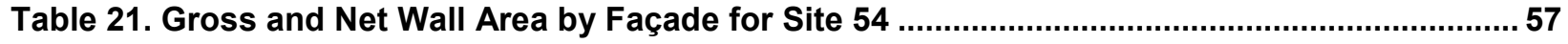

Table 22. Average Daily Interior Temperatures, Internal Gains, and Solar Insolation Pre- and Post-

EIFS Retrofit Evaluation Periods for Site 54 ................................................................... 59

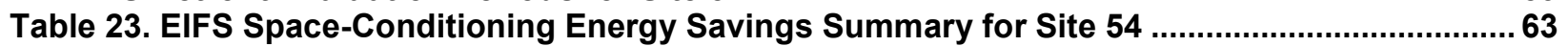

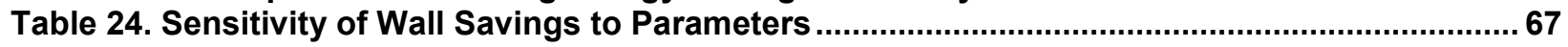

Table 25. General and HVAC Characteristics of the Wind Retrofit Sites .......................................69

Table 26. Average Daily Interior Temperatures, Internal Gains, and Solar Insolation Pre- and Post-

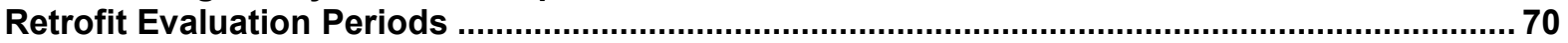

Table 27. As-Found Glazing and Shading Characteristics for Site 23 ........................................ 71

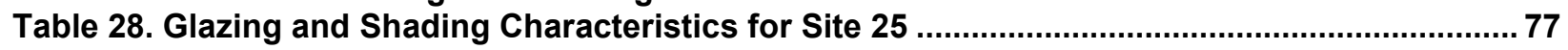

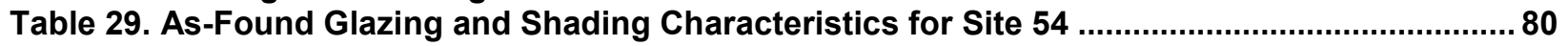

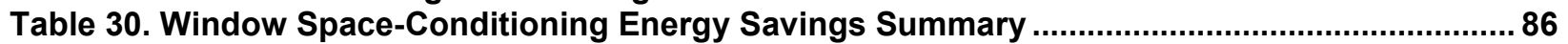

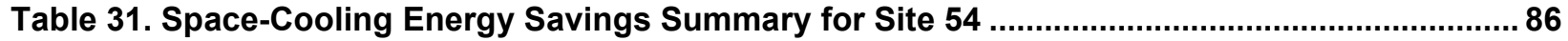

Table 32. Parametric Evaluation of Influences on Savings from Advanced Windows in Florida..... 90

Table 33. Smart Thermostat General Site Characteristics............................................................. 94

Table 34. Thermostat Replacement Site HVAC Characteristics.................................................... 95

Table 35. Nest Thermostat Evaluations: Florida PDR Project 2013-2016 ................................. 105

Table 36. Weather-Normalized Nest Thermostat Projections: Florida PDR Project 2013-2016 ..... 106

Table 37. HPCD Site Characteristics ............................................................................................. 111

Table 38. Average Daily Baseline Dryer Energy by Month for 45-Home Sample for 2013 ............. 111

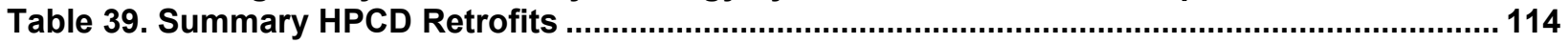

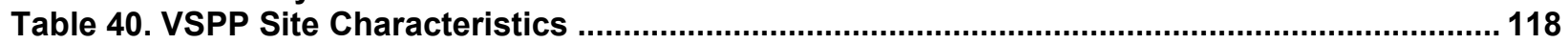

Table 41. Measured Pool Pump Energy for Site 13 ...................................................................... 118

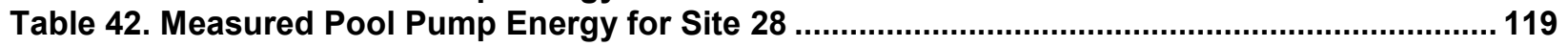

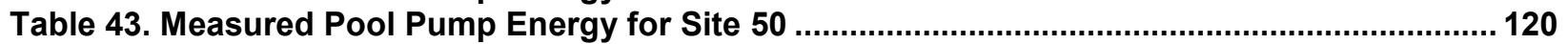

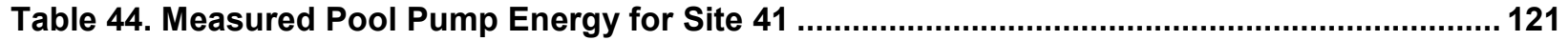

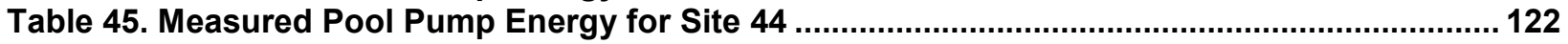

Table 46. Phase I and Phase II PDR Measures Evaluation Savings Summary .............................. 130

Table A-1. Average Raw kWh/day for Sites by End Uses in PDR Sample for 2013........................ 136 


\section{Definitions}

AC

ACH50

ASHRAE

BEopt

Btu

CFL

CFM

CMU

COP

Delta $\mathrm{T}$

DHW

DOE

EIFS

FPL

FSEC

$\mathrm{ft}^{2}$

$\mathrm{ft}^{3}$

GE

FL-HES

hp

HPCD

HPWH

HSPF

HVAC

kWh

LED

MSHP

$\mathrm{Pa}$

PDR

Qn,out

$\mathrm{R}^{2}$

$\mathrm{RH}$

R-Value (R-n)

SEER

SHGC
Air conditioning

Air changes per hour at $50 \mathrm{~Pa}$

American Society of Heating, Refrigerating and Air-Conditioning Engineers, Inc.

Building Energy Optimization software

British thermal unit

Compact fluorescent lamp

cubic feet per minute

Concrete masonry unit

Coefficient of performance

Outdoor temperature minus indoor temperature, in degrees Fahrenheit

Domestic hot water

U.S. Department of Energy

Exterior insulation finish system

Florida Power \& Light Company

Florida Solar Energy Center

square foot

cubic foot

General Electric

Florida home energy survey

horsepower

Heat pump clothes dryer

Heat pump water heater

Heating seasonal performance factor

Heating, ventilating, and air conditioning

Kilowatt-hour

Light-emitting diode

Mini-split heat pump

Pascal

Phased deep retrofit

Duct leakage measured at a test pressure of negative $25 \mathrm{~Pa}$ with respect to the outside, divided by the building's conditioned floor area Coefficient of determination

Relative humidity

Thermal resistance measure

Seasonal energy efficiency ratio

Solar heat gain coefficient 
Tamb

Tint

TMY3

U-value

VSPP

W

Wh
Ambient temperature

Interior temperature

Typical metrological year 3

Heat transfer rate

Variable-speed pool pump

Watt

Watt-hour 


\section{Acknowledgments}

This report describes collaborative research between Florida Power \& Light Company and the U.S. Department of Energy, Office of Energy Efficient and Renewable Energy, Building America Program.

Many individuals and organizations are needed to complete such a large project with meaningful research results. Great thanks are due to the patient homeowners of the 53 research sites who have had a 3-year involvement in the project. Also, we extend appreciation to our colleagues who assisted with project measure installations and data acquisition: David Hoak, Joseph Montemurno, John Sherwin, David Beal, and Carlos Colon. Thank you to Wanda Dutton for her administrative support throughout the project and help preparing this report. The authors also recognize the internal technical review provided by Chuck Withers.

Discounted and donated equipment from the following individuals and companies improved the reach of the phased deep retrofit project: great thanks to Karl Gorbet, Steve Cormier of Panasonic Corporation, and Heather Hsi of Dynatherma Resources, Inc. for mini-split heat pumps; to Jeff Farlow of Pentair Aquatic Systems for variable-speed pool pumps; and to Chuck Hall and Sean Southard of Whirlpool Corporation for ENERGY STAR ${ }^{\circledR}$ clothes dryers and washing machines.

The following companies assisted with the retrofit process: Aladdin's Magic Plumbing \& Air; Atlantic Glass Systems, Inc.; Del-Air LLC; Durham \& Sons, Inc.; Eagle Finishes, Inc.; Emergency Plumbing Services, Inc.; G\&J Pool Remodeling, Inc.; Grand Electric, Inc.; Jeff Wilson Pool Service, Inc.; Patriot Property Services; and Precision AC of Brevard, Inc.

Special thanks to Craig Muccio of Florida Power \& Light Company for his overall support as well as assistance with the research direction for the project. 


\section{A Note about the Revision}

Originally published in February 2016, this revision contains an added section called "Evaluation of Complete Central System Replacement with Inverter-Driven Heat Pump," which presents the designs and energy savings evaluations of two different schemes wherein inverter-driven systems replaced a home's existing central system. Analyses for three additional retrofit measures were bolstered by longer-term data; these are described in the sections on supplemental mini-split heat pumps (MSHPs), smart thermostats, and heat pump clothes dryers. The sections on supplemental MSHPs and smart thermostats were also enhanced with larger sample sizes and projections of weather-normalized annual energy savings. Finally, peak system hour energy demand-reduction predictions are provided for all retrofit measures where meaningful impacts could be drawn. 


\section{Executive Summary}

The U.S. Department of Energy Building America team Partnership for Improved Residential Construction is collaborating with Florida Power \& Light Company (FPL) to conduct a phased residential energy-efficiency retrofit program. This research seeks to determine the impacts on annual energy reductions from the installation of advanced residential technologies. Earlier project work involving the application of two levels of retrofit - shallow and deep-found average savings of $9 \%$ and $38 \%$, respectively. Whole-house demand reduction among the deep retrofit homes averaged 39\% during FPL's peak summer hour. These savings levels approach the Building America program goals of reducing whole-house energy use of existing homes by $40 \%$.

Phase II of the phased deep retrofit (PDR) project includes single retrofit measures applied to shallow retrofitted homes that could be used to refine the deep retrofit package and identify technologies less well proven. This process is also known as "shallow-plus" retrofitting. Phase II involves the installation of eight energy-efficiency retrofit measures among a subsample of 41 of the larger study's 53 existing all-electric homes. This report summarizes end-use energy savings, economic evaluation results, and fundamental findings from the individual measures.

The Central Florida and South Florida homes were built between 1955 and 2006, average approximately $1,700 \mathrm{ft}^{2}$ in conditioned area, and have an average occupancy of 2.4 persons. Total house power as well as very detailed energy end-use data are collected to evaluate energy reductions and the economics of each retrofit. All of the studied homes were audited and instrumented during the second half of 2012, and shallow retrofits were conducted from MarchJune 2013. The retrofit energy-reduction measures for the shallow installed measures included those for lighting (compact fluorescent and light-emitting diode lamps), domestic hot water (water heater tank wraps and low-flow showerheads), refrigeration (cleaning coils), pool pumps (reducing operating hours), and using "smart plugs" for home entertainment centers.

To assess new technology and energy-saving techniques not previously tested, the following retrofit measures were applied to homes that received the shallow retrofit only:

- Supplemental mini-split heat pump (MSHP) (10 homes)

- Complete central system replacement with inverter-driven heat pump (2 homes)

- Ducted and space-coupled heat pump water heater (HPWH) (8 homes)

- Exterior insulation finish system (EIFS) (1 home)

- Window retrofit (3 homes)

- Smart thermostat (27 homes: 25 Nests, 2 Lyrics)

- Heat pump clothes dryer (HPCD) (8 homes)

- Variable-speed pool pump (VSPP) (5 homes).

\section{Supplemental Mini-Split Heat Pump}

Ductless MSHPs have no duct system and often have high efficiency levels that may allow for substantial savings. One-ton, high-efficiency, 25.5 seasonal energy efficiency ratio (SEER), 12 
heating seasonal performance factor, ductless MSHPs were installed in the main living area of 10 Central Florida homes. This specific unit was chosen for the testing because it was from the largest volume residential MSHP manufacturer that also had the highest efficiency units in the 1ton size. One ton was chosen as a reasonable size for a supplemental system and because SEER is reduced with larger systems. Good support from the manufacturer relative to installation and setup practices was also obtained. The supplemental MSHPs were installed with the goal of reducing space-heating and space-cooling energy by reducing the run time of the less-efficient existing central system. Figure ES-1 is an example installation at Site 5.

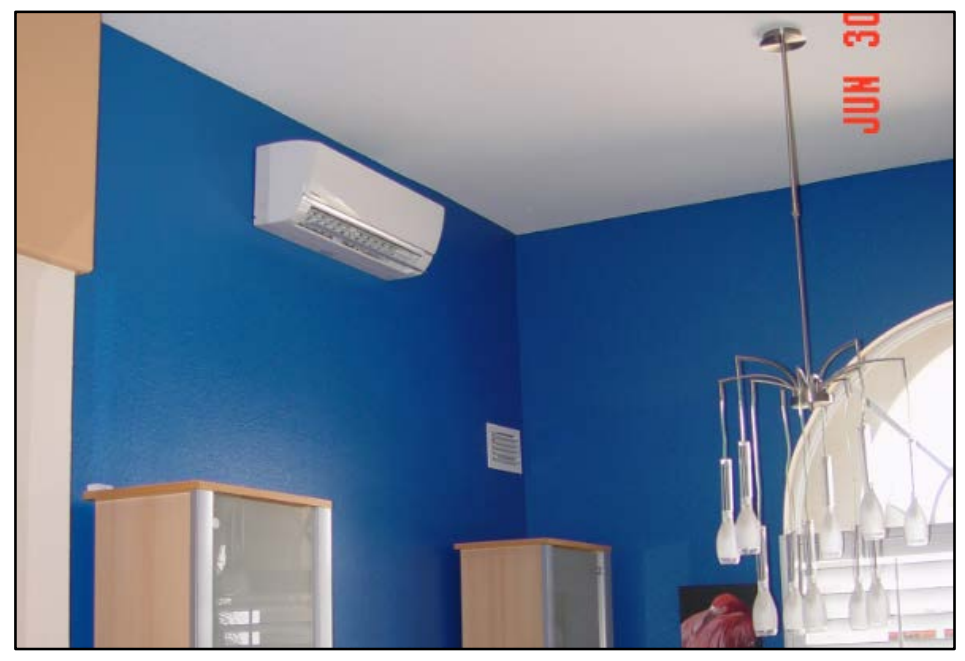

Figure ES-1. Installation of supplemental MSHP at Site 5

Results suggest cooling energy use savings of $32.7 \%(2,007 \mathrm{kWh} /$ year or $7.0 \mathrm{kWh} /$ day $)$ and heating energy use savings of $58.8 \%(390 \mathrm{kWh} /$ year or $6.8 \mathrm{kWh} /$ day $)$, for a total annual savings of $34.2 \%$. The average percent heating energy reductions were considerably greater than cooling for the six homes with electric resistance central heating. The cost-benefit analysis for this measure appears attractive with a payback of 14 years and an annual rate of return of $7.3 \%$. Improved economics are expected as the MSHP market continues to mature because a large part of costs were associated with installation. A large added benefit to the consumer is a redundant heating and cooling system - highly desirable given the failure rate of central systems, which tend to be replaced every 12 years and serviced even more often. Electrical demand reductions during peak system hour were $0.50 \mathrm{~kW}(16 \%)$ for summer and $2.06 \mathrm{~kW}(56 \%)$ for winter.

\section{Complete Central System Replacement with Inverter-Driven Heat Pump}

Two different schemes using inverter-driven heat pumps for complete replacement of a home's existing central system were evaluated to provide insight into contrasting solutions. One was a multi-split design that showed cooling energy use savings of $37.4 \%(2,250 \mathrm{kWh} /$ year or 7.8 $\mathrm{kWh} /$ day). Heating energy use showed negative savings of $1.0 \%$ (5 kWh/year). However, there was considerably large take-back on interior temperature, that is a "taking back" of some of the post-retrofit energy efficiency gains for improved comfort. Nevertheless, this installation proved challenging for the installation contractor and highlighted unresolved comfort issues that should be considered before wide-market adoption in the hot-humid climate. 
The second installation involved a ducted mini-split design. Space-conditioning energy use reduction was large, totaling $38.3 \%(1,548 \mathrm{kWh} /$ year), comprising $29.2 \%$ (948 $\mathrm{kWh} /$ year or 3.5 $\mathrm{kWh} /$ day) for cooling and $76.0 \%(601 \mathrm{kWh} /$ year or $6.7 \mathrm{kWh} /$ day $)$ for heating. Most significant are the improvements to the interior conditions - with large reductions in RH (5.3\%) during the cooling season and with higher summertime and lower wintertime thermostat set points. With an installation price of approximately $\$ 9,100$, measure economics are attractive if installed upon the expiration of the existing system. Electrical demand reductions during peak summer system hour for the two installations were $0.24 \mathrm{~kW}(11 \%)$ and $0.70 \mathrm{~kW}(41 \%)$, respectively.

\section{Ducted and Space-Coupled Heat Pump Water Heater}

In the Phase I project, results showed that HPWHs saved approximately $66 \%$ of the energy needed to heat water with an electric resistance system. HPWHs create a quantity of cooled and dehumidified air from the compressor section of the unit as a by-product of their operation. Eight Central Florida homes were retrofitted with an HPWH coupled to the conditioned living space to determine its effect on space-conditioning and water-heating energy in a cooling-dominated climate. Two different HPWH configurations were evaluated: interior-located (three homes) and attached garage-located with ducting to conditioned space (five homes).

Results for the eight Central Florida homes retrofitted with an HPWH coupled to the conditioned living space show median space-cooling energy savings of $8.2 \%(1.1 \mathrm{kWh} /$ day $)$. Meanwhile, space-heating energy use increased by $8.9 \%$ - although with considerable variation among homes. Among the six homes in which an electric resistance-type tank was replaced with an HPWH coupled to the conditioned space, median domestic hot water (DHW) energy savings were $53.3 \%$ (3.2 kWh/day). Data collected from the two sites at which the effect of the coupling on DHW energy use was isolated show that the coupling reduced potential DHW energy savings from a garage-located HPWH by $0.4 \mathrm{kWh} /$ day or $10.6 \%$. Annual cooling energy savings for the ducted sites yielded a simple payback of approximately 13 years. An average heating energy penalty that extends payback to nearly the expected 20-year life span of the ducting exhibits fairly poor economics for the ducted proposition. This penalty could be reduced or eliminated with a damper system that enables cold HPWH exhaust air to be diverted from the conditioned space during winter. Aside from the premium for the HPWH itself, there is no cost associated with locating an HPWH inside the conditioned space (unless plumbing needs to be rerouted). In this case, net savings on space conditioning and water heating are immediately realized, but the noise level of the operating HPWH may exact another hurdle to acceptance. Electrical demand reductions during peak system hours were $0.23 \mathrm{~kW}(7 \%)$ for summer and $0.18 \mathrm{~kW}(5 \%)$ for winter.

\section{Exterior Insulation Finish System}

The idea of heavily insulating walls in the many existing Florida homes of concrete block construction is a very commonly envisioned energy-savings measure, but what are the actual savings? During Phase II, an EIFS was evaluated in which insulation with an R-value of $7.7 \mathrm{hr}-$ $\mathrm{ft}^{2}-{ }^{\circ} \mathrm{F} / \mathrm{Btu}$ was added to the exterior walls of a Central Florida home. Space-cooling evaluation results predict energy use savings of $18.2 \%\left(5.0 \mathrm{kWh} /\right.$ day at $\left.80^{\circ} \mathrm{F}\right)$. Heating energy use was also evaluated and showed slightly negative savings. Little significance can be attached to the results, however, given very poor statistical models resulting from Florida's short and highly variable heating season. At a cost of nearly $\$ 20,000$, the EIFS retrofit is not a cost-effective proposition for Florida's climate. However, other benefits associated with the measure- such as better 
interior comfort and a stable interior temperature - might justify this measure. Given the poor statistical modeling, the EIFS evaluation was bolstered with a simulation analysis to see how occupancy behavior and integral gains influence results. That evaluation also showed marginal economics for Florida's climate.

\section{Advanced Window Retrofit}

Many Florida homes have standard single-glazed windows with no solar-control characteristics. Modern high-performance windows are widely available but not often used. To evaluate potential energy savings, high-efficiency window retrofits were conducted on three Central Florida homes with single-pane, metal-framed windows. The replacement windows had solar heat gain coefficients ranging from $0.19-0.24$ and window thermal conductivity (U-values) ranging from $0.27-0.30 \mathrm{Btu} / \mathrm{ft}^{2}-{ }^{\circ} \mathrm{F}$. Cooling season energy savings ranged from negative $4.8 \%$ to positive $27.0 \%\left(-0.7-6.9 \mathrm{kWh} /\right.$ day at $\left.80^{\circ} \mathrm{F}\right)$. Heating energy savings of $6.8 \%(4.2 \mathrm{kWh} /$ day at $50^{\circ} \mathrm{F}$ ) were found at the single home evaluated during a winter. Limited observations for many of these evaluations, however, yield low confidence in the heating results. Moreover, the cost of the windows retrofits $(\$ 8,000-\$ 10,000)$ does not make this measure a cost-effective energyefficiency proposition in Florida. However, consumers find the retrofit attractive because of the improvements to house appearance, thermal comfort, and acoustic qualities. Given statistical modeling difficulty, simulation analysis was conducted to help improve understanding of the results, and it showed typical predicted savings levels of approximately $8.6 \%$ annually but still with marginal economics.

\section{Smart Thermostat}

Cooling and heating in Florida are the largest energy end uses: nearly 6,000 kWh/year and heating, ventilating, and air-conditioning (HVAC); thus system control is always important to reducing annual energy use. "Smart" thermostats regulate the home temperature by selfprogramming depending on heuristic evaluation of user control habits as well as sensed homeowner occupancy. Evaluations of 22 of the Nest installations showed that average savings for space cooling was $9.6 \%$ (498 $\mathrm{kWh} /$ year or $2.1 \mathrm{kWh} /$ day — but with a very high degree of variation. The median savings were $6.3 \%(219 \mathrm{kWh} /$ year or $1.0 \mathrm{kWh} /$ day $)$. Six of the 22 sites experienced negative savings, which was largely an artifact of pre-retrofit thermostat habits. However, on average the positive savings were larger in magnitude than the absolute difference in sites experiencing negative savings. Space-heating savings from the Nests were also highly variable - particularly given the very short Florida winter heating season. Average savings were $9.5 \%(39 \mathrm{kWh} /$ year or $1.1 \mathrm{kWh} /$ day $)$, although the median was higher at $18.5 \%(35 \mathrm{kWh} /$ year or $1.9 \mathrm{kWh} /$ day). Simple payback based on median savings for the Nest is estimated to be approximately 4 years with an annual rate of return of $24 \%$. Electrical demand reductions during peak system hours were $0.18 \mathrm{~kW}(7 \%)$ for summer and $0.25 \mathrm{~kW}(14 \%)$ for winter.

On a site-by-site basis, the study found that preinstallation thermostat behavior and consumers' willingness to use available Nest features made a difference. In particular, defeating the occupancy-sensing "away" function appeared to affect savings adversely.

\section{Heat Pump Clothes Dryer}

Electric clothes dryers represent $5 \%(790 \mathrm{kWh})$ of annual energy use in Florida homes. In eight project test sites, electric resistance clothes dryers were replaced with a new unvented HPCD. The estimated median energy savings are $33.6 \%(264 \mathrm{kWh} /$ year or $0.72 \mathrm{kWh} /$ day $)$, and average 
annual savings are $36.4 \%$ (308 $\mathrm{kWh} /$ year or $0.85 \mathrm{kWh} /$ day). Cost-effectiveness, which is based on incremental cost compared to standard resistance models, will depend on consumer preferences; however, currently there is only a minor premium on the HPCD compared to standard resistance models. Estimated electrical demand reductions during utility coincident peak summer system hour were $0.09 \mathrm{~kW}(48 \%)$.

Although HPCDs use less electricity than standard resistance dryers, they still release a significant amount of heat from their operation. The unvented units that were located inside the home led to very high utility room temperatures and increases in space-cooling energy that may compromise identified savings; this is an issue the manufacturer is addressing. Given the heat issues, these unvented appliances are appropriate in Florida only if they will be installed outside of the conditioned space - typically in the garage. We further speculate, based on observed findings, that another technology — vented HPCD — may be the most appropriate dryer system type for Florida conditions.

\section{Variable-Speed Pool Pump}

Thirty-three percent of Florida homes have pool pumps, which often use more than 3,500 $\mathrm{kWh}$ /year. Replacing standard pool pumps in five Central and South Florida homes with variable-speed pumps resulted in high energy and demand savings and rapid payback of the measure. Energy savings averaged $68 \%(7.3 \mathrm{kWh} /$ day $)$ and ranged from $49 \%-80 \%(4.9-10.3$ $\mathrm{kWh}$ /day). Average hourly demand, which often occurred at or near the utility peak period, was typically reduced by approximately $70 \%$. Annual cost savings amounted to $\$ 320$ - assuming mean savings of 2,665 kWh/year-and allowed for an exceedingly rapid simple payback of 2.7 years. Electrical demand reductions during peak summer system hour were very large: $1.08 \mathrm{~kW}$ $(86 \%)$.

\section{Summary}

Among the retrofit technologies evaluated under Phase II, several promising measures might be economically justified as part of a deep retrofit package. The supplemental MSHPs exhibited very favorable economics, especially given a maturing market; and the Nest thermostat is an excellent low-cost retrofit measure. A single-ducted MSHP replacement design showed promising energy use savings and greatly enhanced comfort; a multi-split replacement also showed high energy use savings, but installation and control issues should be considered before wide-market adoption. Space-coupled HPWHs demonstrate space-conditioning savings albeit with a small water-heating energy penalty. The internally-located HPWHs have promising net effects; however, the ducted proposition may not be economically justifiable.

Neither the EIFS nor the window retrofit can be justified strictly based on economics. Other benefits may be considered, however, such as increased comfort or improved acoustics in the case of windows. Given the variation in the results and the savings from both of these building envelope improvement measures, a simulation evaluation was conducted to see how various factors such as occupancy behavior and internal gains might be influencing results. The parametric simulation shows that installations in Florida will differ considerably depending on interior temperature, internal and external shading, and the magnitude of internal gains.

HPCDs can offer good energy savings depending on the consumer's other options and relative intensity of clothes dryer use. A more mature HPCD market will likely bring more promising 
economics. These unvented appliances, however, are not recommended in Florida unless they are installed outside of conditioned space. Other vented HPCDs such as those from LG Electronics may offer more acceptable performance for use in an interior utility room. Last, strengthening findings from Phase I with five new installations to examine, VSPPs continue to show very significant savings with exceedingly strong economics. Given Florida's 33\% saturation of swimming pools, this measure appears quite desirable because consumers are generally unaware of the large potential savings.

The Phase II PDR (shallow-plus) study energy and peak demand savings are summarized in Table ES-1; energy savings are graphically represented in Figure ES-2.

Table ES-1. Phase II PDR Measured Evaluation Savings

\begin{tabular}{|c|c|c|c|c|c|c|c|}
\hline \multirow[b]{2}{*}{ Option } & \multirow[b]{2}{*}{$\begin{array}{c}\text { No. of } \\
\text { Installations }\end{array}$} & \multicolumn{4}{|c|}{ Annual Energy Savings (kWh/year) } & \multicolumn{2}{|c|}{ Demand Savings (kW) } \\
\hline & & $\begin{array}{l}\text { Space } \\
\text { Cooling }\end{array}$ & $\begin{array}{c}\text { Space } \\
\text { Heating }\end{array}$ & $\begin{array}{l}\text { Non- } \\
\text { HVAC }\end{array}$ & Total & $\begin{array}{l}\text { Summer } \\
\text { Peak }\end{array}$ & $\begin{array}{c}\text { Winter } \\
\text { Peak }\end{array}$ \\
\hline Supplemental MSHP & 10 & 2,007 & 390 & - & 2,397 & 0.50 & 2.06 \\
\hline Ducted MSHP & 2 & 1,899 & 298 & & 2,197 & $0.24 \& 0.70$ & $\mathrm{n} / \mathrm{a}$ \\
\hline Space-coupled HPWH' & 8 & 313 & (79) & 1,175 & 1,409 & 0.23 & 0.18 \\
\hline EIFS & 1 & 947 & (34) & - & 913 & $\mathrm{n} / \mathrm{a}$ & $\mathrm{n} / \mathrm{a}$ \\
\hline Advanced windows ${ }^{b}$ & 3 & $(250)$ & 19 & - & $(231)$ & $\mathrm{n} / \mathrm{a}$ & $\mathrm{n} / \mathrm{a}$ \\
\hline Nest thermostat & 22 & 498 & 39 & - & 537 & 0.18 & 0.25 \\
\hline HPCD & 8 & - & - & 264 & 264 & 0.09 & $\mathrm{n} / \mathrm{a}$ \\
\hline VSPP & 5 & - & - & 2,846 & 2,846 & 1.08 & -0.27 \\
\hline
\end{tabular}

${ }^{a}$ Non-HVAC savings for the HPWH measure are the average DHW energy savings for the six sites at which electric resistance tank types were replaced with heat pump types-three of which were located inside the home and three of which were located in the garage and coupled to the interior space.

${ }^{b}$ Predicted space-cooling savings for the window retrofits ranged from negative 0.7 to positive $6.9 \mathrm{kWh} /$ day; the median was negative $0.5 \mathrm{kWh} /$ day. Different sites are used for space-cooling and space-heating savings estimates. 


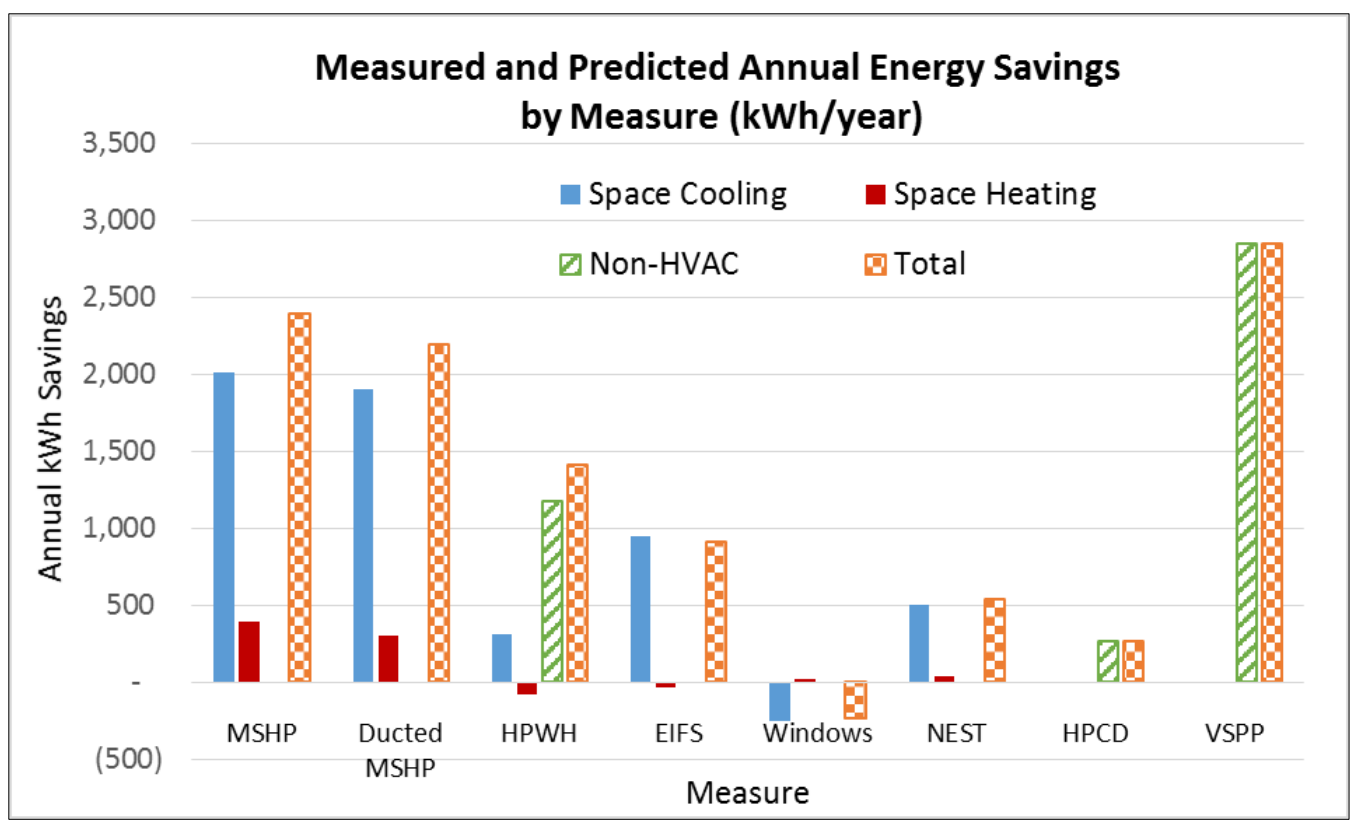

Figure ES-2. Average annual energy savings for the Phase II PDR evaluation measures 


\section{Introduction}

The U.S. Department of Energy (DOE), with the Building America Partnership for Improved Residential Construction team and Florida Power \& Light Company (FPL), pursued a pilot phased energy-efficiency retrofit program in Florida by creating detailed data on the energy and economic performance of two levels of retrofits: shallow and deep. For this phased deep retrofit (PDR) project (Phase I), a total of 56 homes spread across the utility partner's territory in east Central Florida, southeast Florida, and southwest Florida were instrumented between August 2012 and January 2013, and they received simple pass-through retrofit measures between March 2013 and June 2013. The energy-reduction measures for the shallow retrofit included those for lighting (compact fluorescent and light-emitting diode lamps), domestic hot water (water heater tank wraps and low-flow showerheads), refrigeration (cleaning coils), pool pumps (reduction of operating hours), and use of "smart plugs" for home entertainment centers. Ten of these homes received a deeper package of retrofits between August 2013 and December 2013. The measures associated with the deep retrofits included replacement of air-source heat pumps, duct repair, and substitution of conventional thermostats with learning thermostats. Heat pump water heaters were installed to reduce water-heating energy. Pool pumps were changed to variable-speed units, and ceiling insulation was augmented where deficient. Old and inefficient major appliances such as refrigerators and dishwashers were replaced with more efficient units. The shallow retrofits are applicable to all homes and provided critical data to the design of "deep retrofits," which make a major impact on whole-house energy use, averaging 39\% savings during summer peak hour demand, $60 \%$ savings during winter peak hour demand, and 38\% annual energy savings. For a full account of Phase I of this project, including home details and characterization, reference Phased Retrofits in Existing Homes in Florida Phase I: Shallow and Deep Retrofits (Parker et al. 2016).

Phase II of this project, which is the focus of this report, applied additional retrofit measures to select homes that received a shallow retrofit in Phase I, referred to as "shallow-plus" retrofits. The shallow-plus measures included the following:

- Supplemental mini-split heat pump (MSHP) (10 homes)

- Complete central system replacement with inverter-driven heat pump (2 homes)

- Ducted and space-coupled heat pump water heater (HPWH) (8 homes)

- Exterior insulation finish system (EIFS) (1 home)

- Window retrofit (3 homes)

- Smart thermostat (21 homes: 19 Nests, 2 Lyrics)

- Heat pump clothes dryer (HPCD) (8 homes)

- Variable-speed pool pump (VSPP) (5 homes).

Although some of these retrofit technologies, such as windows and EIFS, have been studied in Florida in the past (Barkaszi and Parker 1995), a detailed evaluation with more modern equipment and costs has not been identified and was of interest to the utility partner. Technologies such as supplementing an existing central heating and cooling system with an MSHP, and taking advantage of cooling provided by an HPWH with ducting, had not been done 
in Florida. This report identifies measured energy savings and installation costs of the different technologies, adding to the body of knowledge and enabling the industry to further the Building America goal of $40 \%$ savings in existing housing. Findings also provide utilities with data that facilitates the further optimization and expansion of the shallow and deep retrofit packages piloted in Phase I.

The PDR study sites are all-electric, single-family homes located in Central and South Florida. Selected characteristics for all of the homes evaluated in this report are summarized within each section, including location, year built, occupancy, conditioned floor area, heating, ventilating, and air-conditioning (HVAC) duct and whole-house airtightness test results, and measures included in the Phase II retrofit. 


\section{Measurements and Equipment}

In Phase I, detailed audit data were obtained from all homes, including house size and geometry, insulation levels, materials, finishes, and equipment. Blower door and duct leakage tests were completed on each home. Detailed photographs were also taken of each home's exterior, appliances and equipment, and thermostat. Showerhead flow rate was measured.

Monitoring of house power and the various end uses is accomplished by a 24-channel data logger (SiteSage). This is supplemented by portable loggers (Point Six and HOBO) to take temperature and relative humidity $(\mathrm{RH})$ readings. Data are retrieved daily from the Internet via broadband connection. Data are collected on a 1-hour time step. Ambient temperature and RH are obtained from nearby weather stations. Table 1 summarizes the measurements and equipment used to conduct field tests and data acquisition for the project. A dedicated website ${ }^{1}$ has been set up to host the monitored energy data from the project.

Table 1. Equipment Used for Field Tests

\begin{tabular}{ll}
\hline Measurement & Equipment Used \\
\hline $\begin{array}{l}\text { Temperature and RH } \\
\begin{array}{l}\text { Detailed house power (total, HVAC, water heating, } \\
\text { cooking, clothes drying, refrigeration, pool pump) }\end{array}\end{array}$ & $\begin{array}{l}\text { Point Six temp. and humidity logger } \\
\text { SiteSage by Powerhouse Dynamics }\end{array}$ \\
\hline
\end{tabular}

\subsection{Experimental Instrument Accuracies}

National Weather Service measurements were used for the outdoor temperature, matched to the nearest available weather data, which was typically less than 20 miles away. The stated accuracy of the outdoor temperature measurements by the National Weather Service is $\pm 1^{\circ} \mathrm{F}$ higher than the range of interest (National Weather Service 2014).

Interior temperatures in the project are measured near the thermostat using Onset HOBO U-10003 portable loggers ${ }^{2}$ with a stated accuracy of $\pm 0.95^{\circ} \mathrm{F}$ for temperature and $\pm 3.5 \% \mathrm{RH}$ for relative humidities up to $85 \%$. Power was measured for the air conditioners, heat pump compressors and air handling units, and strip heat circuits by SiteSage loggers ${ }^{3}$ (formerly eMonitor), generally using 50-amp current transformers. These have a stated accuracy of $\pm 1 \%$ between $10 \%$ and $130 \%$ of their rated output. The relative error becomes an artifact of the load itself. For a 3,000-watt (W) compressor at a given point, this would result in approximately \pm 30 $\mathrm{W}$ in measurement uncertainty for evaluating absolute measurements (kilowatt-hours [kWh] for one site compared to another). For retrofit measurements (before/after), the measurement equipment-related variation is much lower, such that measurements should be $\pm 0.5 \%$ or better. For example, if the air conditioning (AC) in a home was using $25 \mathrm{kWh} /$ day, the average load would be $1,042 \mathrm{~W}$ with an absolute uncertainty of $0.5 \mathrm{kWh} / \mathrm{day}$. If the estimate was between preand post-retrofit periods (the situation in this evaluation), the uncertainty would be 0.12 $\mathrm{kWh} /$ day, although this can be computed for individual cases if the results are in doubt.

\footnotetext{
${ }^{1}$ www.infomonitors.com/pdr/

${ }^{2}$ www.onsetcomp.com

${ }^{3} \underline{\mathrm{http}: / / \text { powerhousedynamics.com }}$
} 


\section{Representativeness of the Phased Deep Retrofit Sample}

Given the unique findings of the PDR study, a question often arises as to how representative the sample is to the general population of Florida homes. The 56, all-electric, field-tested homes are located in Central and South Florida and were an opportunity sample. Outreach by the utility was used for recruitment, and participants were largely self-selected within program limits.

Originally, the sample was to be weighted equally between Central and South Florida; however, difficulty with recruitment made it necessary to locate most of the residential sites in Central Florida to meet the project schedule.

Note that no homes more recent than 2006 or larger than 3,000 square feet $\left(\mathrm{ft}^{2}\right)$ were accepted for the study. This was done to make results more appropriate to retrofit programs targeting older and less efficient homes. Table 2 provides selected fundamental characteristics of the homes, including their location, year built, occupancy, conditioned floor area, and whether there is a pool. First, it is useful to understand that the intent of the PDR sample was to:

- Be a statistically meaningful sample representing all-electric homes in Florida

- Include only homes that were to be occupied year-round and not seasonal

- Include only homes typical of existing housing with construction from 2006 or earlier

- Incorporate geographic variation

- Include similar saturation of in-ground swimming pools, which are known to be a major electricity end use.

With these selection guidelines, it was hoped that the measured electricity use would be typical of all electric nonseasonal single-family homes in the FPL service territory (Florida's largest utility).

Periodically, Florida utilities are required to perform a home energy survey (HES) of the housing characteristics in their service territory for submission to the Public Service Commission. The most recent is the 2010 survey, which provides a convenient method to compare the characteristics of the homes in the PDR opportunity sample to the larger statistically drawn survey evaluated by FPL.

Among the 56 PDR sites with varied construction characteristics, the average vintage is 1984, ranging from 1942 to 2006 . Average vintage in the FL-HES survey was 1980. Conditioned floor area in the PDR sample averaged 1,777 $\mathrm{ft}^{2}$; the average size of the FPL HES-sampled singlefamily homes $(\mathrm{n}=424)$ was $1,822 \mathrm{ft}^{2}$.

The average occupancy was identical in both samples: 2.6 persons per household in both the PDR and samples. Nineteen PDR sites (34\%) had pools and associated pool pumping compared to $33 \%$ in the FL-HES sample.

The average wall insulation level was negligible in both samples, largely reflecting concrete masonry unit (CMU) construction-with 77\% of FL-HES homes showing no insulation, and 
only the four frame-walled PDR homes showing visible insulation. ${ }^{4}$ The FL-HES data do not lend themselves to exact comparisons to ceiling insulation levels. The typical PDR home had a ceiling insulation R-value (audited and measured) of R-22. The FL-HES sampling reported 4\% of homes with no ceiling insulation, $20 \%$ with R-1 to R-18, and 74\% with R-19 or more. Using the same classification scheme as the Public Service Commission's FL-HES survey, we found a single home (2\%) without ceiling insulation in the PDR project, but $15 \%$ of homes had R-1 to R18 , and $83 \%$ had R19 or greater.

Relative to heating and cooling equipment, the PDR sample showed an average audited airconditioner seasonal energy efficiency ratio (SEER) of $12.5 \mathrm{Btu} / \mathrm{Wh}$ compared to $12.0 \mathrm{Btu} / \mathrm{Wh}$ in the FL-HES survey. The average air-conditioner or heat pump vintage was 2003 in the PDR study - systems averaged 9 years in age. Perhaps the only apparent difference in the two samples was in the heating system type: the PDR homes with more buildings in the Central Florida region showed $49 \%$ with heat pump heating systems; the FL-HES sample was dominated by resistance heat systems in South Florida and with only 15\% heat pump heating systems. Note that the PDR sample has many other characteristics - including glazing number and type, building air change rate $\left(\right.$ avg. $=8.5$ ACH50 pressure, duct leakage $\left.\mathrm{Q}_{\mathrm{n}}=0.08\right)$ —and many other data for which no comparable contrasting value exists in the FL-HES.

Although the foregoing description shows that the Public Service Commission's survey data and that for the Florida PDR sample are quite comparable, there remains a critical difference in the comparison of the average electricity use for the larger population of homes in the FPL service territory to that of the PDR sample. Here we had a large advantage because the FPL agreed to provide masked data to the DOE project that would allow us to see how the larger system averages compared for the identical time periods measured in the PDR project. For the PDR project, we obtained monthly utility records for all participating homes on a condition of participation. The average consumption for the PDR home sample was $16,963 \mathrm{kWh}$ for all of $2011(\mathrm{n}=56)$.

We then requested averages for the FPL single-family detached home accounts for all averages for all nonseasonal accounts. This comprises 1.35 million accounts across the FPL service territory. The total average 2011 electricity consumption was $17,843 \mathrm{kWh}$, ranging from an average use of $1,074 \mathrm{kWh}$ in February to $1,941 \mathrm{kWh}$ in August of the same year. The FPL single-family home averages are likely higher due to a preponderance of homes in South Florida that have greater cooling use, as shown in Figure 1, from April-November.

\footnotetext{
${ }^{4}$ Often in Florida with CMU construction since the mid-1990s, foil products (e.g., AL-FOIL) that are stretched between the drywall and block walls on the interior face provide approximately the equivalent of $\mathrm{R}-4 \mathrm{hr}-\mathrm{ft}^{2}-\mathrm{F} / \mathrm{Btu}$; however, these could not be audited.
} 


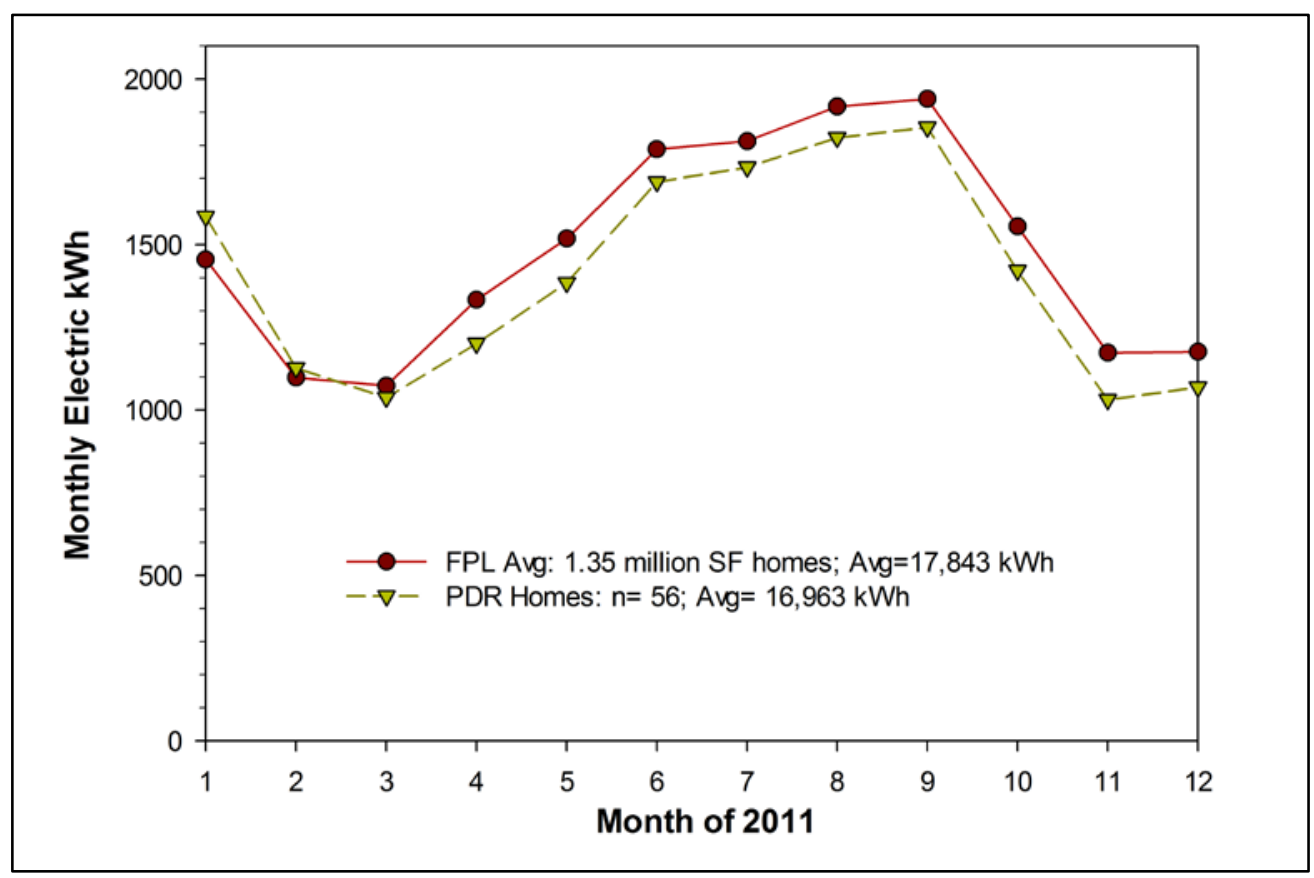

Figure 1. Comparison of South Florida homes in FPL's service territory to PDR sample

In any case, the averages for all of FPL's single-family, nonseasonal occupants agree reasonably well with the PDR sample (within 5\%) prior to any intervention. Although this does not ensure that the PDR sample is representative of the FPL single-family home population, it does improve confidence that it has a high degree of relevance to the intended evaluation.

Table 2. Selected Site Characteristics of PDR Sample

\begin{tabular}{|c|c|c|c|c|c|}
\hline Site & Town & $\begin{array}{l}\text { Year } \\
\text { Built }\end{array}$ & Occupants & $\begin{array}{c}\text { Conditioned Floor } \\
\text { Area }\left(\mathrm{ft}^{2}\right)\end{array}$ & $\begin{array}{c}\text { Pool? } \\
(1=\mathrm{Y}, 0=\mathrm{N})\end{array}$ \\
\hline 1 & Merritt Island & 1961 & 4 & 2,459 & 0 \\
\hline 3 & Merritt Island & 1993 & 1 & 1,856 & 1 \\
\hline 4 & Melbourne & 1971 & 2 & 1,166 & 0 \\
\hline 5 & Rockledge & 2006 & 2 & 2,328 & 0 \\
\hline 6 & Palm Bay & 1981 & 2 & 1,542 & 0 \\
\hline 7 & Merritt Island & 1989 & 2 & 2,650 & 1 \\
\hline 8 & Grant-Valkaria & 1997 & 4 & 2,134 & 0 \\
\hline 9 & Melbourne & 1984 & 2 & 1,013 & 0 \\
\hline 10 & West Melbourne & 2003 & 2 & 1,627 & 0 \\
\hline 11 & Cocoa Beach & 1958 & 3 & 1,672 & 0 \\
\hline 12 & Port Orange & 1984 & 3 & 1,594 & 1 \\
\hline 13 & Merritt Island & 1963 & 2 & 1,052 & 1 \\
\hline 14 & Melbourne & 1942 & 2 & 2,016 & 0 \\
\hline 15 & Melbourne Beach & 1975 & 2 & 1,359 & 1 \\
\hline 16 & Indialantic & 1982 & 3 & 2,231 & 1 \\
\hline 17 & Indialantic & 1964 & 2 & 1,456 & 1 \\
\hline 18 & Cocoa & 1995 & 2 & 1,802 & 1 \\
\hline 19 & Melbourne & 1988 & 3 & 2,554 & 0 \\
\hline 21 & Cocoa Beach & 1981 & 2 & 2,096 & 1 \\
\hline 22 & Cocoa Beach & 1955 & 2 & 1,743 & 0 \\
\hline
\end{tabular}




\begin{tabular}{|c|c|c|c|c|c|}
\hline Site & Town & $\begin{array}{l}\text { Year } \\
\text { Built }\end{array}$ & Occupants & $\begin{array}{c}\text { Conditioned Floor } \\
\text { Area }\left(\mathrm{ft}^{2}\right)\end{array}$ & $\begin{array}{c}\text { Pool? } \\
(1=\mathrm{Y}, 0=N)\end{array}$ \\
\hline 23 & Palm Bay & 1980 & 3 & 1,946 & 0 \\
\hline 24 & Cocoa & 1986 & 3 & 1,978 & 0 \\
\hline 25 & Melbourne & 2000 & 2 & 1,940 & 1 \\
\hline 26 & Palm Bay & 1999 & 5 & 1,502 & 0 \\
\hline 27 & Palm Bay & 1995 & 2 & 2,050 & 0 \\
\hline 28 & Merritt Island & 1966 & 2 & 2,622 & 1 \\
\hline 29 & Cocoa & 1985 & 2 & 1,215 & 0 \\
\hline 30 & Merritt Island & 1976 & 3 & 1,819 & 0 \\
\hline 31 & Cocoa & 1989 & 2 & 1,474 & 0 \\
\hline 33 & Hollywood & 1969 & 3 & 1,752 & 0 \\
\hline 34 & Pembroke Pines & 1978 & 2 & 1,910 & 0 \\
\hline 35 & Plantation & 1993 & 2 & 1,637 & 0 \\
\hline 37 & Cocoa & 1993 & 6 & 1,654 & 1 \\
\hline 38 & Palm Bay & 2006 & 3 & 1,665 & 0 \\
\hline 39 & Palm Bay & 1981 & 4 & 1,559 & 0 \\
\hline 40 & Titusville & 1993 & 3 & 1,983 & 0 \\
\hline 41 & Bonita Springs & 1998 & 2 & 2,471 & 1 \\
\hline 42 & Naples & 2001 & 3 & 1,666 & 0 \\
\hline 43 & Fort Myers & 2000 & 2 & 1,383 & 0 \\
\hline 44 & Naples & 1998 & 2 & 1,808 & 1 \\
\hline 45 & Davie & 1987 & 2 & 1,500 & 1 \\
\hline 46 & Naples & 1989 & 2 & 2,172 & 1 \\
\hline 47 & Fort Myers & 1990 & 4 & 1,088 & 0 \\
\hline 48 & Naples & 1973 & 4 & 1,436 & 0 \\
\hline 49 & Fort Myers & 1979 & 2 & 1,701 & 0 \\
\hline 50 & Melbourne & 1958 & 4 & 2,168 & 1 \\
\hline 51 & Cocoa & 1994 & 2 & 2,233 & 0 \\
\hline 52 & Cocoa & 2000 & 2 & 1,540 & 0 \\
\hline 53 & Melbourne & 1980 & 1 & 1,677 & 0 \\
\hline 54 & Palm Bay & 1999 & 2 & 1,390 & 0 \\
\hline 55 & Melbourne & 1976 & 4 & 1,980 & 1 \\
\hline 56 & Merritt Island & 1963 & 3 & 1,000 & 0 \\
\hline 57 & Melbourne & 1993 & 1 & 1,406 & 0 \\
\hline 58 & Rockledge & 1979 & 2 & 2,020 & 0 \\
\hline 59 & Melbourne Beach & 1985 & 2 & 2,300 & 1 \\
\hline 60 & Palm Bay & 1987 & 3 & 1,520 & 0 \\
\hline Averages & & 1984 & 2.6 & 1,777 & $34 \%$ \\
\hline
\end{tabular}

The end-use load averages of all 45 shallow retrofit PDR homes monitored for the entirety of 2013 were used to estimate Florida residential end uses. This end-use evaluation, including pie charts, is in Appendix A. 


\section{Evaluation Method}

Linear regression analysis was used to project savings for the measures that influence spacecooling and space-heating energy use - the MSHP, space-coupled HPWH, EIFS, window retrofit, and smart thermostat. The same general model, using the measured cooling and heating electrical power and then modeling this against outdoor weather conditions, was applied for each of these evaluations as described below.

From statistical evaluation, the study shows that the average daily AC and space-heating energy had the strongest statistical power to evaluate against weather - much stronger than hourly data because of the time lag posed by temperature on building elements. Averaging the hourly temperatures into daily averages was actually a better statistical predictor of space-conditioning energy than estimating heating degree days and cooling degree days at a $65^{\circ} \mathrm{F}$ base for the same periods. The coefficients of determination tended to be much superior, mainly because heating degree days and cooling degree day periods with zero or negative numbers that were truncated by the degree-day procedure actually influence daily space-conditioning needs. For example, predawn periods with temperatures below $65^{\circ} \mathrm{F}$ actually reduce the required cooling, whereas the degree day calculations assume that these hours have a cooling degree day value of zero; as a result, daily average temperatures were used for the analysis. Space-conditioning energy was then plotted against average outdoor temperature, and the daily average balance temperature for heating and cooling was determined. In some homes with very tight temperature control, these were often the same. The typical daily balance point was approximately $65^{\circ} \mathrm{F}$, although this sometimes varied $\left(60^{\circ}-70^{\circ} \mathrm{F}\right.$ for cooling and $60^{\circ}-70^{\circ} \mathrm{F}$ for heating).

During the process of establishing the most robust statistical formulation to predict space heating and cooling depending on weather, this study found that the same method had been independently identified by Haberl et al. (2005). This is currently recommended in the American Society of Heating, Refrigerating and Air-Conditioning Engineers, Inc. (ASHRAE) "tool kit" recommendations on the methods to estimate savings from retrofit measures applied to buildings. This increases confidence in the methods used for this analysis.

The following theoretical model based on suggested ASHRAE protocols (ASHRAE 2002) was applied for predicting energy use:

$\mathrm{kWh}=\mathrm{A}+\mathrm{B}($ Tamb - Tint $)+\mathrm{C}(\mathrm{Q}$ int $)+\mathrm{D}($ Solar $)$

Where:

$\mathrm{A}=$ regression error or intercept term

$\mathrm{B}=$ coefficient for house heat gain (UA)/coefficient of performance (COP) of cooling system (outdoor temperature - indoor temperature; Delta T)

$\mathrm{C}=1 / \mathrm{COP}$ of cooling system assuming all Qint (internal gains) must be removed

$\mathrm{D}=$ fraction of horizontal solar transmitted through windows and exposed building exterior components/COP. 
An alternative model with a substitute B term was also used, where:

$$
\mathrm{B}=\text { outdoor temperature }
$$

In keeping with the statistical analytical concept of parsimony, this study generally used the simplest model that showed stable and reliable results with strong explanatory power. ${ }^{5}$ Outdoor temperature was used rather than the outdoor temperature minus indoor temperature, in ${ }^{\circ} \mathrm{F}$ (Delta T) unless the interior temperature profile was altered between the pre- and post-retrofit observation periods. This was the case for some of the window, EIFS, and space-coupled HPWH evaluations in which the thermostat position was clearly moved. For the evaluation of the supplemental MSHP and multi-split heat pump system replacement, Delta T was not used because of expected behavioral changes. Differences in interior temperature are likely with the MSHP because uniform interior room temperatures do not typically yield the greatest comfort. Brand (1987) found that space-conditioning systems that facilitate zoning have significantly lower energy use. When supplemental MSHP or mulit-split systems are added, it becomes easy - and even likely - that occupants maintain different heating and cooling conditions in different rooms of the home.

The C term Qint and D term Solar are included only when significant or needed in models that exhibited poor explanatory power or exhibited contrary results. In a perfectly behaved model, the term for $\mathrm{C}$ (internal gains) would be around 0.4 , which indicates that the $\mathrm{COP}$ of the cooling system would be $1 / 0.4=2.5 * 3.412 \mathrm{~W}=8.5$ British thermal units per watt-hour (Btu/Wh) for the SEER (including duct losses).

In the cases of the window and EIFS retrofits, even the best models were often still weak, so these evaluations were bolstered with parametric simulations using the Building Energy Optimization software (BEopt).

Model parameters were collected and compiled in the following ways:

- Hourly energy and interior temperature data were obtained from the PDR database for each particular site and were summarized by day.

- Daily average outdoor temperatures are approximated using ambient temperatures from each site's nearest National Weather Service station.

- The internal heat gains (Qint) parameter represents the energy use of the kitchen range, dishwasher, lighting, fans and entertainment centers, and other appliances located inside the home that is released to the house interior. If the clothes dryer is indoors, the internal gains parameter includes $20 \%$ of its energy use.

- Daily average horizontal solar insolation (W per square meter) data measured at the Florida Solar Energy Center (FSEC) meteorological station in Cocoa, Florida, were used to represent changing sun conditions (Solar).

To estimate pre- and post-retrofit annual heating and cooling energy use, the regressions were used to normalize daily average temperatures against monitored daily HVAC energy use; then

\footnotetext{
${ }^{5}$ https://theartofmodelling.wordpress.com/2012/03/14/why-parsimony/
} 
we assumed that outside temperatures were applied to the resulting site-specific, pre- and postretrofit regression results. The period after the measure installation was then compared to the preinstallation period. This allowed for an evaluation of how energy use changed after the retrofit.

For each site, the relevant typical meteorological year 3 (TMY3) weather data were used to extrapolate the savings. ${ }^{6}$ This allows the savings estimates to be extended to the various climate zones that FPL typically uses for forecasting purposes. The pre- and post-retrofit regression results from the weather-normalization evaluation described above were applied to TMY3 weather data to predict space-heating and space-cooling energy use for the pre- and post-retrofit periods. Table 3 provides the weights applied to TMY3 weather for four of FPL's service areas: Miami, West Palm Beach, Fort Myers, and Daytona.

Table 3. TMY3 Weather FPL Service Area Weights

\begin{tabular}{l|l}
\hline \multicolumn{1}{c|}{ Service Area } & Weight \\
\hline Miami & 0.4319 \\
West Palm Beach & 0.2243 \\
Fort Myers & 0.1921 \\
Daytona & 0.1517 \\
\hline
\end{tabular}

For some measure, savings predictions also include cooling energy estimates in $\mathrm{kWh}$ /day for an $80^{\circ} \mathrm{F}$ day for cooling and $50^{\circ} \mathrm{F}$ day for heating. For reference, note that in Florida's mild winter, the average daily temperature during winter when temperatures are lower than $65^{\circ} \mathrm{F}$ was $58.2^{\circ} \mathrm{F}$ (2014-2015 winter). Similarly, the average daily temperature in summer from June-September (inclusive) was $80.5^{\circ} \mathrm{F}$ in 2014 . The climatic normal using Orlando, Florida, TMY3 data are $79.6^{\circ} \mathrm{F}$ for summer and $60.8^{\circ} \mathrm{F}$ for January and February. This indicates that the evaluated values would be appropriate for typical summer conditions and for "colder days" during winter.

${ }^{6}$ http://rredc.nrel.gov/solar/old data/nsrdb/1991-2005/tmy3/ 


\section{Evaluation of Supplemental Mini-Split Heat Pumps}

\subsection{Site Characteristics and Supplemental Mini-Split Heat Pumps Measure}

A major facet of the Phase II segment of the PDR project was to determine energy savings and indoor comfort improvement from the installation of high-efficiency, supplemental MSHPs. Ten such systems were installed in Central Florida locations from August 27, 2014-July 23, 2015. The systems were 1-ton ductless Panasonic XE12PKUA, SEER 25.5 Btu/Wh, 12 heating seasonal performance factor (HSPF), which has a variable-speed compressor. The single indoor head was located at a central location in the home. The units have a cooling capacity of 11,580 Btu at the 95/80/67 rating condition and a heating capacity of 13,800 Btu/hour at an outdoor temperature of $47^{\circ} \mathrm{F}$.

The homes receiving the supplemental mini-splits spanned a range of vintages and included central AC systems of various ages and efficiencies. Duct systems for the existing central system were all flex duct and located in the attic space of each home. Site characteristics for each home are summarized in Table 4 . Table 5 provides existing HVAC characteristics.

Table 4. Supplemental MSHP Site Characteristics

\begin{tabular}{cccccc}
\hline Site No. & City & $\begin{array}{c}\text { Year } \\
\text { Built }\end{array}$ & $\begin{array}{c}\text { Living } \\
\text { Area }\left(\mathbf{f t}^{2} \text { ) }\right.\end{array}$ & $\begin{array}{c}\text { No. of } \\
\text { Occu. }\end{array}$ & Stories \\
\hline 3 & Merritt Island & 1993 & 1,856 & 1 & 1 \\
\hline 5 & Rockledge & 2006 & 2328 & 2 & 1 \\
12 & Port Orange & 1984 & 1,594 & 2 & 1 \\
16 & Indialantic & 1982 & 2,231 & 3 & 1 \\
\hline 21 & Cocoa Beach & 1981 & 1628 & 2 & 1 \\
\hline 23 & Palm Bay & 1980 & 1946 & 3 & 1 \\
\hline 24 & Cocoa & 1986 & 1,978 & 3 & 2 \\
\hline 27 & Palm Bay & 1995 & 2,050 & 2 & 1 \\
\hline 60 & Palm bay & 1999 & 1390 & 2 & 1 \\
\hline
\end{tabular}


Table 5. Supplemental MSHP Site Existing HVAC Characteristics

\begin{tabular}{cccccccc}
\hline $\begin{array}{c}\text { Site } \\
\text { No. }\end{array}$ & $\begin{array}{c}\text { Year of } \\
\text { Air Handling } \\
\text { Unit }\end{array}$ & $\begin{array}{c}\text { Year of } \\
\text { Compressor }\end{array}$ & $\begin{array}{c}\text { AC Size } \\
\text { (ton) }\end{array}$ & $\begin{array}{c}\text { AC } \\
\text { SEER }\end{array}$ & $\begin{array}{c}\text { Heat Pump or } \\
\text { Electric Resistance }\end{array}$ & $\begin{array}{c}\text { HSPF } \\
\text { Duct } \\
\text { Leakage } \\
\text { (Qn,out) }\end{array}$ \\
\hline 3 & 1993 & 2010 & 3.5 & 13.0 & Heat Pump & 7.5 & 0.05 \\
\hline 5 & 2006 & 2006 & 5.0 & 13.0 & Heat Pump & 7.5 & 0.10 \\
\hline 12 & 2000 & 2000 & 3 & 12.0 & Heat Pump & 7.8 & 0.63 \\
\hline 16 & 2002 & 2014 & 4 & 13.0 & Resistance & 0.07 \\
\hline 21 & 2013 & 2013 & 3.5 & 13.0 & Resistance & $0.12^{\text {c }}$ \\
\hline 24 & 2001 & 2002 & 3.5 & 14.0 & Resistance & 0.05 \\
\hline 54 & 2010 & 2010 & 3.5 & 15.0 & Resistance & 0.09 \\
\hline 60 & 2008 Packaged Unit & 5 & 12.0 & Resistance & 0.05 \\
\hline
\end{tabular}

a Some systems were apparently unmatched; stated are manufactuer listed compressor efficiencies.

${ }^{b}$ Duct leakage measured at a test pressure of negative $25 \mathrm{~Pa}$ with respect to the outside, divided by the building's conditioned floor area.

${ }^{\mathrm{c}}$ Duct leakage test conducted prior to system change out in 2013.

The supplemental MSHPs were expected to reduce space cooling and heating energy by reducing the run time of less efficient existing central systems subject to duct losses; however, the configuration with two different systems with potentially competing thermostats serving a single zone added speculation for how this would work out. Moreover, no existing simulation model can provide savings estimates because having two HVAC systems serve the same zone violates limits for hourly calculations.

In most cases, the indoor unit was located as close as possible to the central return grille of the existing system to help with room-to-room distribution of MSHP air when that unit was

operating. In each house, the cooling set point of the MSHP was set either $2^{\circ} \mathrm{F}$ or $4^{\circ} \mathrm{F}$ lower than the central system temperature. This was done based on post-retrofit communication with the homeowner because there was no way in advance of the experiments to know how the systems would interact with two independent thermostats. Indoor temperature and RH were measured near the central system thermostat. Although duct leakage was measured, there was no attempt to improve the central system prior to installing the MSHPs. Figure 2 shows examples of the MSHP installation. 

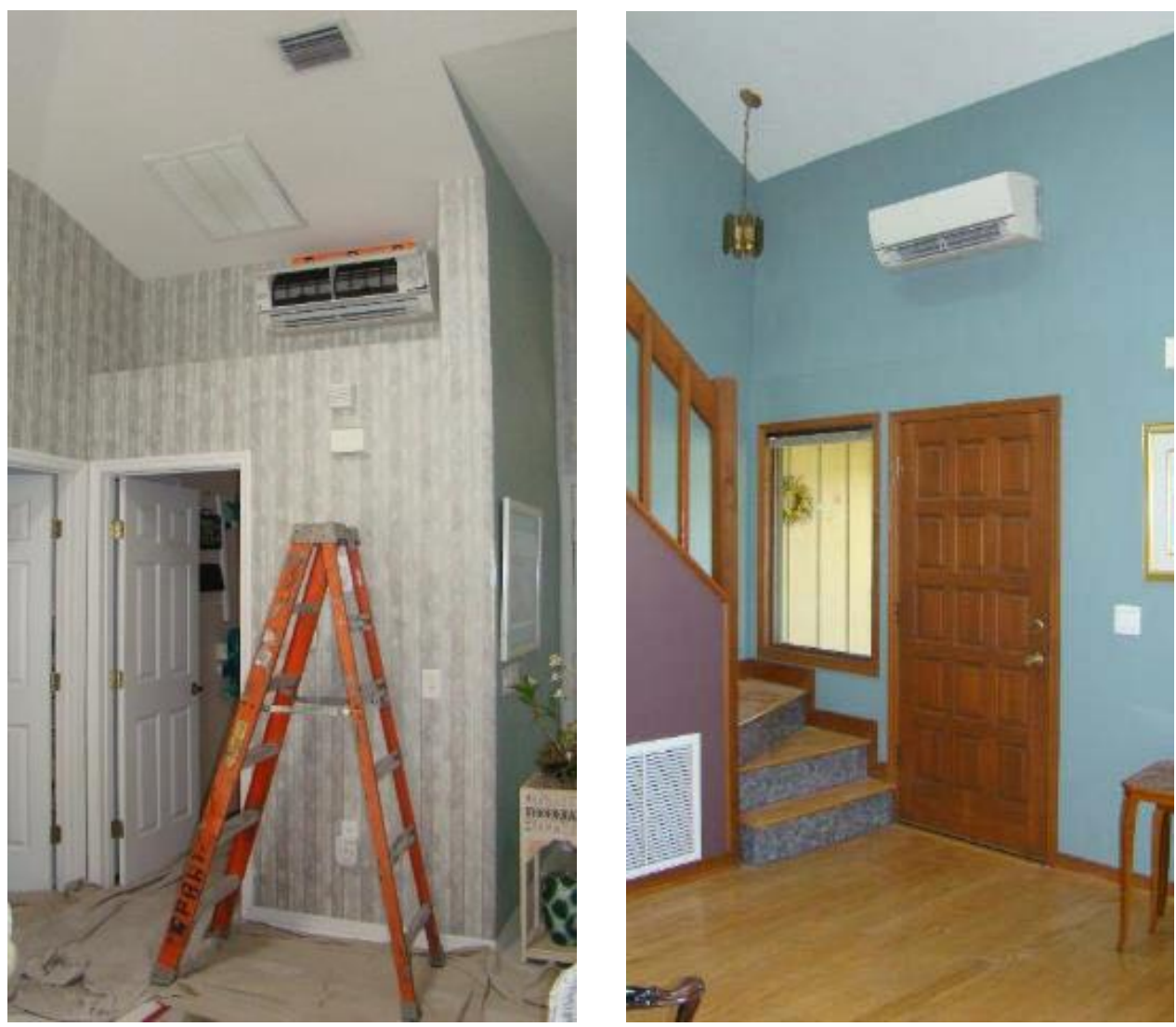

Figure 2. Wall-mounted MSHP fan coil at Site 3 and Site 24

\subsection{Supplemental Mini-Split Heat Pump Annual Savings Evaluation}

To examine how the supplemental MSHP influenced space cooling and heating, the evaluation method described in Section 4 was applied to the pre- and post-retrofit data for the six 2014 and four 2015 installations. Evaluation periods for each installation varied necessarily to avoid dates that would have confounded results because of competing energy retrofit measures or to avoid dates with other significant changes, such as a change in occupancy coinciding with a large difference in interior thermostat set points. The pre- and post-retrofit periods are clearly delineated. The evaluation periods and MSHP installation dates for each site are as follows:

- 2014 installations

- Site 3 evaluation: September 1, 2013-December 31, 2014; installation September 2,2014

- Site 12 evaluation: January 1, 2014-July 9, 2015; installation September 12, 2014

- Site 16 evaluation: September 1, 2013-July 28, 2015; installation September 4, 2014

- Site 24 evaluation: January 1, 2014-July 19, 2015; installation August 27, 2014

- Site 27 evaluation: January 1, 2014-June 25, 2015; installation September 22, 2014

○ Site 60 evaluation: January 1, 2014-July 7, 2015; installation September 9, 2014 
- 2015 installations

- Site 5 evaluation: September 25, 2014-January 11,2016; installation June 30, 2015

- Site 21 evaluation: July 25, 2014-January 13, 2016; installation July 15, 2015

- Site 23 evaluation: October 31, 2014-January 14, 2016; installation July 23, 2015 (The post-retrofit period excludes first six months of 2015 when occupancy increased and interior set point was noticeably altered.)

○ Site 54 evaluation: May 1, 2015-January 17, 2016; installation July 16-18, 2015.

Tables 6 and 7 show the cooling and heating results from the regressions along with the interior temperature (Tint) and RH (for cooling) before and after the MSHP retrofit. Annual savings are summarized in Table 8.

Table 6. TMY3-Normalized Cooling Energy Use and Savings from the Supplemental MSHP Sites

\begin{tabular}{|c|c|c|c|c|c|c|c|c|c|c|c|}
\hline Site No. & $\begin{array}{c}\text { Pre- } \\
\text { Cooling } \\
\text { (kWh/ } \\
\text { year) }\end{array}$ & $\begin{array}{c}\text { Post- } \\
\text { Cooling } \\
\text { (kWh/ } \\
\text { year) }\end{array}$ & $\begin{array}{c}\text { Savings } \\
\text { (kWh/ } \\
\text { year) }\end{array}$ & $\begin{array}{l}\text { Savings } \\
\text { (\%) }\end{array}$ & $\begin{array}{c}\text { Cool } \\
\text { Bal. T } \\
\left({ }^{\circ} \mathrm{F}\right)\end{array}$ & $\begin{array}{l}\text { Tint } \\
\text { pre- } \\
\left({ }^{\circ} \mathrm{F}\right)\end{array}$ & $\begin{array}{c}\text { Tint } \\
\text { post- } \\
\left({ }^{\circ} \mathrm{F}\right)\end{array}$ & $\Delta T$ & $\begin{array}{c}\text { RH } \\
\text { pre- } \\
\text { (\%) }\end{array}$ & $\begin{array}{c}\text { RH } \\
\text { post- } \\
(\%)\end{array}$ & $\Delta \mathrm{RH}$ \\
\hline 3 & 8,049 & 5,419 & 2,631 & $32.7 \%$ & 65 & 75.0 & 75.0 & $(0.0)$ & 51.2 & 54.1 & 2.9 \\
\hline 5 & 15,586 & 10,006 & 5,580 & $35.8 \%$ & 64 & 75.7 & 76.0 & 0.3 & 49.4 & 50.1 & 0.6 \\
\hline 12 & 7,571 & 6,024 & 1,547 & $20.4 \%$ & 65 & & & & & & \\
\hline 16 & 7,014 & 5,344 & 1,670 & $23.8 \%$ & 70 & 76.9 & 76.2 & $(0.7)$ & 56.7 & 55.3 & (1.5) \\
\hline 21 & 4,970 & 2,700 & 2,270 & $45.7 \%$ & 68 & 79.5 & 80.2 & 0.7 & 58.5 & 60.1 & 1.7 \\
\hline 23 & 9,820 & 6,379 & 3,441 & $35.0 \%$ & 69 & 74.8 & 72.4 & (2.4) & 45.3 & 45.0 & (0.3) \\
\hline $24^{a}$ & 7,321 & 7,196 & 125 & $1.7 \%$ & 64 & 74.8 & 73.1 & (1.7) & 54.8 & 48.3 & (6.5) \\
\hline 27 & 13,037 & 8,018 & 5,019 & $38.5 \%$ & 69 & 75.2 & 75.0 & $(0.2)$ & 45.4 & 46.2 & 0.8 \\
\hline 54 & 8,112 & 6,426 & 1,686 & $20.8 \%$ & 65 & 76.4 & 75.6 & (0.9) & 46.4 & 51.6 & 5.2 \\
\hline 60 & 5,321 & 3,577 & 1,745 & $32.8 \%$ & 64 & 76.1 & 76.7 & 0.6 & 52.4 & 50.7 & (1.6) \\
\hline Average & 8,680 & 6,109 & 2,571 & $29.6 \%$ & 66.3 & 76.1 & 75.6 & $(0.5)$ & 51.0 & 50.9 & 0.2 \\
\hline Std. Dev. & 3,327 & & 1,674 & & & & & & & & \\
\hline Median & & & 2,007 & $32.7 \%$ & & & & $(0.2)$ & & & 0.6 \\
\hline
\end{tabular}

${ }^{a}$ Site 24 had significant temperature-related take-back $\left(1.7^{\circ} \mathrm{F} ; 6.5 \% \mathrm{RH}\right)$ relative to the other supplemental MSHP sites, and this had much lower savings than did the other sites. Aside from the initial setup, the project did not direct users on how to use the supplemental mini-split, which meant that some sites could use the mini-split more than the main system or vice versa. For instance, Site 24 used the mini-split in conjunction with continuously running the fan of main air handling unit, which severely reduced HVAC savings. Meanwhile, other sites, such as Site 21, used the MSHP very aggressively to reduce operation of the main HVAC system. This produced widely varying but still valid results that would likely be experienced in a larger supplemental mini-split program. 
Table 7. TMY3-Normalized Heating Energy Use and Savings from the Supplemental MSHP Sites

\begin{tabular}{|c|c|c|c|c|c|c|c|c|}
\hline Site No. & $\begin{array}{c}\text { Pre- } \\
\text { Heating } \\
\text { (kWh/ } \\
\text { year) }\end{array}$ & $\begin{array}{c}\text { Post- } \\
\text { Heating } \\
\text { (kWh/year) }\end{array}$ & $\begin{array}{l}\text { Savings } \\
\text { (kWh/ } \\
\text { year) }\end{array}$ & $\begin{array}{l}\text { Savings } \\
\text { (\%) }\end{array}$ & $\begin{array}{c}\text { Cool } \\
\text { Bal. T } \\
\left({ }^{\circ} \mathrm{F}\right)\end{array}$ & $\begin{array}{l}\text { Tint } \\
\text { pre- } \\
\left({ }^{\circ} \mathrm{F}\right)\end{array}$ & $\begin{array}{c}\text { Tint } \\
\text { post- }\left({ }^{\circ} \mathrm{F}\right)\end{array}$ & $\Delta T$ \\
\hline 3 & 115 & 94 & 22 & $18.7 \%$ & 65 & 68.7 & 70.6 & 2.0 \\
\hline 5 & 734 & 309 & 424 & $57.8 \%$ & 64 & 73.2 & 73.0 & $(0.3)$ \\
\hline $12^{\mathrm{a}}$ & 235 & 218 & 18 & $7.6 \%$ & 65 & & & \\
\hline 16 & 476 & 86 & 390 & $82.0 \%$ & 63 & 68.4 & 70.5 & 2.1 \\
\hline 21 & 585 & 103 & 482 & $82.4 \%$ & 68 & 73.8 & 73.2 & $(0.6)$ \\
\hline 23 & 1,516 & 592 & 925 & $61.0 \%$ & 69 & 73.9 & 72.9 & (1.0) \\
\hline 24 & 361 & 206 & 155 & $43.0 \%$ & 64 & 68.9 & 68.3 & $(0.6)$ \\
\hline 27 & 2,627 & 1,082 & 1,544 & $58.8 \%$ & 69 & 73.8 & 75.1 & 1.3 \\
\hline \multicolumn{9}{|l|}{$54^{b}$} \\
\hline 60 & 427 & 111 & 316 & $74.1 \%$ & 64 & 73.0 & 73.1 & 0.1 \\
\hline Average & 786 & 311 & 475 & $60.4 \%$ & 65.7 & 71.7 & 72.1 & 0.4 \\
\hline Std. Dev. & 800 & & 487 & & & & & \\
\hline Median & & & 390 & $58.8 \%$ & & & & (0.1) \\
\hline
\end{tabular}

${ }^{\mathrm{a}}$ Temperature and $\mathrm{RH}$ were measured with different devices pre- and post-retrofit.

${ }^{b}$ This site had no pre-retrofit heating to measure.

Table 8. TMY3-Normalized Annual Cooling and Heating Energy Use and Savings from the Supplemental MSHP Sites

\begin{tabular}{ccccc}
\hline Site No. & $\begin{array}{c}\text { Pre- } \\
\text { HVAC } \\
\text { (kWh/year) }\end{array}$ & $\begin{array}{c}\text { Post- } \\
\text { HVAC } \\
\text { (kWh/year) }\end{array}$ & $\begin{array}{c}\text { Savings } \\
\text { (kWh/ } \\
\text { year) }\end{array}$ & $\begin{array}{c}\text { Savings } \\
\text { (\%) }\end{array}$ \\
\hline $\mathbf{3}$ & 8,165 & 5,513 & 2,652 & $32.5 \%$ \\
\hline $\mathbf{5}$ & 16,320 & 10,315 & 6,004 & $36.8 \%$ \\
\hline $\mathbf{1 2}$ & 7,807 & 6,242 & 1,565 & $20.0 \%$ \\
\hline $\mathbf{1 6}$ & 7,490 & 5,430 & 2,060 & $27.5 \%$ \\
\hline $\mathbf{2 1}$ & 5,555 & 2,803 & 2,752 & $49.5 \%$ \\
\hline $\mathbf{2 3}$ & 11,337 & 6,971 & 4,366 & $38.5 \%$ \\
\hline $\mathbf{2 7}$ & 7,682 & 7,402 & 280 & $3.6 \%$ \\
\hline $\mathbf{5 4}$ & 15,664 & 9,100 & 6,563 & $41.9 \%$ \\
\hline $\mathbf{6 0}$ & 8,112 & 6,426 & 1,686 & $20.8 \%$ \\
\hline Average & 5,748 & 3,687 & 2,061 & $35.9 \%$ \\
\hline Std. Dev. & $\mathbf{9 , 3 8 8}$ & $\mathbf{6 , 3 8 9}$ & $\mathbf{2 , 9 9 9}$ & $\mathbf{3 1 . 9 \%}$ \\
Median & 3,820 & & $\mathbf{2 , 0 2 0}$ & \\
\hline
\end{tabular}


Examining the sites as a group, cooling season interior temperature and $\mathrm{RH}$ were relatively similar between pre- and post- periods, on average, with dew points averaging $68.3^{\circ} \mathrm{F}$ pre- and $69.2^{\circ} \mathrm{F}$ post-retrofit. On average, no moisture removal advantage of the supplemental MSHP was apparent; however, there were significant variations for some homes. For instance, the novel configuration showed a large improvement to $\mathrm{RH}$ at Site $24-$ a reduction of $6.5 \%$, where the average dew point exceeded $69^{\circ} \mathrm{F}$ both pre-and post-retrofit. Meanwhile, some take-back, a "taking back" of some of the post-retrofit energy efficiency gains for improved comfort, is apparent with this site, having had among the largest reductions in the average cooling season interior temperature $-74.8^{\circ} \mathrm{F}$ (pre) $73.1^{\circ} \mathrm{F}$ (post) — and experienced the smallest cooling energy savings (1.7\%). Among all 10 evaluation sites, the average heating season interior temperature is also essentially unchanged between periods; however there were some increases. Cooling season ambient temperature was typically slightly cooler, averaging $0.4^{\circ} \mathrm{F}$ lower post-retrofit: $76.9^{\circ} \mathrm{F}$ compared to $76.5^{\circ} \mathrm{F}$.

Figure 3 shows the times series data in which electric resistance strip heat is highly visible, as is the reduction to the space cooling in summer and the very low power of the mini-split systems for Site 60 .

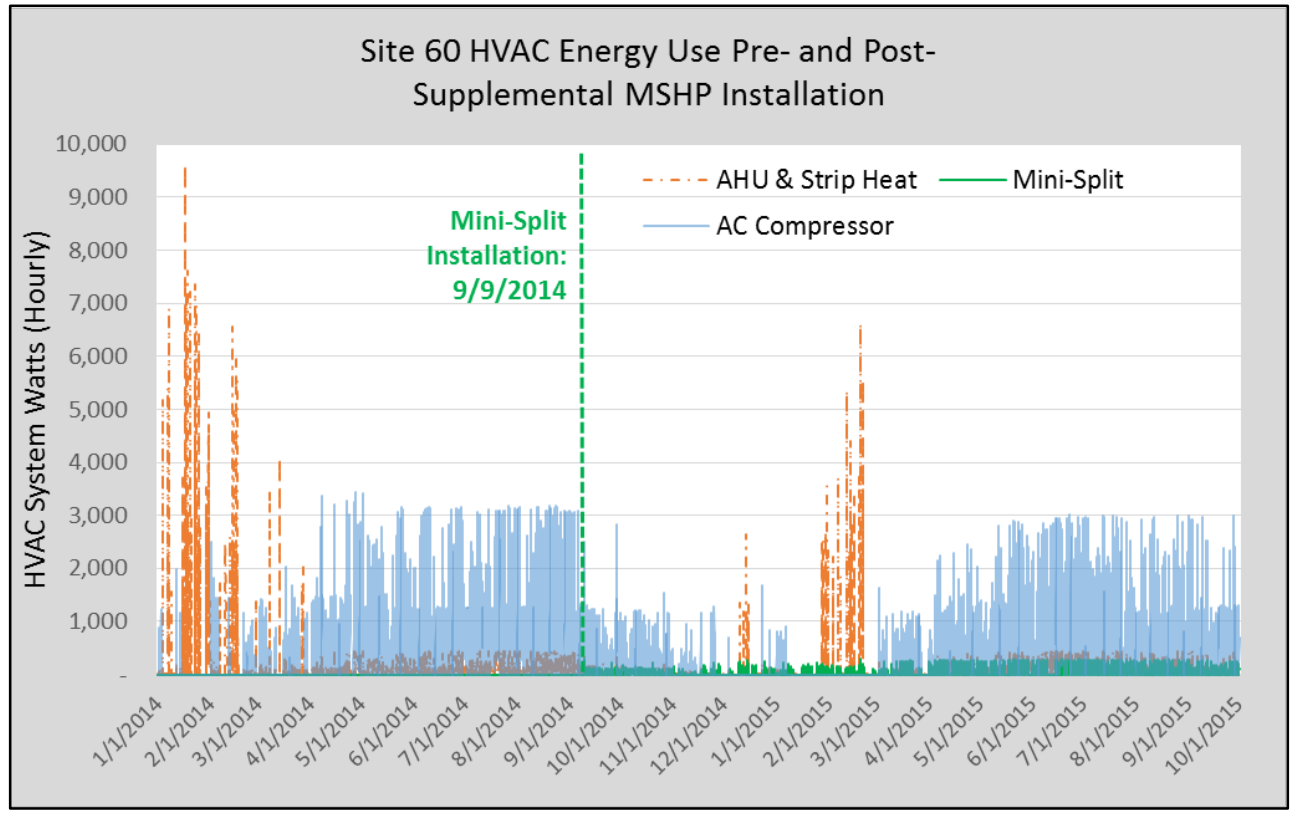

Figure 3. Time series data showing HVAC energy use by air-conditioner compressor (blue), air handling unit and strip heat (orange), and supplemental mini-split (green) for Site $\mathbf{6 0}$

Figures 4 and 5 show examples of the analysis methods used for Site 60 to illustrate how savings estimates were obtained. Figure 4 shows the regression lines for space cooling, indicating the pronounced impact on daily electricity use. The data show average cooling energy savings of $32.8 \%$ or $1,745 \mathrm{kWh} /$ year. Interior temperature was unchanged between periods; however, $\mathrm{RH}$ was $1.6 \%$ lower post-retrofit. 


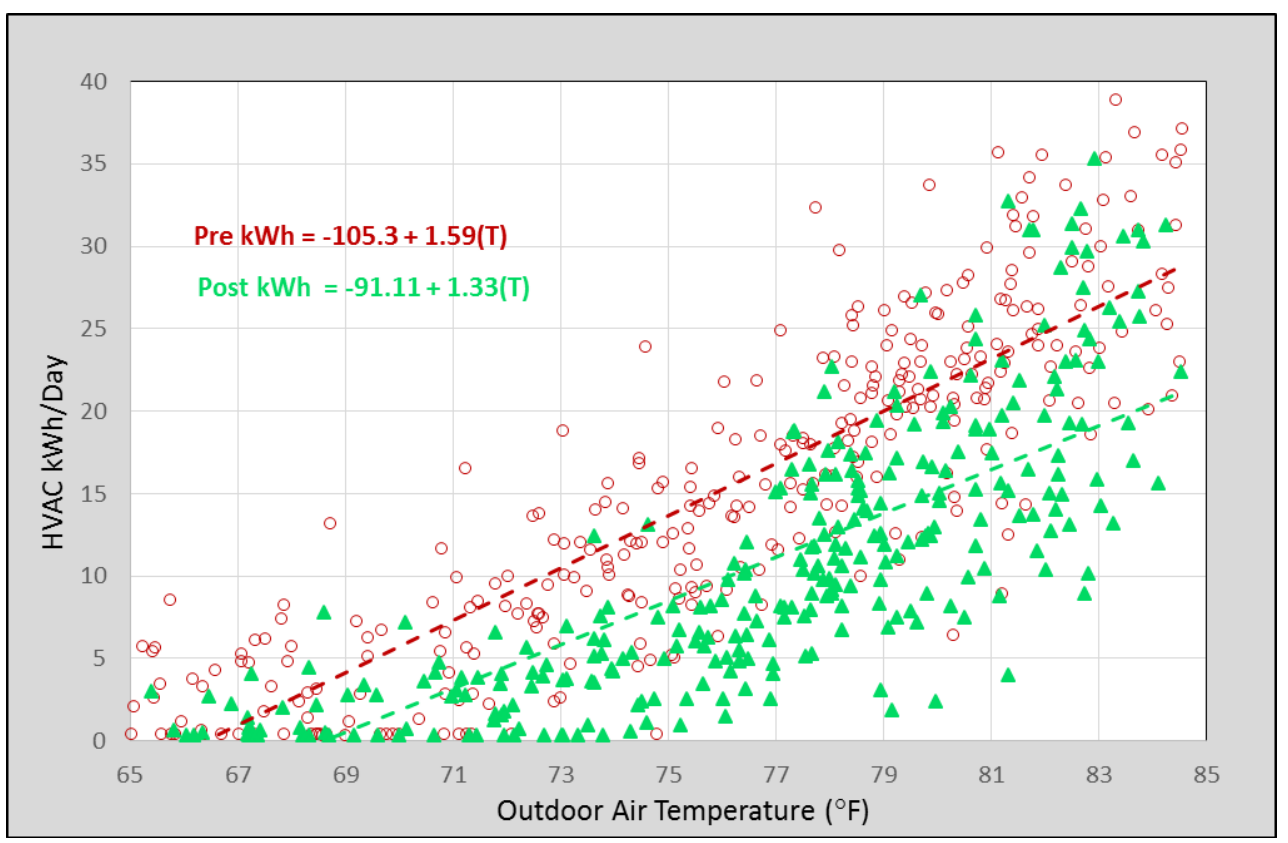

Figure 4. Regression lines for measured daily cooling before and after supplemental mini-split retrofit at Site 60

Figure 5 gives a similar presentation for space heating with large differences shown in the switch from electric resistance heat to primarily MSHP heating.

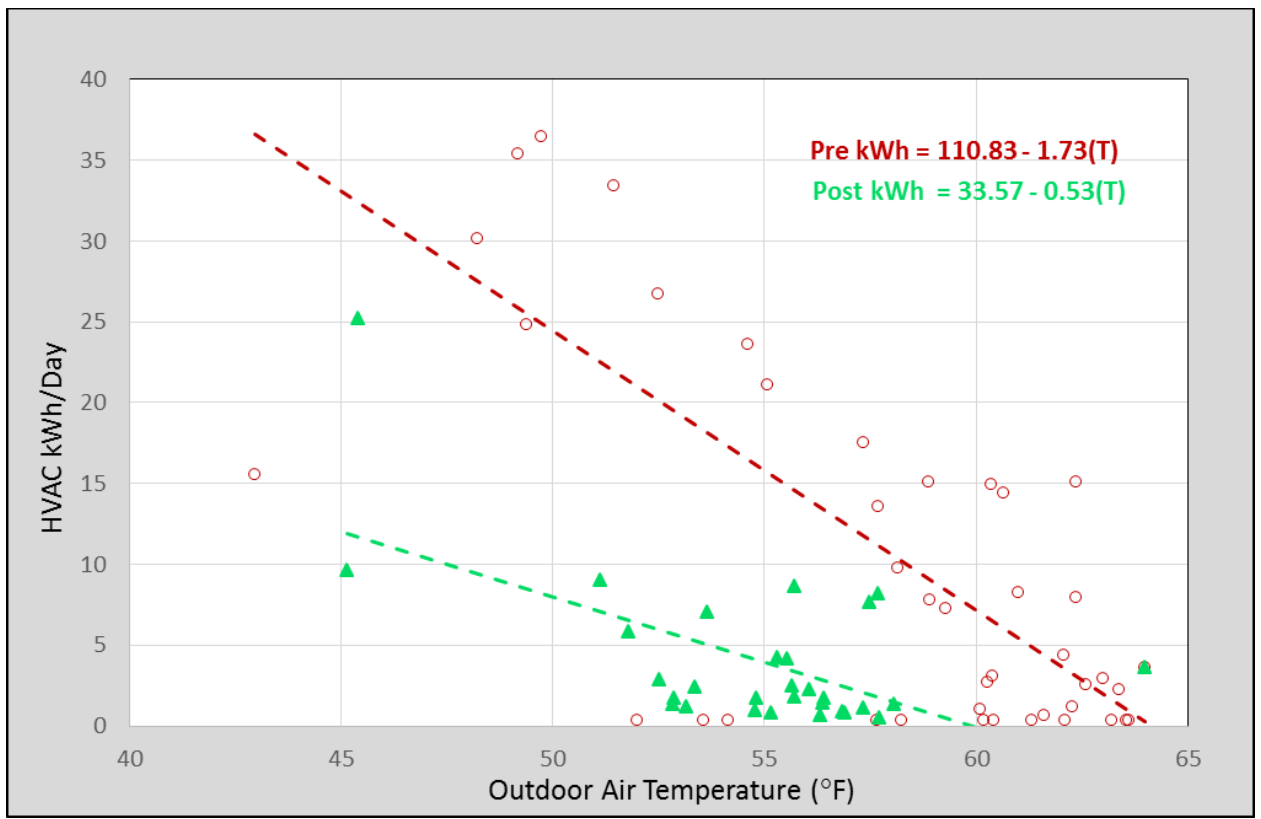

Figure 5. Regression lines for measured daily space heating before and after supplemental mini-split retrofit at Site 60 
The typical percent heating energy reductions achieved by the supplemental mini-splits were considerably greater than they were for cooling. This takes place because sites 16, 21, 23, 24, 27, and 60 had electric resistance heating, whereas the mini-split uses only its much more efficient heat pump. The median daily space-heating savings were $58.8 \%, 390 \mathrm{kWh} /$ year, or approximately $7.0 \mathrm{kWh} /$ day. Space-cooling energy saving were large, with a median of $32.7 \%$, $2,007 \mathrm{kWh} /$ year, or approximately $6.8 \mathrm{kWh} /$ day. Total annual heating and cooling savings were $2,397 \mathrm{kWh}$ or $34 \%$. Regressions from the analysis of the supplemental mini-split installations are provided in Appendix B.

The projected HVAC annual energy savings from the supplemental MSHP measure for all 10 sites are impressive, with a total of $34.2 \%$ or $2,357 \mathrm{kWh} /$ year. The average full retail cost for equipment, materials, and labor for the 10 supplemental MSHP installations was $\$ 3,886$. The median annual HVAC energy savings translates into approximately $\$ 283$ saved per year $(2,357$ $\mathrm{kWh} /$ year $* 0.12 / \mathrm{kWh}$ ), which yields a simple payback in approximately 14 years and an annual rate of return of $7.3 \%$. In a mature market, economics are likely to improve with equipment and labor cost reductions - particularly as crews become more familiar with the relatively simple job of installing MSHPs and there is more competition in the HVAC industry. This cost analysis does not consider one notable benefit to the consumer: the redundant heating and cooling system for the home, which is highly desirable given the failure rate of central AC systems. In Florida's cooling-dominated climate, where systems are often used continuously, AC systems typically last only 10-15 years, and maintenance needs can often take them off-line temporarily.

\subsection{Supplemental Mini-Split Heat Pump Peak Reductions}

In an investigation of the supplemental MSHP's influence during peak summer and winter hours, HVAC power demand at the seasonal peak hours in 2014 were compared to those of 2015; however, a surrogate summertime peak was necessary because not all 10 installations were complete before the summer 2015 peak of June 22. The slightly milder August 20 was used instead.

Figure 6 compares the average HVAC demand of the 10 supplemental MSHP sites during the summer peak of July 28, 2014 (pre-retrofit) to the surrogate peak day on August 20, 2015 (postretrofit), which shows a large demand of $0.50 \mathrm{kWh}$ or $16 \% .{ }^{7,8}$ The HVAC energy use reduction for the day was $32 \%: 50.6 \mathrm{kWh}$ pre-retrofit and $34.1 \mathrm{kWh}$ post-retrofit.

\footnotetext{
${ }^{7}$ Demand reduction is $0.88 \mathrm{~kW}$ or $28 \%$ between the typical peak hour from 4 p.m. to 5 p.m.

${ }^{8}$ Although pre-retrofit peak hour had higher ambient temperatures midday, this is not the only factor involved in utility coincident peak hour. Other factors include temperature distribution, population, and service territory weights; preceding few days' temperature and rainfall; day of the week; and solar irradiance.
} 


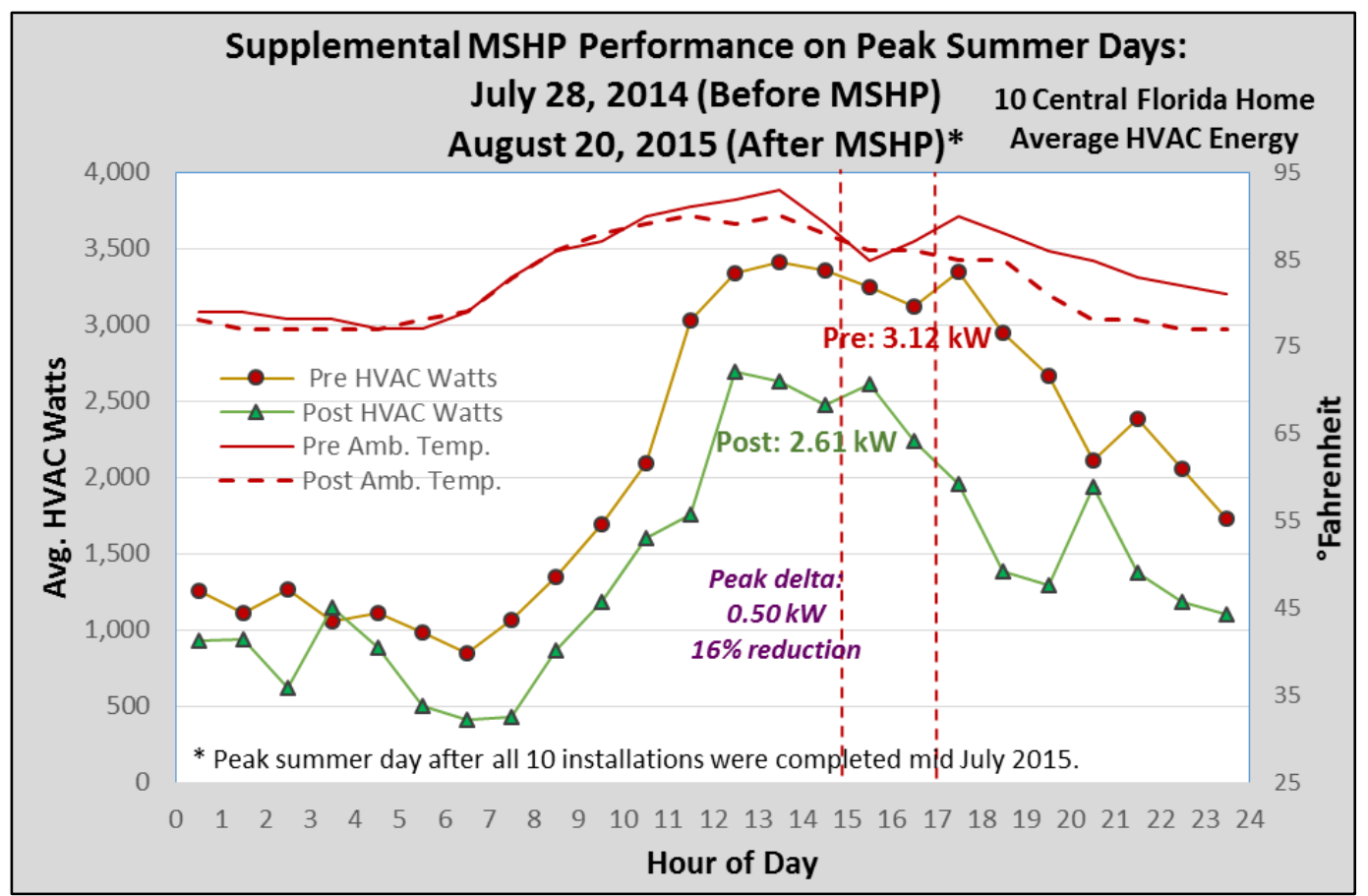

Figure 6. Comparative analysis between pre- and post-retrofit demand on FPL's system peak summer day in 2014 and surrogate peak summer day in 2015

Because four of the MSHPs were installed between June and July 2015, a post-retrofit winter peak for comparison has not yet been determined for these sites; therefore, the winter peak evaluation is limited to the six supplemental MSHPs installed in 2014. Figure 7 compares the average HVAC demand at these sites during the winter peak of January 23, 2014 (pre-retrofit) to the winter peak of February 20, 2015 (post-retrofit), which shows a very large demand reduction of $2.06 \mathrm{~kW}$ or $56 \%$ between 7 a.m. and 8 a.m. The HVAC energy use reduction for the day was 25\%: $37.4 \mathrm{kWh}$ pre-retrofit and $28.2 \mathrm{kWh}$ post-retrofit. 


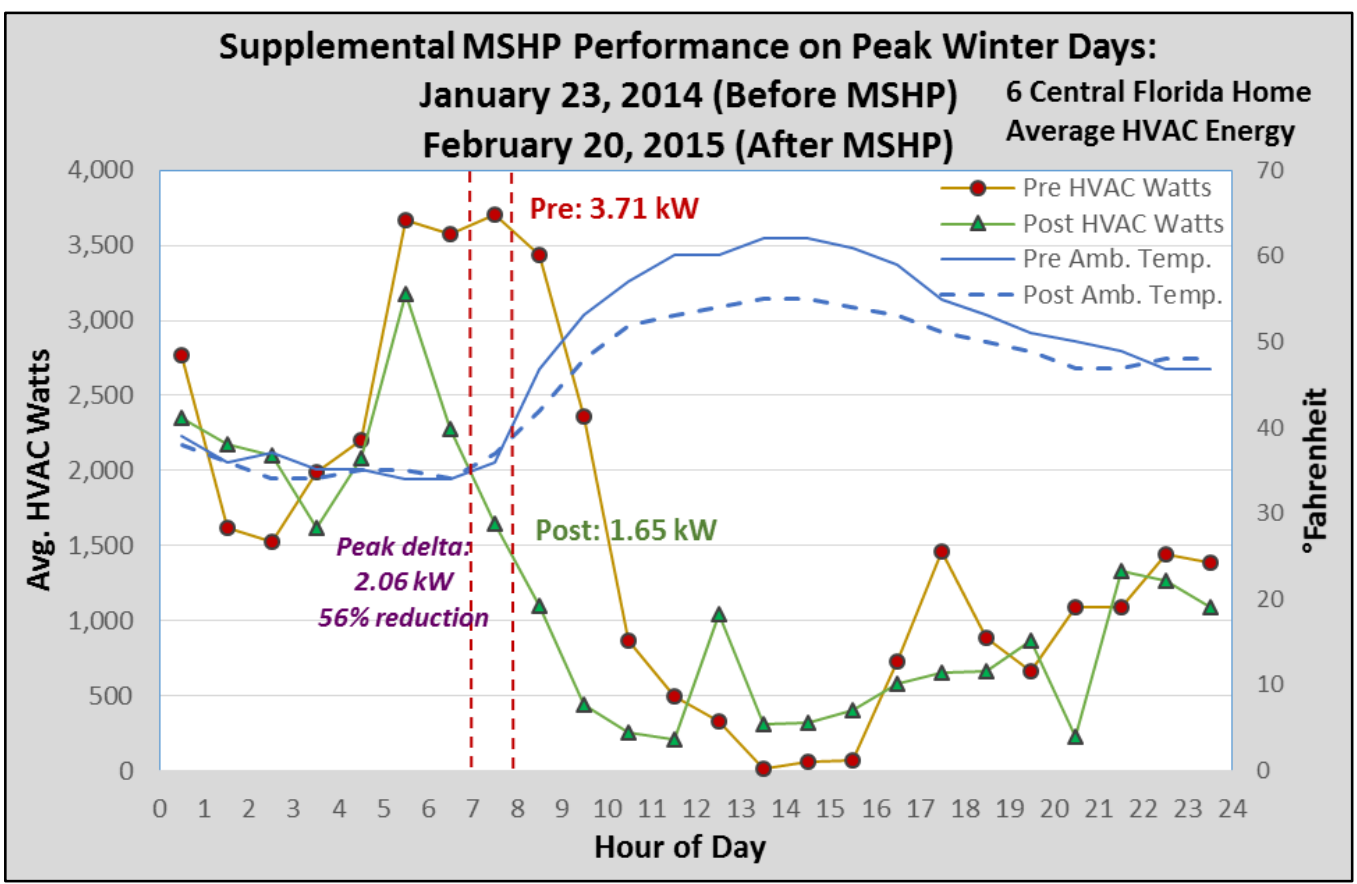

Figure 7. Comparative analysis between pre- and post-retrofit demand on FPL's system peak winter days

In summary, the median annual HVAC energy reductions for the supplemental MSHP were impressive: $34 \%$, with good utility demand reductions of the supplemental mini-split also very large in both summer and winter for our small sample of 10 and 6 sites, respectively. Reductions to long-term average interior RH were sometimes observed, albeit inconsistently. 


\section{Evaluation of Complete Central System Replacement with Inverter-Driven Heat Pumps}

An important facet of the shallow-plus phase of the project was to install high-efficiency, inverter-driven heat pumps as a full replacement to existing central systems. This was conducted at two sites to investigate possible space-cooling and space-heating energy use reductions when a traditional-type central system is replaced. Testing before and after change provides detailed information on impacts on energy use and comfort. Two different replacement schemes were tested to provide insight into contrasting solutions. The first such design involved a multi-split with a single condenser and two fan coils: a ductless unit to condition the main living area and a ducted component to condition the rooms isolated from the main living space, referred to herein as a "multi-split heat pump."

The design for the second site consisted of one MSHP ducted to condition the whole house, referred to herein as a "ducted MSHP." This research is to investigate the expected space-cooling and space-heating energy use reductions when replacing a traditional-type central system with a complete MSHP design. Each system and evaluation will be discussed in turn. Lessons learned and likely advantages for the two approaches are highlighted.

\subsection{Evaluation of Multi-Split Heat Pump 6.1.1 Site Characteristics}

The subject Site 11 is a three-person occupancy, single-story, ranch-style, three-bedroom, twobathroom home with 1,672 $\mathrm{ft}^{2}$ of living space located in Cocoa Beach, Florida. This home, built in 1958, has uninsulated CMU walls and a concrete slab foundation. The windows are singlepane, clear glass, with metal frames. The shallow (2/12 pitch), gravel-covered, single-assembly roof has a combination of insulation applications - primarily R-6 mineral wool insulation at the roof deck. On October 7, 2015, the existing roof was replaced with a highly-reflective white metal roof. The home has only a small semi-conditioned attic buffer space, an area approximately $15^{\prime}$ x $3^{\prime}$ above the bedroom hallway, which is lined with R-13 fiberglass batts at the roof deck. This unvented attic is cooler than typical due to the location of the insulation at the roof deck. The airtightness test results for the houses were poor: 10.9 ACH50; however, this is characteristic of a 1950's house.

The existing air conditioner is a 12.0 SEER, 7.5 HSPF-rated, 3-ton heat pump. A single, centrally-located return feeds into the interior-located fan coil. Supply air is distributed via ducts to the bedrooms and bathrooms through the semi-conditioned attic and to the remainder of the building inside a chase. The flex ducts are of unknown thermal value, but they are suspected to have a thermal resistance of $\mathrm{R}-4 \mathrm{hrft}^{2}-\mathrm{F} / \mathrm{Btu}$, and they are poorly sealed $(\mathrm{Qn}$, out $=0.13)$.

\subsubsection{Measure Description}

A single 3-ton compressor was tied to both a 1.5-ton wall-mounted fan coil installed in the main living area and a 1-ton ceiling-mounted fan coil in the hallway of the home. The ceiling-mounted unit was ducted to condition the home's bedrooms, office, and the second bathroom. A Carrier model set was chosen: the 38MGQF36 variable-speed condensing unit, the 40MAQB18B wallmount, and the $40 \mathrm{MBQB} 12 \mathrm{D}$ ceiling-mount. The performance rating on the system varies from a high of 18 SEER, 10 HSPF, with non-ducted units; to 15 SEER, 9.3 HSPF, with ducted units. The rating for the use of a combination of ducted and non-ducted units is 16.5 SEER, 9.7 HSPF. 
The system has a rated cooling capacity of $35,000 \mathrm{Btu} /$ hour at an outdoor temperature of $95^{\circ} \mathrm{F}$ and heating capacity of $36,000 \mathrm{Btu} /$ hour at an outdoor temperature of $47^{\circ} \mathrm{F}$. In this case, the chosen indoor units' combined capacity ratings are approximately 30,000 Btu/hour for cooling and heating, leaving some capacity to spare. Specifications allow for a maximum of four indoor units, so the homeowners are able to add another indoor unit ranging from $0.75-1$ ton in the future.

The installation of the multi-split heat pump began on July 1, and it was operational on July 8, 2015. Figure 8 provides the locations chosen for the wall-mounted air handling unit in the main living area and the ducted ceiling-mounted air handling unit to service the bedrooms, office, and second bathroom.
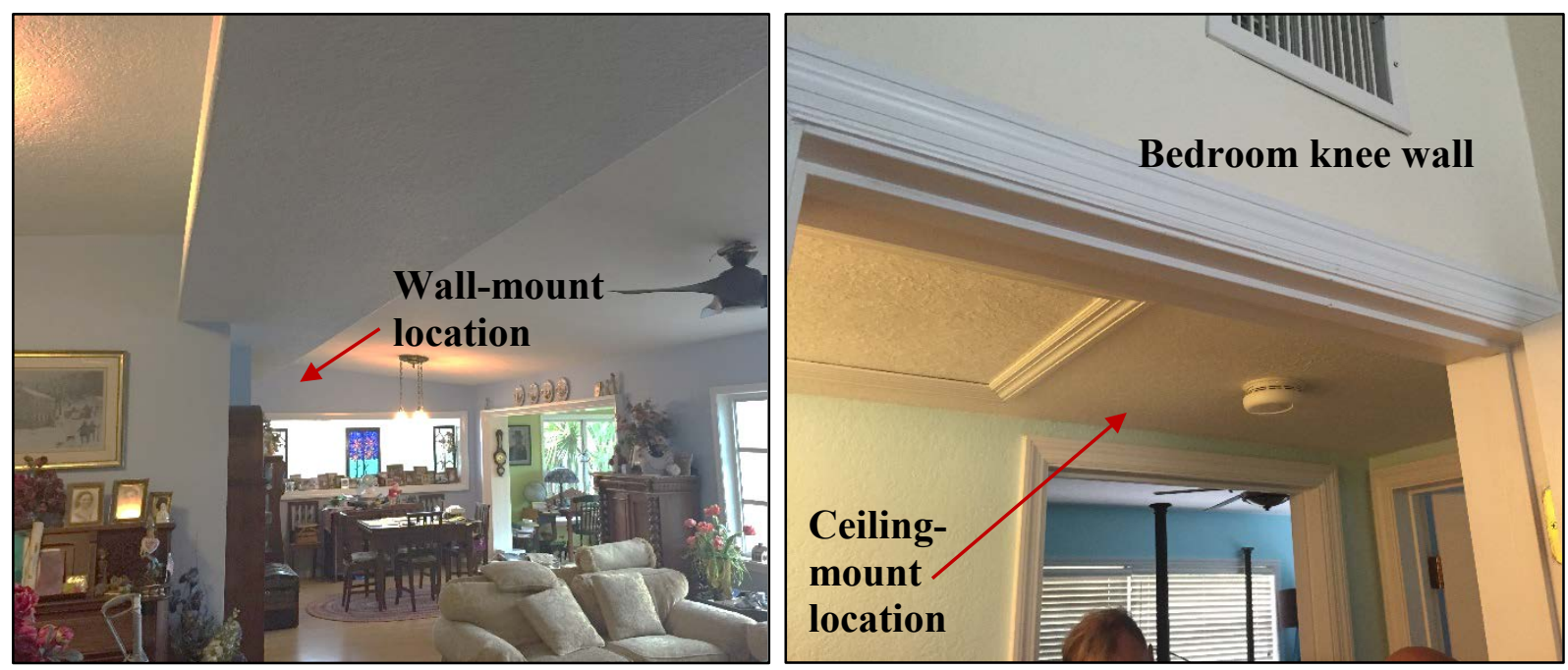

Figure 8. Chosen locations for the wall-mounted fan coil (left) and the ceiling-mounted fan coil and knee wall for supply into bedroom (right)

The installation of the wall-mounted fan coil to service the main living area was straightforward. The dining area exterior wall on the north side of the house provided an ideal location for the system to service the kitchen, living room, and Florida room. The slight pitch of the singleassembly gable provided the requisite space for the unit to be mounted between the top of the window frame and the ceiling for proper airflow. Placing the fan coil on an exterior wall enables a gravity-draining condensate line, avoiding the need for a condensate pump. The electrical panel is only a few feet away, requiring only short runs for both the condenser electrical wiring and the fan coil line set, as illustrated in Figure 9 and in the design sketch in Figure 10. 

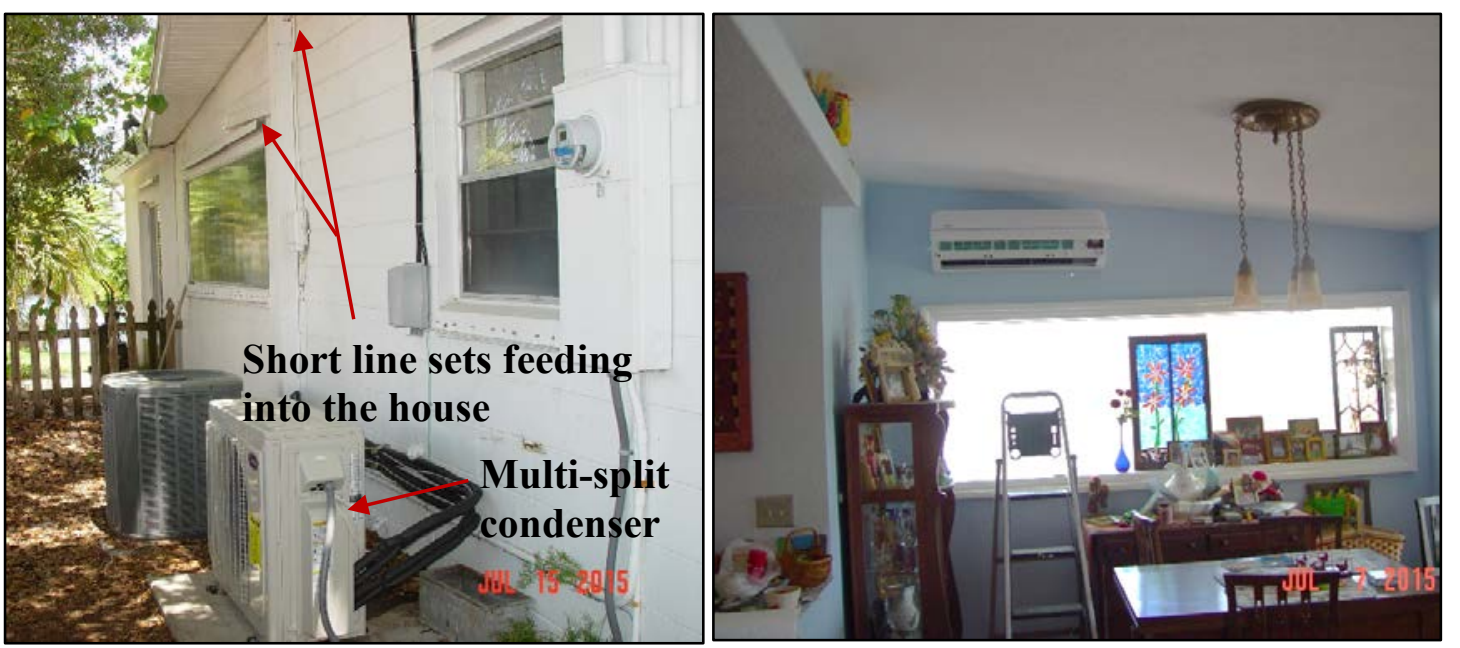

Figure 9. Condenser location, nearby electrical panel, and short exterior line set runs (left); centrally-located, wall-mounted fan coil (right)

Site 11 Ducted Multi-Split Heat Pump Design

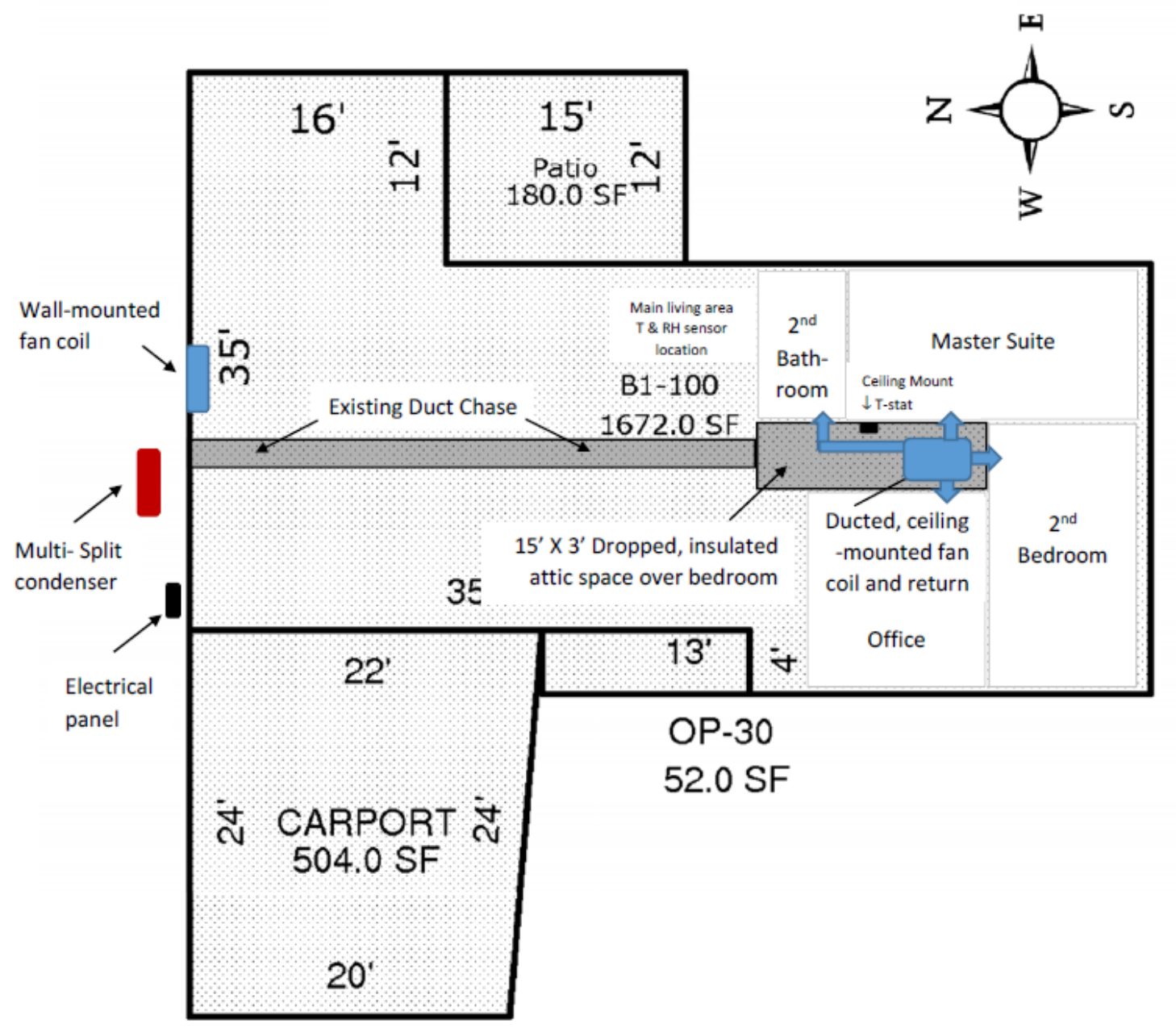

Figure 10. Design sketch of Site 11 multi-split heat pump retrofit 
The short refrigerant lines and electrical wiring lengths are significant because the building has no peripheral attic space in which to pull and hide the indoor equipment service lines. Installing the compressor nearby the electrical panel works well for the wall-mounted air handling, also in close proximity; however, a creative solution was needed to run the service lines to the ducted fan coil at the south end of the house.

The ceiling-mounted fan coil was installed at the far end of the hallway, as indicated in Figure 9, to service the bedrooms, office, and second bathroom. The dropped ceiling above the hallway provided an ideal location to house the fan coil and run very short supply ducts through the knee walls to the adjacent bedrooms with single-assembly ceilings. A longer run was used to supply air to the second bathroom. Ducting supply air to the master bathroom would have required the construction of a chase given the house's singe-assembly ceiling/roof architecture and was dismissed on poor aesthetics and presumed expense. The central system's fan coil is located at the opposite (north) end of the corridor from the bedrooms. The fan coil's condensate line was fed into the nearby existing condensate drain; thus, no pump was required.

In preparation for the ceiling-mount installation, a junction box was fabricated from R-4.3 duct board. Junction box penetrations with dampered collars and the supply vent boots were sealed with mastic, as shown in Figure 11. Pictures of the attic space with the central system supply ducts and the fan coil ceiling penetration are provided in Figure 12. The installed fabricated junction box and fan coil with return plenum are displayed in Figure 13.
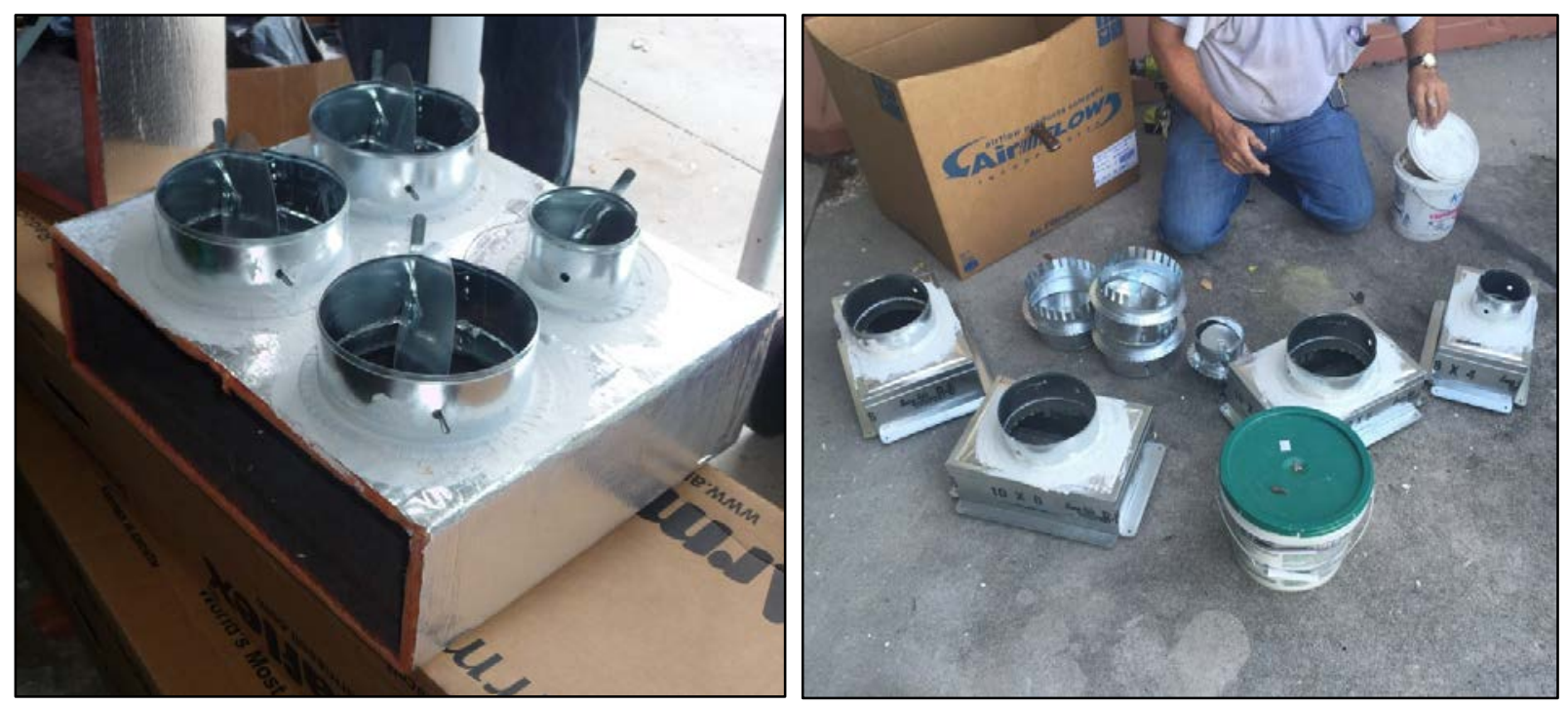

Figure 11. Dampered collars for four supply ducts attached and sealed to fabricated junction box (left); supply register boots sealed with mastic (right) 

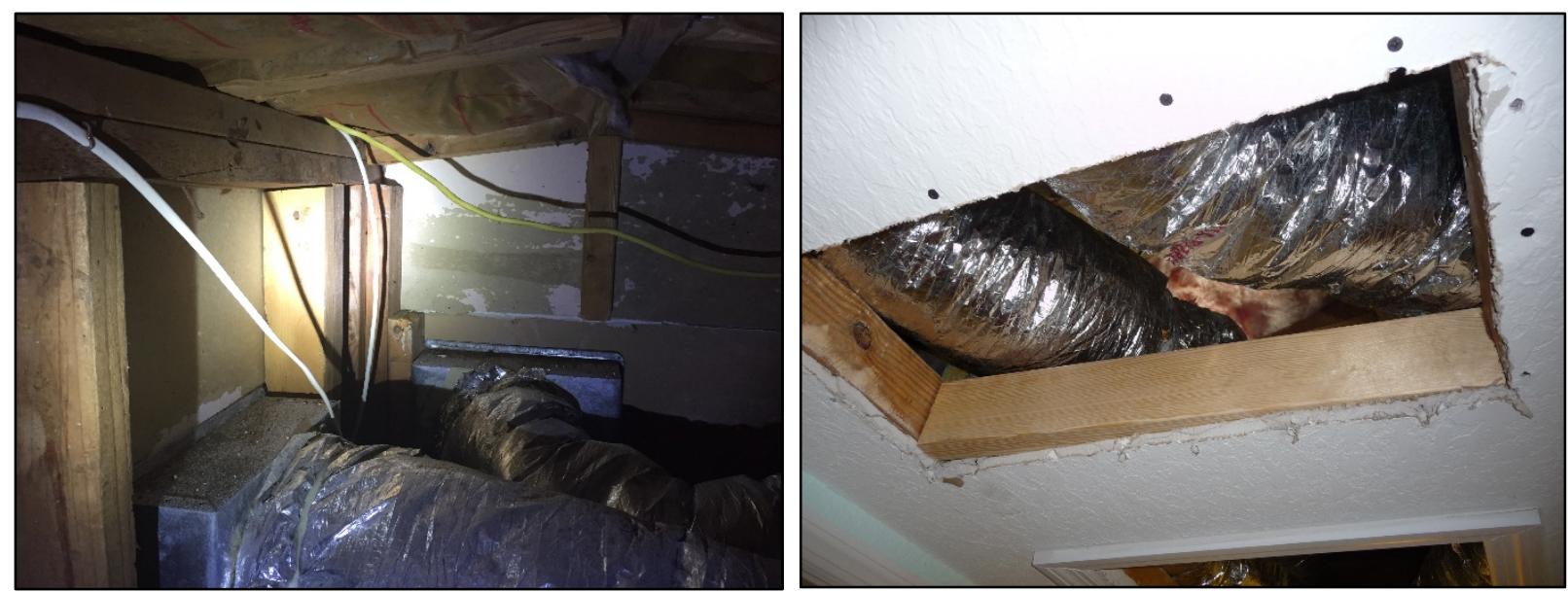

Figure 12. Pre-retrofit attic space used for the ceiling-mounted fan coil and supply air ducting (left); penetration into attic to mount the air handling unit (right)
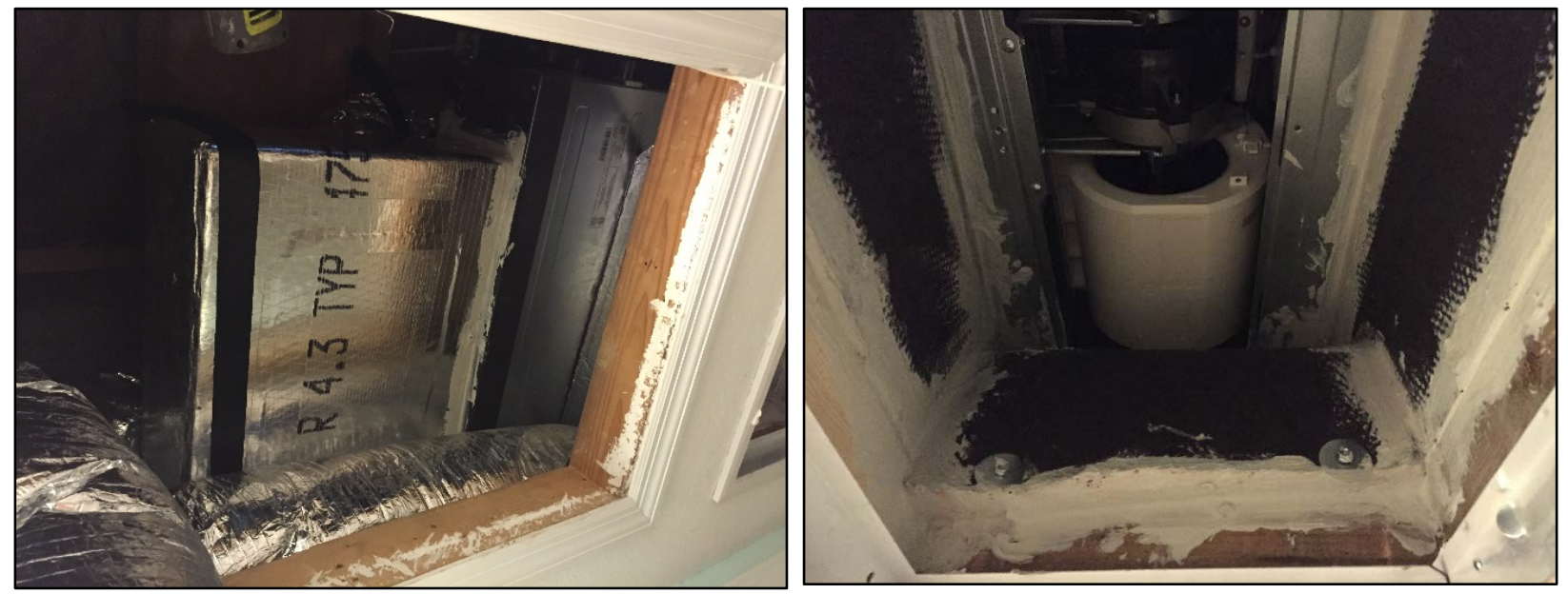

Figure 13. Fabricated junction box installed above attic hatch (left); return plenum and mini-split fan coil installed above ceiling penetration with seams sealed (right)

The existing central system ductwork was left intact for the time being, and the new supply register penetrations were installed adjacent to or above the existing ones. Figure 14 provides images of the finished work, including a view of the return for the ceiling-mounted air handling unit from the hallway and of the old and new opposable blade supply grilles from one of the bedrooms. 

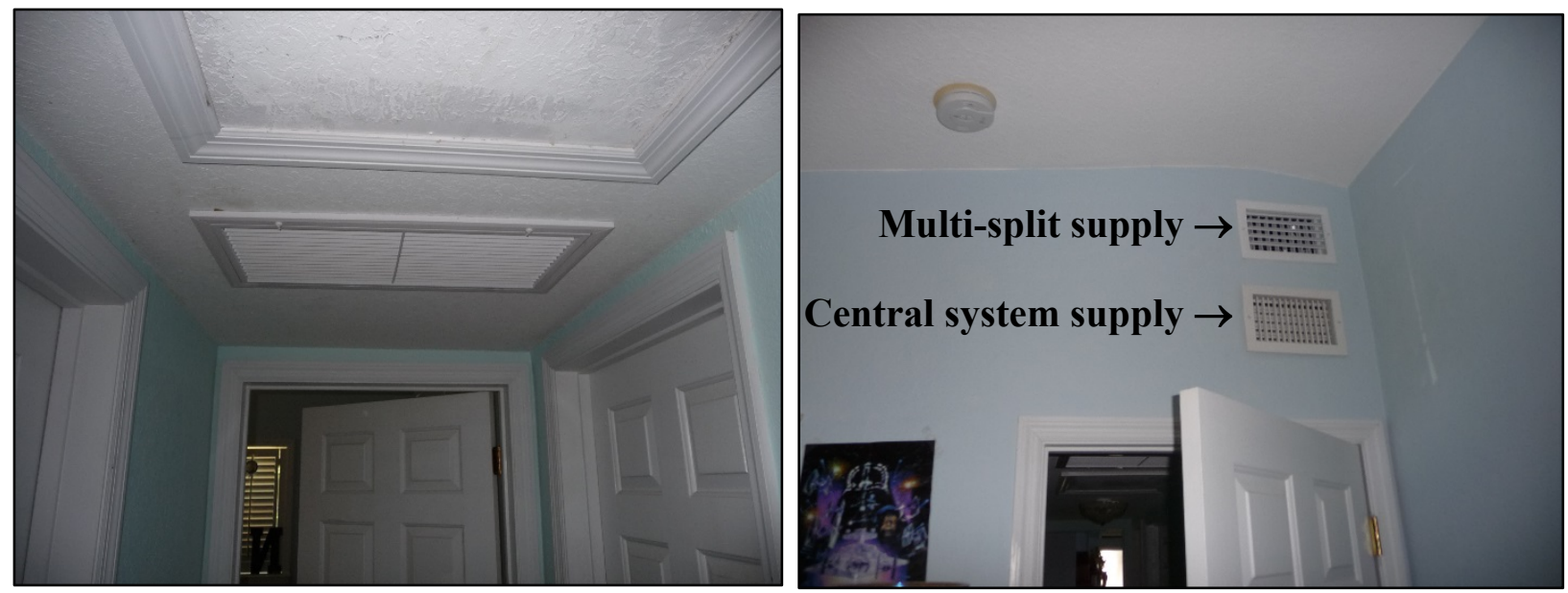

Figure 14. Ceiling-mounted fan coil return grille (left); existing and new supply registers (right)

The central system ductwork passes through a chase with recessed shelving dropped from the central line of the ceiling along the long axis of the home. The discrete shelving provides an aesthetically acceptable place to tuck in the line set, entering the north side of the building and running south to the attic section above the hallway to the bedrooms. The line set run required small holes to be cut in three interior walls. Although the original plan including building an encasement around the line set inside the shelf, the homeowners found that the line set was well hidden and preferred no encasement, except where the wall penetrations were made. Figure 15 shows the line set barely observable from a high vantage point as it passes inside the recessed duct chase shelf from the north side of the house into the attic space where it is attached to the ceiling-mounted fan coil.
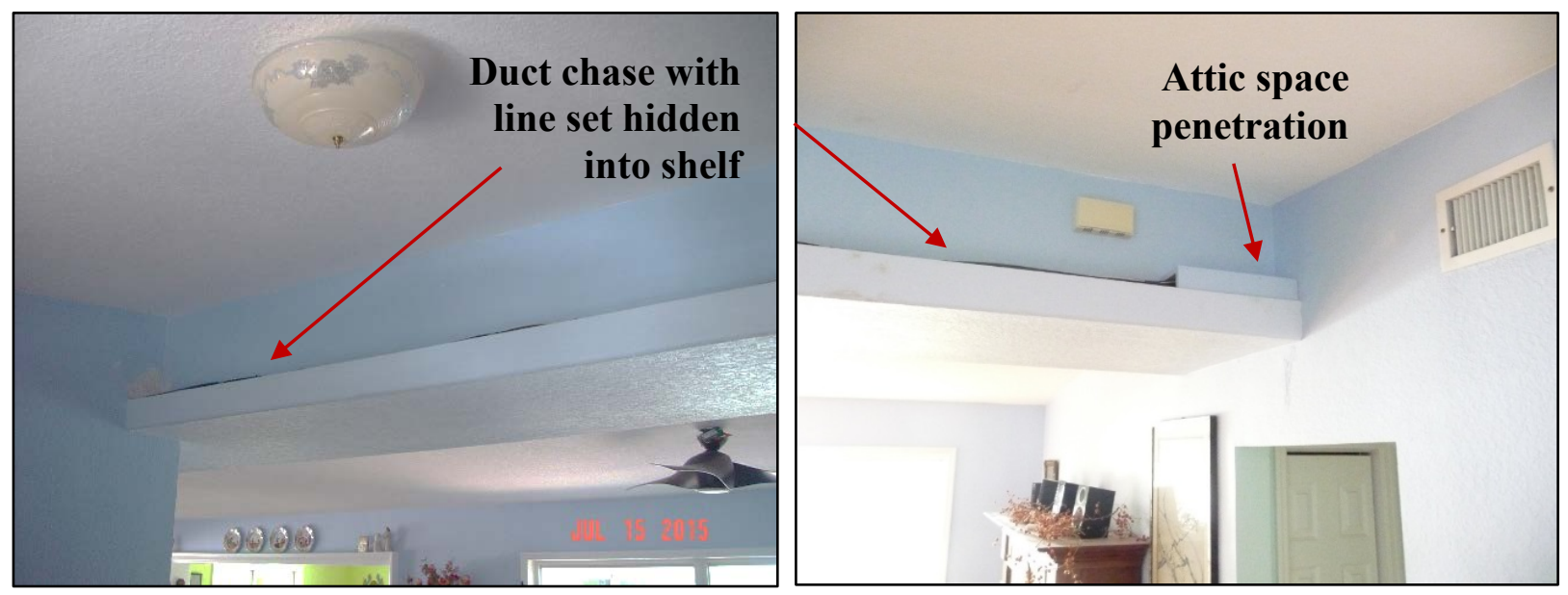

Figure 15. Line set tucked into the existing central system duct chase shelf

The total cost for the multi-split heat pump installation was approximately $\$ 8,000$. Installation costs, delineated by the various trades, involved are provide in Table 9. 
Table 9. Multi-Split Heat Pump Installation Costs

\begin{tabular}{lc}
\hline \multicolumn{1}{c}{ Installation Element } & Cost \\
\hline Mechanical system and materials & $\$ 2,596$ \\
\hline Mechanical labor & $\$ 4,696$ \\
Electrical materials and labor & $\$ 179$ \\
Finish carpentry materials a labor: & $\$ 475$ \\
System tax & $\$ 156$ \\
\hline Total multi-split installation cost & $\$ 8,102$ \\
\hline
\end{tabular}

\subsubsection{Multi-Split Heat Pump Installation Evaluation}

To confirm air distribution of the newly installed ducted system, the Energy Conservatory FlowBlaster was used to measure the airflow coming from the ceiling-mounted fan coil at each supply grille. A total of 258 cubic feet per minute (CFM) at $25 \mathrm{~Pa}$ was measured flowing out of the 1-ton unit, approximately $100 \mathrm{CFM}$ less than expected. Duct leakage results of Qn,out $=0.14$ similarly point to a less than ideal installation. Upon visual observation of the supply plenum site, researcher staff discovered two issues with the installation:

1. The return plenum was sealed from the inside only, not from the outside, at the air barrier.

2. Ducts were not properly attached and sealed to their supply plenum collars, which was apparently the source of the condensation around one junction.

The contractor addressed the first issue by creating a complete air barrier with a layer of mastic applied to the inside of the return plenum, as shown in Figure 16.

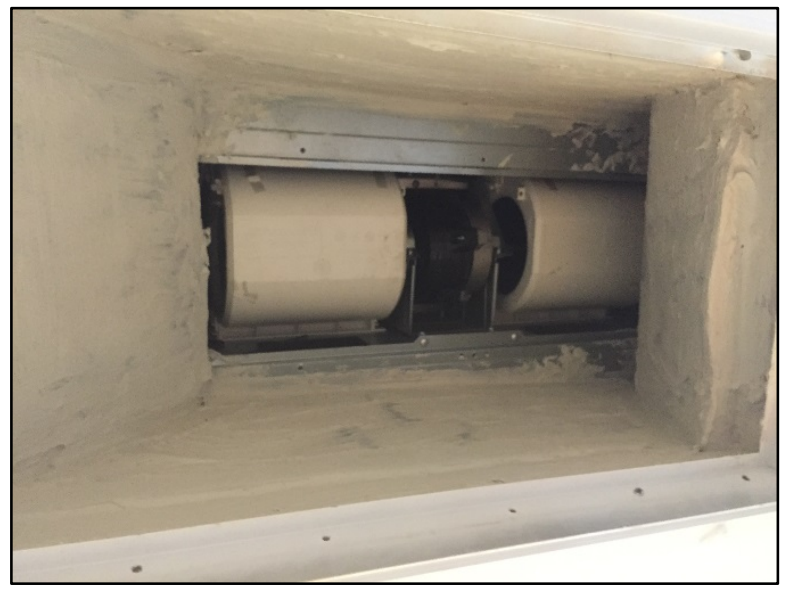

Figure 16. Air barrier applied to inside of return plenum

The second issue was addressed by removing and reattaching the supply ducts from the supply plenum collars and at the supply boot attachment sites for the office and bathroom. The limited work space prevented the contractor from reaching the master and second bedroom boots for reattachment. The effort improved the installation sealing moderately - upon retesting, the airflow from all supplies totaled $313 \mathrm{CFM}$, and Qn,out was reduced to 0.10 . Results from the initial and second FlowBlaster tests are presented in Table 10. 
Table 10. FlowBlaster Supply Grille Results

\begin{tabular}{lcc}
\hline \multicolumn{1}{c}{ Room } & $\begin{array}{c}\text { Initial FlowBlaster } \\
\text { Results } \\
\text { (CFM @ 25 Pa) }\end{array}$ & $\begin{array}{c}\text { Final FlowBlaster } \\
\text { Results } \\
\text { (CFM @ 25 Pa) }\end{array}$ \\
\hline Master & 66 & 115 \\
Second bedroom & 79 & 81 \\
Office & 88 & 97 \\
Bathroom & 25 & 20 \\
Total & $\mathbf{2 5 8}$ & $\mathbf{3 1 3}$ \\
\hline
\end{tabular}

Despite this improvement to system airflow, the occupants expressed discomfort issues from the completed system. Temperature imbalances across rooms were experienced during the height of the cooling season, with the office becoming too cool, whereas the master bedroom was often too warm.

Plotting data from sensors located in rooms throughout the house, researchers evaluated temperature and $\mathrm{RH}$ in each of the bedrooms compared to the conditions in the main living space. Figure 17 shows the hourly average daily temperature profile for four rooms during two summer weeks. The dining room is shown in green is serviced by the un-ducted, 1.5-ton, wall mounted fan coil. Temperatures for the bedrooms and office serviced by the ceiling mount are shown in red, orange, and blue.

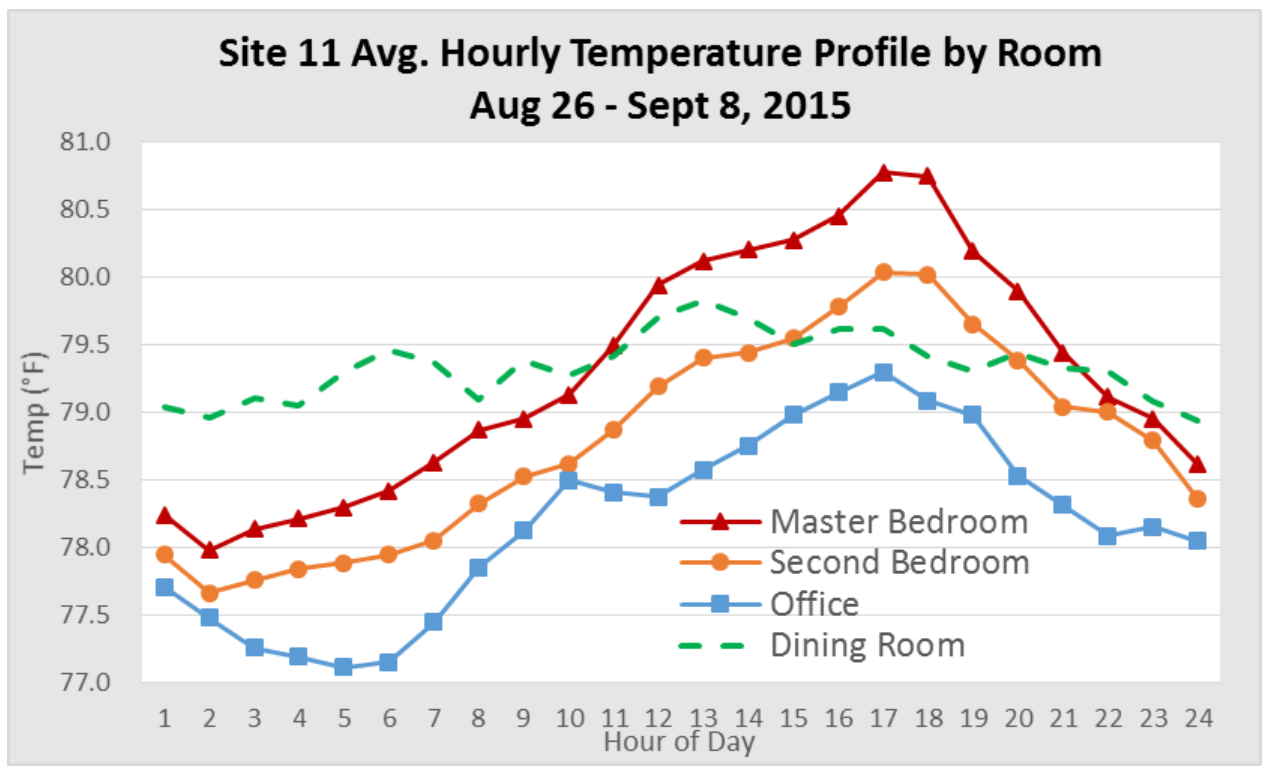

Figure 17. Average hourly temperature profile of four interior locations: bedrooms and office serviced by the ducted ceiling mount unit; dining room serviced by wall-mounted unit

The plot further displays that although the dining area maintains a constant temperature between $79^{\circ} \mathrm{F}-80^{\circ} \mathrm{F}$ throughout the day, the temperatures in the three rooms serviced by the ducted ceiling-mounted fan coil fluctuate considerably, with as much as $2^{\circ} \mathrm{F}$ differences among rooms. The homeowner reported that they frequently altered the ceiling-mounted unit's thermostat set 
point and restricted airflow to the office (which was often too cold) in attempt to achieve comfort in all rooms. At times, he said it gets too cold, in response to which he turns the system off.

An investigation of the RH in the rooms serviced by the ducted, ceiling-mounted unit revealed higher and more variable RH post-retrofit. Figure 18 provides a graphic display of the change in $\mathrm{RH}$ in the second bedroom; post-retrofit, the RH frequently exceeds $60 \%$, with variability a magnitude larger than it was pre-retrofit. Given the very high air leakage of the house, indoor RH may have exceeded $60 \%$ more frequently pre-retrofit than is indicated in Figure 5. This is suggested because although no pre-retrofit RH data were available during the mid- to latesummer period, outdoor conditions are generally moister than cooling season conditions prior to June.

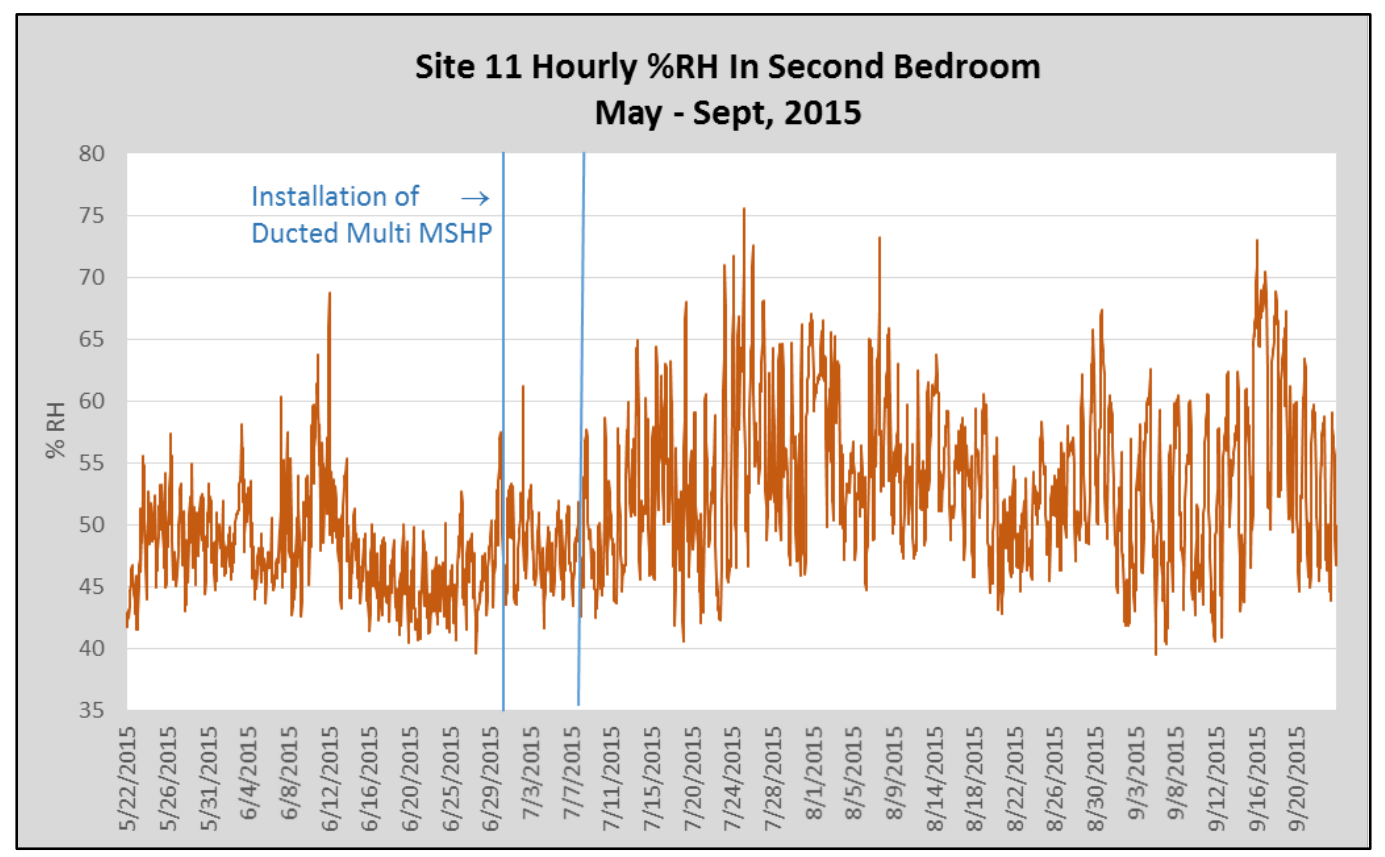

Figure 18. Hourly RH in the second bedroom pre- and post-retrofit

After learning about the interior temperature and humidity issues, FSEC researcher staff arranged for a site visit with Carrier technicians who identified two possible contributing problems.

1. Sensing location issue

A. As found during the site visit, the thermostat settings for the ceiling-mounted fan coil were set to sense temperature at the fan coil, which is located in the attic. The air temperature in the attic is often warmer than it is in the living space. This could prevent the system from sensing that the proper temperature was achieved, thereby keeping the system running. The representatives identified a "follow-me" setting that would force the system to sense temperature at the thermostat instead of the fan coil. 
B. The homeowner, who had tried various settings to try to achieve comfort, believed he had tried the follow-me setting, which didn't appear to solve the comfort issue. This pointed to the question of why the thermostat was located in the hall. The hall is served by the wall-mounted unit rather than the ceilingmounted unit (i.e., the ceiling mount has no supply into the hallway). A potential solution is to move the thermostat into the master bedroom.

2. Temperature-response lag

A. The delta between the set point and the temperature that will trigger the fan coil system to cycle off is approximately $4^{\circ} \mathrm{F}$. This could be why the homeowner was feeling too cold and then shutting the system off, making rooms too warm after extended downtimes. The steady rise and fall of the bedroom temperatures plotted in Figure 16 reflect this behavior.

Scarce monitored data exists regarding the ability of multi-split systems to effectively dehumidify homes in humid climates. ${ }^{9}$ The room temperature and RH specifically examined before and after the duct repair indicated that this was not the likely source of the performance issue.

Although the additional run time of an inverter-driven system may be able to provide enhanced latent removal, it is further restricted in the multi-split case by the maximum turndown ratio- the width of the operational range, defined as the ratio from maximum to minimum capacity. For example, a 3-ton single-unit can typically provide approximately 1 ton (33\%) of the maximum outdoor compressor capacity, whereas a multiunit design consisting of a 2-ton and a 1-ton unit is capable of turning down to $4,000 \mathrm{Btu} / \mathrm{hour}$ ( $33 \%$ of the smallest unit). This renders a multi-split system with a single outdoor unit less capable of operating during low-sensible-load conditions compared to if zoning were accomplished by two independent mini-split systems delivering the same total capacity. This is a known issue that the industry is working to solve.

Although these points may be related to the comfort issues at Site 11, RH appeared to be a problem only in the rooms serviced by the ceiling mount, not the main living area. (See Table 9 for the post-retrofit change in the main living area RH.) This again points to a specific limitation in the multi-split arrangement where the sizing of the single outdoor compressor may be critical to the potential degree of control at low cooling loads.

Finally, proper system layout — including control location — and homeowner operation appear to be challenges of the multi split heat pump design.

\subsubsection{Multi-Split Heat Pump Annual Savings Evaluation}

Graphical displays of the average daily space-cooling energy, interior and exterior temperature, and interior RH spanning pre- and post-retrofit periods are provided in Figure 19. The central system (central system in red) operated until July 10, 2015, and the multi-split system (green) was operational on July 8, 2015. Contractor work began on July 1 and was essentially completed on July 10. Exterior temperature is in orange, interior temperature is in blue, and RH is in purple. Note that the RH in this plot was taken from the main living area sensor.

\footnotetext{
${ }^{9}$ http://www.pnnl.gov/main/publications/external/technical_reports/PNNL-23017.pdf
} 


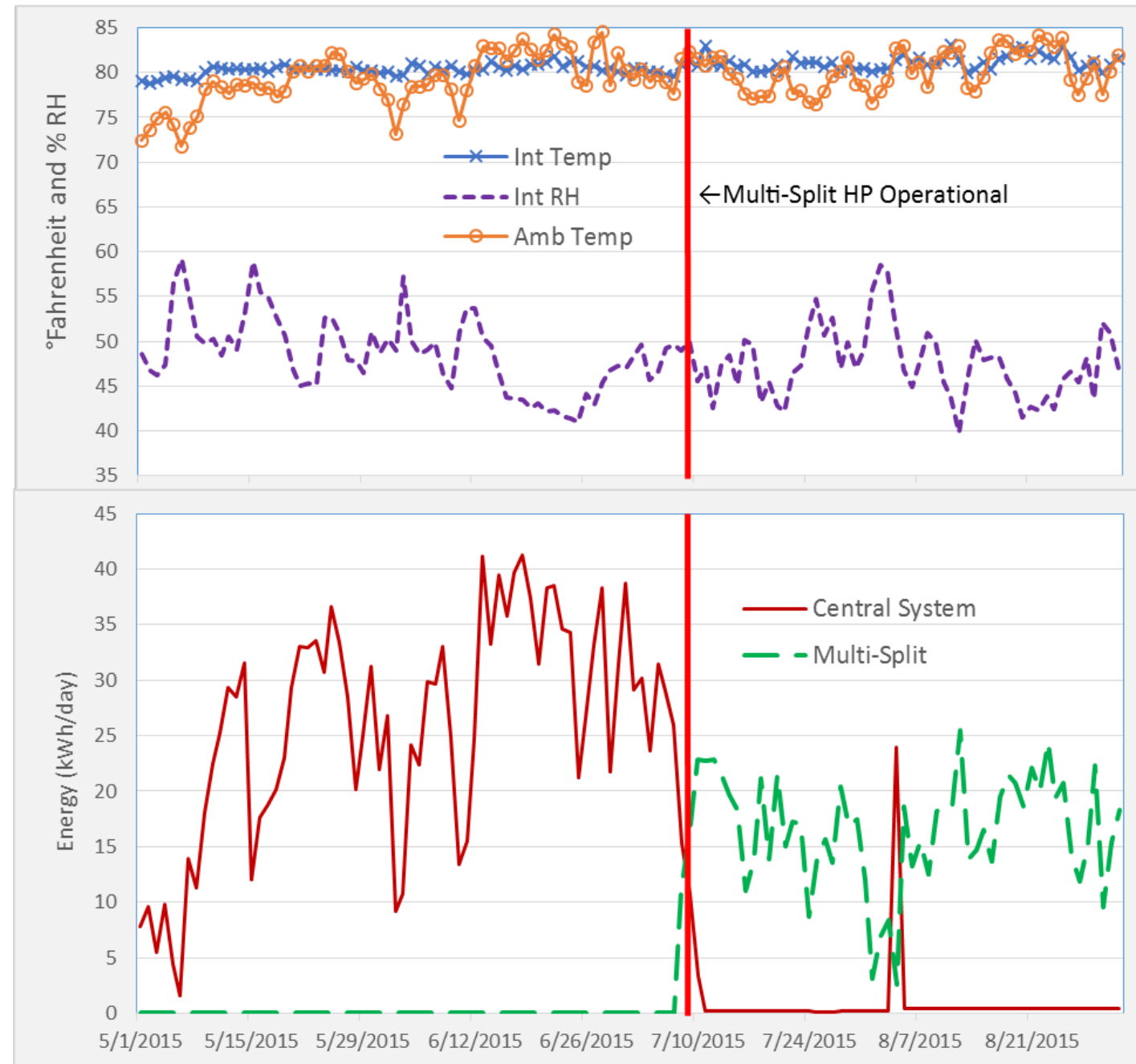

Figure 19. Daily average HVAC energy, indoor and outdoor conditions from May 1, 2015, through August 31, 2015, for Site 11

The sharp decline in HVAC energy use is obvious, whereas the interior temperature appears slightly elevated post-retrofit. There is large variation in $\mathrm{RH}$ during both periods. A partial reason may be that the owners have two dogs for which they often leave a sliding glass door slightly ajar for periods during the day. The short run time of the central system on August 4 (post mechanical system switch) was explained by the owner as a temporary loss of the multisplit remote control. The humidity spike coincident with the precipitous drop in multi-split operation preceding this post-retrofit central system event is evidence of a comfort issue that triggered the owner to run the still-available central system.

Because the homeowners had installed a highly reflective white metal roof a few months after the multi-split, a limited evaluation period was necessary to avoid this confounding retrofit measure. The pre-retrofit period was also bound to exclude data after the installation of a smart thermostat. With the reduced evaluation period, pre- and post-weather conditions were closely matched. Each period consisted of approximately three months of data. The space-cooling evaluation period is from June 16, 2014, through September 4, 2014, ending prior to the 
installation of the Nest thermostat (studied in a later section), because this thermostat is not used to control the multi-split heat pump. The post-retrofit evaluation period spans June 11, 2015 (after the multi-split heat pump installation was complete) through October 7, 2015, just prior to the white metal roof installation. The ambient conditions were similar between periods - the average exterior temperature was slightly cooler post-retrofit $\left(80.5^{\circ} \mathrm{F}\right.$ pre- compared to $79.9^{\circ} \mathrm{F}$ post-retrofit), and the average dew point was slightly higher post-retrofit $\left(73.1^{\circ} \mathrm{F}\right.$ pre- compared to $73.7^{\circ} \mathrm{F}$ post-retrofit).

The pre-retrofit space-heating period similarly avoids the period after the Nest was installed; however, the post-retrofit period falls after the metal roof installation - an unavoidable confounding measure for the space-heating evaluation. Although the new roof's impact on heating energy savings is likely small, the more highly reflective roof may be negatively impacting the savings projection. Table 11 is a summary of the interior conditions and predicted cooling and heating energy savings using the evaluation method described in Section 4.

Table 11. Multi-Split Heat Pump Space-Conditioning Energy Savings

\begin{tabular}{|c|c|c|c|c|c|c|c|c|c|c|c|}
\hline & $\begin{array}{c}\text { Pre- } \\
\text { (kWh/ } \\
\text { year) }\end{array}$ & $\begin{array}{c}\text { Post- } \\
\text { (kWh/ } \\
\text { year) }\end{array}$ & $\begin{array}{c}\text { Savings } \\
\text { (kWh/ } \\
\text { year) }\end{array}$ & $\begin{array}{l}\text { Savings } \\
\text { (\%) }\end{array}$ & $\begin{array}{c}\text { Bal. } \\
\mathrm{T} \\
\left({ }^{\circ} \mathrm{F}\right)\end{array}$ & $\begin{array}{l}\text { Tint } \\
\text { pre- } \\
\left({ }^{\circ} \mathrm{F}\right)\end{array}$ & $\begin{array}{c}\text { Tint } \\
\text { post- } \\
\left({ }^{\circ} \mathrm{F}\right)\end{array}$ & $\Delta T$ & $\begin{array}{c}\text { RH } \\
\text { pre- } \\
\text { (\%) }\end{array}$ & $\begin{array}{c}\text { RH } \\
\text { post- } \\
(\%) \\
\end{array}$ & $\Delta R H$ \\
\hline Cooling & 6,010 & 3,759 & 2,250 & $37.4 \%$ & 67 & 80.4 & 80.9 & 0.5 & 51.2 & 48.8 & (2.4) \\
\hline Heating & 459 & 46 & $(5)$ & $-1.0 \%$ & 67 & 72.8 & 76.9 & 4.1 & $\mathrm{n} / \mathrm{a}$ & $\mathrm{n} / \mathrm{a}$ & $\mathrm{n} / \mathrm{a}$ \\
\hline $\begin{array}{l}\text { Combined } \\
\text { annual }\end{array}$ & 6,469 & 4,224 & 2,245 & $34.7 \%$ & & & & & & & \\
\hline
\end{tabular}

The space-cooling energy savings prediction is $37.4 \%, 2,250 \mathrm{kWh} /$ year, or $7.8 \mathrm{kWh} /$ day; whereas the home is being kept slightly warmer post-retrofit, with the main living area interior temperature averaging $0.5^{\circ} \mathrm{F}$ higher than pre-retrofit. Meanwhile, the average indoor $\mathrm{RH}$ in the main living area is $2.4 \%$ lower post-retrofit than it was pre-retrofit, although it is important not to dismiss the increased RH in the rooms served by the ceiling-mounted fan coil previously discussed.

Space-heating energy savings were slightly negative ( $1 \%$ or $5 \mathrm{kWh} /$ year), although it is noteworthy that the retired central system was also a heat pump, so less savings are expected than if it had been resistance heating. However, occupant take-back looks to have been a factor-it is significant that the post-retrofit main living area interior temperature is approximately $4^{\circ} \mathrm{F}$ warmer than during the pre-retrofit period, so we see some much greater sensible heating demand post-retrofit. Changes in RH are not applicable because space heating does not control the latent load. Regressions from the analysis of the ducted mini-split installations are provided in Appendix C.

The projected space-conditioning energy savings from the multi-split heat pump are impressive: $34.7 \%$ or $2,245 \mathrm{kWh} /$ year. However, with the total cost of $\$ 8,100$, the economics of this measure would make sense only if it is performed at the existing system's end of life. Moreover, the identified comfort issues arising from this design need to be resolved before broad recommendation in the hot-humid climate. 
A multiple-compressor design (two smaller compressors) may perhaps solve the comfort issues, but this would carry a greater cost. Although the industry may be working toward improved latent control for a system design such as that at Site 11, this single case study presented some issues. In the meantime, homeowners and contactors need to work together to understand the best designs and how these systems interact.

\subsubsection{Multi-Split Heat Pump Peak Reduction}

In an investigation of the multi-split heat pump impact on system peak summer day, HVAC power demand at the peak hour in 2014 was compared to that of 2015; however, a surrogate summertime peak was necessary because the installation was completed after the 2015 system peak day: June 22. The slightly milder day of August 20 was used instead. It must be emphasized that this is a single site, so the comparison is limited-i.e., this is a single case study.

Figure 20 compares the HVAC demand during the summer peak of July 28, 2014, (pre-retrofit) to the surrogate peak day on August 20, 2015, (post-retrofit), which shows an energy use reduction of $0.24 \mathrm{kWh}$ or $11 \% .{ }^{10}$ More impressive is the HVAC energy use reduction for the day of 49\%: $37.2 \mathrm{kWh}$ pre-retrofit and $19.0 \mathrm{kWh}$ post-retrofit. Evaluating the impact of the multisplit heat pump on system peak winter day was not yet possible as of the writing of this report.

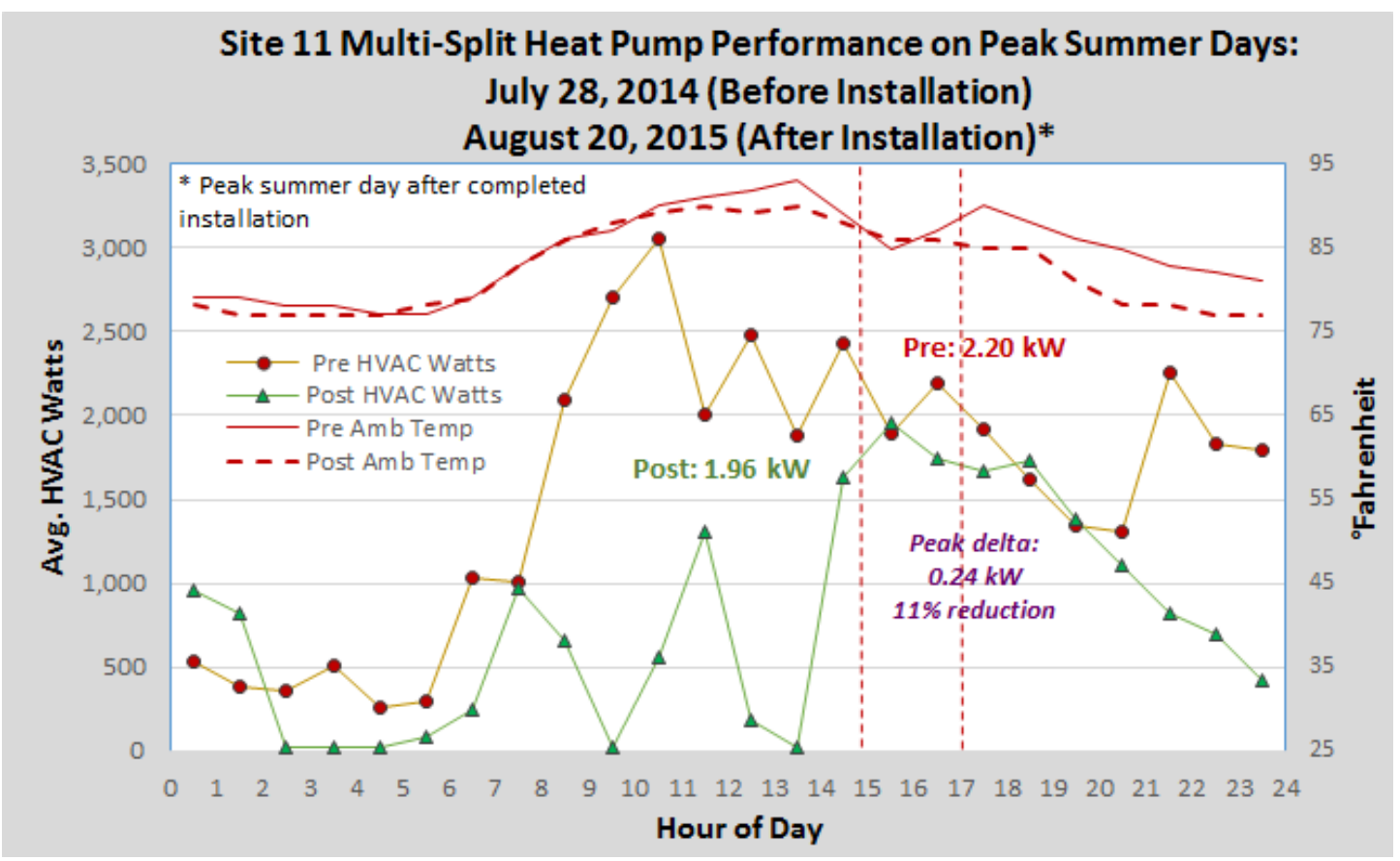

Figure 20. Comparative analysis between pre- and post-retrofit demand on FPL's system peak summer day of 2014 and surrogate peak summer day in 2015

\footnotetext{
${ }^{10}$ Demand reduction is $0.46 \mathrm{~kW}$ or $21 \%$ between the typical peak hour of 4 p.m. and 5 p.m.
} 


\subsection{Evaluation of Ducted Mini-Split Heat Pump \\ 6.2.1 Site Characteristics}

The subject Site 61 for the ducted MSHP is a two-person occupancy, single-story, ranch-style, three-bedroom, one-bathroom home with $875 \mathrm{ft}^{2}$ of living space located in Cocoa Beach, Florida. This home was built in 1955 and has uninsulated CMU and a concrete slab foundation. The windows are double-pane, clear glass with metal frames, and the interior walls are a combination of drywall and plaster. The shallow-pitched (2/12 pitch) asphalt single roof has no insulation at all.

The airtightness test results were poor: $12.0 \mathrm{ACH} 50$, though not surprising for a home of this vintage. The existing air conditioner is rated at 13.5 SEER, and it is a 2.5 -ton system with electric resistance heat. A single, centrally-located return feeds into the interior-located fan coil. Supply air is distributed through the vented attic in insulated rigid ducts of likely R-4.2 value and with poor airtightness $(\mathrm{Qn}$, out $=0.14)$.

\subsubsection{Measure Description}

A single 20.0 SEER, 11.5 HSPF, 1-ton, ceiling-mounted MSHP was installed in the hallway of the subject home, with short duct runs below the ceiling plane distributing conditioned air to the main rooms of the home. A Fujitsu model set was chosen: the ARU12RLF fan coil fan coil unit and matching AOU12RLFC, variable-speed condensing unit. The system has a cooling capacity of $12,000 \mathrm{Btu} /$ hour at an outdoor temperature of $95^{\circ} \mathrm{F}$ and a heating capacity of $13,500 \mathrm{Btu} / \mathrm{hour}$ at an outdoor temperature of $47^{\circ} \mathrm{F}$.

The installation of the ducted MSHP began June 18, 2015, and spanned three weeks, including finish carpentry work. Figure 21 displays the intended location for the new MSHP ductwork and fan coil in the home's centrally-located hallway. All three bedroom doors are accessible from the approximately 12 -foot long hallway.

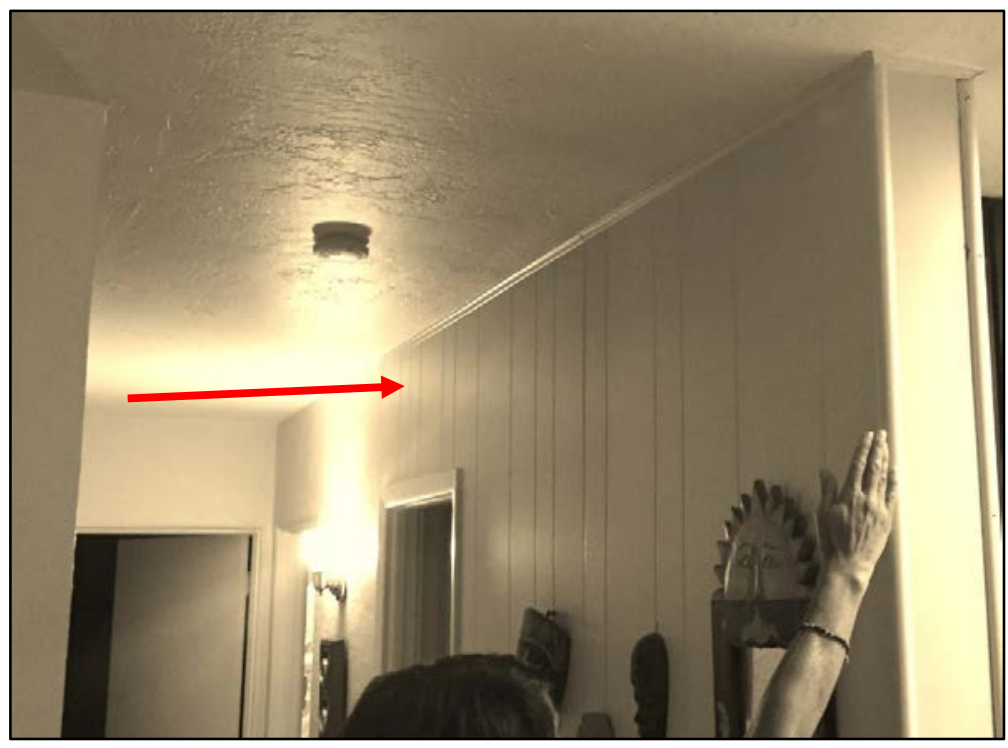

Figure 21. Ducted MSHP installation site. The arrow indicates the new fan coil location. 
A short corridor leading to the bathroom from the hallway had a door between it and the main hallway. The owners preferred to open this corridor area to the main hallway in favor of having the fan coil installed inside the bathroom corridor, under the ceiling, for simpler, single-direction supply airflow design. The alternative fan coil location was the main hallway, which would require ceiling penetrations into the attic to reverse airflow to supply each of the main rooms. Moreover, subsequent to the bidding process the contractor acknowledged that the main hall mounted design would have been exceptionally difficult to complete given the very limited attic space. The fan coil was installed under the ceiling of the bathroom corridor, adjacent the existing fan coil. Figure 22 provides pictures of the installed ceiling-mounted fan coil.

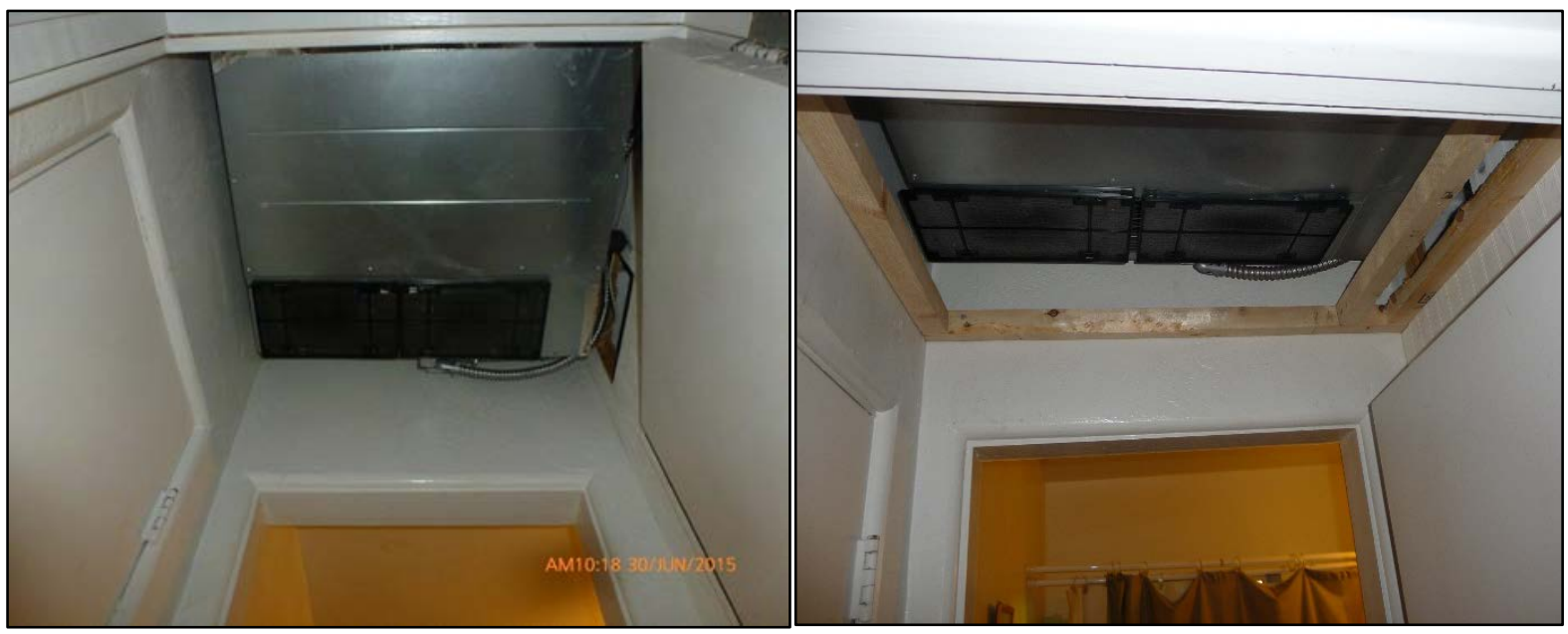

Figure 22. Looking up at installed fan coil unit unframed (left) and framed (right)

Supply air is distributed to all three bedrooms, the living groom, and the kitchen, with each room designed to receive between approximately 50-100 CFM. Figure 23 is a sketch for cooling design conditions of $96^{\circ} \mathrm{F}$ dry bulb, $78^{\circ} \mathrm{F}$ wet bulb. The ducts were fabricated from R-8 duct board and then installed in place with braces to the ceiling. Wall penetrations were required for four of the five supply vents. Penetrations were made through the plaster wall above each bedroom door frame and in the wall adjacent the kitchen. The ducts and wall penetrations were sealed with mastic. The ductwork fabrication is presented in Figure 24. Figure 25 is a view of the supply duct from both sides of one bedroom. 


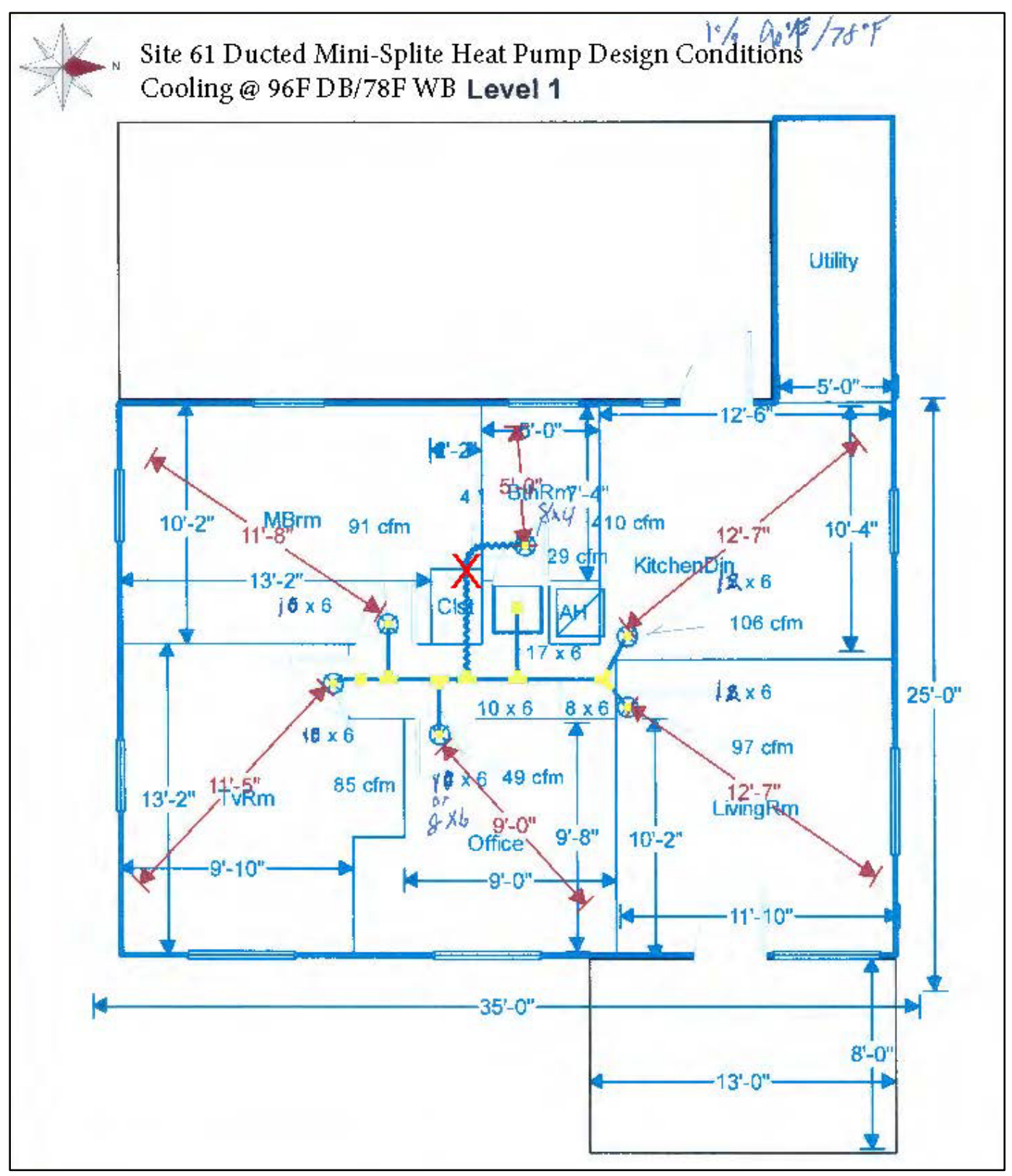

Figure 23. Design sketch of Site 61 ducted MSHP 

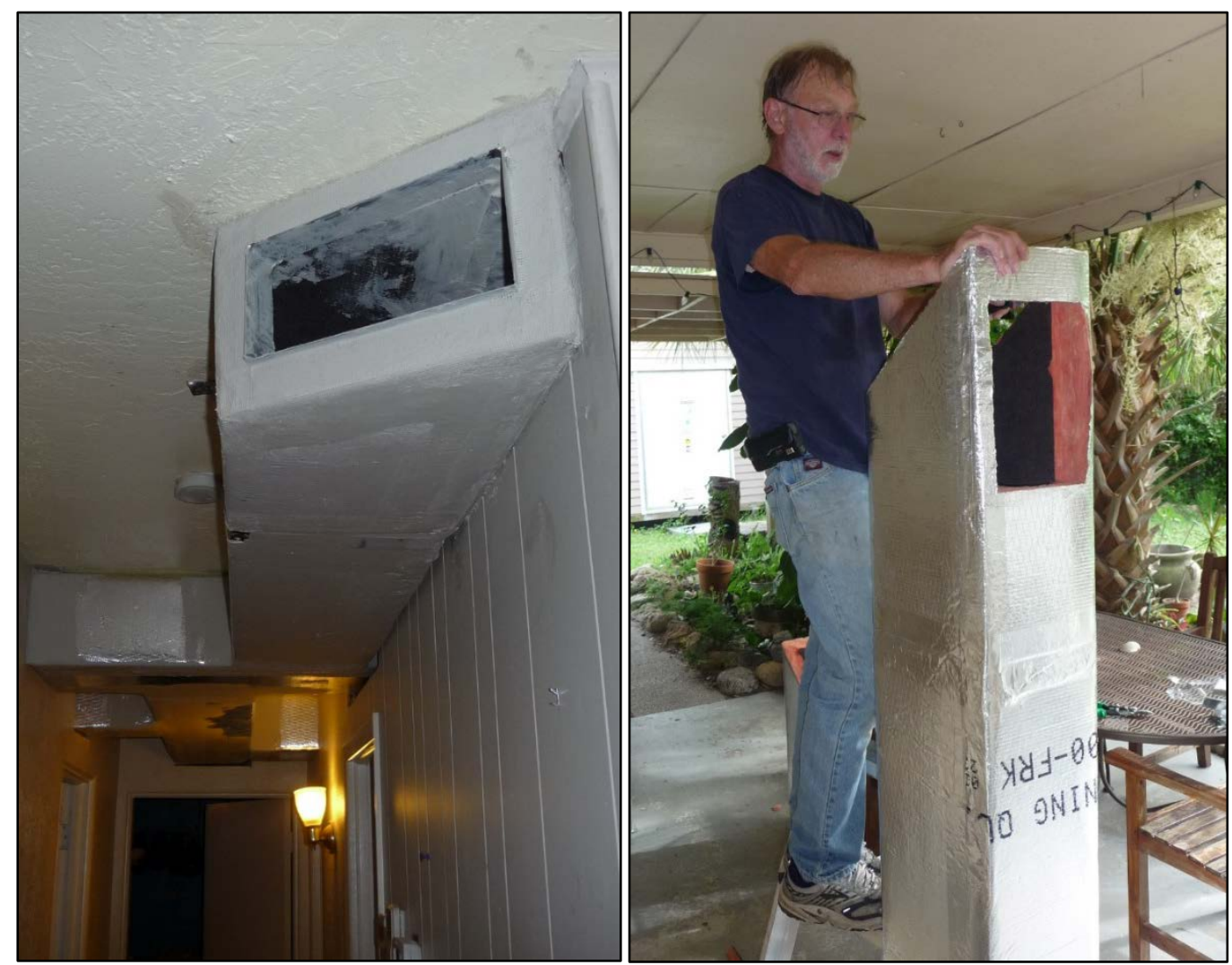

Figure 24. Construction of living room and kitchen supply air duct (left); fabricated ducts installed and sealed with mastic (right)
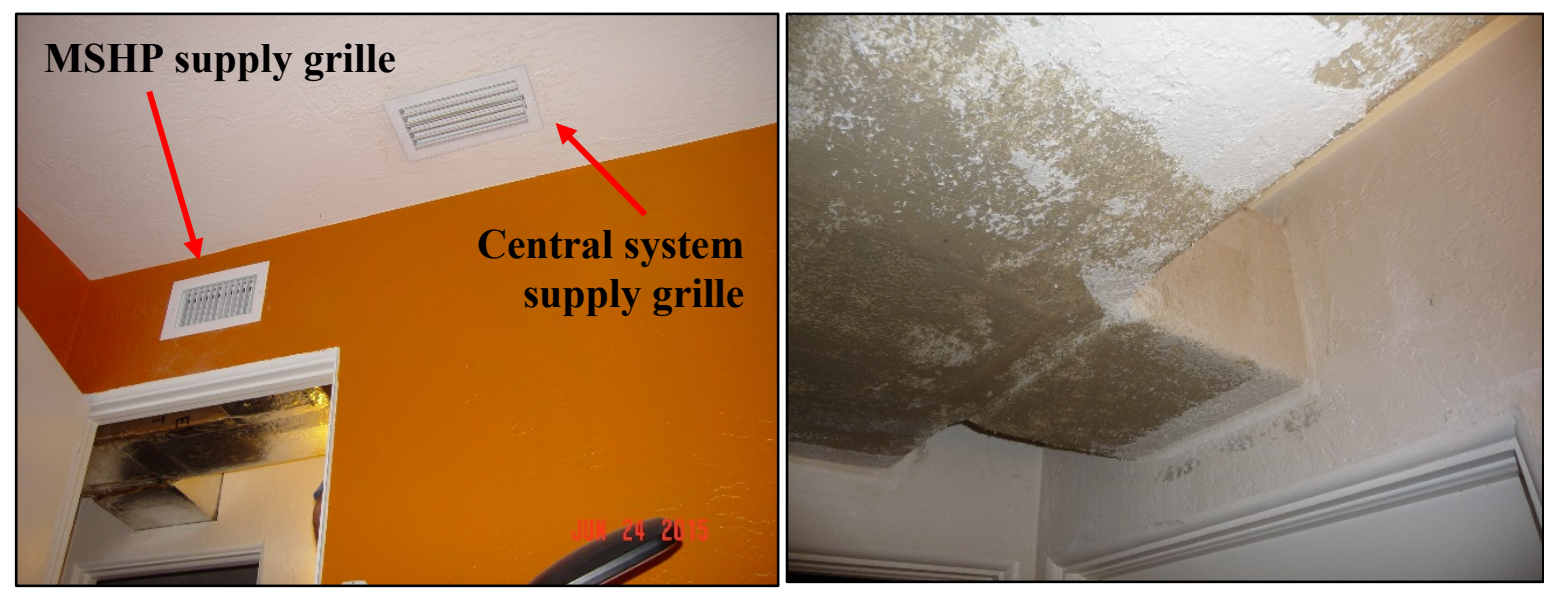

Figure 25. Bedroom view showing both the MSHP and the original central system supply grilles (left); sealed wall penetrations (right)

The original mechanical design included a flex duct running into the small 5' x 7'4" bathroom; however, it would have required the owners to forfeit some of the home's limited closet space, and they preferred to exclude bathroom supply air from the design. Although the contractor encouraged the owners accept the original bathroom-ducted design, the owners believe their 
habit of leaving the bathroom door typically open will prevent any bathroom comfort or air quality issue.

The original design involved a finished dropped ceiling to hide the air distribution system; however, once the ducts were put into place, the homeowners liked the look of the exposed ducts and also believe the exposed ducts have a more open feeling than the dropped ceiling would have. The final elements to the ducted MSHP installation included insulating and sealing the air handling unit and framing, texturing, and painting the duct runs. Figure 26 provides images of the completed ducted MSHP installation.
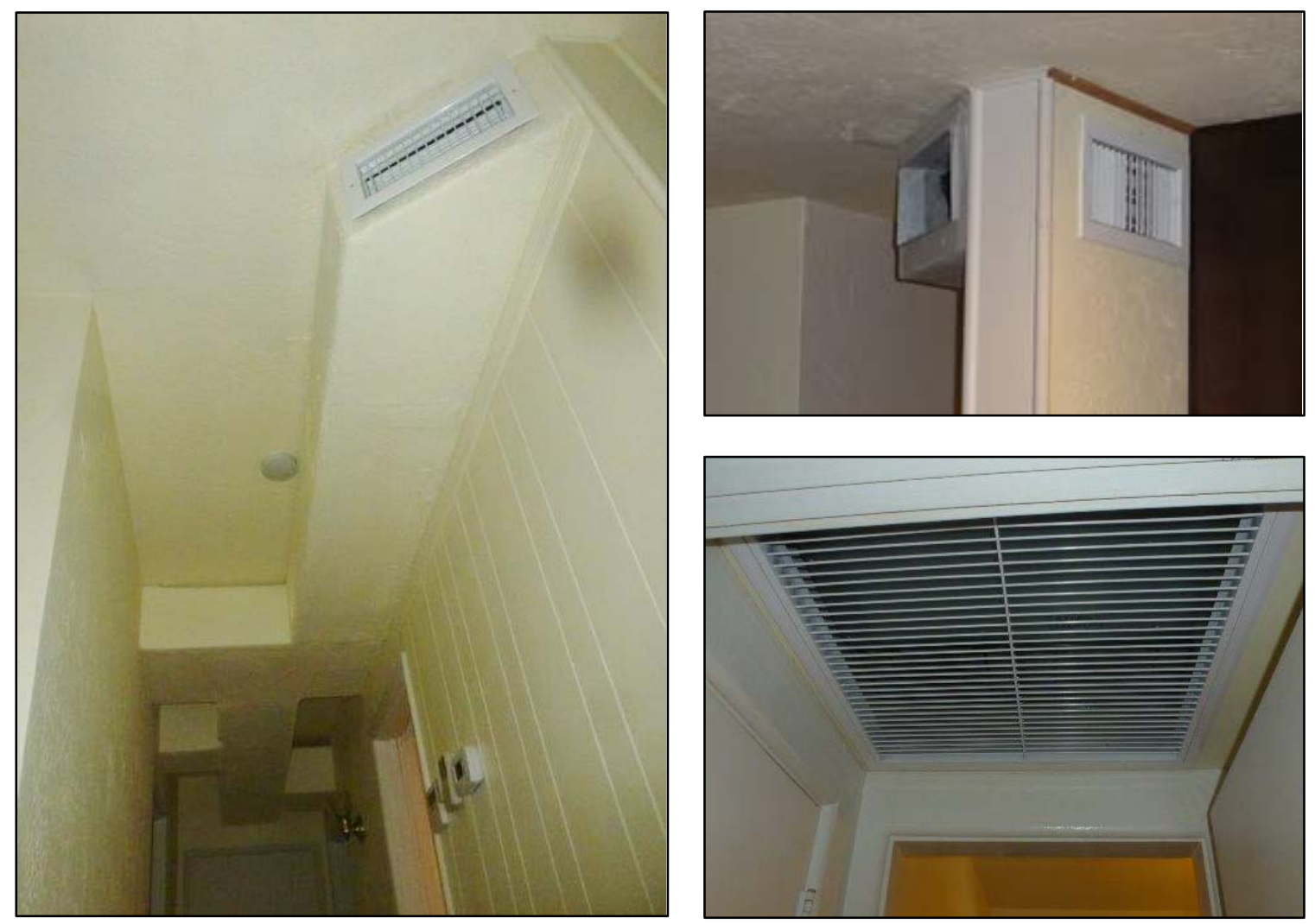

Figure 26. Finished ducted MSHP installation: ductwork (left and upper right) and fan coil (lower right)

The total cost of the ducted MSHP installation was $\$ 9,100$. Table 12 provides a limited breakdown of costs. 
Table 12. Ducted MSPH Installation Cost

\begin{tabular}{lr}
\hline \multicolumn{1}{c}{ Installation Element } & Cost \\
\hline Mechanical system and materials & $\$ 3,228$ \\
Mechanical labor & $\$ 3,472$ \\
Electrical labor and materials & $\$ 750$ \\
Finish carpentry & $\$ 1,450$ \\
System tax & $\$ 194$ \\
Total installation & $\$ 9,094$ \\
\hline
\end{tabular}

\subsubsection{Ducted Mini-Split Heat Pump Installation Evaluation}

The contractor used a flow hood to measure the return and supply airflow of the new system. Results were a total supply airflow of $311 \mathrm{CFM}$ and return of $337 \mathrm{CFM}$ at $25 \mathrm{~Pa}$ pressure, as presented in Table 13.

Table 13. Flow Hood Supply and Return Airflow Results

\begin{tabular}{lc}
\hline \multicolumn{1}{c}{ Room } & $\begin{array}{c}\text { Flow Hood } \\
\text { Results } \\
\text { (CFM @ 25Pa) }\end{array}$ \\
\hline Master & 81 \\
\hline $\begin{array}{l}\text { Second } \\
\text { bedroom }\end{array}$ & 70 \\
Office & 30 \\
\hline Kitchen & 37 \\
\hline Living room & 93 \\
\hline Supply total & $\mathbf{3 1 1}$ \\
\hline Return & $\mathbf{3 3 7}$ \\
\hline
\end{tabular}

The ducted mini-spit design significantly improved latent control and provided large energy savings. Much of this improvement was likely due to the abandonment of leaky attic ducts and use of an interior duct system. Figure 27 plots the RH for all rooms and exterior dew point before and after the retrofit. Though RH remains variable during pre- and post-retrofit, we see that the $\mathrm{RH}$ in all rooms is sharply reduced. In fact, the average $\mathrm{RH}$ for all rooms during this snapshot was $55 \%$ pre-retrofit and $45 \%$ post-retrofit, whereas the exterior dew point rose between these same periods. 


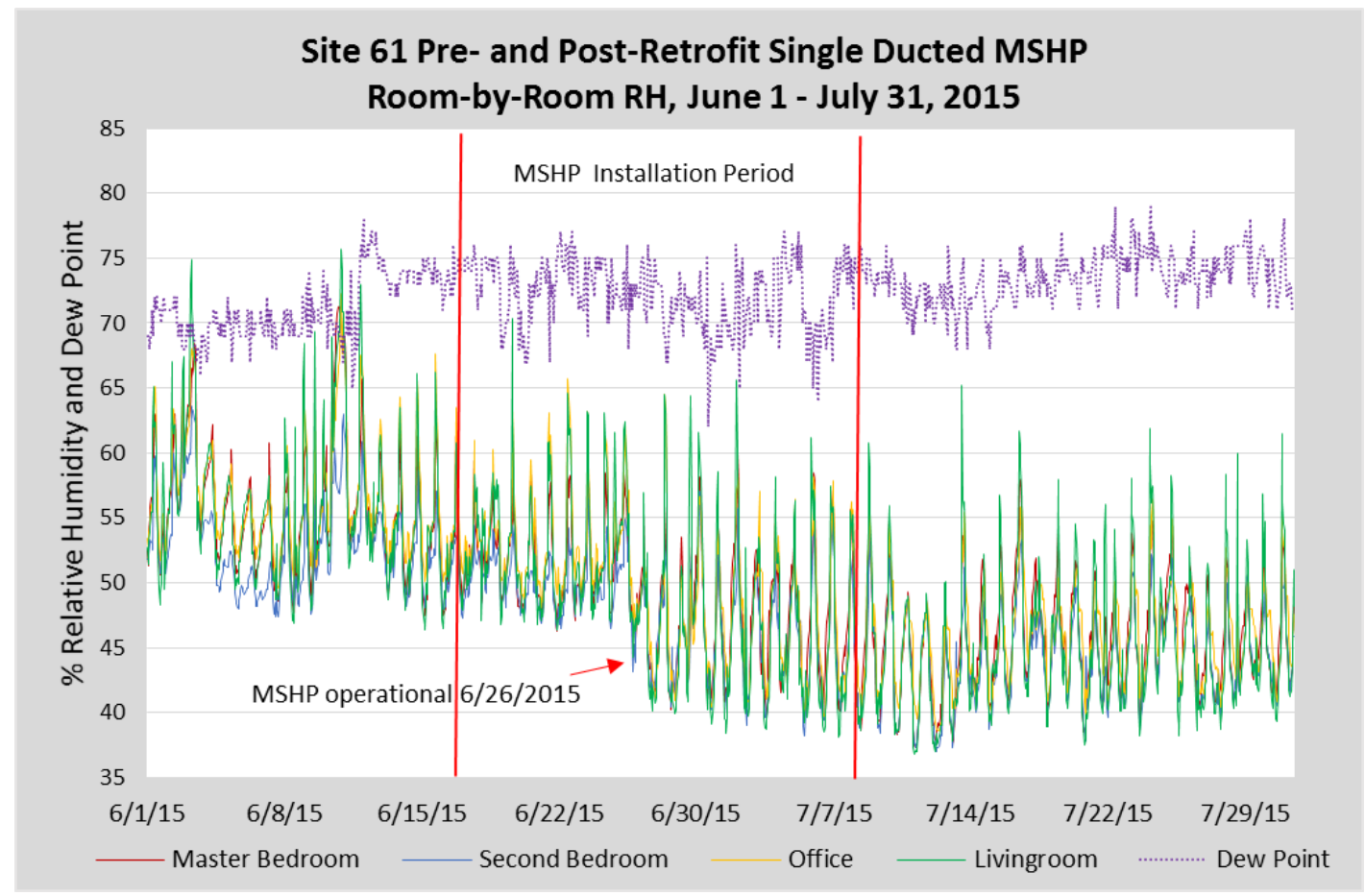

Figure 27. Pre- and post-retrofit room-by-room RH

More importantly, follow-up conversations with the homeowner indicated that they are very pleased with the new system.

All summer we were able to keep the thermostat set at $78^{\circ} \mathrm{F}-80^{\circ} \mathrm{F}$ degrees and felt very cool and comfortable in the house. We used to feel like we had to crank down the thermostat to $76^{\circ} \mathrm{F}$ or $74^{\circ} \mathrm{F}$ to refrain from sweating or running around in bare minimum clothes in the house! I believe we are able to keep the thermostat set higher and still feel comfortable due to the mini-split's ability to greatly reduce the amount of humidity in our home. This is a big bonus for us [because] we have always felt like we were battling mold or mildew issues in the rooms and closets due to moisture issues. With the mini-split cooling system, we feel cooler and no longer have the humid smell in the house during the summer. Our wooden cabinets and doors even close more easily [because] they are no longer swollen with moisture during the hot months! We also really appreciate the efficiency of the new unit...energy bills seem to consistently stay lower all summer long.

\subsubsection{Ducted Mini-Split Heat Pump Annual Savings Evaluation}

Figure 28 graphically displays the daily average space-cooling energy, interior and exterior temperature, and interior RH. The operational status of each system (central system in red; ducted MSHP in green) was switched on June 26, 2015; however, contractor work spanned June 18-July. Exterior temperature is in orange, interior temperature in blue, and RH in purple. 


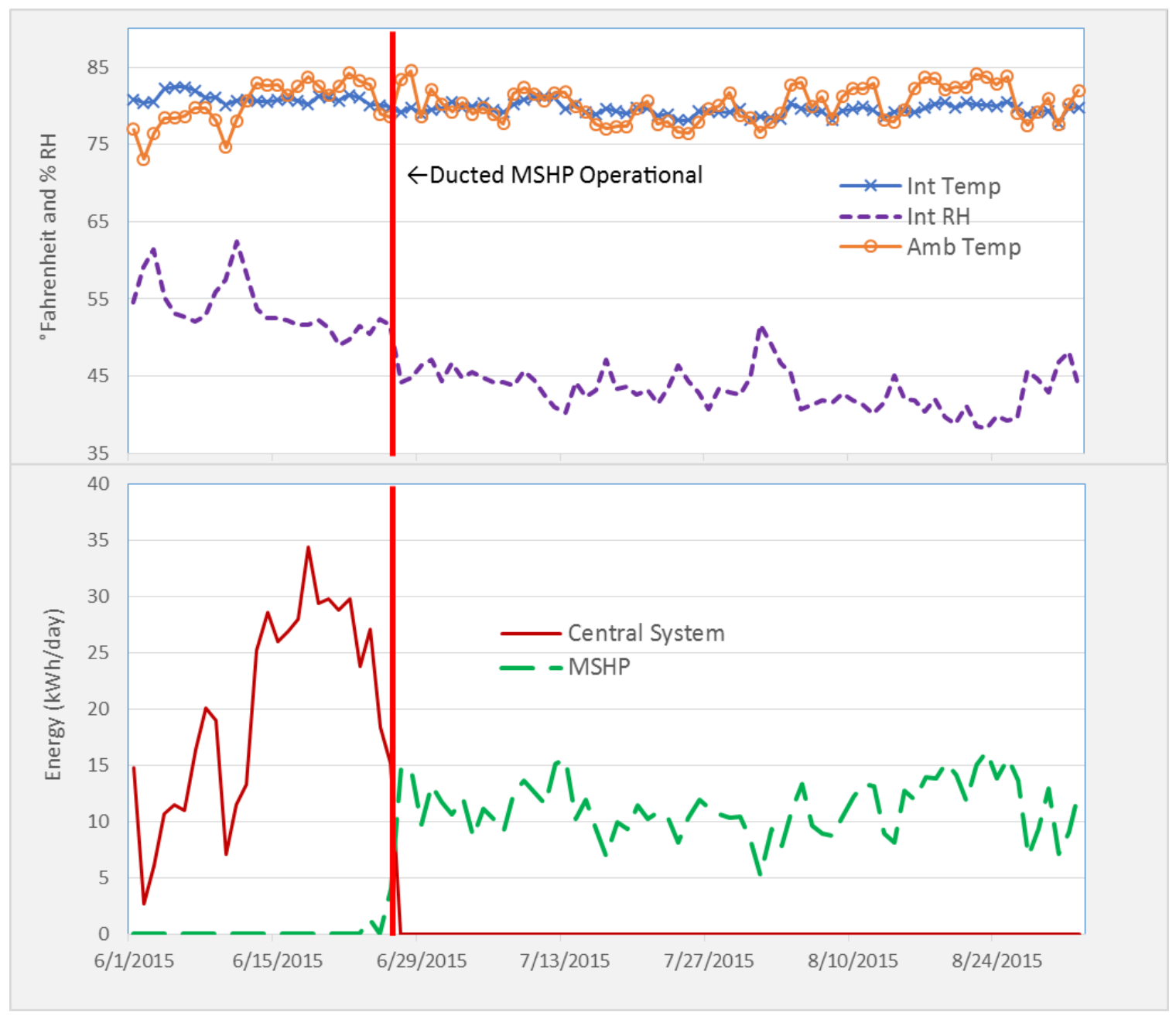

Figure 28. Daily average HVAC energy, indoor and outdoor conditions from June 1, 2015, through August 31, 2015, for Site 61

Within the graph, post-retrofit space-cooling energy savings are obvious, as is a reduction in interior RH. Table 14 is a summary of the pre- and post-retrofit conditions and space-cooling energy use savings of the ducted MSHP using the evaluation method described in Section 4.

The space-conditioning evaluation period is from July 16, 2014, through January 21, 2016. The post-retrofit space-heating period unavoidably includes a confounding measure: R-value of 30 $\mathrm{hr}-\mathrm{ft}^{2}-{ }^{\circ} \mathrm{F}$ fiberglass insulation was blown into the attic on January 6,2016 . (The shallow attic did not likely accommodate R-30 in much of the area.) 
Table 14. Ducted MSHP Space-Conditioning Energy Savings

\begin{tabular}{|c|c|c|c|c|c|c|c|c|c|c|c|}
\hline & $\begin{array}{c}\text { Pre- } \\
\text { (kWh/ } \\
\text { year) }\end{array}$ & $\begin{array}{c}\text { Post- } \\
\text { (kWh/ } \\
\text { year) }\end{array}$ & $\begin{array}{c}\text { Savings } \\
\text { (kWh/ } \\
\text { year) }\end{array}$ & $\begin{array}{l}\text { Savings } \\
\text { (\%) }\end{array}$ & $\begin{array}{c}\text { Bal. } \\
\mathrm{T} \\
\left({ }^{\circ} \mathrm{F}\right)\end{array}$ & $\begin{array}{l}\text { Tint } \\
\text { pre- } \\
\left({ }^{\circ} \mathrm{F}\right)\end{array}$ & $\begin{array}{l}\text { Tint } \\
\text { post- } \\
\left({ }^{\circ} \mathrm{F}\right)\end{array}$ & $\Delta T$ & $\begin{array}{c}\text { RH } \\
\text { pre- } \\
(\%)\end{array}$ & $\begin{array}{c}\text { RH } \\
\text { post- } \\
\text { (\%) }\end{array}$ & $\Delta R H$ \\
\hline Cooling & 3,248 & 2,300 & 948 & $29.2 \%$ & 70 & 79.1 & 78.2 & (0.9) & 62.4 & 57.1 & (5.3) \\
\hline Heating & 791 & 190 & 601 & $76.0 \%$ & 70 & 72.0 & 73.1 & 1.1 & $\mathrm{n} / \mathrm{a}$ & $\mathrm{n} / \mathrm{a}$ & $\mathrm{n} / \mathrm{a}$ \\
\hline $\begin{array}{l}\text { Combined } \\
\text { annual }\end{array}$ & 4038 & 2490 & 1548 & $38.3 \%$ & & & & & & & \\
\hline
\end{tabular}

The space-cooling energy savings prediction is $29.2 \%, 948 \mathrm{kWh} /$ year, or $3.5 \mathrm{kWh} /$ day; on average the home was approximately $1^{\circ} \mathrm{F}$ cooler, and $\mathrm{RH}$ was $5.3 \%$ lower post-retrofit compared to the pre-retrofit conditions. Although the post-retrofit average exterior temperature was similar between evaluation periods $\left(77.9^{\circ} \mathrm{F}\right.$ pre- compared to $78.3^{\circ} \mathrm{F}$ post-retrofit), the reduced post-retrofit $\mathrm{RH}$ is not an artifact of dryer post-retrofit ambient conditions. In fact, the post-retrofit period was moister, with an average dew point $1.6^{\circ} \mathrm{F}$ higher $\left(69.5^{\circ} \mathrm{F}\right.$ precompared to $71.1^{\circ} \mathrm{F}$ post-retrofit). Greater savings would have been achieved without this apparent take-back behavior; however, it is clear from the homeowners' comments that the existing central system was unable to satisfy comfort needs.

Space-heating energy savings is large, which is as expected given that the pre-retrofit heating was electric resistance. The heating savings of $76.0 \%, 601 \mathrm{kWh} /$ year, or $6.7 \mathrm{kWh} /$ day also includes some behavioral take-back because the occupants preferred a warmer post-retrofit period by approximately $1^{\circ} \mathrm{F}$; however, a portion of the post-retrofit heating evaluation period includes the attic insulation measure, which most certainly contributes to some of these large savings. Changes in RH are not applicable to the winter period because space heating does not remove interior moisture.

Unlike the supplemental mini-split and multi-split evaluations, zoning is not an option with the ducted mini-split design. That occupants cannot maintain different heating and cooling conditions in different rooms of the home is an argument to use Delta $\mathrm{T}$ to project energy savings; however, the tack-back in interior temperature - for both cooling and heating - and related reduction in cooling season RH are real. Delta T would increase projected energy savings compared to a substandard system that could not accommodate the occupant's needs; thus, space-conditioning energy savings for this measure were projected using ambient temperature alone, knowing these savings are a conservative estimate without take-back. Regressions from the analysis of the ducted mini-split installations are provided in Appendix C.

The projected space-conditioning energy savings from the ducted MSHP is impressive: $8.3 \%$ or $1,548 \mathrm{kWh} /$ year. Although space-heating savings are inflated due to confounding measures, we also see take-back during both the heating and cooling seasons. However, with the total cost of $\$ 9,100$, the economics of this measure make sense only if it is performed at the existing system's end of life. Assuming incremental costs over a new central system are approximately $\$ 3,000$, the savings combined with the markedly improved interior conditions make the ducted MSHP an attractive option for complete space-conditioning needs in the hot-humid climate. All things equal, this appears a superior option to the multi-split strategy — at least until the latent removal issues of that technology are addressed. 


\subsubsection{Ducted Mini-Split Heat Pump Peak Reduction}

In an investigation of the ducted MSHP's impact on the system's peak summer day, HVAC power demand at the peak hour in 2014 was compared to that of 2015. However, a second highest summertime peak was necessary because the installation was completed after the 2015 system peak day, June 22. The slightly milder day of August 20 was used instead.

Figure 29 compares the HVAC demand during the summer peak of July 28, 2014, (pre-retrofit) to the surrogate peak day on August 20, 2015 (post-retrofit), which shows an energy demand reduction of $0.70 \mathrm{kWh}$ or $41 \% .{ }^{11}$ The HVAC energy use reduction for the day was also impressive at 36\%: $22.4 \mathrm{kWh}$ pre-retrofit and $14.2 \mathrm{kWh}$ post-retrofit. The impact of the multisplit heat pump on system peak winter day is not possible because of confounding measures during the post-retrofit period. Note that this peak load comparison, as with the multi-split site, is a single case study, and many more installations would need to be available to establish any kind of statistical meaning.

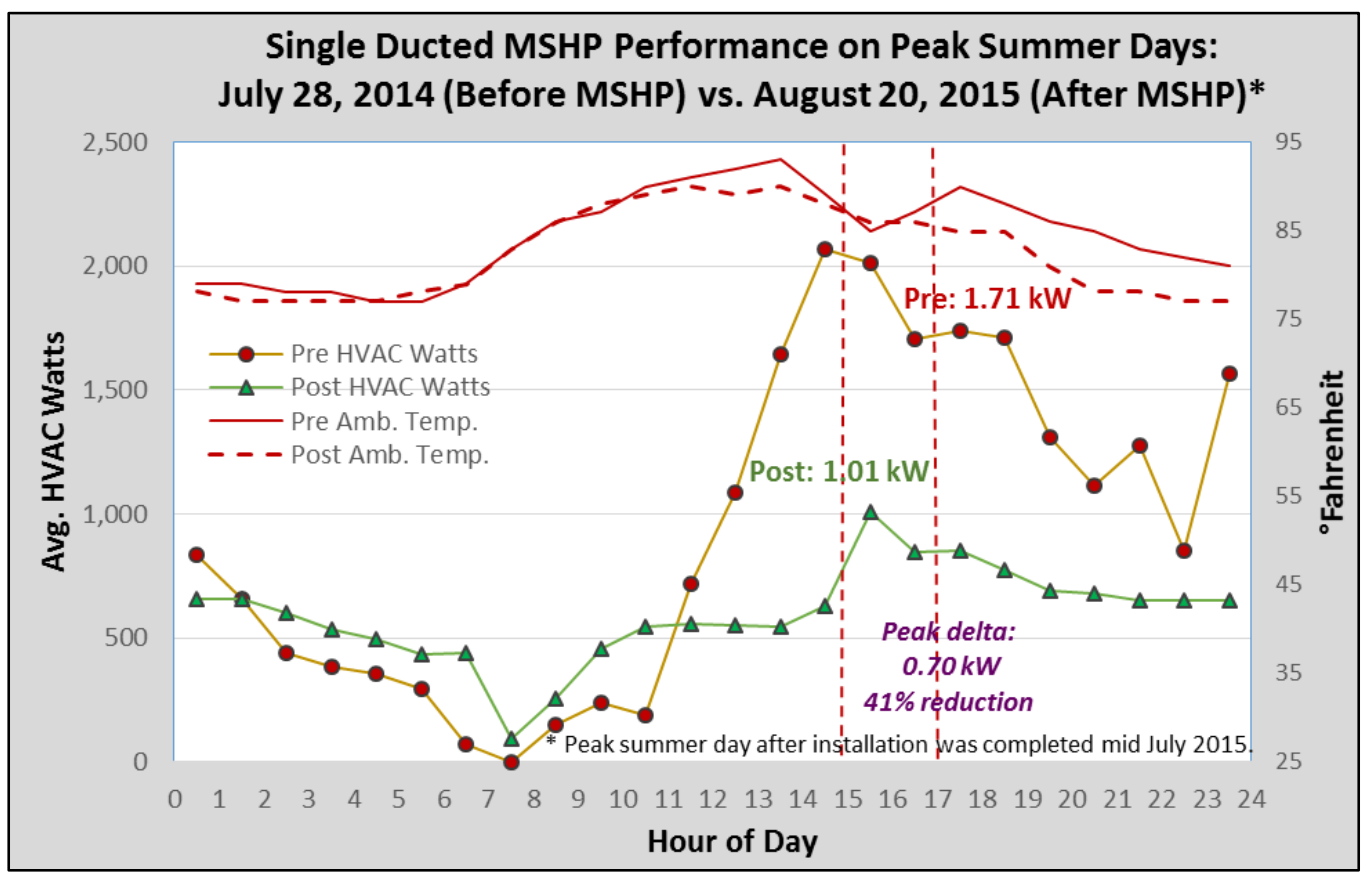

Figure 29. Comparative analysis between pre- and post-retrofit demand on FPL's system peak summer day of 2014 and surrogate peak summer day in 2015

\subsection{Lessons Learned from the Complete System Replacements with Inverter- Driven Heat Pumps}

The evaluation conducted within the PDR project of two sites with differing approaches compares the performance of the standard unitary system to that of the mini- and multi-splits in homes with long track records with the standard systems. One system was a multi-split system with a single outdoor compressor and two indoor heads. The other system was also a single outdoor unit, but it had a single indoor fan coil, which was then ducted to multiple zones.

\footnotetext{
${ }^{11}$ Demand reduction is $0.86 \mathrm{~kW}$ or $50 \%$ between the typical peak hour of 4 p.m. to 5 p.m.
} 
Both systems showed impressive cooling energy savings compared to unitary air conditioners of $30 \%$ or more (the specific saving are influence by post-retrofit temperature take-back as well as the characteristics of the existing unitary system). However, the multi-split system showed problems with controlling indoor humidity and also providing zone temperature control compared to the ducted single indoor head. These problems could be only partially addressed. On the other hand, the ducted mini-split approach showed significantly lower achieved indoor $\mathrm{RH}$, which seems to be a large potential advantage in many instances.

In interpreting these results, however, it is important to keep in mind that these are for a limited number of mini-split and a single multi-split systems, and there are known differences in the ways in which manufacturers control systems via proprietary software. These differences point to both the limitations of our case studies as well as the need for further research to more confidently recommend these as fully reliable substitutions for central unitary systems.

Both retrofits were relatively expensive, but the multi-split approach would be competitive with replacing a conventional unitary AC system when the standard system needs replacement as a matter of course. In fairness, to consider the ducted mini-split approach, it must be noted that in a standard full-sized house, two to three ducted mini-splits would be needed, depending on room layout, to achieve the same impressive results seen at Site 61. If two such systems could be used to substitute for a unitary system, there would still be a cost premium given current system pricing. Still, the potential to provide both energy savings with superior interior RH control for the ducted MS system concept could be a large factor in their potential attractiveness.

The average annual savings for the ducted mini-split designs were $2,397 \mathrm{kWh}$ or $37 \%$. As expected, these inverter-driven, full-system replacements (with a SEER 16.5 multi-split and a SEER 20 single mini-split) were greater than those for the supplemental MSHPs (with a SEER 25.5), even though they have lower SEERs. Although the SEERs may indicate that the supplemental units are more efficient, the supplemental units are operating only part of the time. The standard ducted system is often operating more of the time with the supplemental strategy, and the duct losses and the inefficiencies in the standard systems remain with the supplemental scheme. Even so, the savings are still quite high for the supplemental mini-split strategy, at 34\%; these savings are nearly as high as they would be if the main heat pump were replaced with a state-of-the-art, high-efficiency, ducted unit. The SEER 16.5 multi-split achieves higher savings because it takes over all of the responsibility for cooling and heating the home, and it has much lower duct losses in contrast to the main system in the supplemental mini-split segment. Further, the multi-split has no resistance auxiliary heat, unlike several of the supplemental MSHP sites. These results suggest:

- Supplemental MSHPs are capable of reducing space-conditioning needs by $34 \%$ in Florida homes when added to supplement the main HVAC system.

- Ducted MSHPs are capable of reducing space-conditioning needs by nearly $40 \%$ in Florida homes when used to eliminate the main ducted HVAC system, although more research and field-testing is needed. 


\section{Evaluation of Ducted and Space-Coupled Heat Pump Water Heaters}

\subsection{Site Characteristics and Space-Coupled Heat Pump Water Heater Measure}

As a by-product of their operation, HPWHs create a quantity of cooled and dehumidified air from inlet to the outlet compressor section of the unit. The effect on space-conditioning and water-heating energy of coupling an HPWH to the conditioned living space is of particular interest in a cooling-dominated climate such as Florida's. This was investigated in eight homes in the PDR project. Site characteristics for these homes are provided in Table 15.

Table 15. HPWH Retrofit Site Characteristics

\begin{tabular}{clcccccc}
\hline $\begin{array}{c}\text { Site } \\
\text { No. }\end{array}$ & \multicolumn{1}{c}{ City } & $\begin{array}{c}\text { Year } \\
\text { Built }\end{array}$ & $\begin{array}{c}\text { Living } \\
\text { Area } \\
\text { (ft }{ }^{2} \text { ) }\end{array}$ & $\begin{array}{c}\text { House } \\
\text { Airtightness } \\
\text { (ACH5) }\end{array}$ & $\begin{array}{c}\text { AC } \\
\text { SEER }\end{array}$ & Heating & $\begin{array}{c}\text { Duct } \\
\text { Leakage } \\
\text { (Qn,out) }\end{array}$ \\
\hline 1 & Merritt Island & 1961 & 2,028 & 13.7 & 13.0 & Heat pump & 0.04 \\
\hline 5 & Rockledge & 2006 & 2,328 & 5.6 & 13.0 & Heat pump & 0.10 \\
\hline 9 & Melbourne & 1984 & 1,013 & 12.9 & $<13$ & Resistance & 0.11 \\
\hline 13 & Merritt Island & 1963 & 1,052 & 16.4 & 15.5 & Heat pump & 0.10 \\
\hline 26 & Palm Bay & 1999 & 1,502 & 4.7 & 17.0 & Heat pump & 0.04 \\
\hline 50 & Melbourne & 1958 & 2,168 & 5.5 & 17.0 & Resistance & 0.03 \\
\hline 51 & Cocoa & 1994 & 2,233 & 8.3 & 16.0 & Heat pump & 0.06 \\
\hline 56 & Merritt Island & 1963 & 1,000 & 13.5 & 10.0 & Resistance & 0.16 \\
\hline
\end{tabular}

Three different HPWHs were evaluated: the General Electric (GE) 50-gallon GeoSpring, Air Generate 66-gallon model ATI66DV, and A.O. Smith Voltex model PHPT-60. The FSEC has previously reported on the performance of these units in a laboratory setting at its Hot Water Systems Laboratory (Colon and Parker 2013; Colon forthcoming).

Three homes received a GeoSpring unit as a replacement for an electric resistance tank; two were the newer model GEH50DFEJSR, and one was the original model GEH50DNSRSA. The GE units were located in interior utility rooms in each home. Three additional homes each received an Air Generate unit as a replacement for an electric resistance tank. This unit comes equipped for ducting air to and from the unit, and each unit was installed in an attached garage.

Two homes had previously received a Voltex as a replacement for an electric resistance tank during an earlier phase of this research (see Phased-Retrofits in Existing Homes in Florida Phase I: Shallow and Deep Retrofits by Parker et al. [2016]). These two units, each located in attached garages, were modified with A.O. Smith's available ducting kit for the Voltex. The Voltex and Air Generate units were then ducted such that air used for heat pump operation was pulled from and returned to the conditioned living environment. A combination of insulated metal and flex duct was used for ducting, and air was pulled from and supplied to the same general location in each home. Figure 30 shows examples of water heater installations in the project. 


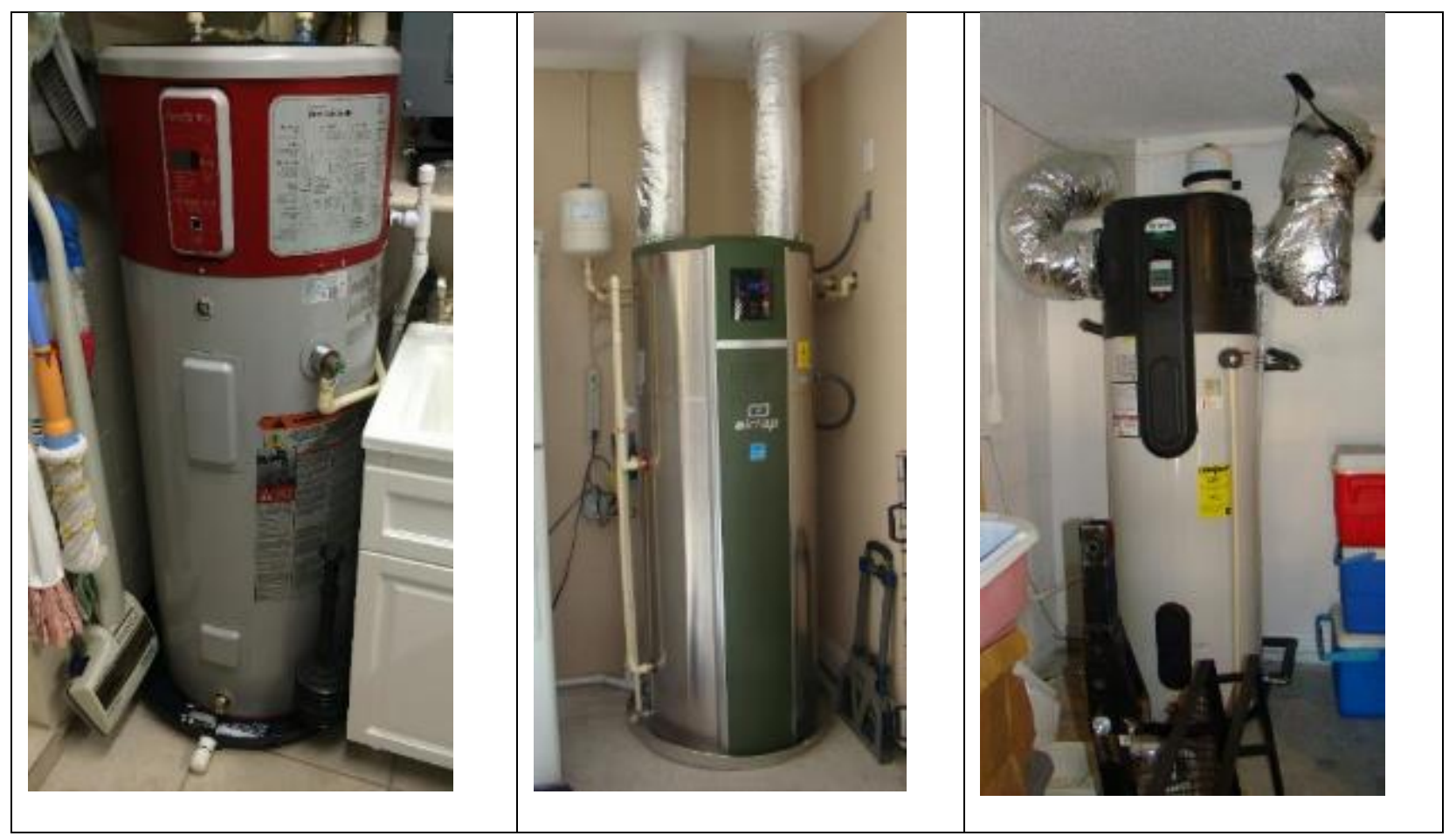

Figure 30. HPWH configurations: interior GE unit in utility room at Site 13 (left); ducted Air Generate unit at Site 5 (center); ducted A.O. Smith unit at Site 26 (right)

The Energy Conservatory Flow Blaster duct blaster attachment was used to measure the airflow entering the conditioned space for all ducted units. Airflow for the GE units was not measured because there is no ducting option. Ducted airflow was in the range of 113-130 CFM for three of the five ducted units. One unit had very low airflow (31 CFM) due to a long duct run. One unit had higher airflow (225 CFM) due to a very short duct run. Table 16 provides an installation and commissioning summary with these data.

Table 16. Space-Coupled HPWH Installation and Commissioning Summary

\begin{tabular}{|c|c|c|c|}
\hline Site No. & Model & Ducted Airflow (CFM) & Location Receiving HPWH Air \\
\hline 1 & GE & $\mathrm{n} / \mathrm{a}$ & Utility room \\
\hline 5 & Air Generate & 130 & Dining room \\
\hline 9 & Air Generate & 113 & Office \\
\hline 13 & GE & $\mathrm{n} / \mathrm{a}$ & Utility room \\
\hline 26 & A.O. Smith & 115 & Bedroom \\
\hline 50 & Air Generate & 225 & Dining room \\
\hline 51 & A.O. Smith & 31 & Kitchen \\
\hline 56 & GE & $\mathrm{n} / \mathrm{a}$ & Utility room \\
\hline
\end{tabular}

\subsection{Space-Coupled Heat Pump Water Heater Evaluation}

All the HPWHs were installed and/or ducted between July and October 2014. For most sites, data for the period from July 2013-July 2015 were analyzed. For sites 1, 13, and 51, the preretrofit period was censured to shorter periods due to other HVAC installation measures potentially confounding data, and heating analysis was prevented due to lack of pre-retrofit heating data. 
The statistical evaluation method is generally described in Section 4. To evaluate the impact of coupled HPWH on space-cooling energy, Delta T was used in the regressions because it normalized differences in average indoor temperature between pre- and post-retrofit periods, which exceeded $1^{\circ} \mathrm{F}$ in some houses. This seemed more appropriate because operation of the ducted HPWH tended to alter the interior temperature profile. Also, rather than evaluating performance at $80^{\circ} \mathrm{F}$ and $50^{\circ} \mathrm{F}$, energy use and savings are evaluated seasonally, using data from the entire pre- and post-retrofit periods evaluated each day to determine a weighted average daily heating and cooling energy use. Cooling results are provided in Table 17. Regression formulas for the analysis of the space-coupled HPWH s are provided in Appendix D.

Table 17. Cooling Analysis Results for Conditioned Space-Coupled HPWH Retrofits

\begin{tabular}{cccccccc}
\hline Site No. & $\begin{array}{c}\text { No. of } \\
\text { Occupants }\end{array}$ & Coupling & $\begin{array}{c}\text { HPWH } \\
\text { Energy } \\
\text { Post- } \\
\text { (kWh/day) }\end{array}$ & $\begin{array}{c}\text { Cooling } \\
\text { Energy Pre- } \\
\text { (kWh/day) }\end{array}$ & $\begin{array}{c}\text { Cooling } \\
\text { Energy Post- } \\
\text { (kWh/day) }\end{array}$ & $\begin{array}{c}\text { Cooling } \\
\text { Savings } \\
\text { (kWh/day) }\end{array}$ & $\begin{array}{c}\text { Cooling } \\
\text { Savings } \\
\text { (\%) }\end{array}$ \\
\hline 1 & 4 & Interior & 2.07 & 16.26 & 14.50 & 1.76 & 10.8 \\
\hline 5 & 2 & Ducted & 2.69 & 44.68 & 42.99 & 1.69 & 3.8 \\
\hline 9 & 2 & Ducted & 3.20 & 11.54 & 10.01 & 1.53 & 13.2 \\
\hline 13 & 2 & Interior & 2.64 & 6.81 & 6.08 & 0.73 & 10.7 \\
\hline 26 & 5 & Ducted & 3.53 & 11.48 & 10.07 & 1.41 & 12.3 \\
\hline 50 & 4 & Ducted & 2.65 & 18.50 & 17.78 & 0.72 & 3.9 \\
\hline 51 & 2 & Ducted & 1.25 & 14.99 & 14.16 & 0.83 & 5.6 \\
\hline 56 & 3 & Interior & 3.09 & 18.86 & 18.71 & 0.15 & 2.7 \\
\hline Average & $\mathbf{3}$ & n/a & $\mathbf{2 . 6 4}$ & $\mathbf{1 7 . 8 9}$ & $\mathbf{1 6 . 7 9}$ & $\mathbf{1 . 1 0}$ & $\mathbf{7 . 9}$ \\
\hline Median & $\mathbf{2 . 5}$ & n/a & $\mathbf{2 . 6 7}$ & $\mathbf{1 5 . 6 3}$ & $\mathbf{1 4 . 3 3}$ & $\mathbf{1 . 1 2}$ & $\mathbf{8 . 2}$ \\
\hline
\end{tabular}

The median estimated space-cooling energy savings from the ducted HPWH are $1.41 \mathrm{kWh} /$ day and $412 \mathrm{kWh} /$ year. Median space-cooling energy savings among all sites are $1.12 \mathrm{kWh} /$ day and $313 \mathrm{kWh} /$ year and are similar to those found in a recent side-by-side laboratory study at FSEC's Flexible Research Test Facility (Colon, Martin, and Parker forthcoming). The laboratory study found typical daily cooling energy savings in the summer of 2014 to be approximately 0.86 $\mathrm{kWh}$ /day or $3.8 \%$ with an average HPWH energy use of $1.88 \mathrm{kWh} /$ day and average cooling energy of $22 \mathrm{kWh} /$ day.

Figure 31 shows the regression for Site 9, clearly demonstrating reductions in space-cooling energy after coupling the HPWH to the conditioned space. Similar to Site 9, sites 1, 13, and 26 also exhibit relatively parallel regression lines indicating cooling savings across a wide range of daily average outdoor temperatures. Each of these sites also exhibits the largest percentage reductions in cooling energy use. Figure 32 shows the post-retrofit composite average day's water-heating power for these sites. Notably, sites 9, 13, and 26 display both a morning and an evening hot water energy use peak (bimodal), with the evening peak dominating for sites 13 and 26. Site 1 peaks in the middle of the day, with some evening operation. It is possible that this late-day HPWH operation is providing cooling because the house is recovering from load imposed during the hottest part of the day (summer peak demand), when it is needed most. 


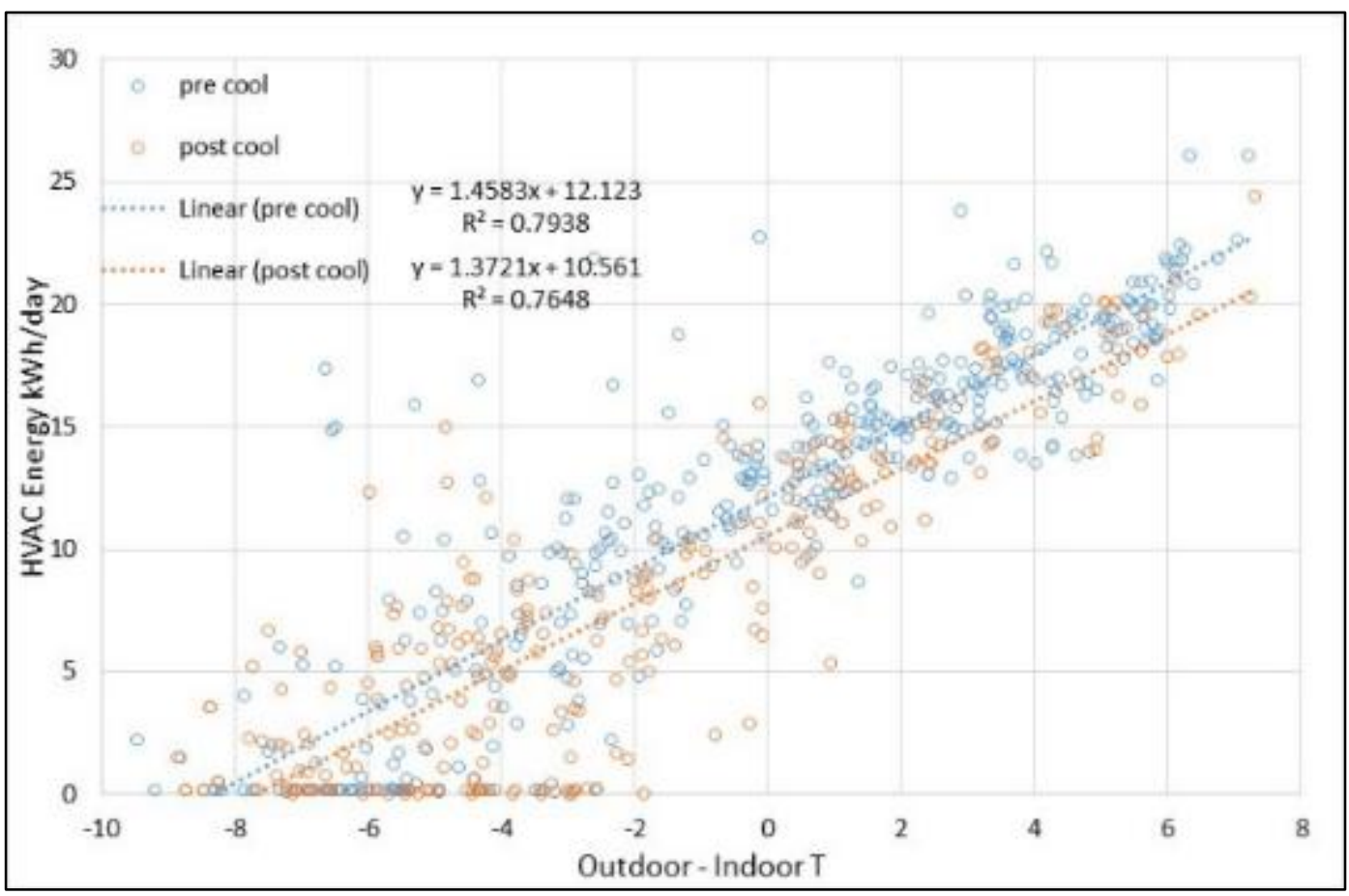

Figure 31. Parallel regression lines for Site 9

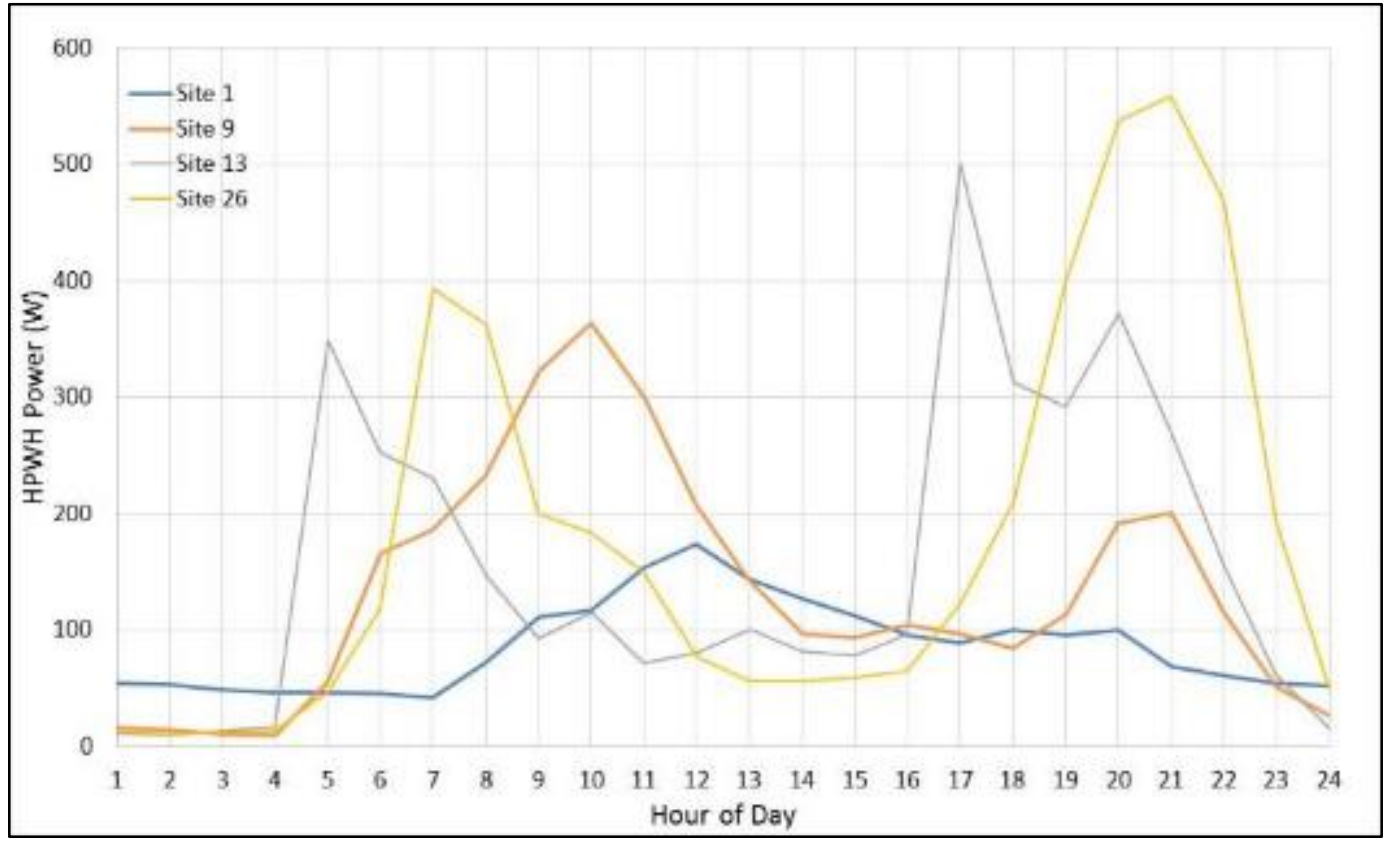

Figure 32. Post-retrofit composite average day's water-heating power for sites 1, 9, 13, and 26

Sites 5, 50, 51, and 56 show lower cooling savings. Regression lines for these sites show savings at low Delta $\mathrm{T}$, but they converge at Delta Ts between $2^{\circ}-4^{\circ} \mathrm{F}$. Figure 33 shows an example regression for Site 5 . Figure 34 shows the post-retrofit composite average day's water-heating power for sites $5,50,51$, and 56 . 


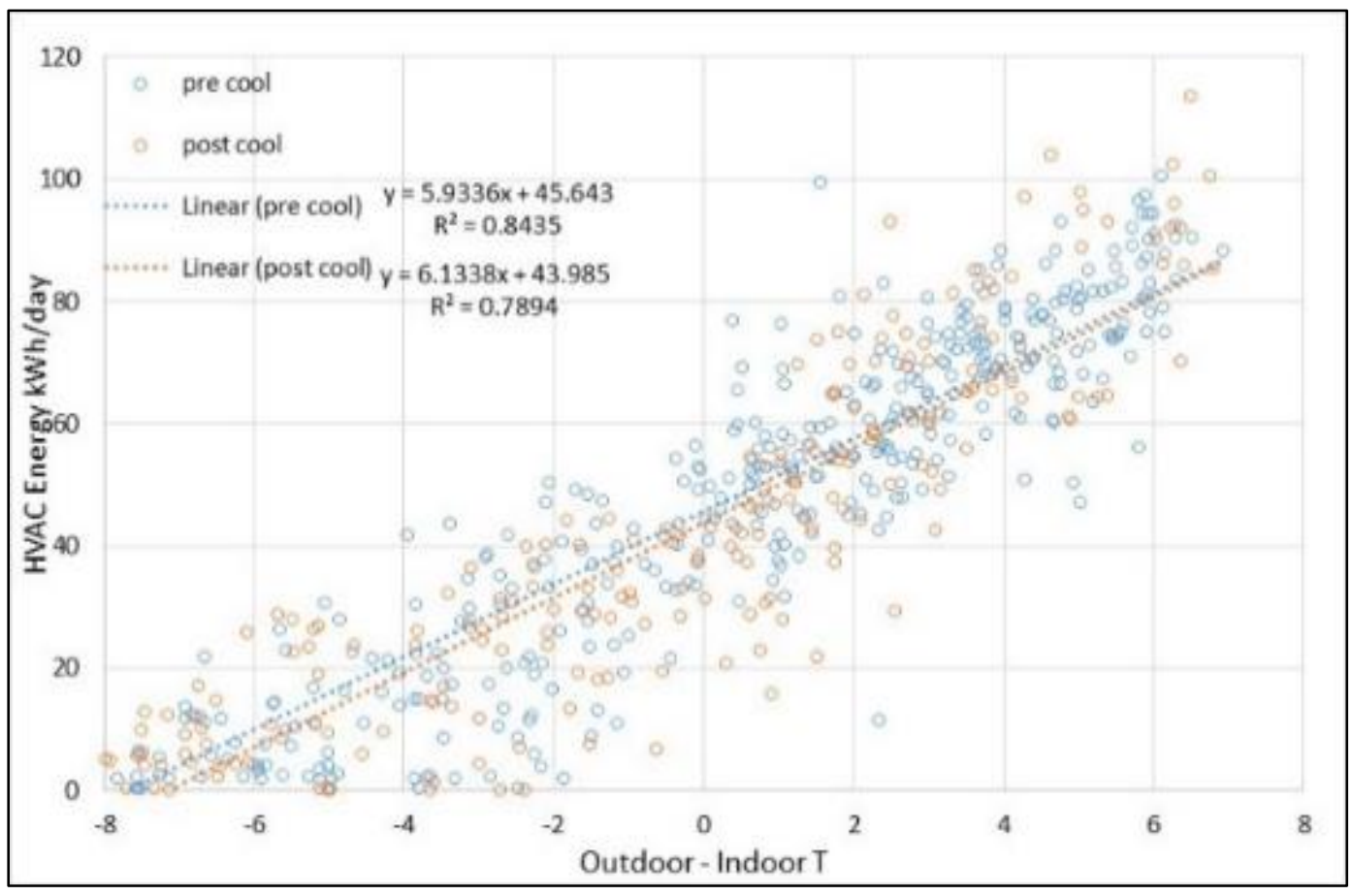

Figure 33. Cooling regression showing convergence for Site 5

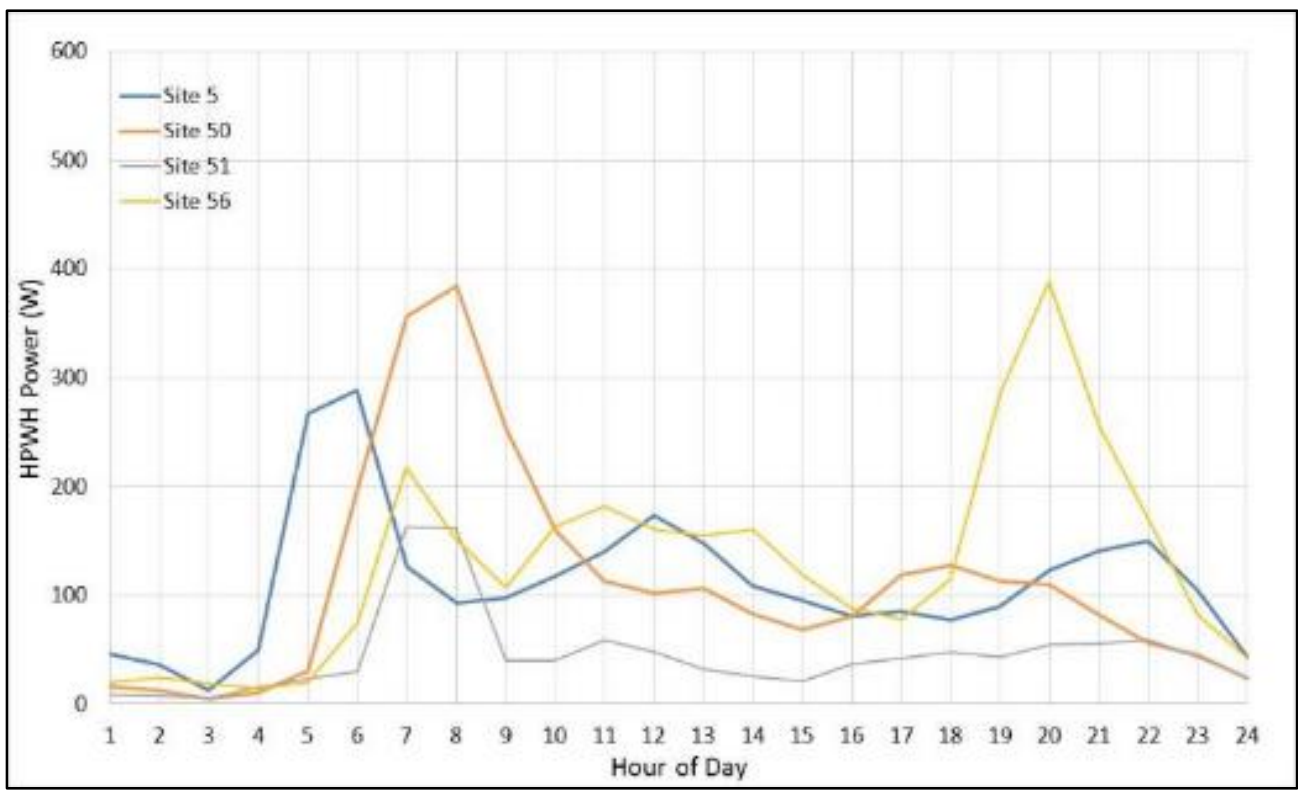

Figure 34. Post-retrofit composite average day's water-heating power for sites 5, 50, 51, and 56

Notably, sites 5, 50, and 51 exhibit peak HPWH run time in the early morning hours, with little daytime and evening operation. It is likely that during the early morning, when outdoor temperatures are cooler and less demand is placed on the cooling system, the extra cooling provided by a coupled HPWH is less beneficial. This is because the space temperature is further depressed below the thermostat set point but without immediate energy savings. Although Site 
56 has a regression and cooling savings similar to the other homes in this group, it exhibits an HPWH run time similar to the previous group, with a similar daily profile that includes an evening peak.

Heating regressions were conducted using outdoor temperature rather than Delta $\mathrm{T}$, and results are provided in Table18. The need for heating in Florida is variable and sporadic, and changing occupant preferences and tolerances result in variable indoor temperature, as opposed to the relatively consistent thermostat set point used during the cooling season.

Table 18. Heating Analysis Results for Conditioned Space-Coupled HPWH Retrofits

\begin{tabular}{|c|c|c|c|c|c|c|c|}
\hline Site No. & $\begin{array}{c}\text { No. of } \\
\text { Occupants }\end{array}$ & Coupling & $\begin{array}{c}\text { HPWH } \\
\text { Energy Post- } \\
\text { (kWh/day) }\end{array}$ & $\begin{array}{c}\text { Heating } \\
\text { Energy Pre- } \\
\text { (kWh/day) }\end{array}$ & $\begin{array}{c}\text { Heating } \\
\text { Energy Post- } \\
\text { (kWh/day) }\end{array}$ & $\begin{array}{c}\text { Heating } \\
\text { Savings } \\
\text { (kWh/day) }\end{array}$ & $\begin{array}{c}\text { Heating } \\
\text { Savings } \\
(\%)\end{array}$ \\
\hline 1 & \multicolumn{7}{|c|}{ Insufficient data } \\
\hline 5 & 2 & Ducted & 2.69 & 6.06 & 16.56 & -10.51 & -173.4 \\
\hline 9 & 2 & Ducted & 3.20 & 4.85 & 9.16 & -4.31 & -88.8 \\
\hline 13 & \multicolumn{7}{|c|}{ Insufficient data } \\
\hline 26 & 5 & Ducted & 3.53 & 3.71 & 4.03 & -0.33 & -8.9 \\
\hline 50 & 4 & Ducted & 2.65 & 14.83 & 12.85 & 1.98 & 13.4 \\
\hline 51 & \multicolumn{7}{|c|}{ Insufficient data } \\
\hline 56 & 3 & Interior & 3.09 & 14.42 & 15.18 & -0.76 & -5.3 \\
\hline Average & 3.2 & n/a & 2.64 & 8.77 & 11.56 & -2.89 & -24.1 \\
\hline Median & 3 & $\mathrm{n} / \mathrm{a}$ & 3.09 & 6.06 & 12.85 & -0.76 & -8.9 \\
\hline
\end{tabular}

As expected, coupling the HPWH to the conditioned space increases the heating energy. Median heating savings are approximately negative $0.76 \mathrm{kWh} /$ day among all sites as well as among those that are ducted only; therefore, considering cooling and heating impacts collectively, the net annual space-conditioning savings among the ducted sites is $332 \mathrm{kWh}$ or $8 \%$. The net annual space-conditioning savings among all sites is approximately $234 \mathrm{kWh}$ or $5 \%$. This general result matches those found in unoccupied lab homes (Colon, Martin, and Parker forthcoming);

however, the increase in heating energy resulting from coupling the HPWH, with a median of $0.76 \mathrm{kWh} /$ day $(8.9 \%)$ or $79 \mathrm{kWh} /$ year, is greater than the $0.42 \mathrm{kWh} /$ day $(5.9 \%)$ increase found in lab home studies, with a magnitude of increases in heating energy predicted by the model for sites 5 and 9. Figure 35 shows the regression for Site 5, which has a heat pump. The trend looks similar to the regression for Site 9, which has strip heat. It is clear that there is more heating in the post period, but it is likely that other variables in addition to the HPWH contribute to this trend. The occurrence of some days with relatively low heating energy at average daily outdoor temperatures lower than $55^{\circ} \mathrm{F}$ is unexplained. 


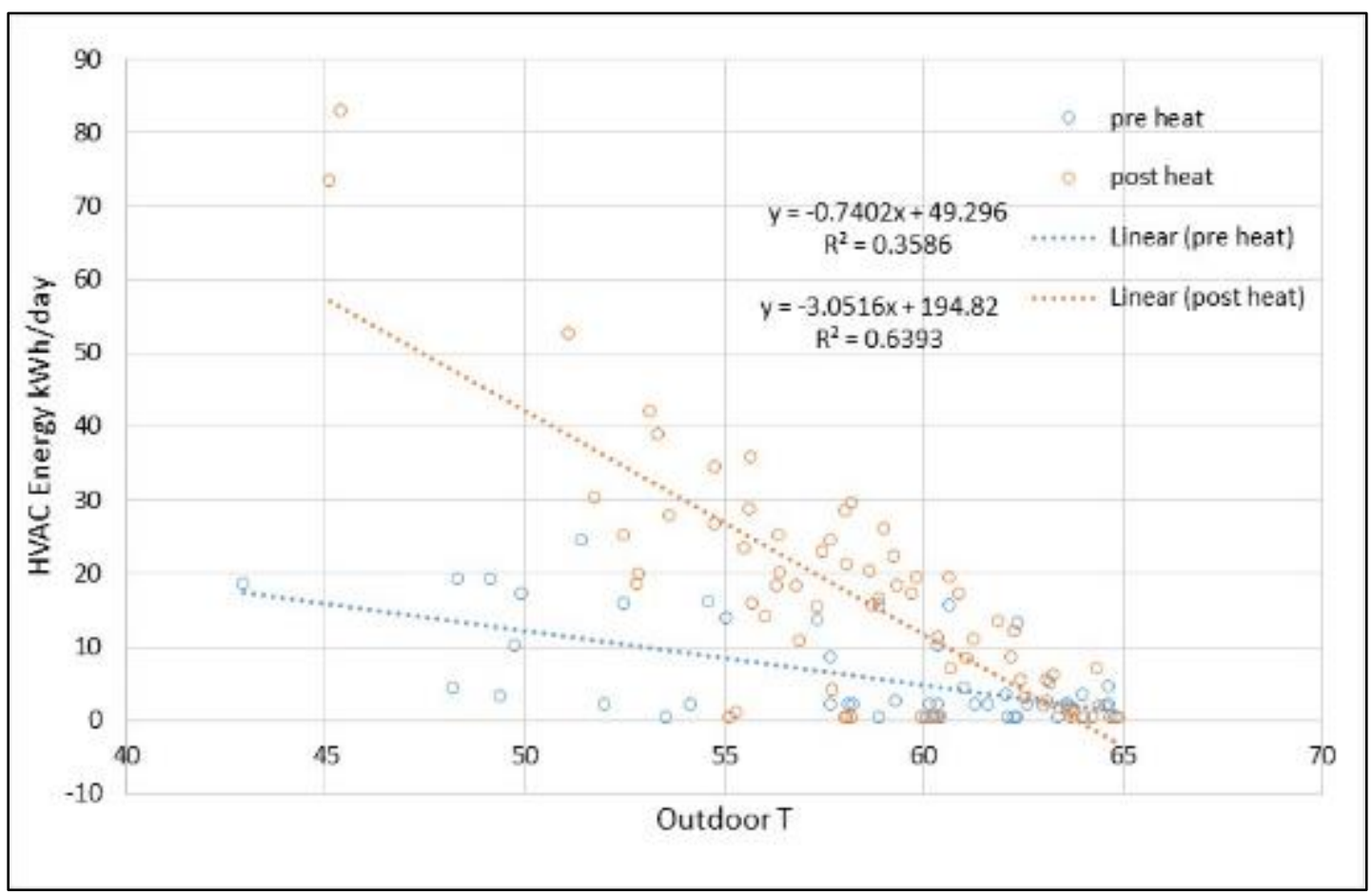

Figure 35. Heating regression for Site 5

Figure 36 shows the regression for Site 56. Site 56 has strip heat, and the trend looks similar to Site 26 , which has a heat pump, and it is indicative of more consistent heating behavior.

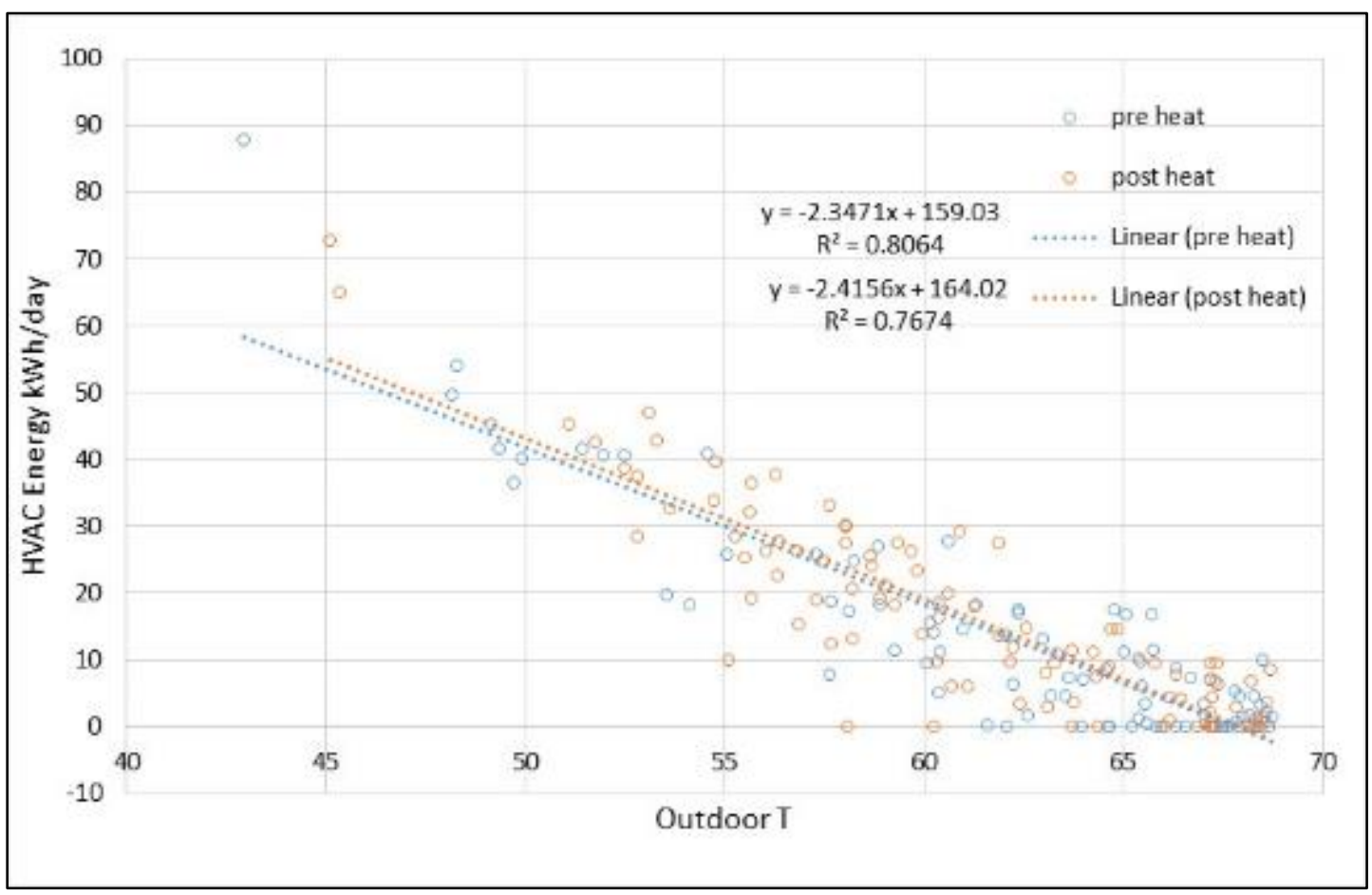

Figure 36. Heating regression for Site 56 
In any event, it is clear from these results as well as past research that coupling an HPWH to the conditioned space has a negative effect on heating. One way to counter this effect for a ducted HPWH is to install a damper system in the ductwork allowing cold HPWH exhaust air to be diverted from the conditioned space. Many of the ducted installations described in this report were installed with such a damper system, allowing the homeowner to take action if the cold exhaust air became a comfort problem (Figure 37), but findings indicate that none of the homeowners used the system. It is important to note that without a corresponding damper on the HPWH intake allowing air to be drawn from outside of the conditioned space — such as that used in Colon, Martin, and Parker (forthcoming) — some amount of space depressurization could occur during HPWH operation. The impact of that space depressurization and possible increase in infiltration on space-conditioning energy is not known.

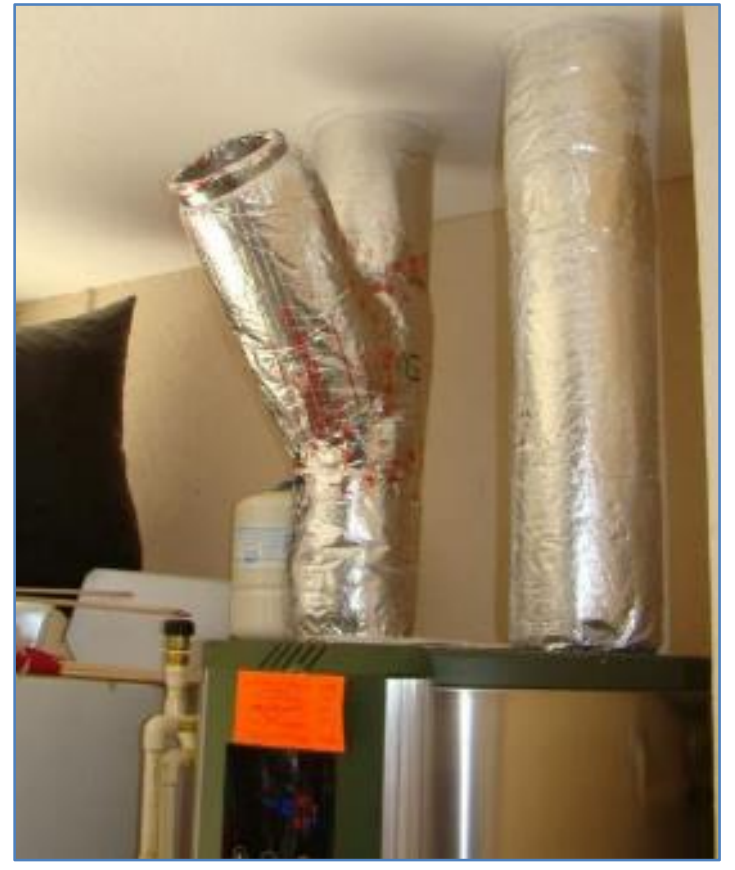

Figure 37. Y-type ducting arrangement at Site 5 allowing cold exhaust air to be diverted from the conditioned living environment

The effect of HPWH retrofits on domestic hot water (DHW) energy use was also investigated, again using data for the period from July 2013-July 2015, inclusive of both heating and cooling seasons. As shown in Table 19, the six sites receiving coupled HPWH as replacements to electric resistance tanks had a median savings of $53.3 \%$ in DHW energy.

Table 19. HPWH Electrical Energy Savings

\begin{tabular}{|c|c|c|c|c|c|c|}
\hline Case & $\begin{array}{l}\text { Site } \\
\text { No. }\end{array}$ & $\begin{array}{c}\text { No. of } \\
\text { Occupants }\end{array}$ & $\begin{array}{c}\text { DHW Energy } \\
\text { Pre- } \\
\text { (kWh/day) }\end{array}$ & $\begin{array}{l}\text { DHW Energy } \\
\text { Post- } \\
\text { (kWh/day) }\end{array}$ & $\begin{array}{l}\text { DHW Savings } \\
\text { (kWh/day) }\end{array}$ & $\begin{array}{c}\text { DHW Savings } \\
\text { (\%) }\end{array}$ \\
\hline \multirow{3}{*}{$\begin{array}{l}\text { Electric resistance } \\
\text { replaced with space- } \\
\text { coupled HPWH }\end{array}$} & 1 & 4 & 3.57 & 2.07 & 1.50 & 42.1 \\
\hline & 5 & 2 & 6.96 & 2.69 & 4.27 & 61.3 \\
\hline & 9 & 2 & 6.99 & 3.20 & 3.79 & 54.3 \\
\hline
\end{tabular}




\begin{tabular}{ccccccc}
\hline Case & $\begin{array}{c}\text { Site } \\
\text { No. }\end{array}$ & $\begin{array}{c}\text { No. of } \\
\text { Occupants }\end{array}$ & $\begin{array}{c}\text { DHW Energy } \\
\text { Pre- } \\
\text { (kWh/day) }\end{array}$ & $\begin{array}{c}\text { DHW Energy } \\
\text { Post- } \\
\text { (kWh/day) }\end{array}$ & $\begin{array}{c}\text { DHW Savings } \\
\text { (kWh/day) }\end{array}$ & $\begin{array}{c}\text { DHW Savings } \\
\text { (\%) }\end{array}$ \\
\hline & 13 & 2 & 6.20 & 2.64 & 3.56 & 57.4 \\
& 50 & 4 & 5.53 & 2.65 & 2.88 & 52.2 \\
Average & 56 & 3 & 5.89 & 3.09 & 2.80 & 47.6 \\
\hline Median & & $\mathbf{2 . 8}$ & $\mathbf{5 . 8 6}$ & $\mathbf{2 . 7 2}$ & $\mathbf{3 . 1 4}$ & $\mathbf{5 3 . 6}$ \\
\hline $\begin{array}{c}\text { Existing HPWH } \\
\text { Ducted }\end{array}$ & 26 & $\mathbf{2 . 5}$ & $\mathbf{6 . 0 5}$ & $\mathbf{2 . 6 7}$ & $\mathbf{3 . 2 2}$ & $\mathbf{5 3 . 3}$ \\
Average & 51 & 2 & 2.90 & 3.53 & -0.63 & -21.7 \\
\hline & & $\mathbf{3 . 5}$ & $\mathbf{2 . 0 1}$ & $\mathbf{2 . 3 9}$ & $-\mathbf{0 . 3 8}$ & -11.7 \\
\hline
\end{tabular}

As expected, the two sites that had HPWHs for more than 1 year prior to having them ducted showed slight increases in DHW energy use after the HPWHs were coupled to the conditioned space $(0.38 \mathrm{kWh} /$ day $)$. This study estimates that the coupling reduced potential DHW energy savings from a garage-located HPWH by $10.6 \%(0.38 / 3.60 \mathrm{kWh} /$ day, where $3.60=3.22$ $\mathrm{kWh} /$ day saving for electric resistance replacements $+0.38 \mathrm{kWh} /$ day loss for existing ducting). This negative water-heating savings of $139 \mathrm{kWh} /$ year reduces the annual savings for spacecoupling HPWH (234 kWh) to $95 \mathrm{kWh}$ or $2 \%$.

Although the lab home results presented in Colon, Martin, and Parker (forthcoming) found a negligible change in COP when using air from the conditioned space as a heat source instead of using air from the garage, Colon (forthcoming) found a higher COP when testing unducted versions of the A.O. Smith unit in a garage environment. In Florida, using garage air as a heat source is beneficial for HPWH water-heating operation because garage temperatures are high for much of the year. Changing to a room temperature heat source can be expected to impact waterheating efficiency. Analysis of the seven Phase I sites at which the HPWHs were not ducted was conducted to act as a control group for this measure. Although the results varied among sites, ranging from a $13 \%$ reduction in DHW heating energy to a $26 \%$ increase, an average of a $6.5 \%$ increase in DHW energy for this control group is less than the $16 \%$ found for the ducted sites; therefore, DHW energy savings when replacing an electric resistance tank with an HPWH is expected to be greater if the unit is coupled to the garage rather than the conditioned space. In Phase I of this research (see Phased-Retrofits in Existing Homes in Florida Phase I: Shallow and Deep Retrofits by Parker et al. [2016]), DHW energy savings from replacing an electric resistance water heater with an uncoupled HPWH was found to average $68.5 \%(5.27 \mathrm{kWh} /$ day $)$. Phase I percent savings for uncoupled HPWH matches well with the Phase II results if the 15.9\% savings loss from coupling is added to the observed 53.3\% savings for the coupled units $(53.3 \%$ $+15.9 \%=69.2 \%)$. Absolute savings from uncoupled units in Phase I $(5.27 \mathrm{kWh} /$ day $)$ are greater than what can be extracted from Phase II $(3.22 \mathrm{kWh}$ /day newly installed HPWH + negative 0.38 $\mathrm{kWh}$ /day existing $\mathrm{HPWH}=3.60 \mathrm{kWh} /$ day) because Phase I targeted households with the highest DHW energy consumption and had a mix of 60- and 80-gallon HPWH retrofits. Phase II homes used less DHW on average, and retrofits included only 60-gallon HPWHs.

The cost to install the ducting to couple the HPWH to the conditioned space, inclusive of materials and labor, was $\$ 620$. Although details of each installation varied, the contractor charged a flat rate for each job. In hindsight, the contractor felt they underbid the jobs, and they are likely to charge more in the future. Median annual cooling savings for the ducted sites was $\$ 49 /$ year, assuming $\$ 0.12 / \mathrm{kWh}$, yielding a simple payback of 12.6 years. A median heating 
energy penalty of $\$ 16$ cut these savings by one-third, yielding a simple payback of 18.4 years, nearly the ducting's 20-year expected life span. Therefore, due to the cost of ducting, it is not cost-effective to couple an HPWH installed in a garage to the conditioned space. However, there is a small benefit to installing an HPWH in a location inside the conditioned space instead of a garage location. One could expect a small ( $\sim 17 /$ year) penalty on water-heating energy savings due to the relatively cooler indoor air versus garage air, but the overall savings on spaceconditioning energy ( $\sim 34$ /year) outweighs this penalty. These savings, however, may not adequately cover the cost of rerouting plumbing to accommodate an interior location if the water heater was originally designed to be located somewhere else.

\subsubsection{Space-Coupled Heat Pump Water Heater Peak Reductions}

In an investigation of the impact of space-coupled HPWHs during peak summer and winter hours, HVAC power demand at the seasonal peak hours in 2014 were compared to those of 2015. Figure 38 compares the average HVAC demand of six of the retrofits during the summer peak of July 28, 2014, (pre-retrofit) to peak day on June 22, 2015, (post-retrofit), which shows a reduction of $0.23 \mathrm{~kW}$ or $7 \%$ between 4 p.m. and 5 p.m. ${ }^{12}$ The HVAC energy demand for the day increased by 16\%: $38.89 \mathrm{kWh}$ pre-retrofit and $45.19 \mathrm{kWh}$ post-retrofit.

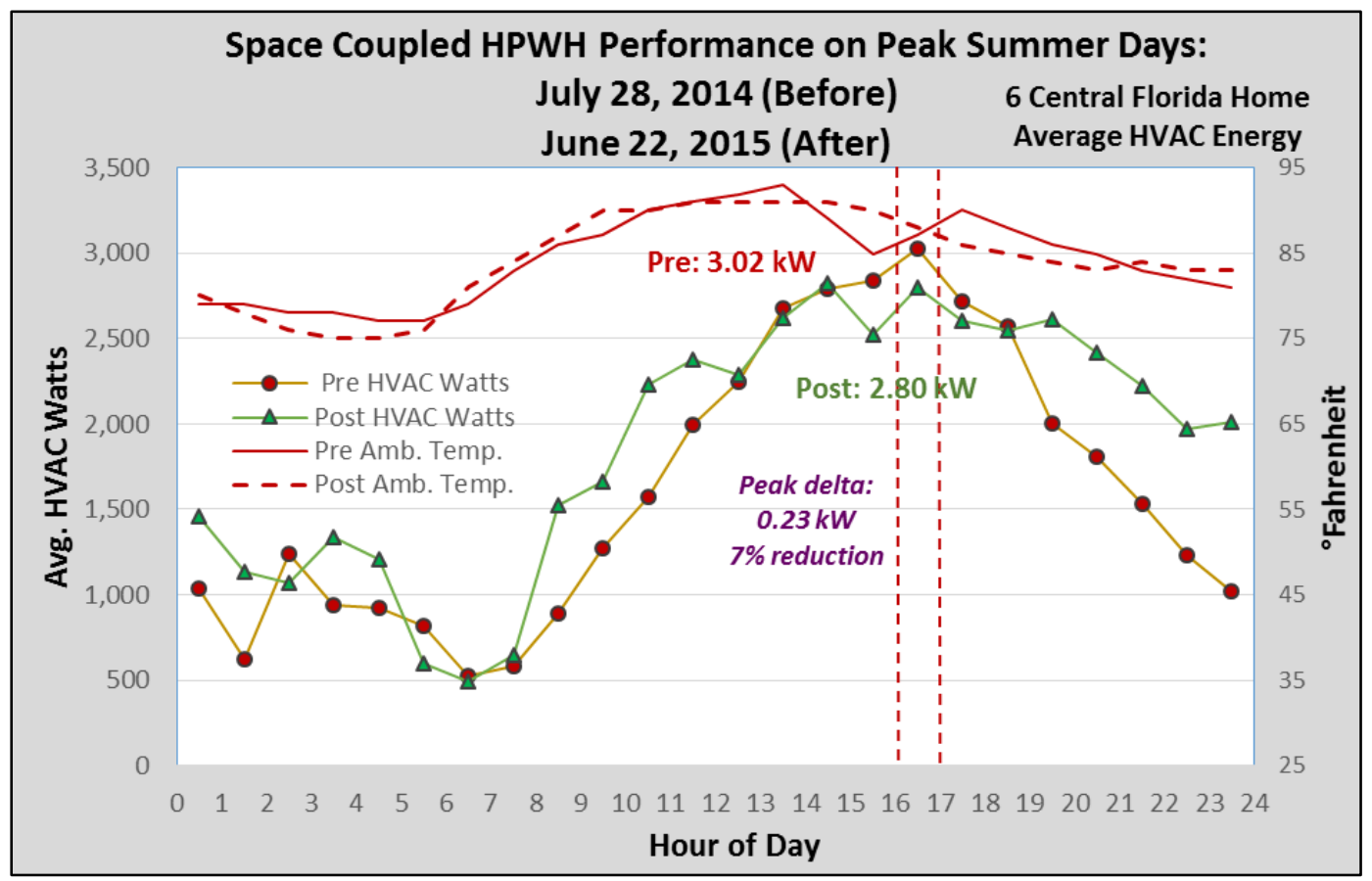

Figure 38. Comparative analysis between pre- and post-retrofit demand on FPL's system peak summer day of 2014 and surrogate peak summer day in 2015

Figure 39 compares the average HVAC demand at seven of the space-coupled HPWH sites during the winter peak of January 23, 2014, (pre-retrofit) to the winter peak of February 20,

\footnotetext{
${ }^{12}$ One site was excluded from the summer system peak analysis because the water heater was installed before the 2014 peak; a second site was excluded because the ducting was removed before the post-retrofit peak.
} 
2015, (post-retrofit), which shows a reduction of $0.18 \mathrm{~kW}$ or $5 \%$ between 7 a.m. and 8 a.m. ${ }^{13}$ The HVAC energy demand for the day increased by 7\%: $44.70 \mathrm{kWh}$ pre-retrofit and $47.74 \mathrm{kWh}$ post-retrofit.

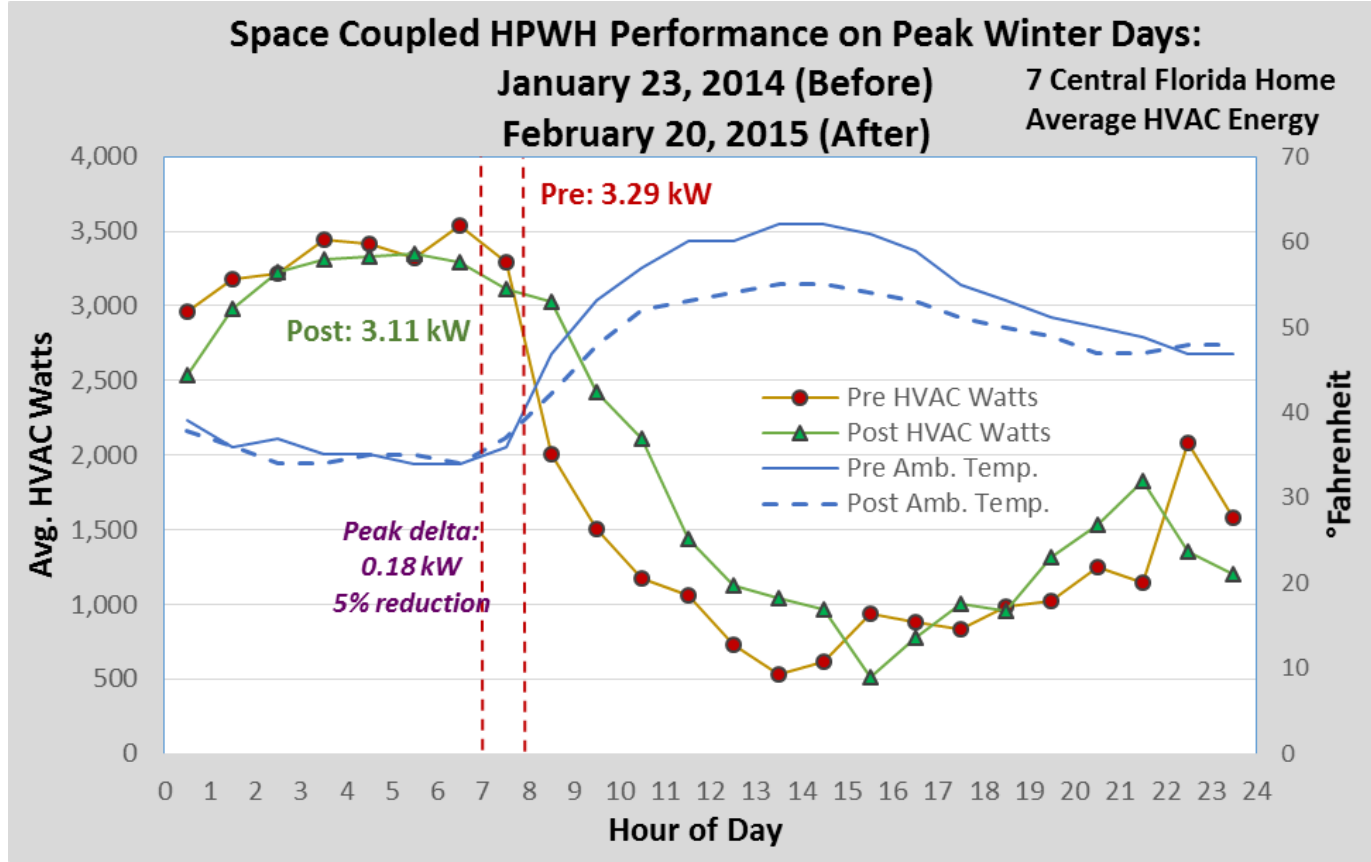

Figure 39. Comparative analysis between pre- and post-retrofit demand on FPL's system peak winter days

${ }^{13}$ One site was excluded from the winter system peak analysis because a new HVAC system was installed between the pre- and post-retrofit peak days. 


\section{Evaluation of Exterior Insulation Finish System}

Another measure investigated under the Phase II PDR project was the installation of an EIFS on a single site. Prior research on energy savings resulting from exterior insulation shows that the interior thermostat set point in a cooling-dominated climate has a large impact on potential savings.

A field test conducted by the FSEC and Oak Ridge National Laboratory evaluated changes in space-cooling energy use associated with EIFS applied to two Central Florida homes (Barkaszi and Parker 1995). The space-conditioning energy use evaluations showed post-retrofit cooling energy savings from $9 \%-14 \%$ at one site, with an average daily interior temperature of $73^{\circ} \mathrm{F}$, and $-1 \%$ at the second home because the occupants maintained a much higher interior temperature of $79^{\circ} \mathrm{F}$. A fundamental finding of this study was that the EIFS retrofit generates little cooling energy savings with higher thermostat settings. The PDR study involved evaluating the impacts of a home with an EIFS as well as an advanced window retrofit. The EIFS retrofit was the first of these two measures installed at the subject site and is evaluated in this section in a case-wise manner. The impact from the window retrofit and combination of measures is discussed in Section 7.

\subsection{Characteristics and Exterior Insulation Finish System Retrofit Measure for Site 54}

The site chosen for this measure, pictured in Figure 40, is a two-person occupancy, single-story home with 1,390 $\mathrm{ft}^{2}$ of living space located in Palm Bay, Florida. This home, built in 1999, has CMU walls with a stucco finish, a concrete slab foundation, an asphalt shingle roof, and R-19 fiberglass insulation at the attic floor and knee walls.

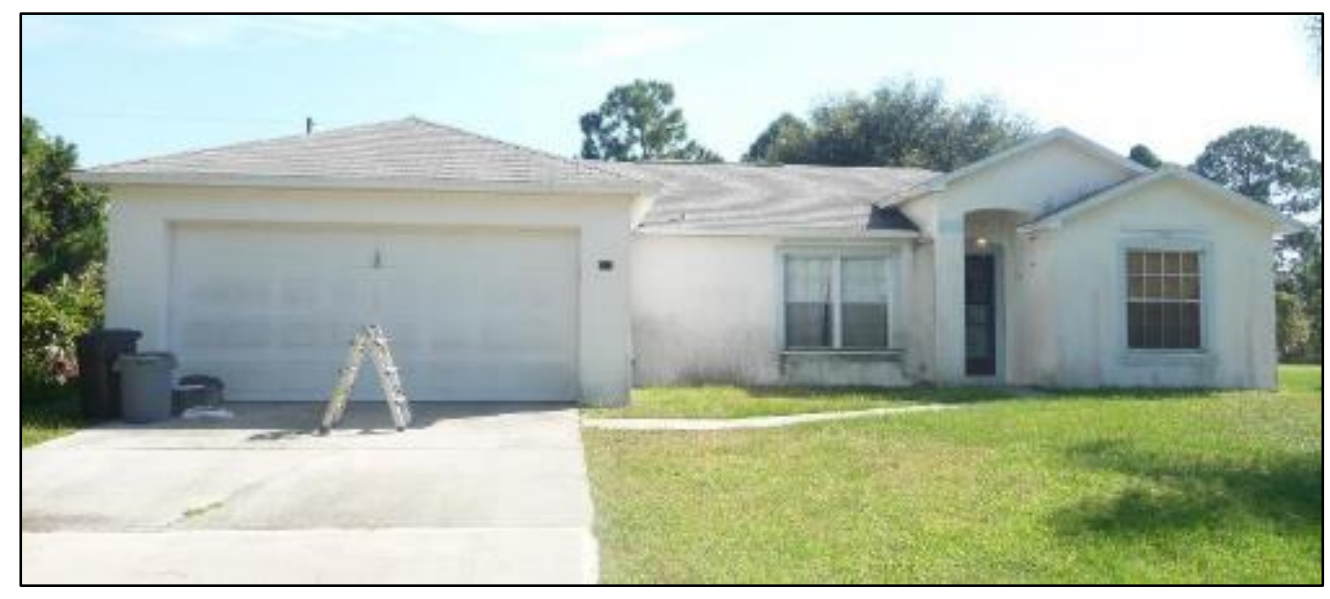

Figure 40. Site 54 prior to EIFS and window retrofits

The living space adjacent to the garage wall consists of framed $2 \times 4$ construction with a drywall finish. The home has 10 windows and a single sliding glass door. With a pre-retrofit tested 5.38 $\mathrm{ACH} 50$, this home has good airtightness for its vintage. The existing AC system is the original, manufacturer-rated 10 SEER heat pump. A single, centrally-located return feeds into the interiorlocated air handling unit. Supply air is distributed through R-6 insulated flex ducts with limited 
duct leakage $(Q n, o u t=0.03)$ running through the vented attic. General characteristics for Site 54 are provided in Table 20. Table 21 provides a detailed description of wall area by façade.

Table 20. General Characteristics for Site 54

\begin{tabular}{ll}
\hline Characteristic & Palm Bay \\
\hline City & 1999 \\
\hline Year built & 1,390 \\
Living area $\left(\mathrm{ft}^{2}\right.$ ) & 2 \\
No. of occupants & 1 \\
Stories & $\mathrm{CMU}$ \\
Wall construction & $\mathrm{R}-19$ \\
Ceiling insulation & 5.3 \\
\hline House airtightness (ACH50) & 1999 \\
Year of HVAC & 2.5 \\
\hline AC size (tons) & 10 \\
AC SEER & Heat pump \\
Heating & 0.03 \\
\hline Duct leakage (Qn,out) & \\
\hline
\end{tabular}

Table 21. Gross and Net Wall Area by Façade for Site 54

\begin{tabular}{ccccccccccc}
\hline $\begin{array}{l}\text { Site } \\
\text { No. }\end{array}$ & $\begin{array}{c}\text { Wall } \\
\text { Construction }\end{array}$ & $\begin{array}{c}\text { Wall } \\
\text { Color }\end{array}$ & $\begin{array}{c}\text { Gross Wall Area } \\
\left(\mathrm{ft}^{2}\right)\end{array}$ & \multicolumn{5}{c}{$\begin{array}{c}\text { Net Wall Area } \\
\left(\mathbf{f t}^{2}\right)\end{array}$} \\
\hline & & & & Total & East & South & West & North & NE & SE \\
\hline 54 & $\mathrm{CMU}$ & Off-white & 1,347 & 1,143 & 285 & 251 & 348 & 230 & 15 & 15 \\
\hline
\end{tabular}

An EIFS was applied consisting of 2-in. Type I expanded polystyrene insulation with an R-value specification of 3.85 per inch. The total added R-value of $7.7 \mathrm{hr}-\mathrm{ft}^{2}-{ }^{\circ} \mathrm{F} /$ Btu was installed between November 1 and December 16, 2014. (For evaluation purposes, the insulation was complete on November 13, but final finish work was delayed, in part, due to rain.) Before installing the EIFS, all items attached or close to the exterior wall were moved or removed. The exterior walls were pressure-washed, and a pull test was conducted to ensure that the fully-cured insulation adhered to the wall.

The EIFS installation process consisted of the following steps:

- A primer was applied to the exterior wall to support the adhesion of the insulation.

- Adhesive was applied to the 2-in. insulation sheets, and the insulation was adhered to the exterior wall.

- The installed insulation was rasped to provide a level finish.

- A reinforced base coat and final finish textured coat were next applied, as shown in Figure 41.

- In lieu of painting, the chosen wall color (off-white, similar to pre-retrofit) was premixed with a finish coat, allowing the final texture and color to be applied in one step. 
With no change in exterior finish color, the building has similarly low solar absorptance pre- and post-retrofit.

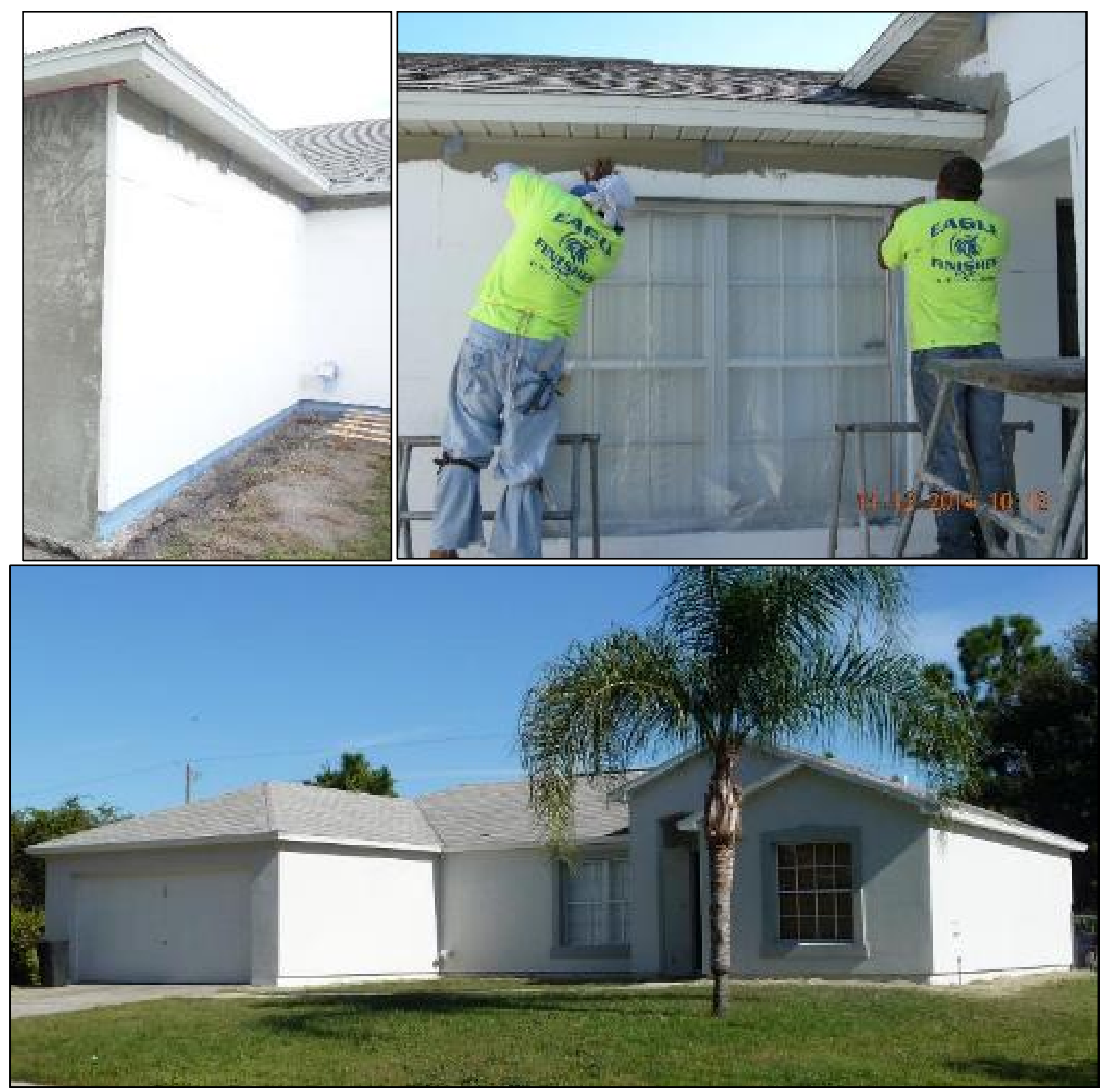

Figure 41. Attachment of 2-in. polystyrene insulation (top left), final textured coat application (top right), and completed EIFS retrofit (bottom) for Site 54

\subsection{Exterior Insulation Finish System Space-Cooling Energy Evaluation}

The pre-retrofit EIFS space-cooling observations were drawn from November 2013 through May 2014, and post-retrofit observations were drawn from November 2014 through April 2015, before the window retrofit began. The evaluation method used to predict energy use savings is presented in Section 4. 
Pre- and post-retrofit average daily exterior and interior temperatures, internal gains, and solar insolation are provided in Table 22. It is noteworthy that the post-retrofit daily average interior temperature is cooler by approximately $1.5^{\circ} \mathrm{F}$ post-retrofit in both of the season evaluations. This is perhaps an artifact of the better-insulated home causing nighttime float temperature to rise, inspiring occupants to select a lower temperature setting. Note also that the internal gains are much higher during the pre-retrofit periods, dropping by $26 \%$ between cooling periods and $32 \%$ between heating periods. Regressions from the analysis of the EIFS installation are provided in Appendix E.

Table 22. Average Daily Interior Temperatures, Internal Gains, and Solar Insolation Pre- and Post-EIFS Retrofit Evaluation Periods for Site 54

\begin{tabular}{lcccccccc}
\hline $\begin{array}{c}\text { Evaluation } \\
\text { Season }\end{array}$ & $\begin{array}{c}\text { Pre- T } \\
\text { Outdoor } \\
\left({ }^{\circ} \mathrm{F}\right)\end{array}$ & $\begin{array}{c}\text { Post- T } \\
\text { Outdoor } \\
\left({ }^{\circ} \mathrm{F}\right)\end{array}$ & $\begin{array}{c}\text { Pre- T } \\
\text { Indoor } \\
\left({ }^{\circ} \mathrm{F}\right)\end{array}$ & $\begin{array}{c}\text { Post- T } \\
\text { Indoor } \\
\left({ }^{\circ} \mathrm{F}\right)\end{array}$ & $\begin{array}{c}\text { Pre- } \\
\text { Internal } \\
\text { Heat Gains } \\
(\mathbf{k W h} / \text { day) }\end{array}$ & $\begin{array}{c}\text { Post- } \\
\text { Internal } \\
\text { Heat Gains } \\
(\mathbf{k W h} / \text { day) }\end{array}$ & $\begin{array}{c}\text { Pre- Solar } \\
\text { Insol. } \\
\left(\mathbf{k W h} / \mathbf{m}^{2} /\right. \\
\text { day) }\end{array}$ & $\begin{array}{c}\text { Post- Solar } \\
\text { Insol. } \\
\left(\mathbf{k W h} / \mathbf{m}^{2} /\right. \\
\text { day) }\end{array}$ \\
\hline Cooling & 72.1 & 72.4 & 76.4 & 74.7 & 14.1 & 10.4 & 4.5 & 4.1 \\
Heating & 55.7 & 56.9 & 71.9 & 70.5 & 14.3 & 9.7 & 4.3 & 4.2 \\
\hline
\end{tabular}

Observations for each period include when the daily average ambient temperature exceeded $63^{\circ} \mathrm{F}$, the point at which space-cooling energy is evident at this particular site. The scatterplot in Figure 42 demonstrates the trend of cooling energy use by outdoor temperature for the pre- and post-retrofit periods. The pre-retrofit observations and trend line are orange; the post-retrofit observations are blue. The trend lines portray post-retrofit energy savings as the outdoor temperature increases.

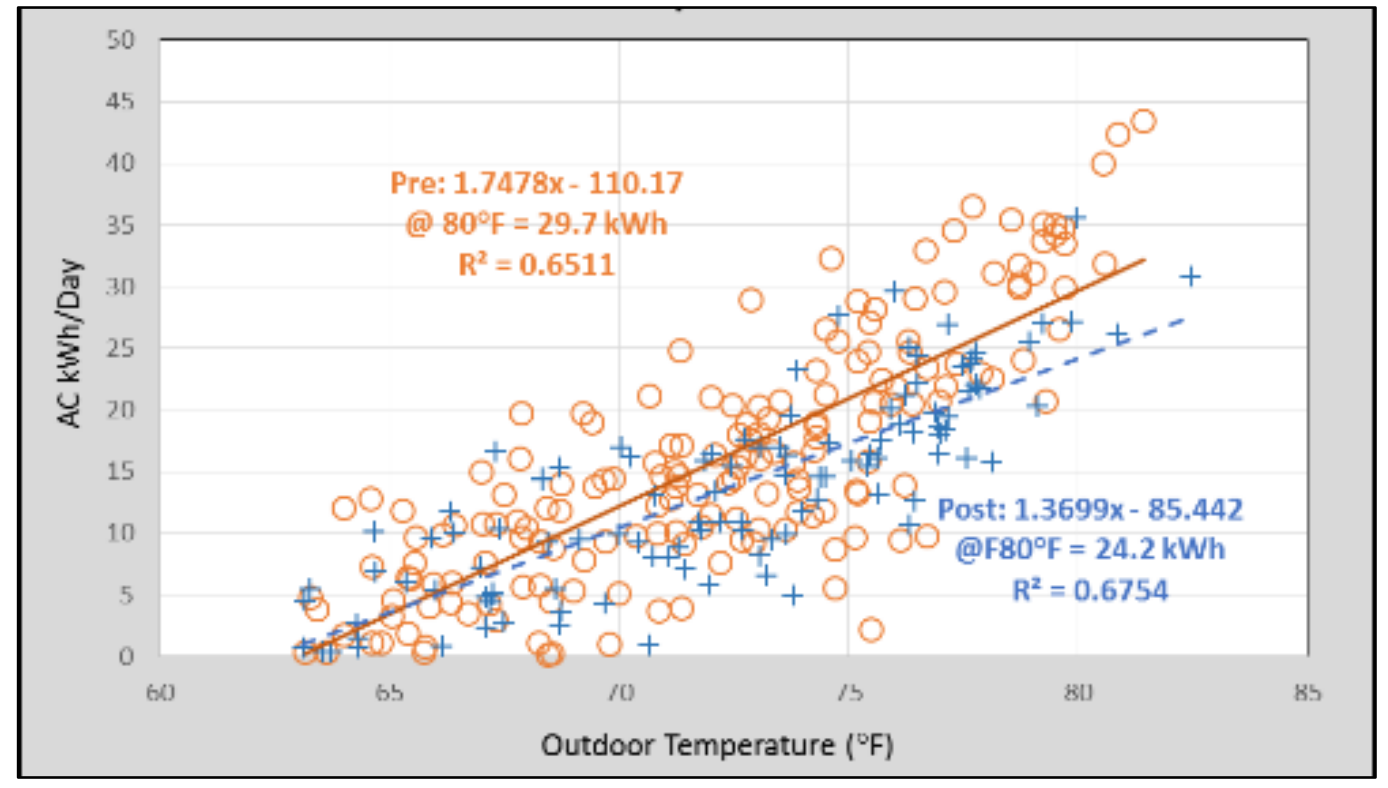

Figure 42. Regression lines for space-cooling pre- and post-EIFS retrofit for Site 54

Although the scatter in the data is very large, a general trend of lower cooling consumption in the post-retrofit period (blue) can be observed. Moreover, the Site 54 occupants maintained a much 
cooler average daily interior temperature during the post-retrofit period $\left(74.7^{\circ} \mathrm{F}\right)$ than the preretrofit period $\left(76.4^{\circ} \mathrm{F}\right)$. This temperature difference is consistent through the day, as shown in the daily temperature profile plotted in Figure 43. The hourly interior (solid line labeled "Tint") and ambient (dashed line labeled "Tamb") temperature profiles are red for the pre-retrofit period and green for the post-retrofit period.

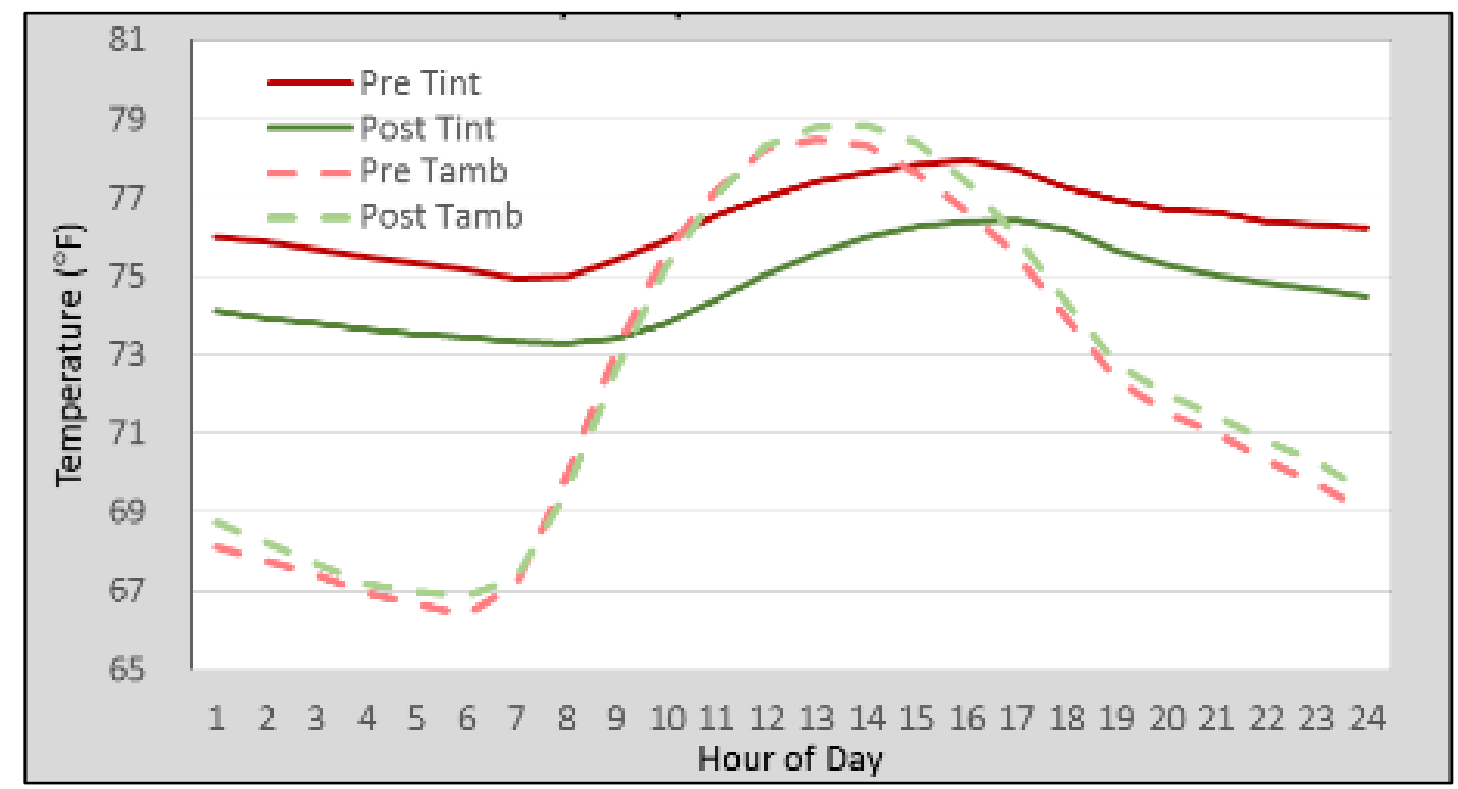

Figure 43. Pre- and post-EIFS retrofit indoor and outdoor temperature profiles for cooling season observations for Site 54

With fairly similar ambient temperatures among periods, the interior temperature was consistently lower post-retrofit. This indicates a change in occupant preferences rather than the building's thermal performance as influenced by the added wall insulation. The occupants have apparently taken back some of the savings for improved comfort. Savings were therefore evaluated based on the Delta T.

Solar insolation and internal gains, which were both greater during the pre-retrofit period (internal gains: 14.1 compared to $10.4 \mathrm{kWh}$; solar insolation 4.3 compared to $4.1 \mathrm{kWh} / \mathrm{m}^{2}$ ), were both significant in each model $(p<0.01)$. Both pre- and post-retrofit regression results show stronger model fits than using outdoor temperature alone $\left(\mathrm{R}^{2}=0.76\right.$ pre-retrofit; 0.72 postretrofit). Using these models, and assuming an average outdoor temperature of $80^{\circ} \mathrm{F}$, daily cooling energy needs are likely to be reduced during the warmest summer months from 27.2 to 22.2 , a savings of $5.0 \mathrm{kWh} /$ day (18.2\%) or $947 \mathrm{kWh} /$ year when applying the percent savings to the PDR average annual pre-retrofit space-cooling energy use of 5,205 kWh/year (Appendix A) as a result of the EIFS retrofit. These findings are somewhat higher than expected given the 3-5 $\mathrm{kWh} /$ day $(9 \%-14 \%)$ savings found for the home with an interior temperature setting of $73^{\circ} \mathrm{F}$ (Barkaszi and Parker 1995).

For insight into the impact of internal gains, the savings projection is $25.9 \%$ assuming the preretrofit internal gains of $14.1 \mathrm{kWh} /$ day and post-retrofit internal gains of $10.4 \mathrm{kWh} / \mathrm{day}$. To ignore the change in internal gains inflates the savings projection by $7.7 \%$. Also, if the analysis 
were confined to using the outdoor temperature and did not account for the lower interior temperatures, the indicated savings drop to approximately $10 \%$ or $2.8 \mathrm{kWh} /$ day at an $80^{\circ} \mathrm{F}$ outdoor temperature.

\subsection{Exterior Insulation Finish System Space-Heating Energy Evaluation}

Space heating is limited in Florida's climate as evidenced by the zero recorded heating energy uses shown below in Figure 44. However, it is also evident at Site 54 that when the daily average outdoor temperature falls below $62^{\circ} \mathrm{F}$, the occupants begin to heat; thus, days with average temperatures below $62^{\circ} \mathrm{F}$ were used as the threshold for model inclusion.

The pre-retrofit observations were drawn from November 1, 2013, through March 2014, and post-retrofit observations were drawn from November 14, 2014, through March 2015. The scatterplot in Figure 44 displays pre- and post-retrofit space-heating use compared to outdoor temperature, and it reveals higher space-heating energy use post-EIFS retrofit.

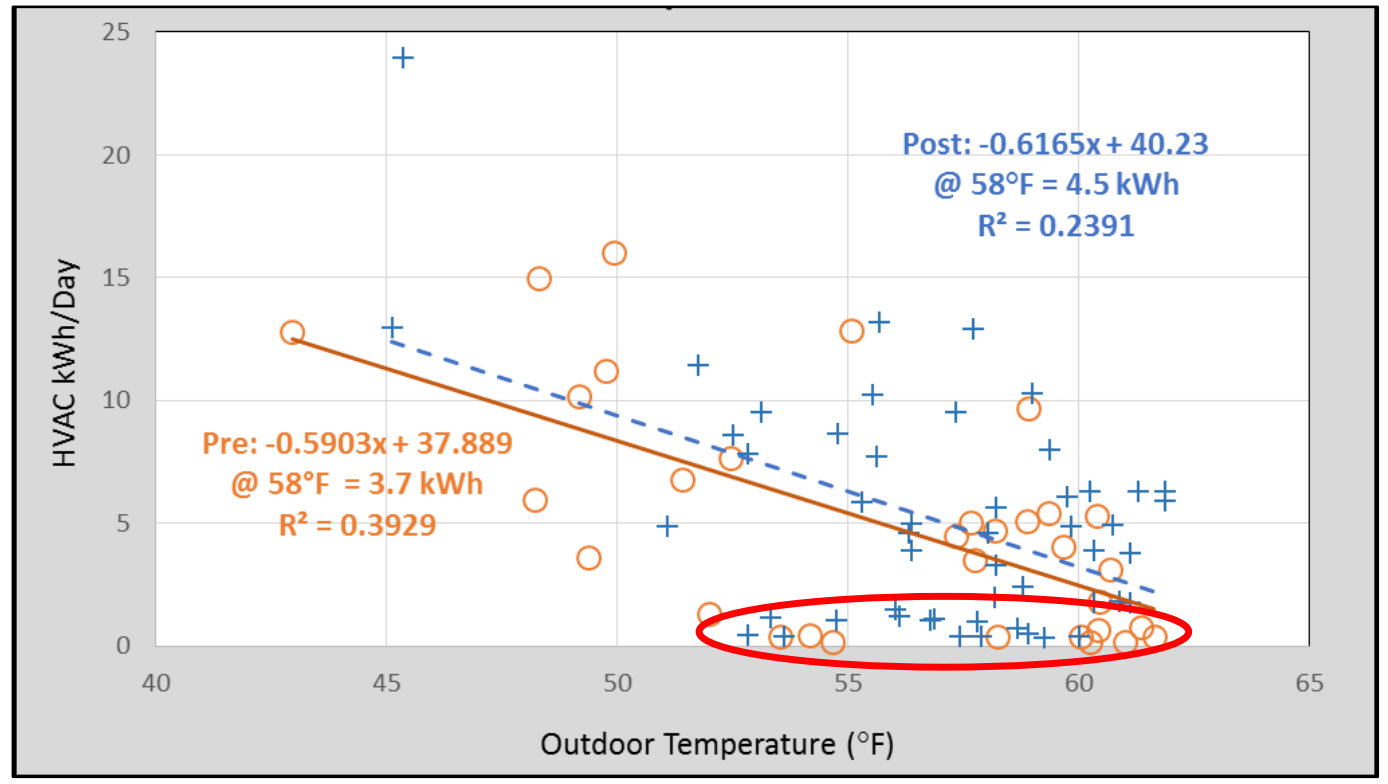

Figure 44. Regression lines for space-heating pre- and post-EIFS retrofit for Site 54

The limited and sporadic heating needs in Central Florida limit statistical modeling for spaceheating use predictions. First, there are few observation-days with significant heating loads. For example, there were only 32 days during the 2013-2014 winter and 51 days during the 20142015 winter when the average daily ambient temperature fell below $62^{\circ} \mathrm{F}$. Second, the timing and duration of the cold fronts that pass through the area impact heating needs greatly. The great amount of scatter in Figure 44 demonstrates this point. Circled in red is the wide distribution of temperatures, from $52^{\circ}-62^{\circ} \mathrm{F}$, for which sometimes little or no space heating is used. Other observations show considerable space-heating energy use (up to $13 \mathrm{kWh} /$ day) at these same temperatures.

Although neither internal gains nor solar insolation were significant for modeling with the very limited sample set, each of these parameters was greater during the pre-retrofit period. Internal heat gains were particularly dissimilar- $14.3 \mathrm{kWh}$ /day pre-retrofit, $9.7 \mathrm{kWh}$ /day post-retrofit. 
This is important because the pre-retrofit conditions were more favorable for reducing spaceheating energy needs. On the other hand, the savings model does not consider the change in interior temperature, which was cooler post-retrofit $\left(71.9^{\circ} \mathrm{F}\right.$ pre-retrofit compared to $70.5^{\circ} \mathrm{F}$ postretrofit). Figure 45 shows that the post-retrofit interior temperature was consistently lower throughout the day.

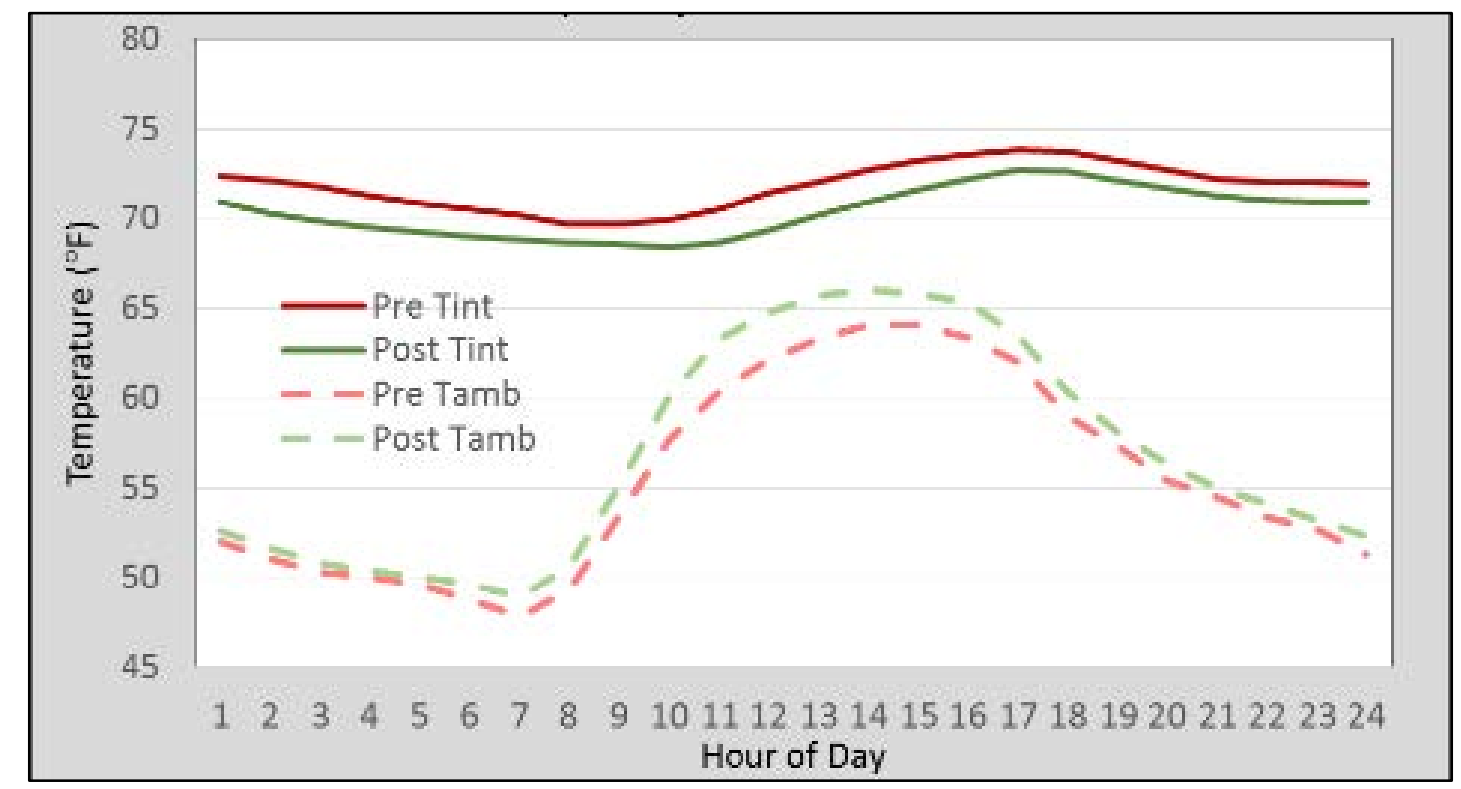

Figure 45. Pre- and post-EIFS retrofit indoor and outdoor temperature profiles for heating season observations for Site 54

Given the consistently lower interior temperature, it is arguable that savings should be evaluated based on the Delta T; however, the poorly-fitting outdoor temperature regression models (pre: $\mathrm{R}^{2}$ $=0.39$; post: $\mathrm{R}^{2}=0.24$ ) deteriorated further as a whole with Delta $\mathrm{T}$ (pre: $\mathrm{R}^{2}=0.28$; post: $\mathrm{R}^{2}=$ 0.28 ) and were not suitable for characterizing heating performance. Solar insolation and internal heat gains parameters were also considered, but they were not significant.

Predicting space-heating energy savings in response to outdoor temperature for a cold day with an average outdoor temperature of $50^{\circ} \mathrm{F}$, the models suggest energy use increases from $8.4 \mathrm{kWh}$ to $9.4 \mathrm{kWh}$, suggesting negative savings of $1.0 \mathrm{kWh} /$ day $(-12.3 \%)$, or negative $34 \mathrm{kWh} /$ year when applying the percent savings to the PDR average annual pre-retrofit space heating energy use of $275 \mathrm{kWh} /$ year (Appendix A); however, given the very poor statistical models, which explain less than $30 \%$ of the variation in the post-retrofit heating, not much significance can be attached to these results.

As noted above, the climate in Central Florida, and particularly the coastal regions, requires limited annual space heating. Given the limited statistical power of the found relationships, the heating effects should be reevaluated when more post-retrofit data are available for the site that may allow better characterization of heating performance. 


\subsection{Exterior Insulation Finish System Retrofit Savings Summary}

In the evaluation of the EIFS at Site 54, seasonal space-cooling energy savings was $5.0 \mathrm{kWh} /$ day $(18.2 \%)$ for an average day among the warmer summer months; however, space heating indicated negative savings of $1.0 \mathrm{kWh}(-12.3 \%)$ on a cold Central Florida day but with unreliable statistical models from a limited sample of heating days. Estimated annual savings based on the PDR average annual pre-retrofit space-conditioning energy use of 5,480 $\mathrm{kWh}$ (Appendix A) are $913 \mathrm{kWh}$, or $17 \%$. Table 23 provides a summary of the EIFS energy savings results.

Table 23. EIFS Space-Conditioning Energy Savings Summary for Site
\begin{tabular}{ccccc}
\hline $\begin{array}{c}\text { Evaluation } \\
\text { Season }\end{array}$ & $\begin{array}{c}\text { Pre- } \\
\text { (kWh/day) }\end{array}$ & $\begin{array}{c}\text { Post- } \\
\text { (kWh/day) }\end{array}$ & $\begin{array}{c}\text { Daily } \\
\text { Savings } \\
\text { (kWh) }\end{array}$ & $\begin{array}{c}\text { \% Savings } \\
\text { Cooling @ 80 } \\
\text { Heating @ 50 }\end{array}$ \\
\hline Cooling & 27.2 & 22.2 & 5.0 & $18.2 \%$ \\
\hline Heating & 8.4 & 9.4 & -1.0 & $-12.3 \%$ \\
\hline
\end{tabular}

Costs incurred for the EIFS retrofit measure, including modifications to electrical outlets and plumbing fixtures, were $\$ 19,438$. In terms of a cost benefit alone, the EIFS measure is not an energy-efficiency measure. If the HVAC energy savings results are applied to the average annual HVAC energy use of the untreated PDR sample reported in Phase I, the annual savings are \$124 with $\$ 128 /$ year cooling energy savings $(5,880 \mathrm{kWh} /$ year $* 0.182 * \$ 0.12 / \mathrm{kWh})$ and $-\$ 4 /$ year heating energy savings $(275 \mathrm{kWh} /$ year $*-0.123 * \$ 0.12 / \mathrm{kWh})$. With little space-conditioning impact during the swing seasons and unknown savings for the coldest winter days, it is clear that the EIFS retrofit at Site 54 is not a cost-effective energy-efficiency proposition for Florida's climate. Other benefits associated with the measure, such as better interior comfort and a stable interior temperature, however, might justify the EIFS measure, but this is beyond the scope of this evaluation.

The evaluation of the EIFS retrofit is a heavily examined case study. Given the considerable variance in the regressions, variations in occupancy behavior, and internal gains, the savings from the EIFS in Florida will differ considerably for individual homes and will likely depend on:

- Average interior temperature maintained (the lower the temperature, the greater the savings)

- The preexisting shading from outdoor features (buildings, setback shading, vegetation) and indoor shading (blinds and drapes and insect screening)

- The magnitude of internal gains (the greater the internal gains, the lower the savings from insulation because internal heat cannot be lost to the outdoors during the evening hours when it is cooler outside than inside)

- Exterior wall color (with white or light wall color, such as in this case study, solar radiation is reflected, and the savings are reduced).

The weaknesses in the modeling did not lend this measure for further evaluation under the TMY3 weather normalization. Peak system hour impacts were also not warranted for the evaluation of the single site. 
To investigate the sensitivity of these influences on the energy saving results, a detailed parametric evaluation was conducted using the BEopt hourly energy simulation running EnergyPlus.

\subsection{Parametric Evaluation of Factors Affecting Wall Insulation Savings in Florida Homes}

The single-wall retrofit experiment in the Phase II PDR showed mixed results, with $18 \%$ spacecooling savings and inconclusive heating savings. As described in the narrative, it is likely that the negative heating energy savings are because the internal gains were higher in the pre-retrofit heating period than in the post-retrofit period; however, the interior temperature was lower postretrofit. Given the single-case study nature of the monitoring effort in Phase II, a simulation evaluation was conducted to see how various factors might be influencing results.

The expectation coming into the evaluation was that savings would likely be fairly low, as shown earlier in testing in Cocoa, Florida (Barkaszi and Parker 1995). That study found annual cooling energy savings of $9 \%-14 \%$ with a $73^{\circ} \mathrm{F}$ set point, but negative savings $(-1 \%)$ at $79^{\circ} \mathrm{F}$ for a building with white walls.

The BEopt simulation software running EnergyPlus was used to evaluate the influences. A prototype 1,790 $\mathrm{ft}^{2}$ building, portrayed in Figure 46, was produced with characteristics similar to what would be found in a typical home in the PDR project but with several specifics similar to those at Site 54, the home that received the EIFS retrofit. These included insulation (R-4 walls, R-19 ceiling, uninsulated slab floor, 8 ACH50), AC systems, and heating. For BEopt rendering for windows, the base case windows were single-glazed with aluminum frames (U-value $=1.16$ $\mathrm{Btu} /$ hour- $\mathrm{ft}^{2}-^{\circ} \mathrm{F}$, solar heat gain coefficient $\left.[\mathrm{SHGC}]=0.76\right) .{ }^{14}$ A SEER 10/ HSPF 6.8 heat pump was assumed with base thermostat set points of $75^{\circ} \mathrm{F}$ for cooling and $71^{\circ} \mathrm{F}$ for heating and R-4 ducts with $15 \%$ duct leakage. Site 54 effectively had no neighboring houses, as assumed in the baseline analysis.

\footnotetext{
${ }^{14}$ According to the 2014 Florida Building Code, the maximum allowed SHGC as a prescriptive requirement for new homes is 0.25 . The SHGC for standard, single-glazed windows with an aluminum frame is approximately 0.96 . The SHGC is the fraction of incident solar radiation admitted through a window, both directly transmitted and absorbed and subsequently released inward. SHGC is expressed as a number between 0 and 1 . The lower a window's SHGC, the less solar heat it transmits. The ratio is of the integrated solar irradiance on the exterior of a window unit to that transmitted to the interior, and it accounts for many factors.
} 


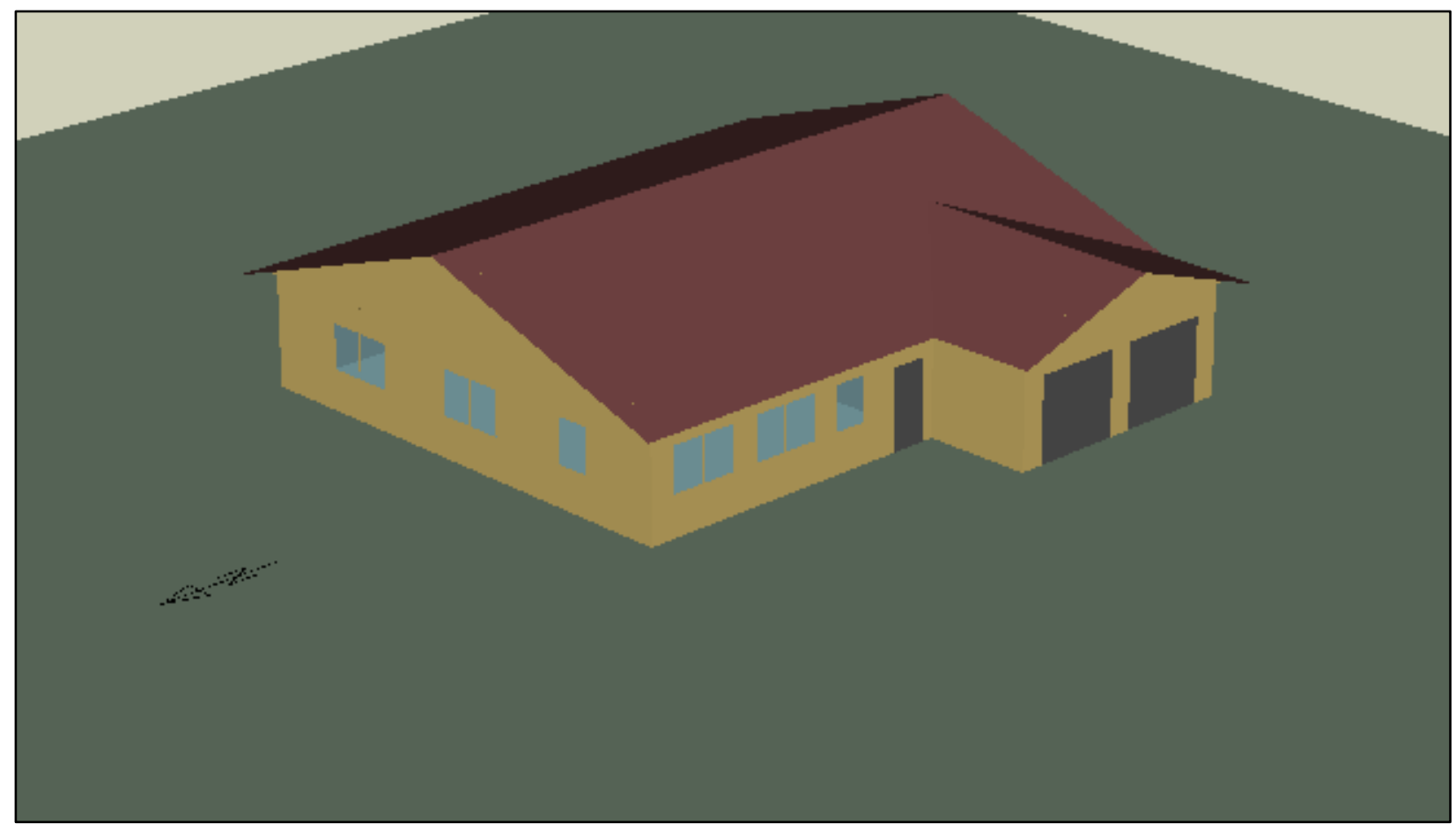

Figure 46. Prototypical PDR residence rendered in BEopt with no adjacent home as at Site 54

The standard 8-in. hollow-core concrete block wall (medium-density concrete aggregate) was used as the base case, with a light-colored exterior finish with a solar absorptance of 0.5 . The 2in. expanded polystyrene insulation had a measured R-value of $7.7 \mathrm{hr}-\mathrm{ft}^{2}-{ }^{\circ} \mathrm{F} / \mathrm{Btu}$, and this was simulated along with the other factors expected to influence space-cooling savings from walls.

The Site 54 savings evaluation assessed cooling and heating energy; however, the focus here was on the cooling energy savings in particular. High levels of internal and window heat gain lead to overheating in the spring and fall seasons, and BEopt has the potential to simulate year-round venting - although in the project natural ventilation was fairly uncommon except during the Florida winter season. This operational capability was then subjected to evaluation.

Other parameters that can be expected to influence wall savings include wall color, interior thermostat temperature, and internal heat gain rate. The higher the temperature set point, the lower the savings from the lower U-factor of walls. Moreover, at some point the lower heat loss from the walls at night will begin to exert a negative influence on savings.

Similarly, with high levels of internal heat gain from greater appliance and interior plug loads, the home's interior temperature will tend to be elevated such that greater heat loss at night from less-insulated walls and single-glazed windows is actually desirable. For Site 54, this study found that assuming 50\% greater than normal plug loads (1.5) worked fairly well to match preretrofit data.

Figure 47 shows the results for a case similar to Site 54 with $50 \%$ greater plug loads and a cooling set point of $75^{\circ} \mathrm{F}$. The predicted cooling energy savings from the exterior wall insulation amounts to only $349 \mathrm{kWh} /$ year if the building takes advantage of natural ventilation-a $6 \%$ 
cooling energy savings. The results are shown in Table 24 below in the form of an analysis result table from BEopt.

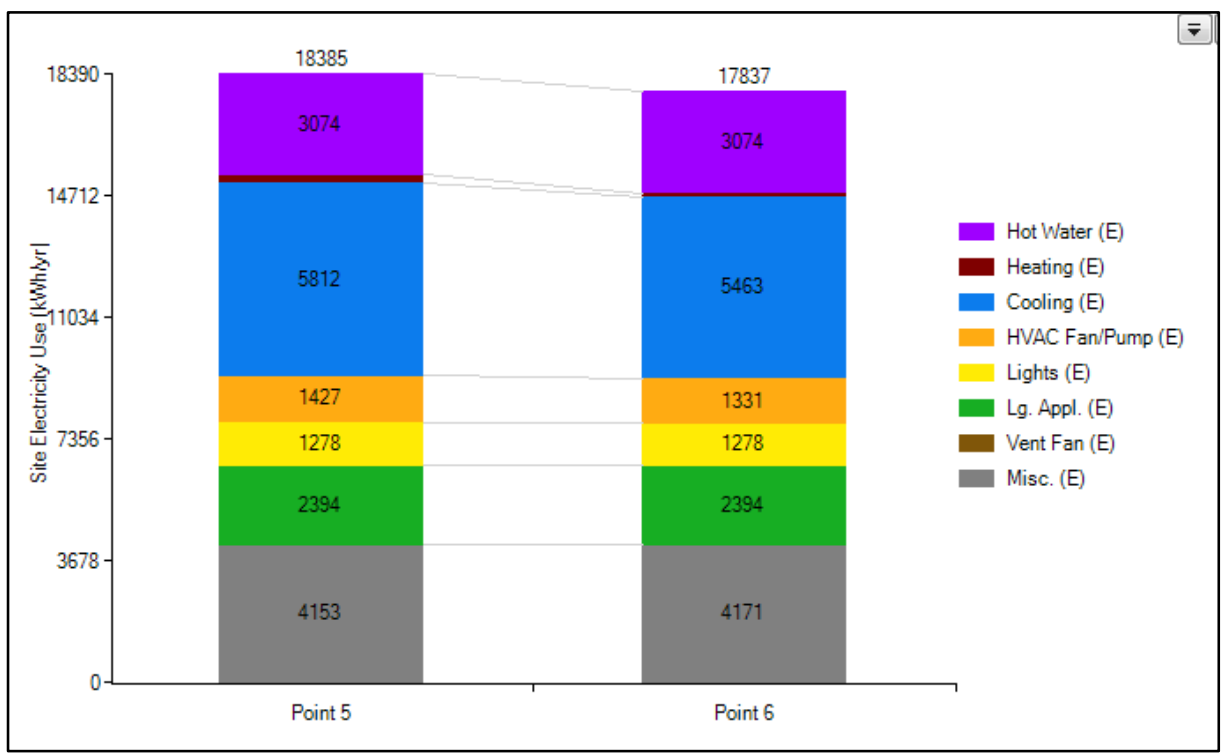

Figure 47. Estimated savings from standard uninsulated block walls (Point 5 ) compared to the addition of R-7.7 expanded polystyrene on exterior; $75^{\circ} \mathrm{F}$ set point with 1.5 times normal plug loads 
Table 24. Sensitivity of Wall Savings to Parameters

a Bolded rows represent the parameter selected for the general model used in the remaining parameters' sensitivity runs.

\begin{tabular}{|c|c|c|c|c|c|c|c|c|}
\hline \multirow[b]{2}{*}{$\begin{array}{l}\text { Set Point } \\
\left({ }^{\circ} \mathrm{F}\right)\end{array}$} & \multicolumn{4}{|c|}{ No Ventilation } & \multicolumn{4}{|c|}{ With Year-Round Ventilation } \\
\hline & $\begin{array}{l}\text { Uninsulated } \\
\text { 8-in. Block } \\
\text { (kWh) }\end{array}$ & $\begin{array}{c}\text { 8-in. Block w/ } \\
\text { R7.7 Expanded Polystyrene } \\
\text { (kWh) }\end{array}$ & $\begin{array}{c}\text { Savings } \\
\text { (kWh) }\end{array}$ & $\begin{array}{c}\text { Savings } \\
\%\end{array}$ & $\begin{array}{l}\text { Single-Glazed } \\
\text { (kWh) }\end{array}$ & $\begin{array}{c}\text { Double-LowE_Solar } \\
\text { (kWh) }\end{array}$ & $\begin{array}{c}\text { Savings } \\
\text { (kWh) }\end{array}$ & $\begin{array}{c}\text { Savings } \\
\text { (kWh) }\end{array}$ \\
\hline $72^{\circ}$ & 7753 & 7271 & 482 & $6.2 \%$ & 7770 & 7268 & 502 & $6.5 \%$ \\
\hline $73^{\circ}$ & 7151 & 6720 & 431 & $6.0 \%$ & 7110 & 6659 & 451 & $6.3 \%$ \\
\hline $74^{\circ}$ & 6537 & 6169 & 370 & $5.7 \%$ & 6454 & 6052 & 402 & $6.2 \%$ \\
\hline $75^{\circ} \mathrm{a}$ & 5932 & 5624 & 308 & $5.2 \%$ & 5812 & 5463 & 349 & $6.0 \%$ \\
\hline $76^{\circ}$ & 5340 & 5088 & 252 & $4.7 \%$ & 5205 & 4906 & 299 & $5.7 \%$ \\
\hline $77^{\circ}$ & 4766 & 4563 & 203 & $4.3 \%$ & 4625 & 4379 & 246 & $5.3 \%$ \\
\hline $78^{\circ}$ & 4209 & 4053 & 156 & $3.7 \%$ & 4077 & 3880 & 197 & $4.8 \%$ \\
\hline $79^{\circ}$ & 3678 & 3567 & 111 & $3.0 \%$ & 3564 & 3414 & 150 & $4.2 \%$ \\
\hline $80^{\circ}$ & 3174 & 3101 & 73 & $2.3 \%$ & 3077 & 2972 & 105 & $3.4 \%$ \\
\hline $81^{\circ}$ & 2699 & 2664 & 35 & $1.3 \%$ & 2623 & 2556 & 67 & $2.6 \%$ \\
\hline $82^{\circ}$ & 2260 & 2254 & 6 & $0.3 \%$ & 2201 & 2169 & 32 & $1.5 \%$ \\
\hline \multicolumn{9}{|l|}{ Internal Gains } \\
\hline $0.5 \times \mathrm{PL}$ & 5390 & 5029 & 361 & $6.7 \%$ & 5290 & 4903 & 387 & $7.3 \%$ \\
\hline $1 \times P L$ & 5659 & 5325 & 334 & $5.9 \%$ & 5548 & 5182 & 366 & $6.6 \%$ \\
\hline $1.5 \times \mathrm{PL}$ & 5932 & 5624 & 308 & $5.2 \%$ & 5812 & 5463 & 349 & $6.0 \%$ \\
\hline $2 \times \mathrm{PL}$ & 6208 & 5923 & 285 & $4.6 \%$ & 6079 & 5750 & 329 & $5.4 \%$ \\
\hline $3 \times \mathrm{PL}$ & 6773 & 6523 & 250 & $3.7 \%$ & 6621 & 6334 & 287 & $4.3 \%$ \\
\hline $4 \times \mathrm{PL}$ & 7345 & 7145 & 200 & $2.7 \%$ & 7175 & 6926 & 249 & $3.5 \%$ \\
\hline \multicolumn{9}{|l|}{ External and Internal Shade } \\
\hline Hvy. Int. shade, w/nhbrs & 5604 & 5322 & 282 & $5.0 \%$ & 5522 & 5205 & 317 & $5.7 \%$ \\
\hline Hvy. Int. shade, no nhbrs & 5932 & 5624 & 308 & $5.2 \%$ & 5812 & 5463 & 349 & $6.0 \%$ \\
\hline Less int. shade, w/nhbrs & 6079 & 5835 & 244 & $4.0 \%$ & 5988 & 5709 & 279 & $4.7 \%$ \\
\hline Less int. shade; no nhors & 6468 & 6202 & 266 & $4.1 \%$ & 6331 & 6020 & 311 & $4.9 \%$ \\
\hline \multicolumn{9}{|l|}{ Wall Color and Solar Reflectance } \\
\hline Med./dark stucco $(A B S=0.75)$ & 6401 & 5832 & 569 & $8.9 \%$ & 6266 & 5665 & 601 & $9.6 \%$ \\
\hline Light stucco $(A B S=0.5)$ & 5932 & 5624 & 308 & $5.2 \%$ & 5812 & 5463 & 349 & $6.0 \%$ \\
\hline White stucco $(A B S=0.3)$ & 5557 & 5454 & 103 & $1.9 \%$ & 5448 & 5302 & 146 & $2.7 \%$ \\
\hline
\end{tabular}


Note that the results suggest the following influences to AC savings from wall insulation in a cooling-dominated climate:

- Annual savings from EIFS varies strongly by the interior thermostat setting. For example, a home maintaining $80^{\circ} \mathrm{F}$ instead of $75^{\circ} \mathrm{F}$ would see $77 \%$ less savings. At an $82^{\circ} \mathrm{F}$ set point (which some project participants did select), with no ventilation used, savings effectively disappear. On the other hand, a home maintaining $72^{\circ} \mathrm{F}$ inside would see $56 \%$ greater savings from the added insulation compared to one maintaining a set point of $75^{\circ} \mathrm{F}$.

- Wall color has a large impact on potential EIFS cooling energy savings. White walls have savings one-third those of medium-/dark-colored stucco walls.

- Preexisting shading from adjacent buildings and porches has some impact on wall insulation savings, but these are modest with light-colored walls; the influence is greater with darker walls.

- Greater internal heat gains from appliance and plug loads reduce the savings from better wall insulation, particularly for cooling. For example, a home with low plug loads will see savings nearly double that of a home with very high internal heat gains.

- There was an interaction between window and wall insulation savings. For example, with less interior blind shading of windows, there is greater window heat gain, reducing the advantage of wall insulation.

- Natural ventilation has only modest influences on savings, but using natural ventilation to control overheating was shown to boost savings for wall insulation in all cases.

Although not analyzed, the savings from two-story buildings with EIFSs would almost certainly be greater given the much larger area and the lower likelihood of shading of the second-story vertical sections.

Although 10\%-15\% cooling savings are possible with the right combination of factors (darker walls, low internal gains, low existing shading, and low set points), the opposite is true as well. A very high set point with high internal gains with light or white walls mostly shaded by other buildings, vegetation, porches, or blinds would see negligible savings from an EIFS. In particular, light-colored walls with preexisting shading in existing Florida homes is likely to limit savings in many applications. Indeed, savings would be unlikely in homes that maintain higher interior temperature in summer and already have light-colored walls. 


\section{Evaluation of Advanced Window Retrofits}

Under Phase II of the PDR study, window retrofits were conducted in three occupied homes to evaluate the impact of advanced windows on space-conditioning energy consumption. One of these homes received an EIFS installation prior to the window retrofit. In past research, the FSEC evaluated the impact of energy-efficient windows on HVAC energy use comparing two identically-constructed Central Florida homes: one with clear, single-pane, aluminum-framed windows and the other with advanced windows (Anello et al. 2000). Cooling energy consumption during a 17-day, unoccupied summer period indicated $15 \%$ savings for the home with energy-efficient windows. Space-heating energy savings of 36\% were shown in the home with advanced windows during one very cold day (relative to the Central Florida climate) after the homes were occupied. Unlike the Anello et al. window study in 2000, however, the current research is conducted on occupied homes. The current research is also unique in that it looks at the effects of multiple thermal improvement measures on one home.

The window retrofit homes are single-story homes with approximately 1,400 to $2,000 \mathrm{ft}^{2}$ of living space. General characteristics for these three homes are provided in Table 25. More detailed site descriptions are provided within the evaluation sections for each site.

Table 25. General and HVAC Characteristics of the Wind Retrofit Sites

\begin{tabular}{llll}
\hline Site No. & \multicolumn{1}{c}{$\mathbf{2 3}$} & \multicolumn{1}{c}{$\mathbf{2 5}$} & \multicolumn{1}{c}{$\mathbf{5 4}$} \\
\hline City & Palm Bay & Melbourne & Palm Bay \\
Year built & 1980 & 2000 & 1999 \\
Living area $\left(\mathrm{ft}^{2}\right.$ ) & 1,946 & 1,788 & 1,390 \\
No. of occupants & 3 & 2 & 2 \\
\hline Stories & 1 & 1 & 1 \\
\hline Wall construction & CMU & CMU & CMU \\
Ceiling insulation & R-19 & R-30 & R-19 \\
House airtightness & 8.4 & 4.6 & 5.3 \\
(ACH50) & & & \\
Year of HVAC & $2001 / 02$ & 2010 & 1999 \\
AC size (tons) & 3.5 & 3.5 & 2.5 \\
AC SEER & 14 & 15.5 & 10 \\
\hline Heating & Resistance & Heat Pump & Heat Pump \\
Duct leakage (Qn,out) & 0.05 & 0.06 & 0.03 \\
\hline
\end{tabular}

This evaluation assesses the impacts of the window retrofits on the homes' HVAC energy consumption using measured end-use space-conditioning energy with regression modeling techniques, as described in Section 4, to evaluate the impacts from exterior temperature, internal heat gains, and solar insolation on HVAC energy. The regression model used outdoor temperature in place of Delta $T$ unless an interior temperature change between pre- and postretrofit observation periods was apparently behavioral and not a change in the thermal characteristics of the home.

Pre- and post-retrofit average daily external and interior temperatures, internal gains, and solar insolation are summarized in Table 26. Regressions from the analysis of the advanced window retrofits are provided in Appendix F. 
Table 26. Average Daily Interior Temperatures, Internal Gains, and Solar Insolation Pre- and Post-Retrofit Evaluation Periods

\begin{tabular}{|c|c|c|c|c|c|c|c|c|c|}
\hline $\begin{array}{l}\text { Site } \\
\text { No. }\end{array}$ & $\begin{array}{c}\text { Evaluation } \\
\text { Season }\end{array}$ & $\begin{array}{c}\text { Pre- } \\
\text { Outdoor } \\
\text { Temp } \\
\left({ }^{\circ} \mathrm{F}\right)\end{array}$ & $\begin{array}{l}\text { Post- } \\
\text { Outdoor } \\
\text { Temp } \\
\left({ }^{\circ} \mathrm{F}\right)\end{array}$ & $\begin{array}{c}\text { Pre- } \\
\text { Indoor } \\
\text { Temp } \\
\left({ }^{\circ} \mathrm{F}\right)\end{array}$ & $\begin{array}{c}\text { Post- } \\
\text { Indoor } \\
\text { Temp } \\
\left({ }^{\circ} \mathrm{F}\right)\end{array}$ & $\begin{array}{c}\text { Pre- } \\
\text { Internal } \\
\text { Heat Gains } \\
\text { (kWh/day) }\end{array}$ & $\begin{array}{c}\text { Post- } \\
\text { Internal } \\
\text { Heat Gains } \\
\text { (kWh/day) }\end{array}$ & $\begin{array}{l}\text { Pre- } \\
\text { Solar } \\
\text { Insol. } \\
\text { (kWh/ } \\
\text { m²/day) }^{2} \text {. }\end{array}$ & $\begin{array}{c}\text { Post- } \\
\text { Solar } \\
\text { Insol. } \\
\text { (kWh/m²/ } \\
\text { day) }\end{array}$ \\
\hline 23 & Cooling & 74.4 & 73.5 & 75.2 & 74.8 & 10.9 & 12.7 & 5.0 & 3.3 \\
\hline 23 & Heating & 58.0 & 58.3 & 73.8 & 73.4 & 10.4 & 12.0 & 4.1 & 4.1 \\
\hline 25 & Cooling & 79.9 & 80.4 & 81.3 & 80.8 & 16.3 & 14.4 & 5.9 & 6.7 \\
\hline 54 & $\begin{array}{c}\text { Cooling } \\
\text { (windows) }\end{array}$ & 76.9 & 77.1 & 76.4 & 76.8 & 10.0 & 9.8 & 5.5 & 6.6 \\
\hline 54 & $\begin{array}{l}\text { Cooling } \\
\text { (EIFS and } \\
\text { windows) }\end{array}$ & 78.3 & 79.1 & 77.3 & 76.5 & 14.0 & 10.5 & 6.3 & 6.6 \\
\hline
\end{tabular}

To evaluate the impact of a window retrofit on space-conditioning energy use, it is important to note the presence and position of shading, both external and internal. This is because the advanced windows being evaluated have a large influence on solar heat gain transmittance with the potential to be significantly altered by the conditions before and after the glazing is installed. In addition to the exterior shading from trees or adjacent buildings, drawn blinds/drapes and insect screening on the preexisting windows may significantly reduce the impact of the SHGC on the solar radiation because there is less solar radiation than without such shading. Work at NREL (Farrar-Nagy et al. 2000) has shown that architectural shading and site shading have a major impact on measured building cooling needs. Based on this work and much preceding ASHRAE fenestration research during recent decades, it appears that conventional blinds and curtains on the interior part of buildings have a major influence on space cooling as well—particularly because many are drawn. Insect screening is also relevant in the assessment of window retrofit energy savings. For single- or double-hung windows with insect screening on the lower part, solar transmission is reduced. A study (Kotey et al. 2009) found that insect screening decreases solar transmission by $40 \%$ for the window section covered. As such, detailed accounts of the interior and exterior shading characteristics are provided in the evaluation section of each window retrofit.

Space-cooling energy savings is projected using an assumed average cooling season outdoor temperature of $80^{\circ} \mathrm{F}$ and space heating with an average outdoor temperature of $50^{\circ} \mathrm{F}$. It is noteworthy that the post-retrofit daily average interior temperatures (Table 17) were observed to be typically cooler. As described in the EIFS section, changes in interior temperature may be the result of changed thermal characteristics of the home - a rising nighttime float temperature for example-influencing occupants to set thermosets lower. To help determine if a change in indoor temperature is a by-product of the window retrofit, the daily temperature profiles for the pre-and post-retrofit periods were evaluated. If a behavioral change between evaluation periods is evident, the savings predictions consider Delta $\mathrm{T}$ rather than outdoor temperature alone. The evaluation of each of these retrofits is described below in a case study fashion. 


\subsection{Window Retrofit for Site 23 \\ 9.1.1 Characteristics for Site 23}

Site 23 is two-person-occupied, single-story home with 1,946 $\mathrm{ft}^{2}$ of living space located in Palm Bay, Florida. This 1980 home has CMU walls on a concrete slab foundation and an asphalt shingle roof. The attic floor is insulated with blown fiberglass with an approximate R-value of 19. The pre-retrofit airtightness test reveals moderate whole-house air leakage for the building's age (8.4 ACH50). The home has 10 windows and 2 sliding glass doors. The original windows and glass doors are single-pane clear glass with metal frames. The building's front façade faces north, and the back porch roof shades most of the south-facing glazing. Adjacent buildings partially shade the few east- and west-facing windows. In numerous visits to this home, all bedroom and north-facing blinds were typically closed; only the blinds to the windows shaded by the back porch were typically open. Table 27 provides an account of glazing area and shading by façade.

Table 27. As-Found Glazing and Shading Characteristics for Site 23

\begin{tabular}{|c|c|c|c|c|}
\hline \multirow[t]{3}{*}{ Site No. } & \multicolumn{2}{|c|}{ Existing Type } & \multicolumn{2}{|c|}{ Single, Clear w/Metal Frame } \\
\hline & \multicolumn{2}{|c|}{ Total Window Area $\left(\mathrm{ft}^{2}\right)$} & \multicolumn{2}{|c|}{197} \\
\hline & \multicolumn{2}{|c|}{ Window-to-Floor Area (\%) } & \multicolumn{2}{|l|}{$10 \%$} \\
\hline Glazing by Face & East & South & West & North \\
\hline Net window area $\left(\mathrm{ft}^{2}\right)$ & 18 & 104 & 41 & 34 \\
\hline Interior drapes or blinds & White blinds & White blinds & White blinds & White blinds \\
\hline Exterior screening & $50 \%$ & $\begin{array}{l}35 \% \text { w/50\% screen } \\
65 \% \text { w/100\% screen }\end{array}$ & $\begin{array}{l}52 \% \text { w/50\% screen } \\
48 \% \text { w/100\% screen }\end{array}$ & $50 \%$ \\
\hline Overhang avg./width (ft) & 1.5 & 10.0 & 70 & 20 \\
\hline Exterior shading & Moderate & Moderate & Moderate & None \\
\hline Shading type & Adj. bldg. & $\begin{array}{l}\text { Trees, } \\
65 \% \text { porch }\end{array}$ & $\begin{array}{l}\text { Adj. Bldg., trees, } \\
48 \% \text { porch }\end{array}$ & \\
\hline Distance to adj. bldg. (ft) & 20 & None & 20 & None \\
\hline
\end{tabular}

The existing space-conditioning system is a 200214 SEER air conditioner with electric resistance heating. A single, centrally-located return feeds into the garage-located air handling unit. Supply air is distributed through R-4.4 insulated flex ducts with moderate duct leakage $(\mathrm{Qn}$, out $=0.05)$ running through the vented attic.

All exterior glass and frames were replaced from October 29-30, 2014. The replacement doubleglazed solar-control windows have SHGCs ranging from $0.20-0.24$ and U-factors from $0.28-$ $0.30 \mathrm{Btu} / \mathrm{ft}^{2}{ }^{\circ}{ }^{\circ}$. Figure 48 shows Site 23 before and after the window retrofit. The timing of this retrofit enabled both space-heating and space-cooling evaluations. The evaluation period for Site 23 was November 2013-June 2015. 

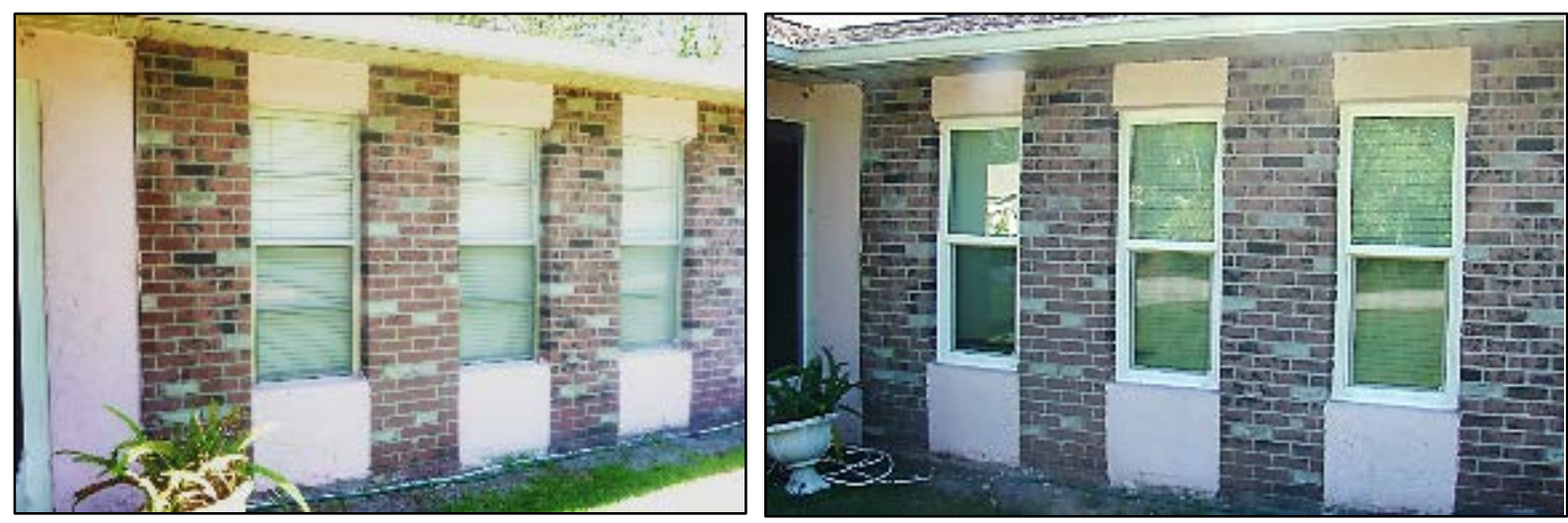

Figure 48. Window retrofit for Site 23: pre-retrofit with existing single-pane, metal-framed windows (left); post-retrofit with double-pane, vinyl-frame windows (right)

\subsubsection{Window Retrofit Space-Cooling Energy Evaluation for Site 23}

From an examination of the end-use metered data, the occupants of Site 23 use space cooling when the daily average exterior temperature rises above $69^{\circ} \mathrm{F}$. The initial investigation into space-cooling energy savings showed that the average internal temperature was approximately $2^{\circ} \mathrm{F}$ cooler post-retrofit $\left(75^{\circ} \mathrm{F}\right)$ than it was during the pre-retrofit cooling period $\left(77^{\circ} \mathrm{F}\right)$. HVAC energy use increased coincidently with this internal temperature change. The homeowner confirmed a temporary occupancy increase for the first six months of 2015 and reported that the new occupant preferred a lower thermostat set point than is typically maintained in the home. In an attempt to isolate the occupancy change from the impact of the window retrofit, a shorter, milder period prior to the occupancy change was analyzed. This spanned October 2014 to early December 2014, including observations only when the daily average ambient temperature exceeded $69^{\circ} \mathrm{F}$ and excluding the warmest pre-retrofit days to compare periods of alike average daily ambient temperatures (pre: October 4, 2014-October 28, 2014; post: October 31, 2014December 6, 2014).

The scatterplot in Figure 49 of this limited period with consistent occupancy demonstrates the cooling energy use trend compared to outdoor temperature for the pre- and post-retrofit periods. The pre-retrofit observations and trend line are in orange, the post-retrofit observations are in blue, and both show a high degree of scatter. 


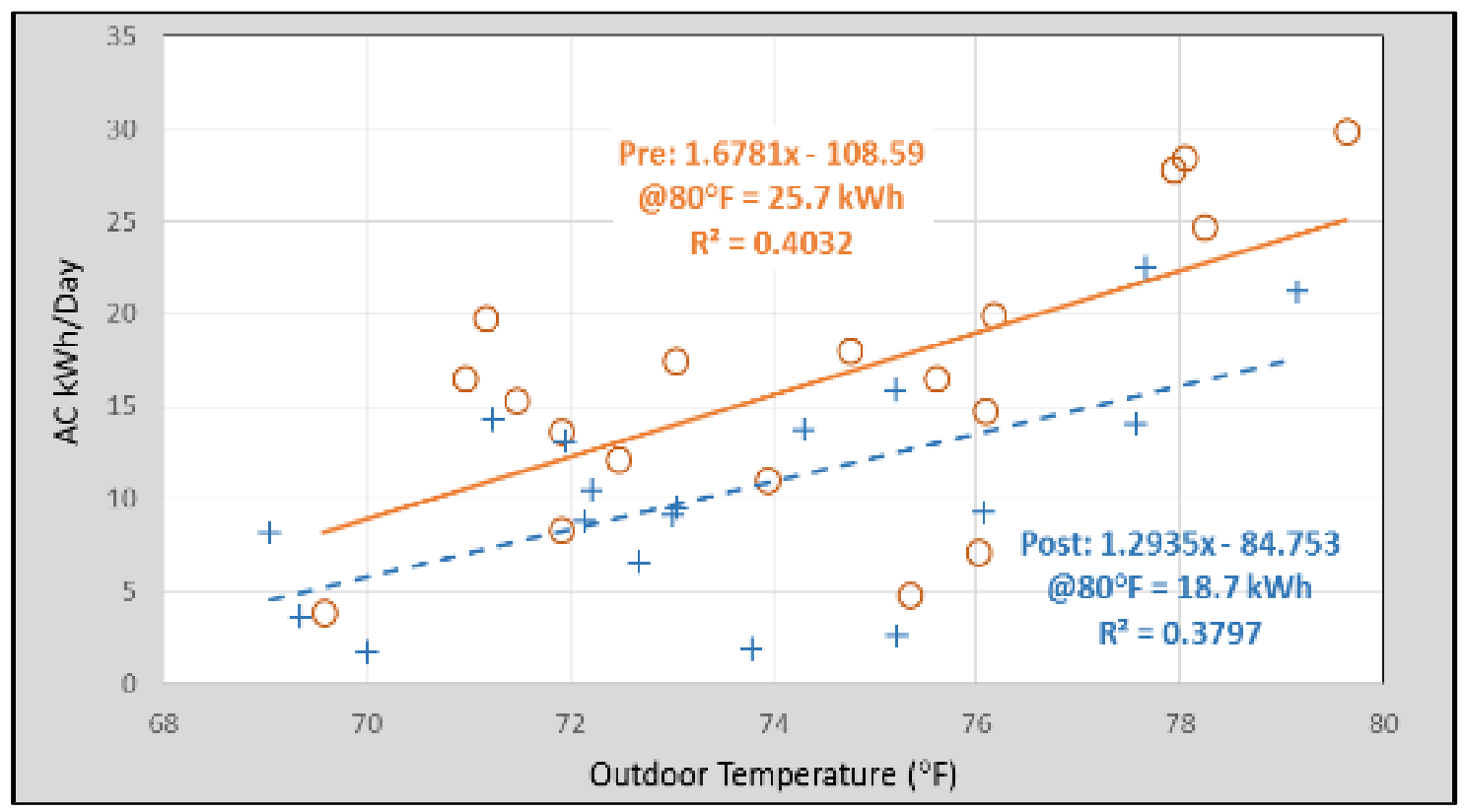

Figure 49. Regression lines for space-cooling pre- and post-window retrofit for Site 23

Avoiding the occupancy change and large coincident behavior change provides us evaluation periods with few observations (19 pre-retrofit, 18 post-retrofit) and at a time of year with less extreme high temperatures and limited space cooling. These factors had negative impacts on the model strength $\left(\mathrm{R}^{2}=0.40\right.$ and 0.38$)$ and thus the strength of the savings projections.

The daily average interior temperatures were fairly consistent during the evaluation period $\left(75.2^{\circ} \mathrm{F}\right.$ pre-retrofit, $74.8^{\circ} \mathrm{F}$ post-retrofit). Figure 50 shows the daily interior (solid line labeled "Tint") and ambient (dashed line labeled "Tamb") temperature profiles for the pre-retrofit (red) and post-retrofit (green) periods. The plot reveals a more evenly-maintained interior temperature post-retrofit. The difference between the pre- and post-retrofit interior temperatures does not appear to be a change in thermostat preferences (as evidenced by the similar nighttime profiles) but rather a difference in the building's thermal qualities; thus, Delta T was not a parameter used in this evaluation. 


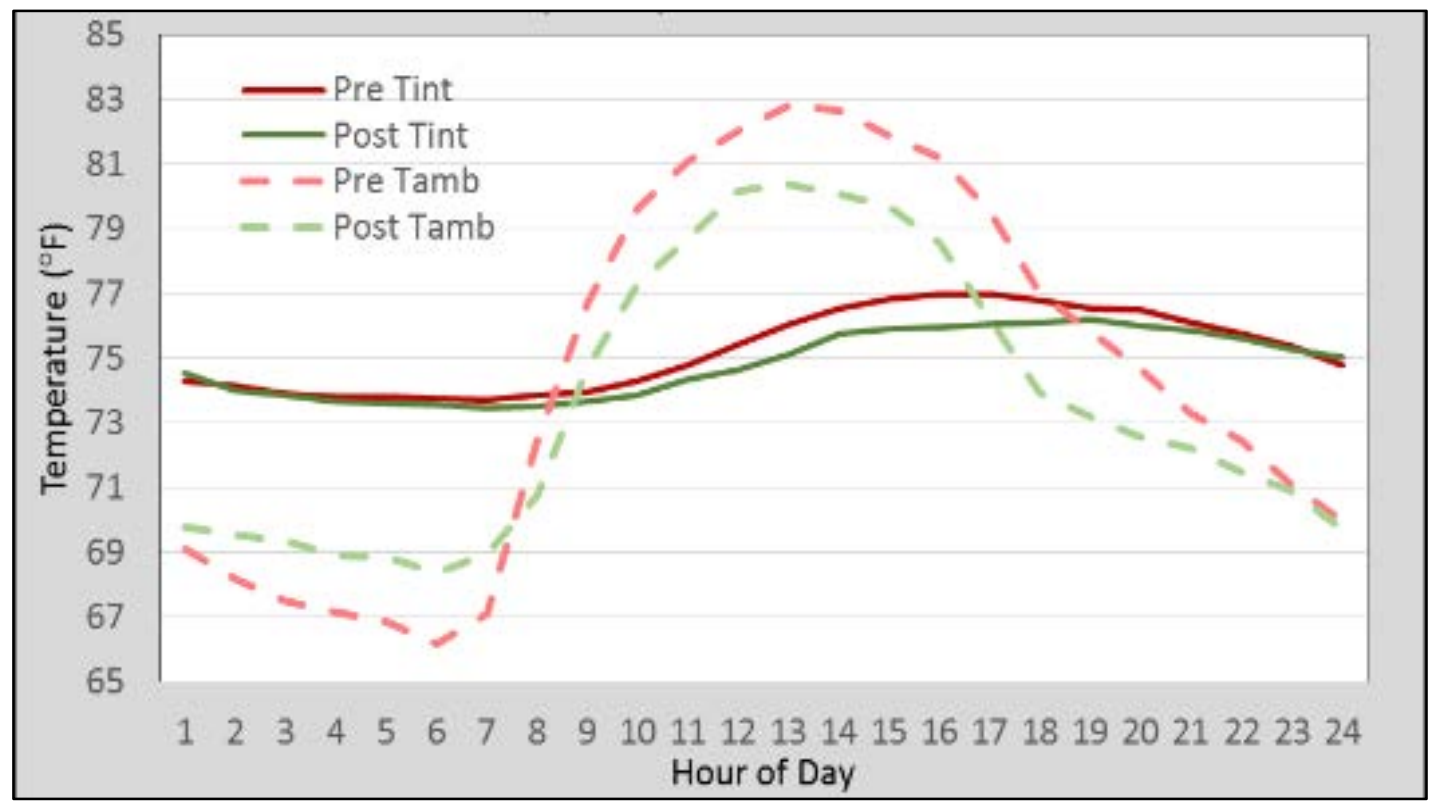

Figure 50. Pre- and post-window retrofit indoor and outdoor temperature profiles for cooling season observations for Site 23

The energy use prediction models also considered solar insolation and internal heat gains, but neither parameter was significant in either period and they were not used.

The post-retrofit daily cooling energy for this internally and externally well-shaded home, with a set point of approximately $75^{\circ} \mathrm{F}$, is reduced from 25.7 to $18.7 \mathrm{kWh}$ at an average outdoor temperature of $80^{\circ} \mathrm{F}$, a savings of $6.9 \mathrm{kWh}$ /day or $27.0 \%$. This projection is weak, however, given the poor R-squared values and few observations at the average summertime temperature used for the savings prediction. Thus, the standard error on the regression is quite large, and although the savings appear real, the result has a considerable uncertainty in the exact magnitude.

\subsubsection{Window Retrofit Space-Heating Energy Evaluation for Site 23}

Plotting HVAC energy use against exterior temperature indicated that the Site 23 occupants begin space heating when the daily average exterior temperature drops below $65^{\circ} \mathrm{F}$. The demand for space heating is limited in this hot-humid climate, although heating energy consumption is high at this home, which has electric resistance heating. Pre-retrofit observations were drawn from November 2013 through March 2014; post-retrofit observations were drawn from November 2014 through March 2015 and when the average ambient temperature was below $65^{\circ} \mathrm{F}$ and the daily compressor power was less than $2.5 \mathrm{kWh}$.

Figure 51 displays the pre- and post-retrofit daily average space heating energy use by outdoor temperature. Note that on the coolest days, space-heating energy consumption exceeds 90 $\mathrm{kWh}$ /day. Again, there is large scatter in the limited heating energy data set. The trend lines' convergence at $59^{\circ} \mathrm{F}$ demonstrates slightly greater post-retrofit heating energy savings as the outdoor temperature becomes lower. This is expected because the advanced windows save more when the temperature is lower. The solar-control glazing, however, transfers less of the sun's heat, potentially limiting heating savings, particularly at higher temperatures at which the window thermal conductance becomes less important. 


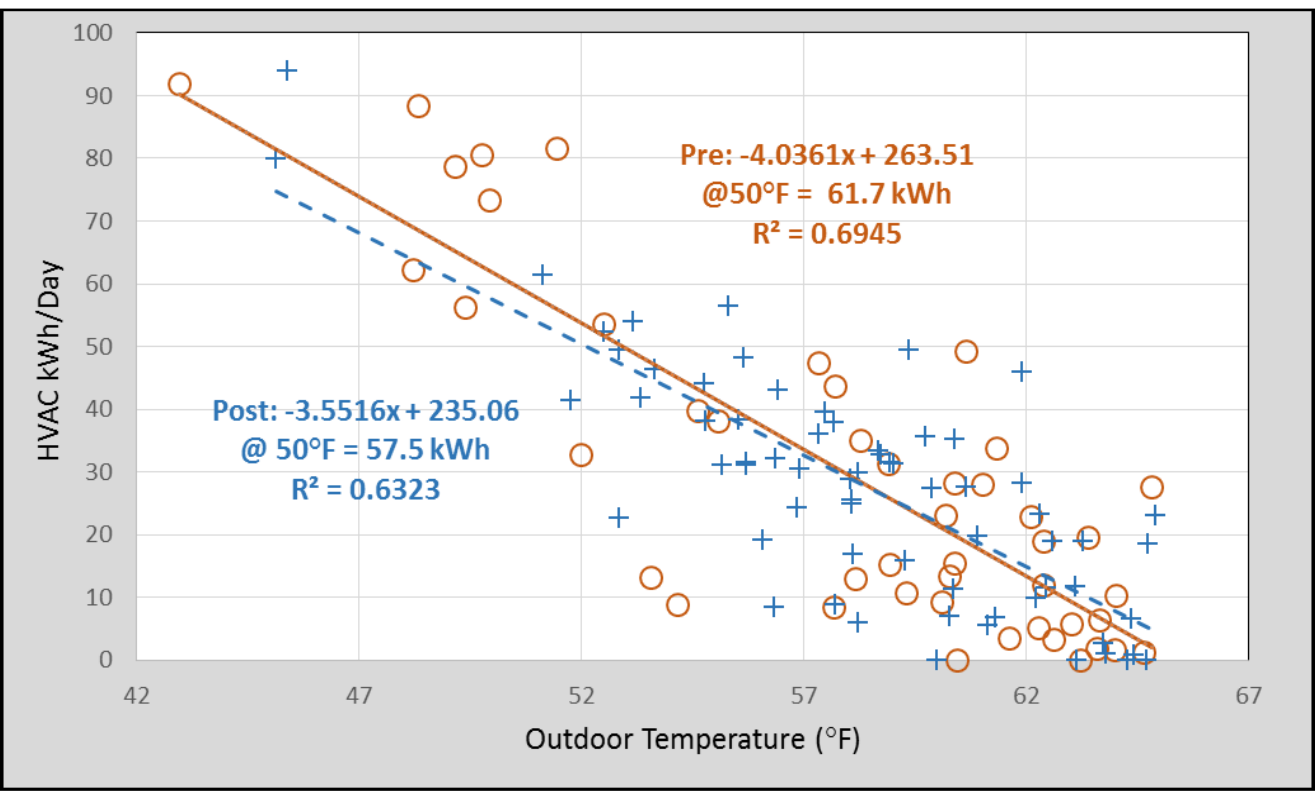

Figure 51. Regression lines for space-heating pre- and post-window retrofit for Site 23

Daily average interior temperature was slightly cooler post-retrofit $\left(73.8^{\circ} \mathrm{F}\right.$ pre-retrofit, $73.4^{\circ} \mathrm{F}$ post-retrofit). The daily temperature profile in Figure 52 shows that for both periods the building maintains the same temperature during the morning hours; however, post-window retrofit the home maintains a lower temperature after the warmest hours, despite having higher internal gains $(12.7 \mathrm{kWh}$ /day post-retrofit compared to $10.9 \mathrm{kWh}$ /day pre-retrofit) and slightly warmer daytime ambient temperatures. This afternoon difference likely comes from the lower solar heat gain transmission characteristics of the windows.

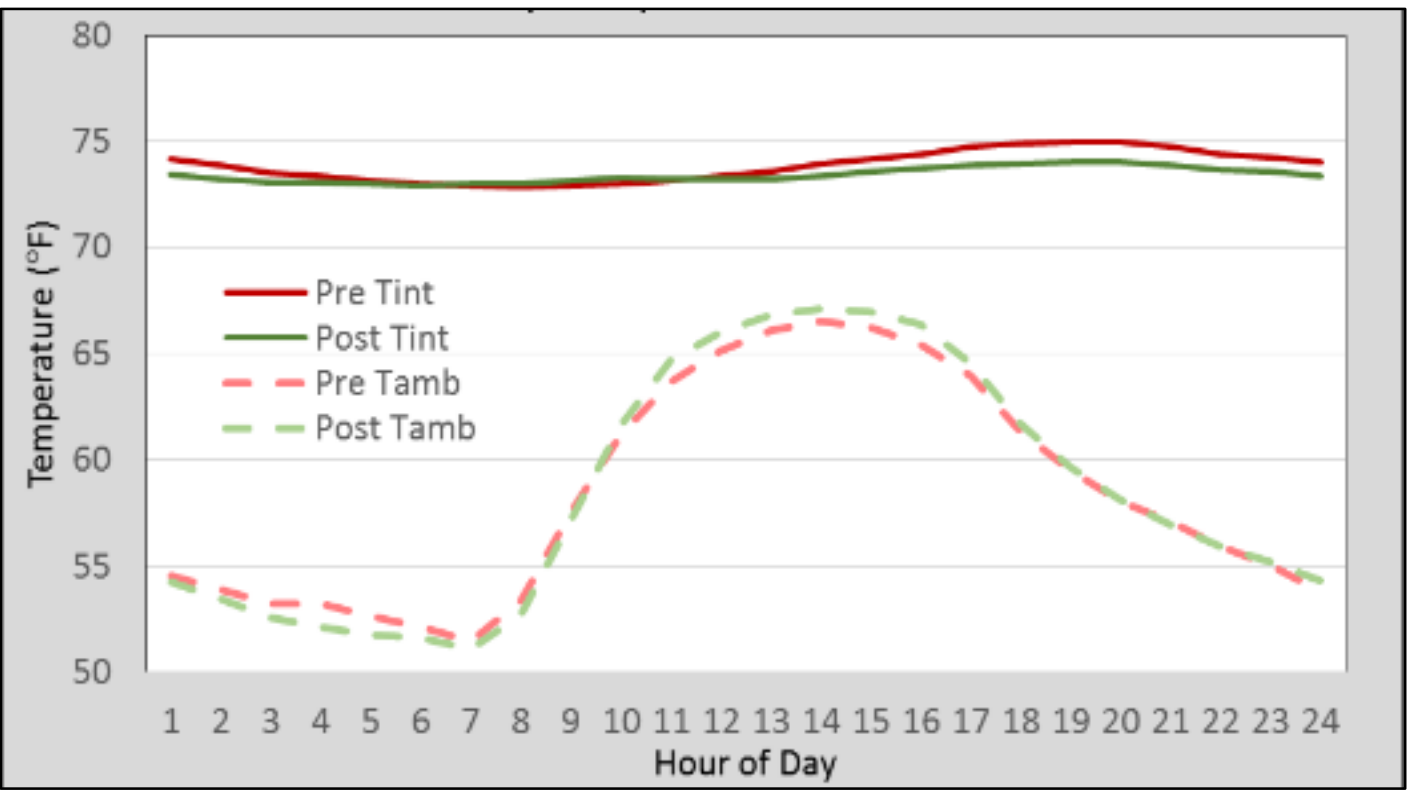

Figure 52. Pre- and post-retrofit indoor and outdoor temperature profiles for heating season observations for Site 23 
Because the difference between the pre- and post-retrofit interior temperatures appears to be a change in the building's thermal properties, Delta T was not a parameter used for the savings projection. Internal gains and solar insolation parameters were also considered for modeling, but they were not significant; however, internal gains were slightly higher post-retrofit (pre-retrofit: $10.4 \mathrm{kWh} /$ day; post-retrofit: $12.0 \mathrm{kWh} /$ day). Using the simple regression based on ambient temperature, this home with an interior set point of $73^{\circ}-74^{\circ} \mathrm{F}$ shows savings of $4.2 \mathrm{kWh} /$ day or $6.8 \%$ at an average outdoor temperature of $50^{\circ} \mathrm{F}$. Note that during periods with milder temperatures, the high-efficiency windows show slightly negative heating energy savings. Given higher internal gains during the post-retrofit period, this savings projection may be overstated.

\subsection{Window Retrofit for Site 25}

\subsubsection{Characteristics for Site 25}

Site 25, pictured in Figure 53, is a two-person occupied, single-story home with 1,788 $\mathrm{ft}^{2}$ of living space located in Melbourne, Florida. The home, built in 2000, has CMU walls on a concrete slab foundation and an asphalt shingle roof. R-30 fiberglass insulation covers the attic knee walls and most of the attic floor, but it is missing from some of the attic perimeter, a common windstorm result found in some Florida homes. Pre-retrofit whole-house airtightness testing shows moderately tight construction (4.6 ACH50).

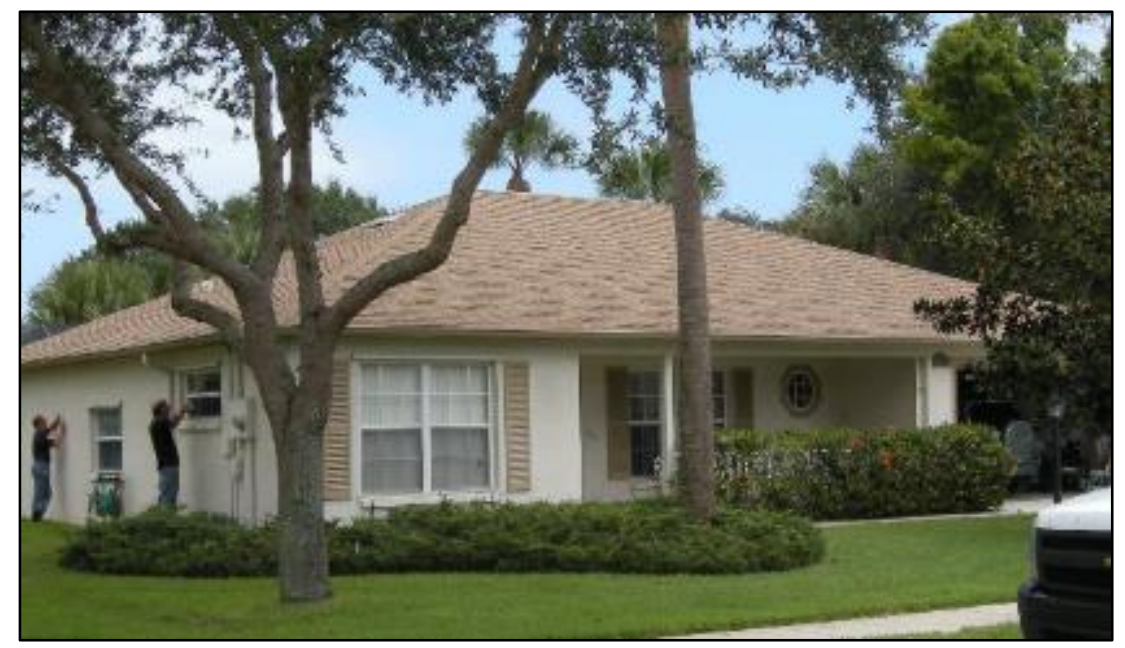

Figure 53. Site 25 in Melbourne, Florida

Site 25 has 10 windows and 1 sliding glass door. Prior to the window retrofit, all of the glazing units were single-pane clear glass with metal frames. The home faces southwest with a front porch roof shading one large window. A deep back porch shades the northwest-facing sliding glass door, and the two southeast-facing windows are partially shaded by vegetation. The remaining southwest- and northwest-facing glazing receives little shading. Bedroom blinds were observed to be drawn, with living room and kitchen blinds open. An account of glazing area and shading by façade is summarized in Table 28. 
Table 28. Glazing and Shading Characteristics for Site 25

\begin{tabular}{|c|c|c|c|c|}
\hline \multirow[t]{3}{*}{ Site 25} & \multicolumn{2}{|c|}{ Existing Type } & \multicolumn{2}{|c|}{ Single, Clear w/Metal Frame } \\
\hline & \multicolumn{2}{|c|}{ Total Window Area $\left(\mathrm{ft}^{2}\right)$} & \multicolumn{2}{|c|}{243} \\
\hline & \multicolumn{2}{|c|}{ Window-to-Floor Area (\%) } & \multicolumn{2}{|c|}{$14 \%$} \\
\hline Glazing by Face & SE & SW & NW & NE \\
\hline Net window area $\left(\mathrm{ft}^{2}\right)$ & 61 & 67 & 20 & 95 \\
\hline Interior drapes or blinds & White blinds & White blinds & White blinds & White blinds \\
\hline \multirow[t]{2}{*}{ Exterior screening } & $50 \%$ & $50 \%$ & $36 \%$ w/50\% screen & $69 \% \mathrm{w} / 50 \%$ screen \\
\hline & & & $64 \%$ w/100\% screen & $31 \% \mathrm{w} / 100 \%$ screen \\
\hline Exterior shading & Moderate & Moderate & Moderate & Moderate \\
\hline Shading type & $\begin{array}{c}\text { Adj. bldg., } \\
\text { trees }\end{array}$ & $\begin{array}{c}\text { Trees, } \\
52 \% \text { porch }\end{array}$ & $\begin{array}{l}\text { Adj. bldg., } \\
64 \% \text { porch }\end{array}$ & $\begin{array}{c}\text { Trees, } \\
\text { 31\% porch }\end{array}$ \\
\hline Overhang avg./width (ft) & 1.3 & 4.5 & 9 & 3.7 \\
\hline Distance to adj. bldg. (ft) & 20 & None & 20 & None \\
\hline
\end{tabular}

The AC system is a 2010 vintage, 15.5 SEER heat pump. A single, centrally-located return feeds into the interior-located air handling unit. Supply air is distributed through R-6 insulated flex ducts with moderate duct leakage $(\mathrm{Qn}$, out $=0.06)$ running through the vented attic.

The window retrofit was conducted between April 22 and May 28, 2015, and included the replacement of all exterior glass and frames (with the exception of one small, well-shaded, decorative, southwest-facing window). The replacement glazing units are insulated double-pane windows with vinyl frames. The SHGC ranges from $0.19-0.21$, and all the windows have a Ufactor of $0.29 \mathrm{Btu} / \mathrm{ft}^{2}-{ }^{\circ} \mathrm{F}$.

\subsubsection{Window Retrofit Space-Cooling Energy Evaluation for Site 25}

The timing of the Site 25 window retrofit allows for an evaluation of only its space cooling for this report. Because there was little space cooling called for prior to April 22, 2015, when the window installation began, the pre-retrofit period consists of observations in 2014. For each year (2014 for pre-retrofit and 2015 for post-retrofit), observations were pulled from the end of May into July (pre-retrofit: May 23, 2014-July 31, 2014; post-retrofit: May 29, 2015-July 13, 2015).

Based on an examination of the data, Site 25 occupants use space cooling when the daily average exterior temperature rises above $73^{\circ} \mathrm{F}$. The scatter plot in Figure 54 displays daily average spacecooling consumption by outdoor temperature along with a fitted regression model on the data for the pre- and post-retrofit periods. 


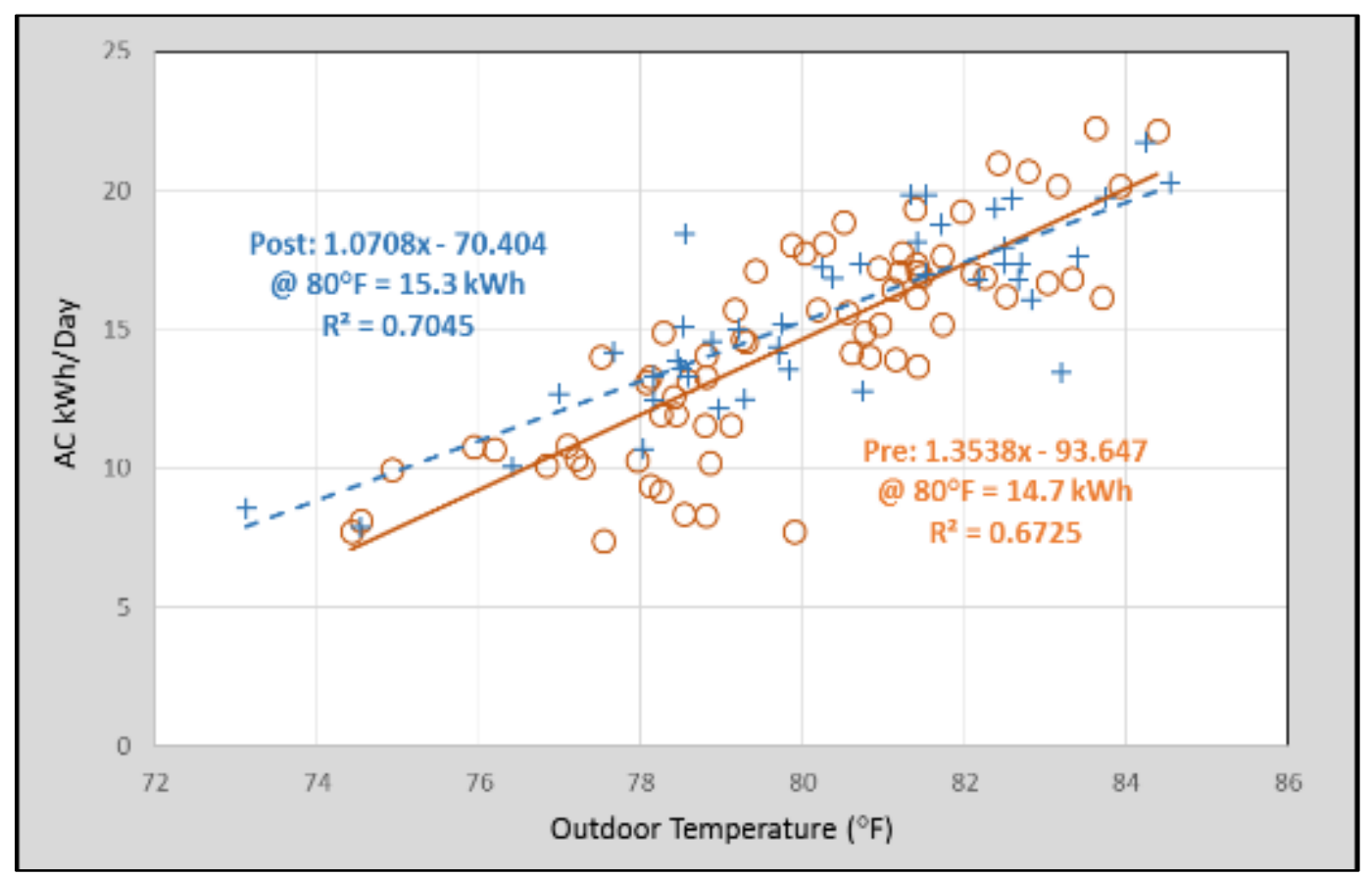

Figure 54. Regression lines for space-cooling pre- and post-window retrofit for Site 25

The occupants of Site 25 prefer a warm home. On average, the interior temperature was maintained at $0.4^{\circ} \mathrm{F}$ cooler post-retrofit $\left(81.3^{\circ} \mathrm{F}\right.$ pre-retrofit compared to $80.8^{\circ} \mathrm{F}$ post-retrofit). The daily indoor and outdoor temperature profiles for the pre- and post-retrofit periods are plotted in Figure 55. The daily average Delta $\mathrm{T}$ is negative for both periods; that is, during the course and for most of the hours of the day, it is cooler outside than inside. Note that the postretrofit indoor temperature maintains a level temperature throughout the day, despite the higher outdoor temperatures. Post-retrofit, the home appears to be better at maintaining comfort, helping to explain the lower average indoor temperature, which appears to be the result of a change in the building's thermal properties rather than a behavioral change. Thus, the saving projection ignores the difference in indoor temperature. 


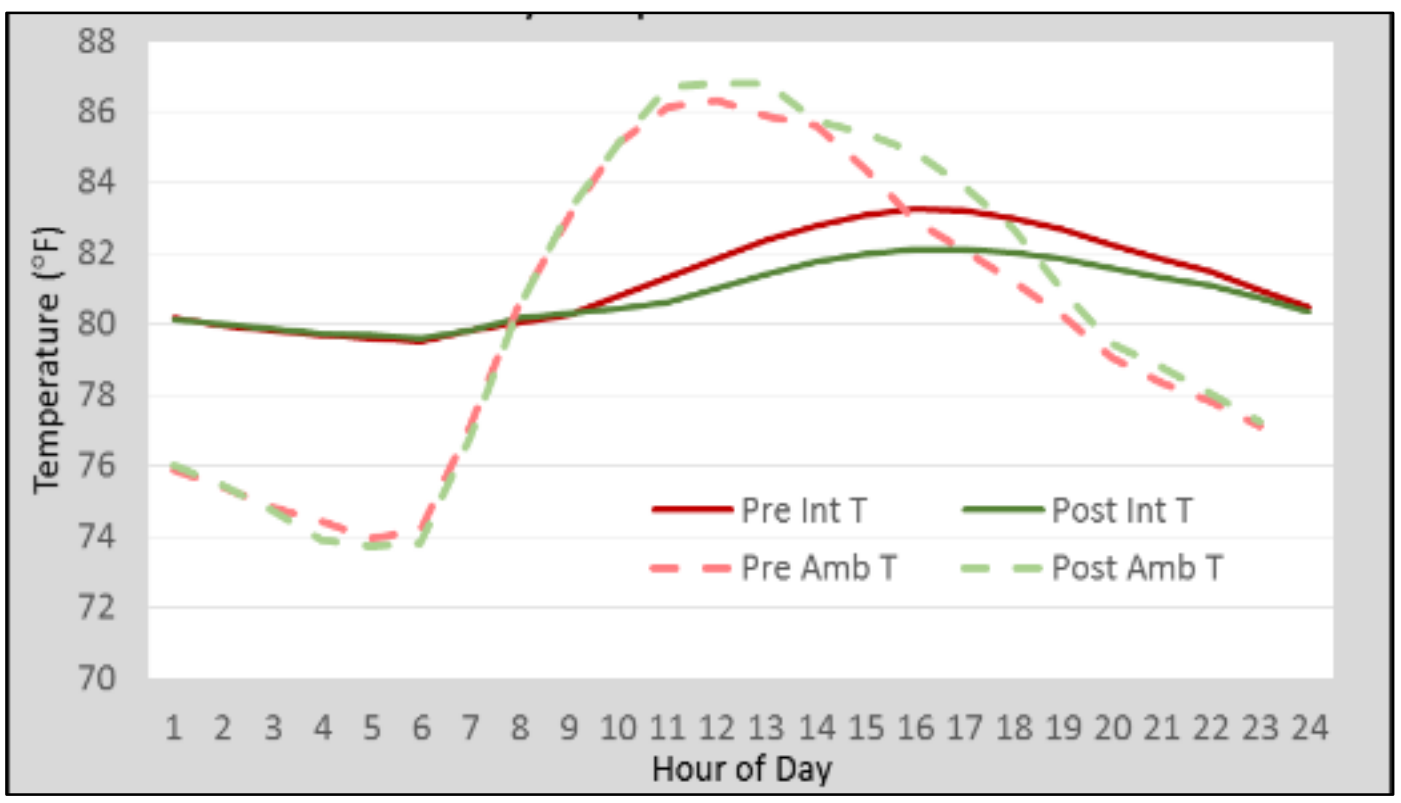

Figure 55. Pre- and post-window retrofit indoor and outdoor temperature profiles for cooling season observations for Site 25

Next, the analysis considered the internal heat gains and solar insolation parameters. The internal gains calculation changed between the pre- and post-retrofit because the timing of the window retrofit coincided with the installation of an unvented HPCD. As presented in Section 11.2, the utility room is much warmer during operation of the new unvented appliance. To account for this lack of hot air venting, the post-retrofit internal heat gains calculation assumes $90 \%$ of the dryer energy. Still, the internal gains parameter is lower post-retrofit $(16.3 \mathrm{kWh} /$ day pre-retrofit compared to $14.4 \mathrm{kWh}$ /day post-retrofit). Solar insolation also varied between periods, but it moved in the reverse direction: from $5.9 \mathrm{kWh} / \mathrm{m}^{2} /$ day pre-retrofit compared to $6.7 \mathrm{kWh} / \mathrm{m}^{2} /$ day post-retrofit.

Solar insolation and internal gains were each significant in the pre-retrofit model $(p<0.01)$ but less so in the post-retrofit model (solar insolation $p<0.05$; internal gains $p<0.10$ ). The resulting model fits improved ( $\mathrm{R}^{2}$ improved from 0.70 to 0.77 pre-retrofit and from 0.67 to 0.75 postretrofit). Using an average cooling season ambient temperature of $80^{\circ} \mathrm{F}$ and assuming an average of the daily internal gains and solar insolation of both periods, the savings prediction is slightly negative in this well-shaded home with a high thermostat set point of approximately $81^{\circ} \mathrm{F}$. Postretrofit, the daily cooling energy consumption increased from $14.6 \mathrm{kWh}$ to $15.3 \mathrm{kWh}$, for negative savings of $0.7 \mathrm{kWh} /$ day $(-4.8 \%)$, assuming an average outdoor temperature of $80^{\circ} \mathrm{F}$. In any case, as shown above in Figure 28, the home has improved comfort in the cooling season with smaller differences in the amplitude of the interior temperature.

\subsection{Window Retrofit for Site 54 \\ 9.3.1 Characteristics for Site $\mathbf{5 4}$}

Site 54 is a two-person occupied single-story home with $1,390 \mathrm{ft}^{2}$ of living space located in Palm Bay, Florida. This home, built in 1999, has CMU walls with a stucco finish, a concrete slab foundation, an asphalt shingle roof, and R-19 fiberglass insulation at the attic floor and attic knee walls. The garage wall adjacent to the living space consists of framed $2 \times 4$ construction with a 
drywall finish, and, after the EIFS retrofit, all walls had exterior insulation of R-value of $7.7 \mathrm{hr}-$ $\mathrm{ft}^{2}-{ }^{\circ} \mathrm{F} / \mathrm{Btu}$ added. The home has 10 windows and 1 sliding glass door. With a pre-retrofit 5.38 $\mathrm{ACH} 50$, this home has good airtightness for its vintage. The existing AC system is the original heat pump, rated 10 SEER. A single, centrally-located return feeds into the interior-located air handling unit. Supply air is distributed through R-6 insulated flex ducts with limited duct leakage $\left(\mathrm{Qn},{ }_{\text {out }}=0.03\right)$ running through the vented attic.

The existing windows and glass doors at the home were single-pane clear glass with metal frames. The home faces west, with most of the wall area and all of the glazing (except one small window on the north side) on the building's east and west sides. The home's fenestration has little shading apart from the east-facing sliding glass door, which is shaded by a porch.

Researchers observed bedroom blinds drawn and main living area blinds partially drawn. Table 29 provides an account of glazing area and shading by façade.

Table 29. As-Found Glazing and Shading Characteristics for Site 54

\begin{tabular}{|c|c|c|c|c|c|c|}
\hline Site 54 & \multicolumn{3}{|c|}{ Existing Type } & \multicolumn{3}{|c|}{ Single, Clear w/Metal Frame } \\
\hline & \multicolumn{3}{|c|}{ Total Window Area $\left(\mathrm{ft}^{2}\right)$} & \multicolumn{3}{|c|}{167} \\
\hline & \multicolumn{3}{|c|}{ Window-to-Floor Area (\%) } & \multicolumn{3}{|c|}{$12 \%$} \\
\hline Glazing by Face & East & South & West & North & $\mathrm{NE}$ & SE \\
\hline Net window area $\left(\mathrm{ft}^{2}\right)$ & 91 & 0 & 56 & 3 & 9 & 9 \\
\hline Interior drapes or blinds & White blinds & & White blinds & & White blinds & White blinds \\
\hline Exterior screening & $\begin{array}{l}56 \% \text { w/50\% screening } \\
44 \% \text { w/100\% screening }\end{array}$ & & $50 \%$ & $50 \%$ & $50 \%$ & $50 \%$ \\
\hline Exterior shading & Moderate & & None & $100 \%$ & None & Light \\
\hline Shading type & $\begin{array}{l}\text { Trees, } \\
44 \% \text { porch }\end{array}$ & & & $\begin{array}{l}\text { Hurricane } \\
\text { shutter }\end{array}$ & & $\begin{array}{c}\text { Partially shaded } \\
\text { by adjacent } \\
\text { porch }\end{array}$ \\
\hline Overhang avg./width (ft) & 8.2 & & 1 & 1.2 & 1 & 1 \\
\hline Distance to adj. bldg. (ft) & None & 25 & None & None & None & None \\
\hline
\end{tabular}

All windows and the sliding glass door were replaced on April 29-30, 2015, with insulated double-pane glazing units with vinyl frames. The new components have an SHGC ranging from $0.21-0.24$ and a U-factor ranging from $0.27-0.29 \mathrm{Btu} / \mathrm{ft}^{2}-{ }^{\circ} \mathrm{F}$. Figure 56 shows a picture of the home after the completion of the EIFS and window retrofits. 


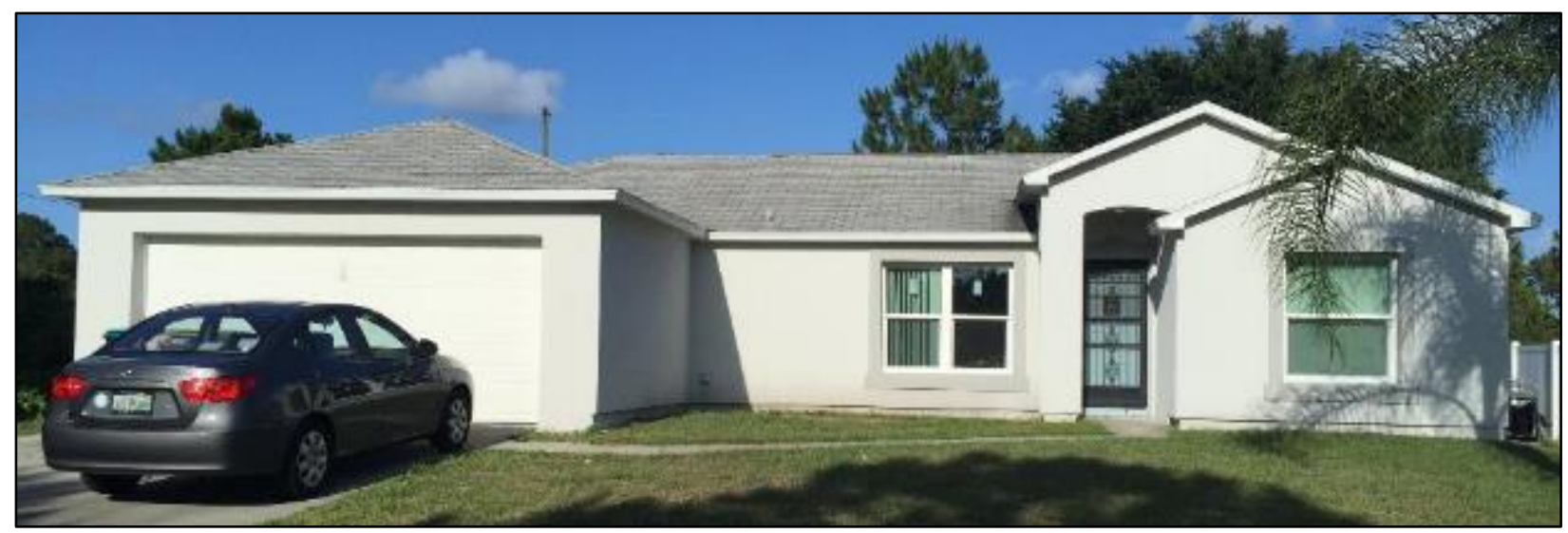

Figure 56. Site 54 after the EIFS and window retrofit

The following section includes analyses for the window retrofit and the window and EIFS retrofit measures combined. The timing of the window retrofits allows us to examine only the cooling season at this time.

\subsubsection{Window Retrofit Space-Cooling Energy Evaluation for Site 54}

As the second of the two building envelope retrofit measures, the window retrofit cannot be measured in isolation from the EIFS application - that is, the pre-window retrofit period came after the EIFS installation. The pre-retrofit observations are drawn from April 2015; the postretrofit observations are drawn from May 2015 and for each period in which the average daily ambient temperature exceeds $63^{\circ} \mathrm{F}$. The scatterplot in Figure 57 displays energy savings as the outdoor temperature increases. At milder temperatures, the window retrofit shows no impact on cooling energy consumption; however, negative cooling energy savings seem apparent with warmer ambient conditions. Unfortunately, there are currently limited data available for an evaluation of the energy savings. 


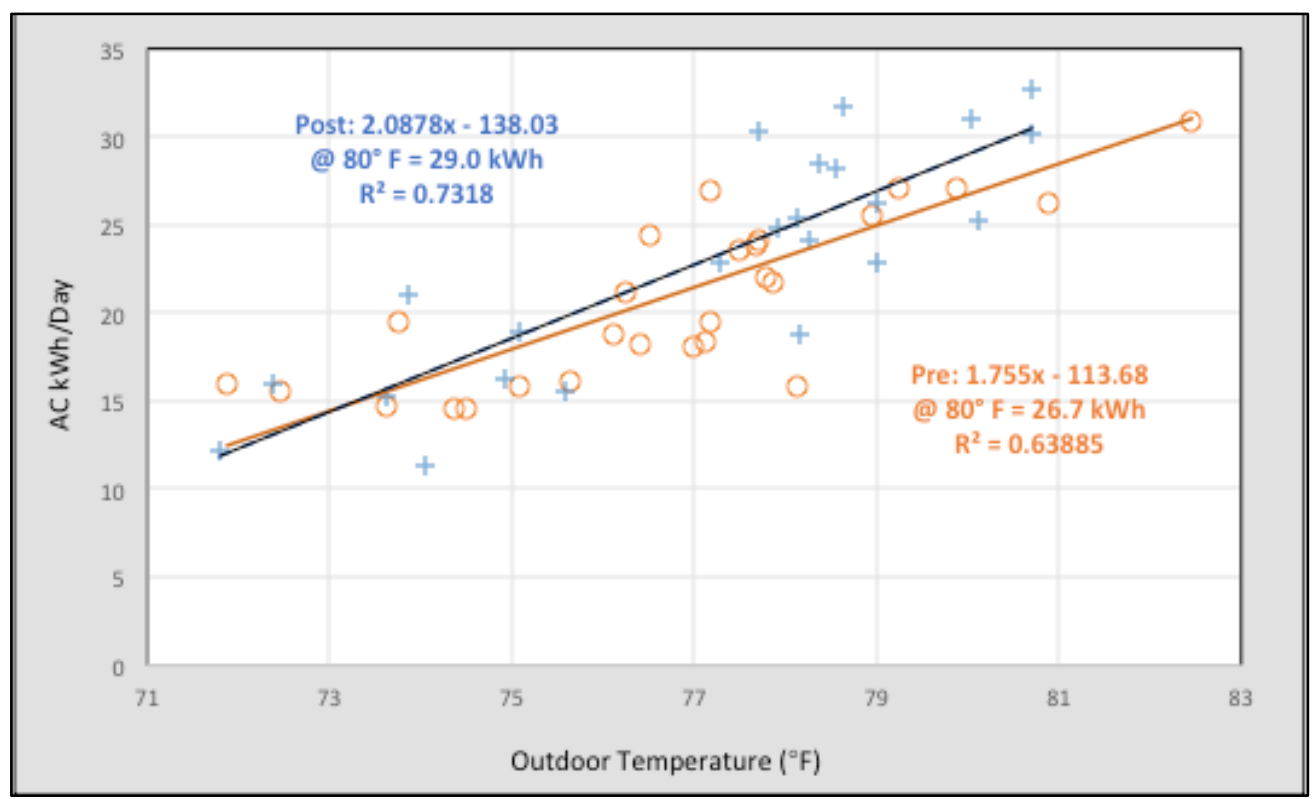

Figure 57. Regression lines for space-cooling pre- and post-window retrofit for Site 54

The daily average interior temperature was similar between evaluation periods $-76.4^{\circ} \mathrm{F}$ preretrofit compared to $76.8^{\circ} \mathrm{F}$ post-retrofit_-yet there is a difference in the interior temperature profiles. Figure 58 shows that both periods have consistent ambient temperature profiles and attain a similar interior temperature during the afternoon; however, during the evening and into mid-morning, the post-retrofit building maintains a higher temperature. This warmer temperature indicates a change in the building's thermal qualities, a by-product of the retrofit rather than a behavioral change. Thus, interior temperature was excluded from the modeling projection. The warmer nighttime temperature conditions likely come from the lower thermal conductance of the building after the retrofit.

This takes place because higher interior temperatures result from internal heat gains when the temperature outdoors is lower than the indoor temperature - in other words, the post-retrofit building loses heat to the outdoors at a lower rate. 


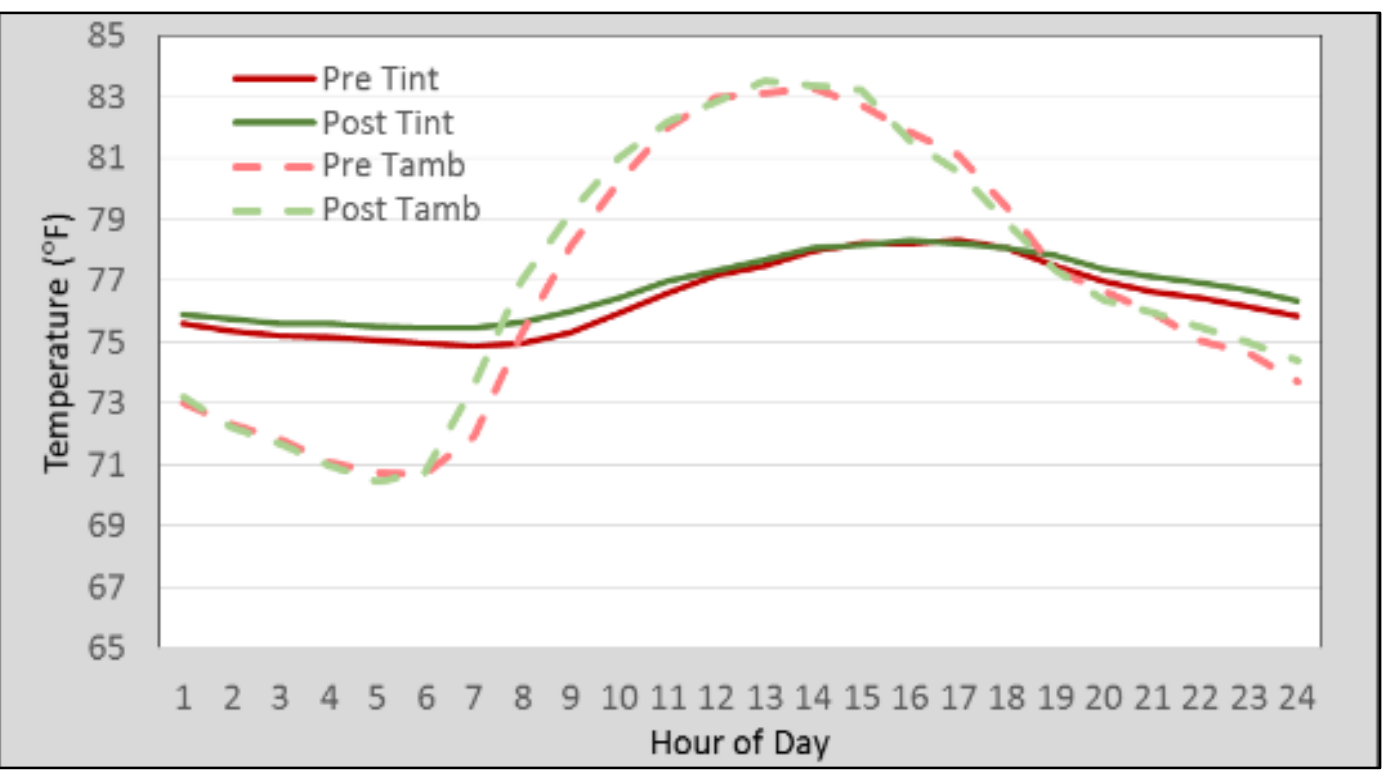

Figure 58. Pre- and post-window retrofit indoor and outdoor temperature profiles for cooling season observations for Site 54

Although the internal heat gains varied little between the pre- and post-window retrofit periods, daily average solar insolation was greater during the post-retrofit period $\left(5.5 \mathrm{kWh} / \mathrm{m}^{2}\right.$ pre-retrofit, $6.6 \mathrm{kWh} / \mathrm{m}^{2}$ post-retrofit). The solar insolation and internal gains parameters varied in their significance in each model. The internal heat gains variable is significant in the pre-retrofit model $(p<0.05)$, but it has a low level of significance in the post-retrofit model $(p<0.15)$. Solar insolation has a low level of significance in the pre-retrofit model $(p<0.15)$, but it is highly significant in the post-retrofit model $(p<0.01)$. These added parameters improve the model strength (pre-retrofit: $\mathrm{R}^{2}=0.72$; post-retrofit: $\mathrm{R}^{2}=0.87$ ).

Projected daily space-cooling energy for this moderately-shaded home with a thermostat set point of $76^{\circ}-77^{\circ} \mathrm{F}$ is $26.8 \mathrm{kWh}$ pre-retrofit and $27.4 \mathrm{kWh}$ post-retrofit, for a negative savings of $0.5 \mathrm{kWh} /$ day $(-2.0 \%)$, assuming an average outdoor temperature of $80^{\circ} \mathrm{F}$; thus, some of the 5.0 $\mathrm{kWh}$ /day space-cooling savings from the EIFS installation appears lost after the advanced window retrofit. However, although the window retrofit cooling energy savings model appears statistically strong, there are few observations with an average daily summer temperature near the $80^{\circ} \mathrm{F}$ used for the savings prediction; thus, although this evaluation seems to indicate no savings from the combination of measures, the data set used to create the models is quite limited, and the conclusions must remain suspect until additional data are accumulated to allow for a more conclusive evaluation.

\subsubsection{Preliminary Exterior Insulation Finish System and Window Retrofit Space- Cooling Energy Evaluation}

For the EIFS and window retrofit evaluation, pre- and post-retrofit analysis periods are necessarily discontinuous. To capture a similar part of the cooling season before and after both the measures, observations were drawn from May through mid-July 2014 for the pre-retrofit period and May through mid-July 2015 for the post-retrofit period. At first glance, the combined measures appear to improve space-cooling energy consumption. The scatterplot in Figure 59 
displays slight space-cooling energy savings, with shrinking savings as the outdoor temperature rises.

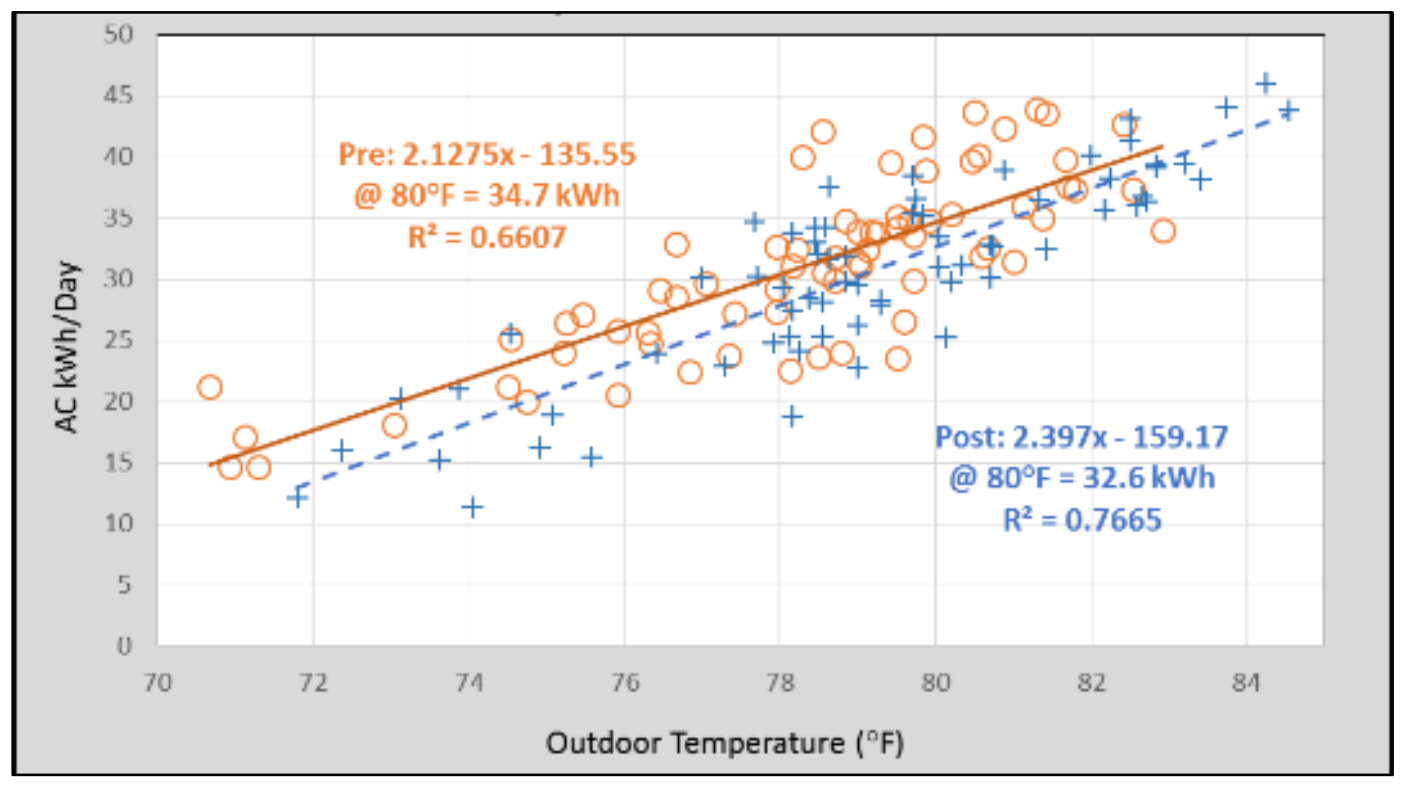

Figure 59. Regression lines for space-cooling pre- and post-EIFS and window retrofit for Site 54

The daily average interior temperatures were again cooler post-retrofit: $77.3^{\circ} \mathrm{F}$ pre-retrofit compared to $76.5^{\circ} \mathrm{F}$ post-retrofit. Figure 60 displays ambient and indoor temperatures for both evaluation periods. Evening indoor temperatures are similar between periods, though postretrofit has warmer afternoons. Meanwhile, the building maintains a lower temperature from the early hours through midday. The period of time during which the post-retrofit building remains cooler than the pre-retrofit building is indicative of behavioral change with a different thermostat setting; thus, Delta T was included in the savings evaluation. 


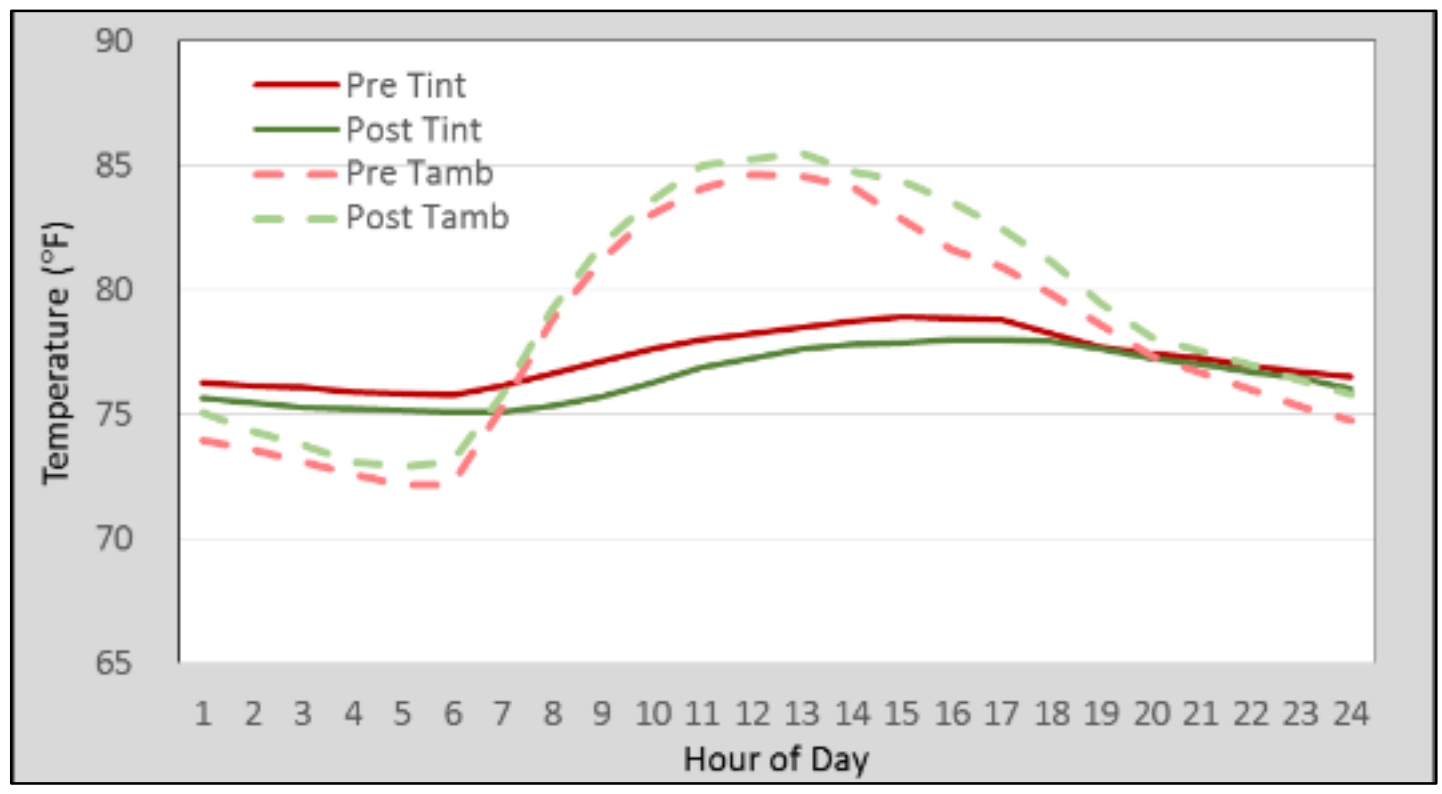

Figure 60. Pre- and post-EIFS and window retrofit indoor and outdoor temperature profiles for cooling season observations for Site 54

There were large differences in average daily internal heat gains among analysis periods (preretrofit: $14.0 \mathrm{kWh}$; post-retrofit: $10.5 \mathrm{kWh}$ ). The internal gains parameter was significant in both models $(p<0.01)$, and solar insolation was moderately so (pre-retrofit: $p<0.10$; post-retrofit: $p$ $<0.01$ ). The three-term regression models have relatively strong fits (pre-retrofit: $\mathrm{R}^{2}=0.70$; post-retrofit: $\mathrm{R}^{2}=0.87$ ).

The resulting cooling energy savings projection for the combined EIFS and window retrofit measures is $1.9 \mathrm{kWh} /$ day (pre-retrofit: $34.9 \mathrm{kWh} /$ day; post-retrofit: $33.0 \mathrm{kWh} /$ day) or $5.4 \%$, at an average summer temperature of $80^{\circ} \mathrm{F}$. The savings are lower than expected, given the 5.0$\mathrm{kWh} /$ day $(18.2 \%)$ cooling energy use savings experienced after the EIFS measure and -1.0$\mathrm{kWh} /$ day $(-2.0 \%)$ savings post-window retrofit. Also, it is noteworthy that the daily spacecooling energy consumption prediction is much higher (pre-retrofit: approximately $33 \mathrm{kWh}$; post-retrofit: approximately $35 \mathrm{kWh}$ ) than that for the EIFS only (pre-retrofit: approximately 22 $\mathrm{kWh}$; post-retrofit: approximately $27 \mathrm{kWh}$ ) and windows only (approximately $27 \mathrm{kWh}$ pre- and post-retrofit) evaluations; however, there is reason to believe that some models are potentially biased and of limited value for the assessment. These differences may be attributed to modeling with observations among the three different evaluations unavoidably taken from different times of the calendar year and sometimes lacking observations representing typical summer days. This creates considerable bias in the data and the models that result from using them. Another complication is that internal gains and solar insolation parameters were not always significant and could not be used consistently for modeling. A reevaluation of the combined EIFS and window retrofit measures using a longer time series will be examined for the final PDR report.

\subsection{Window Retrofits and Site $\mathbf{5 4}$ Savings Summaries}

As summarized in Table 30 for the three window retrofits and Table 31 for the Site 54 wall and window measures, the impact of these measures on space-conditioning energy are mixed. Seasonal space-cooling energy savings for the window retrofit ranged from $-0.7 \mathrm{kWh} /$ day $(-$ 
$4.8 \%$ ) to $6.9 \mathrm{kWh} /$ day $(27.0 \%)$, and the single projection for space-heating savings is 4.2 $\mathrm{kWh} /$ day $(6.8 \%)$ on a cold Central Florida day averaging $50^{\circ} \mathrm{F}$. Given the timing of this report, this study cannot evaluate the impacts on space heating at two sites. Average estimated annual savings based on the PDR average annual pre-retrofit space-heating and space-cooling energy use of 5,480 kWh (Appendix A) are poor: median space-cooling energy increased by 250 $\mathrm{kWh} / \mathrm{year}$, and space heating was quite modest for the single site evaluated for space heating, 19 $\mathrm{kWh} /$ year. The net space-conditioning energy use results for these selected sites is $231 \mathrm{kWh} /$ year negative savings.

Table 30. Window Space-Conditioning Energy Savings Summary

\begin{tabular}{cccccc}
\hline $\begin{array}{c}\text { Site } \\
\text { No. }\end{array}$ & $\begin{array}{c}\text { Evaluation } \\
\text { Season }\end{array}$ & $\begin{array}{c}\text { Pre- } \\
\text { (kWh/day) }\end{array}$ & $\begin{array}{c}\text { Post- } \\
\text { (kWh/day) }\end{array}$ & $\begin{array}{c}\text { Daily } \\
\mathbf{k W h} \\
\text { Savings }\end{array}$ & $\begin{array}{c}\text { \% Savings } \\
\text { Cooling @ 80 } \\
\text { Heating @ } \mathbf{~ 5 0}\end{array}$ \\
\hline 23 & Cooling & 25.7 & 18.7 & 6.9 & $27.0 \%^{\mathrm{a}}$ \\
\hline 23 & Heating & 61.7 & 57.5 & 4.2 & $6.8 \%^{\circ}$ \\
\hline 25 & Cooling & 14.6 & 15.3 & -0.7 & $-4.8 \%^{\circ}$ \\
\hline 54 & Cooling (windows only) & 26.8 & 27.4 & -0.5 & $-2.0 \%^{\mathrm{a}}$ \\
\hline
\end{tabular}

a Limited observations and period bias in the pre- and post-retrofit periods makes these estimates suspect.

Table 31. Space-Cooling Energy Savings Summary for Site 54

\begin{tabular}{lcccc}
\hline Evaluation Measure & $\begin{array}{c}\text { Pre- } \\
\text { (kWh/day) }\end{array}$ & $\begin{array}{c}\text { Post- } \\
\text { (kWh/day) }\end{array}$ & $\begin{array}{c}\text { Daily kWh } \\
\text { Savings }\end{array}$ & $\begin{array}{c}\text { \% Savings } \\
\text { Cooling @ 80 }\end{array}$ \\
\hline EIFS & 27.2 & 22.2 & 5.0 & $18.2 \%$ \\
EIFS and windows & 34.9 & 33.0 & 1.9 & $5.4 \%$ \\
\hline
\end{tabular}

The cost of the window retrofits at sites 23 and 54 were $\$ 9,943$ and $\$ 8,383$, respectively. ${ }^{15}$ If the HVAC energy savings results at Site 23 are applied to the average annual HVAC energy use of the untreated PDR sample reported in Phase I, the annual savings are \$213, with \$191/year cooling energy savings $(5,880 \mathrm{kWh} /$ year $* 0.27 * \$ 0.12 / \mathrm{kWh})$ and $\$ 22 /$ year heating energy savings $(275 \mathrm{kWh} /$ year $* 0.68 * \$ 0.12 / \mathrm{kWh})$. Extrapolating using the site that revealed the greatest savings, the window retrofit is not a cost-effective energy retrofit proposition. This evaluation, however, demonstrates the potential for a window retrofit to improve comfort in each case with more stable indoor temperatures. Comfort, acoustic, and aesthetic improvements could also be part of the justification for an advanced window retrofit.

The space-cooling energy savings for the EIFS measure at Site 54 was $5.0 \mathrm{kWh} /$ day $(18.2 \%)$, as presented in Section 5.3. The windows-only savings could not be conclusively established because of the limitation in the available monitoring periods with consistent conditions. Because this evaluation period lacks the warmest summer weather, the collective impact of these measures (windows and EIFS) will be reevaluated in a subsequent report when more data are available; however, given the total cost of $\$ 27,821$, the Site 54 EIFS and window retrofit measures cannot be justified solely on energy-related cost-effectiveness.

\footnotetext{
${ }^{15}$ The actual costs for the window retrofits included impact-resistant windows that were necessary project expenses resulting from government code changes. The premium for nonenergy window performance has been removed from these costs. The retrofit at Site 25 was conducted by the homeowner with no installation cost.
} 
The three window retrofits amount to a series of heavily examined case studies. Given the variation in the results, savings from advanced windows in Florida will differ considerably for individual homes and will likely depend on:

- Average interior temperature maintained (the lower the temperature, the greater the savings)

- The preexisting shading from outdoor features (buildings, setback shading, vegetation) and indoor shading (blinds and drapes and insect screening)

- The magnitude of internal gains. The greater the internal gains, the lower the savings from either advanced windows or insulation because internal heat cannot be lost to the outdoors during the evening hours when it is cooler outside than inside.

The weaknesses in modeling, the availability of only three sites for analysis and variability in results do not lend this measure to further evaluation under the TMY3 weather normalization. For the same reasons, it is impossible to draw meaningful peak system hour impacts without a much larger sample.

\subsection{Parametric Evaluation of Factors Affecting Window Savings in Florida Homes}

The measured and analyzed results of the three window retrofit experiments in the Phase II PDR project were decidedly mixed, with savings estimates ranging from negative savings to positive savings of $27 \%$. Given the case study nature of the monitoring effort, a simulation evaluation was conducted to see how various factors might be influencing results in a more controlled fashion.

The expectation coming into the evaluation was that savings would likely be around $15 \%$, as shown earlier in testing in Melbourne, Florida (Anello et al. 2000); however, these results were obtained with unoccupied buildings with lower internal gain levels than would be experienced in real occupied homes. Because the Melbourne homes in Anello's study were new construction, there was little in the way of vegetative shading, which is very common in established Florida homes.

The BEopt simulation software running EnergyPlus was used to evaluate the influences. A prototype 1,790 $\mathrm{ft}^{2}$ building, shown in Figure 61, was modeled with characteristics similar to what would be found in a typical home in the PDR project relative to insulation (R-4 walls, R-19 ceiling, uninsulated slab floor, 8 ACH50), AC systems, and heating. A SEER 13/HSPF 7.7 heat pump was assumed, with base thermostat set points of $77^{\circ} \mathrm{F}$ for cooling and $72^{\circ} \mathrm{F}$ for heating and R4 ducts with $15 \%$ duct leakage. 


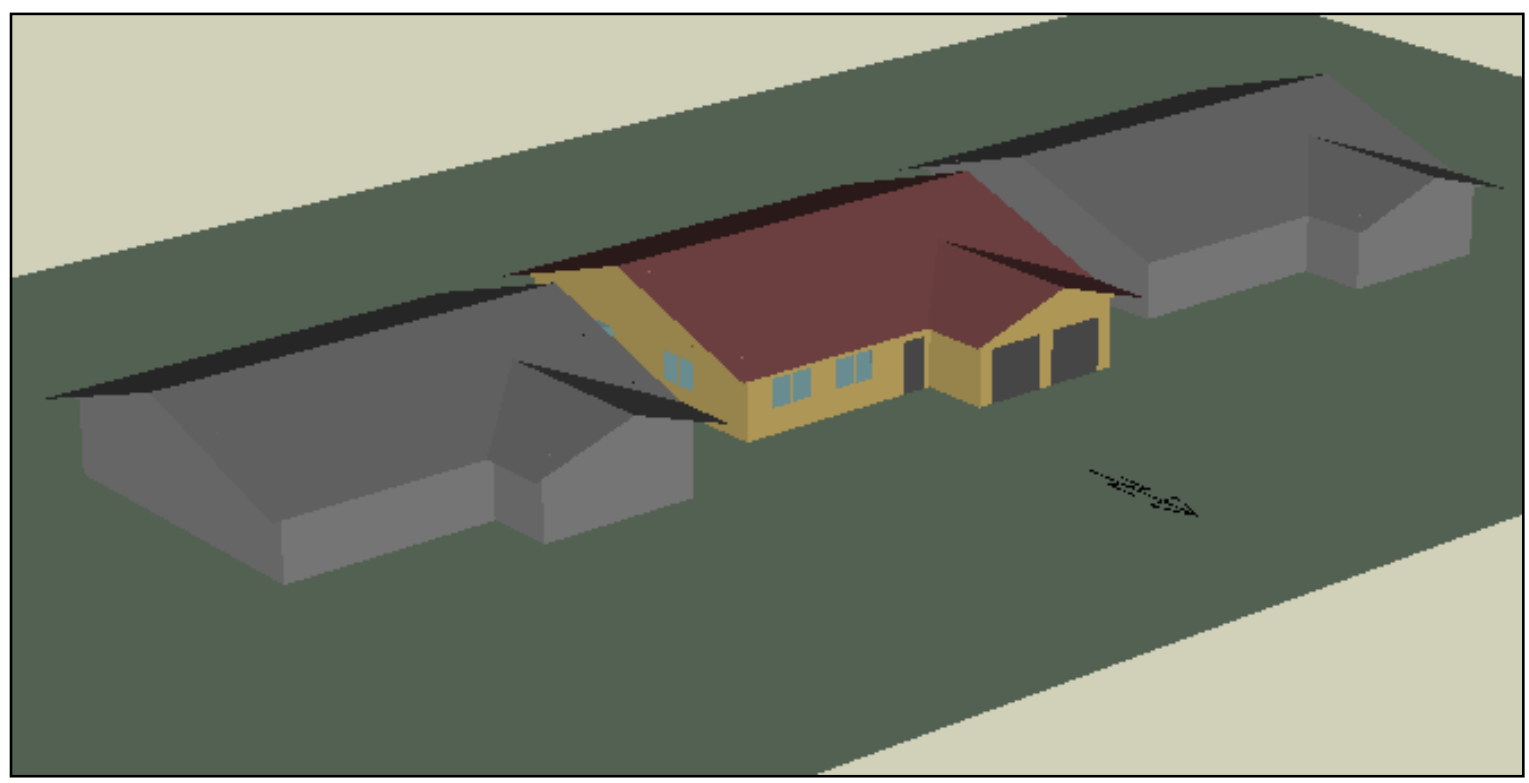

Figure 61. Prototypical PDR residence rendered in BEopt with adjacent home on either side

For the BEopt rendering for windows, the model assumed single-glazed, aluminum-framed base case windows $\left(\mathrm{U}=1.16 \mathrm{Btu} /\right.$ hour- $\left.\mathrm{ft}^{2}-{ }^{\circ} \mathrm{F}, \mathrm{SHGC}=0.76\right)$ and then simulated high-performance windows similar to those used in the project $(\mathrm{U}=0.28$; $\mathrm{SHGC}=0.22)$. It also assumed that there were adjacent homes (as is common in the suburbs and in the cases we encountered) and 3-ft. overhangs to approximate the high degree of shading from porches (see Table 19). Further, based on the characterization shown in Table 19, the model included the assumption that interior shading was extensive from observed blind position and also from $50 \%$ of the windows commonly being covered by insect screening that has been shown to reduce solar transmittance by nearly $40 \%$. In addition, the effective solar transmittance was assumed to be $30 \%$ of the fully exposed value in the cooling season and $50 \%$ of the value in winter. These values contrast with the BEopt standard values of $50 \%$ in the cooling season and $70 \%$ in winter, which would reflect different blind management than was observed in the project homes. High levels of window heat gain can lead to overheating in spring and fall, and BEopt has the potential to simulate yearround venting, although in this project natural ventilation was fairly uncommon except during the Florida winter season.

Other parameters that can be expected to influence window savings include interior thermostat temperature and internal heat gain rate. The higher the temperature set point, the lower the savings from the lower U-factor of windows. Moreover, at some point the lower heat loss from the windows at night will begin to exert a negative influence on savings.

Similarly, with high levels of internal heat gain from greater appliance and interior plug loads, the home's interior temperature will tend to be elevated such that greater heat loss at night from single-glazed windows is actually desirable. This is clearly shown in Figure 55 for Site 25, which has a cooling set point of nearly $82^{\circ} \mathrm{F}$ and has very high plug loads with daily home entertainment power of $5.7 \mathrm{kWh} /$ day. Based on modeling, it appears that assuming twice the normal plug loads worked fairly well in many cases. 
Figure 62 shows the results for a case similar to Site 25 with twice the normal plug loads and a cooling set point of $81^{\circ} \mathrm{F}$. The predicted cooling energy savings from the advanced windows amount to only $202 \mathrm{kWh} /$ year. Note that the measured cooling energy at Site 25 during the entire year of 2013 was $2,227 \mathrm{kWh}$, which corresponds well to the $2,172 \mathrm{kWh}$ predicted. The results are shown below in the form of an analysis result table (Table 32) from BEopt.

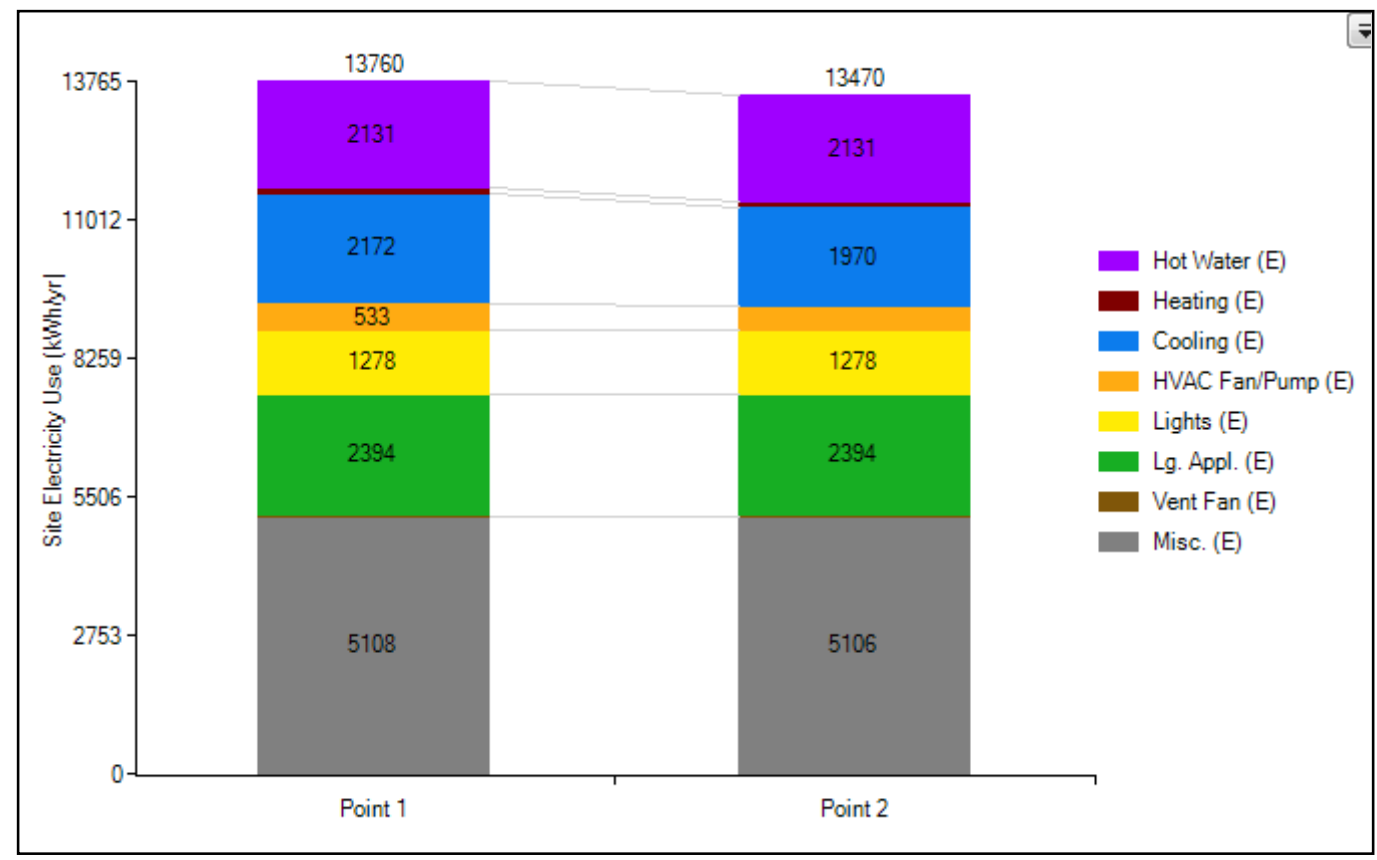

Figure 62. Estimated savings from single-glazed windows (Point 1) compared to double-glazed, low-e, solar-control windows, with a set point of $81^{\circ} \mathrm{F}$ and two times normal plug loads 
Table 32. Parametric Evaluation of Influences on Savings from Advanced Windows in Florida

\begin{tabular}{|c|c|c|c|c|c|c|c|c|}
\hline \multirow[b]{2}{*}{ Set Point ${ }^{\circ} \mathrm{F}$} & \multicolumn{4}{|c|}{ No Ventilation } & \multicolumn{4}{|c|}{ Year-Round Ventilation } \\
\hline & $\begin{array}{l}\text { Single- } \\
\text { Glazed } \\
\text { (kWh) }\end{array}$ & $\begin{array}{c}\text { Double- } \\
\text { Low-e Solar } \\
\text { (kWh) }\end{array}$ & $\begin{array}{l}\text { Savings } \\
\text { (kWh) }\end{array}$ & $\begin{array}{c}\text { Savings } \\
\%\end{array}$ & $\begin{array}{l}\text { Single- } \\
\text { Glazed } \\
\text { kWh }\end{array}$ & $\begin{array}{l}\text { Double- } \\
\text { Low-e } \\
\text { Solar } \\
\text { (kWh) }\end{array}$ & $\begin{array}{l}\text { Savings } \\
\text { (kWh) }\end{array}$ & $\begin{array}{l}\text { Savings } \\
\%\end{array}$ \\
\hline $72^{\circ}$ & 6,413 & 5,891 & 522 & $8.1 \%$ & 6,413 & 5,888 & 525 & $8.2 \%$ \\
\hline $73^{\circ}$ & 5,888 & 5,404 & 484 & $8.2 \%$ & 5,888 & 5,404 & 484 & $8.2 \%$ \\
\hline $74^{\circ}$ & 5,372 & 4,927 & 445 & $8.3 \%$ & 5,349 & 4,903 & 446 & $8.3 \%$ \\
\hline $75^{\circ}$ & 4,865 & 4,458 & 407 & $8.4 \%$ & 4,804 & 4,396 & 408 & $8.5 \%$ \\
\hline $76^{\circ}$ & 4,367 & 3,998 & 369 & $8.4 \%$ & 4,282 & 3,916 & 366 & $8.5 \%$ \\
\hline $77^{\circ}$ & 3883 & 3,549 & 334 & $8.6 \%$ & 3,790 & 3,458 & 332 & $8.8 \%$ \\
\hline $78^{\circ}$ & 3,420 & 3,118 & 302 & $8.8 \%$ & 3,326 & 3,030 & 296 & $8.9 \%$ \\
\hline $79^{\circ}$ & 2,978 & 2,708 & 270 & $9.1 \%$ & 2,896 & 2,629 & 267 & $9.2 \%$ \\
\hline $80^{\circ}$ & 2,562 & 2,327 & 235 & $9.2 \%$ & 2,491 & 2,257 & 234 & $9.4 \%$ \\
\hline $81^{\circ}$ & 2,172 & 1,970 & 202 & $9.3 \%$ & 2,113 & 1,914 & 199 & $9.4 \%$ \\
\hline $82^{\circ}$ & 1,805 & 1,638 & 167 & $9.3 \%$ & 1,761 & 1,591 & 170 & $9.7 \%$ \\
\hline \multicolumn{9}{|l|}{ Internal Gains } \\
\hline $0.5 \times \mathrm{PL}$ & 3,086 & 2,729 & 357 & $11.6 \%$ & 3,033 & 2,679 & 354 & $11.7 \%$ \\
\hline $1 \times P L$ & 3,344 & 2,989 & 355 & $10.6 \%$ & 3,277 & 2,931 & 346 & $10.6 \%$ \\
\hline $2 \times P L$ & 3,883 & 3,549 & 334 & $8.6 \%$ & 3,790 & 3,458 & 332 & $8.8 \%$ \\
\hline $3 \times \mathrm{PL}$ & 4,449 & 4,135 & 314 & $7.1 \%$ & 4,356 & 4,015 & 341 & $7.8 \%$ \\
\hline $4 \times \mathrm{PL}$ & 5,029 & 4,733 & 296 & $5.9 \%$ & 4,880 & 4,584 & 296 & $6.1 \%$ \\
\hline \multicolumn{9}{|c|}{ External and Internal Shade } \\
\hline $\begin{array}{l}\text { Hvy. Int. and ext. } \\
\text { shade, w/neighbors }\end{array}$ & 3,883 & 3,549 & 334 & $8.6 \%$ & 3,790 & 3,458 & 332 & $8.8 \%$ \\
\hline Less int. shade & 4,124 & 3,631 & 493 & $12.0 \%$ & 4,015 & 3,538 & 477 & $11.9 \%$ \\
\hline $\begin{array}{c}\text { Hvy int. and ext. } \\
\text { shade, no neighbors }\end{array}$ & 4,528 & 3,913 & 615 & $13.6 \%$ & 4,390 & 3,801 & 589 & $13.4 \%$ \\
\hline $\begin{array}{l}\text { Less int. shade, } \\
\text { no neighbors }\end{array}$ & 4,938 & 4,050 & 888 & $18.0 \%$ & 4,774 & 3,927 & 847 & $17.7 \%$ \\
\hline
\end{tabular}

${ }^{\text {a } B o l d e d ~ r o w s ~ r e p r e s e n t ~ p a r a m e t e r ~ s e l e c t e d ~ f o r ~ t h e ~ g e n e r a l ~ m o d e l ~ u s e d ~ i n ~ t h e ~ r e m a i n i n g ~ p a r a m e t e r s ' ~ s e n s i t i v i t y ~}$ runs

Note that the results suggest the following influences on AC savings from windows in a coolingdominated climate:

- Preexisting shading from adjacent buildings, porches, blinds, and insect screens has a very large impact on savings, reducing them by more than $50 \%$ relative to standard assumptions (which also includes interior shading).

- Greater internal gains from appliance and plug loads reduce the cooling energy savings from advanced windows because interior temperatures tend to be higher during nighttime hours when ambient temperatures are lower and heat loss is beneficial. For example, a home with low plug loads will see savings nearly double those of a home with very high internal heat gains. 
- The annual savings of advanced windows varies significantly by the interior thermostat setting. For example, a home maintaining $81^{\circ} \mathrm{F}$ instead of $77^{\circ} \mathrm{F}$ would see $40 \%$ less savings. On the other hand, a home maintaining an inside temperature of $73^{\circ} \mathrm{F}$ would see $56 \%$ greater savings from the better windows.

- Natural ventilation has only modest influences on produced savings, at least according to the algorithms in BEopt.

Although $20 \%-30 \%$ savings are possible with the right combination of factors (low internal gains, minimal existing shading, and low set points), the opposite is true as well. A very high set point with high internal gains with windows mostly shaded by other buildings, vegetation, porches, or blinds would see negligible savings from advanced windows. In particular, preexisting shading in existing Florida homes is likely to limit savings in many applications. 


\section{Evaluation of Smart Thermostats}

\subsection{Background}

Because thermostats are the central switch that control the operation of heating and cooling systems - commonly the largest energy end use in homes - it follows that understanding how the occupants and thermostat interact is key to achieving potential energy savings; however, this potential is complex, comprising the control hardware and how homeowners use it (behavior). ${ }^{16}$ That this technique has potential for energy savings has been demonstrated in well-controlled laboratory measurements. For example, experimental work by Levins at Oak Ridge National Laboratory (Levins 1988) showed 20\% measured heating savings from thermostat setback in the highly instrumented and unoccupied Karns homes compared to the use of a constant thermostat setting. More recently, detailed National Research Council Canada test homes in Canada (Manning et al. 2007) showed that both thermostat setback (winter) and setup (summer) reliably produce savings of $13 \%$ and $11 \%$, respectively; however, until the advent of smart thermostats, such savings levels have depended on the willingness of occupants to manage their thermostats and make effective control decisions. Somewhat lower energy savings in occupied homes are well-documented. For example, Blasnik as cited by Bailes (2012) has shown heating savings of $5 \%-8 \%$ in multiple studies in many occupied homes in the northeastern United States from 1998-2008. Also, Roberts and Lay (2013) showed that in 20 homes in New York, the measured interior nighttime temperatures were only approximately $3^{\circ} \mathrm{F}$ lower than midday temperatures, and in a similar sample of Florida homes, the same differences were only approximately $2^{\circ} \mathrm{F}$ during the day. This appears substantially lower than the potential, however, based on the laboratory experiments.

\subsubsection{Unrealized Potential with Standard Programmable Thermostats}

From 1999-2001, a large monitoring project in Central Florida for Florida Power Corporation evaluated 150 submetered homes and found that homes with programmable thermostats actually used more space cooling than those with manual slide thermostats because homeowners were more likely to change the daily settings on the manual thermostats (Nevius 2000). ${ }^{17}$ Verifying this finding, the influence of thermostats and load controls has been evaluated in Florida homes by utilities that want to enhance load control. The utilities' findings also showed that programmable thermostats increased cooling consumption (Lopes and Agnew 2010). The problems were not confined to Florida; data from Minnesota showed much the same contrary result from programmable thermostats (Nevius and Pigg 2000). Other efforts (Vastamaki, Sinkkonen, and Leinonen 2005; Meier et al. 2011) indicated that much of the problem emerged because the user interface of the programmable thermostat for homeowners was too complicated, and only one in four households with programmable thermostats had been programming them.

Newer "smart" thermostats get around these problems by self-programming depending on heuristic evaluations of user control habits as well as sensed homeowner occupancy. Such smart thermostats include Nest (see Figure 63), Lyric, and Ecobee. These modern devices use a

\footnotetext{
${ }^{14}$ www.energyvanguard.com/blog-building-science-HERS-BPI/bid/50152/If-You-Think-Thermostat-SetbacksDon't-Save-Energy-You're-Wrong

${ }^{17}$ Part of the problem identified during occupant interviews as part of the Florida Power Corporation monitoring project had to do with complexity (e.g., "technological nuisance factor"), which kept many from programming devices. Manual thermostats are easy to operate and set back, whereas homeowners with programmable thermostats tended to leave them at a constant "Hold" setting.
} 
combination of data on occupancy, weather, and thermostat-setting preference to help consumers with automated setback/setup schedules. These devices have also been shown in other studies in other regions to produce cooling energy savings. For example, the Nest thermostats have been shown to provide savings of $1.16 \mathrm{kWh} /$ day or $11.3 \%$ in a very large sample of homes in Southern California (Nest 2014). There are reasons to believe savings may differ in Florida, however, with different demographics, construction practices, and intense cooling consumption.

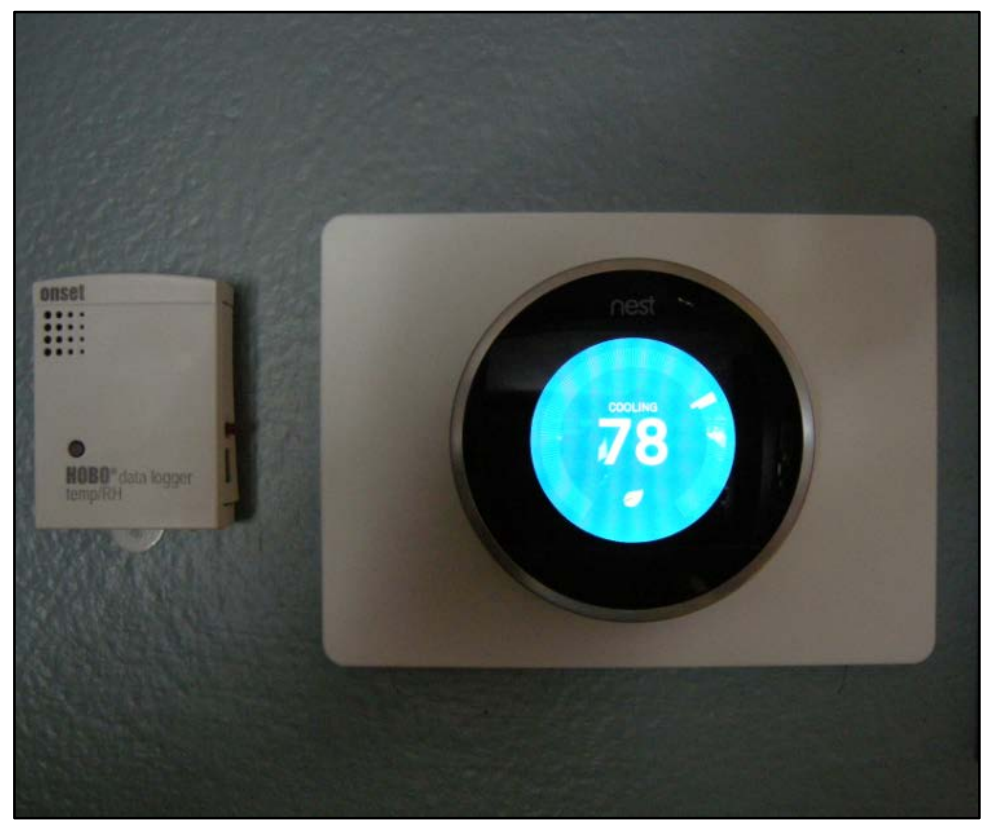

Figure 63. The Nest learning thermostat installed at one of the PDR sites showing the redundant temperature and humidity measurement

\subsection{Installation Campaign}

A total of 44 PDR sites were considered for installation of the Nest or Lyric "smart" thermostat Phase II evaluation. The installation sites were chosen based on homeowner acceptance, compatibility, and no confounding measures being installed in the home (nine sites received a Nest in 2013 as part of the deep retrofit and are not included in this analysis because of confounding retrofit measures):

- Two sites already had a Nest.

- Five sites had incompatible AC systems - typically very high-efficiency systems.

- Four sites were not appropriate because of the need to not confound other measures being installed.

- Four sites rejected the offer of a smart thermostat.

Among the 29 smart thermostats installed as part of the PDR Phase II program, 22 sites received a Nest or Lyric in 2014, and 7 sites received a Nest in 2015. An installed Lyric was subsequently traded for a Nest and eliminated from analysis, leaving 26 Nest and 2 Lyric thermostat installations for initial evaluation. 
Within the analysis we carefully attempted to reduce confounding influences. Three sites had the evaluation time periods censured due to a change-out of the air-conditioning equipment (very visible within the analysis periods due to the ability to monitor the HVAC circuits). A subset of three Nests installed in 2015 in homes with supplemental MSHPs operating and controlled independently were evaluated, but they are not considered part of the main sample. Finally, it was never clear that one site (Site 46) had installed the Nest; thus, it was excluded. This left 25 Nest sites and 2 Lyric sites for the final evaluation. Site characteristics for the installations are summarized in Table 1. HVAC characteristics are given in Table 33.

Table 33. Smart Thermostat General Site Characteristics

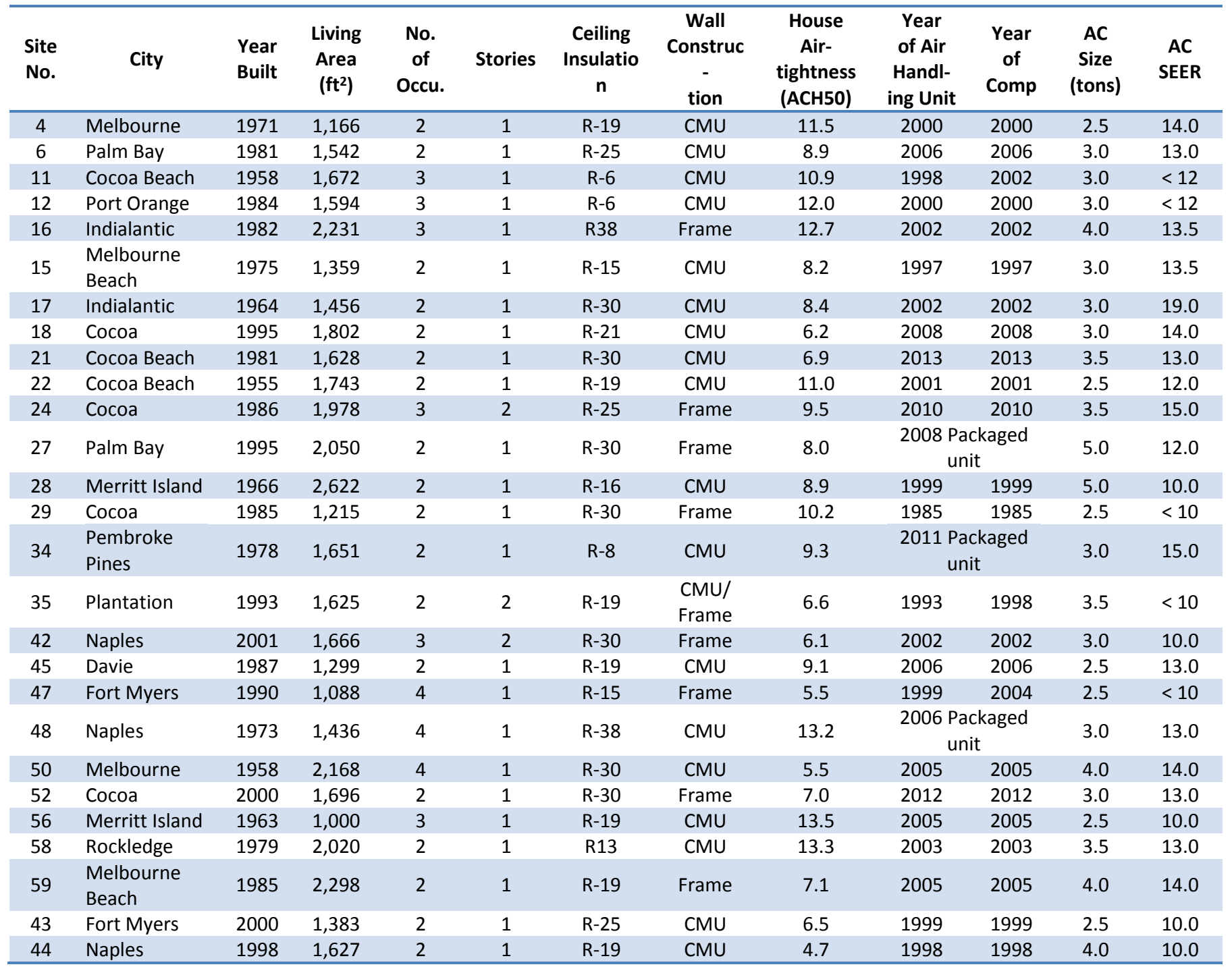

Site characteristics for the 25 Nest and 2 Lyric installations are summarized in Table 34, HVAC characteristics for these sites are provided in Table 33, and serial numbers for the Nest installations are in Appendix G. 
Table 34. Thermostat Replacement Site HVAC Characteristics

\begin{tabular}{|c|c|c|c|c|c|c|c|}
\hline $\begin{array}{l}\text { Site } \\
\text { No. }\end{array}$ & Heating & $\begin{array}{c}\text { Duct } \\
\text { Leakage } \\
\text { (Qn,out) }\end{array}$ & $\begin{array}{l}\text { Existing } \\
\text { T-Stat } \\
\text { Make }\end{array}$ & $\begin{array}{c}\text { Existing } \\
\text { Technology }\end{array}$ & $\begin{array}{c}\text { As } \\
\text { Found Program } \\
\text { Setting }\end{array}$ & $\begin{array}{c}\text { T-Stat } \\
\text { Installed }\end{array}$ & Install Date \\
\hline 4 & Heat pump & 0.17 & Robertshaw & Nonprogrammable & $\mathrm{n} / \mathrm{a}$ & Nest & Sept 3, 2014 \\
\hline 6 & Resistance & 0.10 & Honeywell & Nonprogrammable & $n / a$ & Nest & Aug 27, 2014 \\
\hline 11 & Heat pump & 0.13 & Honeywell & Nonprogrammable & $n / a$ & Nest & Sept 5, 2014 \\
\hline 12 & Heat pump & 0.63 & Honeywall & Nonprogrammable & $n / a$ & Nest & July 10, 2015 \\
\hline 15 & Heat pump & 0.13 & White Rogers & Nonprogrammable & $\mathrm{n} / \mathrm{a}$ & Nest & Oct 10, 2014 \\
\hline 16 & Resistance & 0.07 & Carrier & Programmable & Program Running & Nest & July $29,2015^{a}$ \\
\hline 17 & Heat pump & 0.12 & Trane (XT500C) & Programmable & 'Hold' & Nest & Sept 10, 2014 \\
\hline 18 & Heat pump & 0.05 & Honeywell & Programmable & 'Hold' & Nest & Sept 11, 2014 \\
\hline 21 & Heat pump & 0.12 & White Rogers & Programmable & Program running & Nest & July 24, 2014 \\
\hline 22 & Resistance & 0.08 & $\begin{array}{l}\text { White Rogers } \\
\text { (1F82-261) }\end{array}$ & Programmable & Program running & Nest & Sept 4, 2014 \\
\hline 24 & Resistance & 0.09 & Trane & Programmable & $\mathrm{n} / \mathrm{a}$ & Nest & July $20,2015^{a}$ \\
\hline 27 & PkgHP & 0.05 & Maple/Chase & Programmable & Running & Nest & July $17,2015^{a}$ \\
\hline 28 & Heat pump & 0.06 & Trane (XT500C) & Programmable & Unknown & Nest & Sept 12, 2014 \\
\hline 29 & Resistance & 0.07 & Honeywell & Nonprogrammable & $\mathrm{n} / \mathrm{a}$ & Nest & Aug 20, 2014 \\
\hline 34 & Resistance & 0.06 & Trane & Programmable & 'Hold' & Nest & Nov 20, 2014 \\
\hline 35 & Resistance & 0.08 & Filtrete & Programmable & Program running & Nest & Nov 22, 2014 \\
\hline 42 & Resistance & 0.04 & $\begin{array}{l}\text { White Rodgers } \\
\text { (1F86-344) }\end{array}$ & Nonprogrammable & $\mathrm{n} / \mathrm{a}$ & Nest & Oct 29, 2014 \\
\hline 45 & Resistance & 0.09 & $\begin{array}{l}\text { Climate } \\
\text { Technology }\end{array}$ & Nonprogrammable & $\mathrm{n} / \mathrm{a}$ & Nest & Nov 20, 2014 \\
\hline 47 & Resistance & 0.03 & Not recorded & Programmable & Program running & Nest & Oct 30, 2014 \\
\hline 48 & Resistance & 0.20 & $\begin{array}{l}\text { White Rogers } \\
\text { (IF86-344) }\end{array}$ & Nonprogrammable & $\mathrm{n} / \mathrm{a}$ & Nest & Oct 29, 2014 \\
\hline 50 & Resistance & 0.03 & Honeywell & Programmable & Hold & Nest & July 22, 2015 \\
\hline 52 & Heat pump & 0.06 & Honeywell & Programmable & 'Hold' & Nest & Aug 27, 2014 \\
\hline 56 & Resistance & 0.16 & LuxPro & NonProgrammable & $\mathrm{n} / \mathrm{a}$ & Nest & July 22, 2015 \\
\hline 58 & Heat pump & --- & Honeywell & Programmable & Program running & Nest & Aug 25, 2014 \\
\hline 59 & Resistance & 0.10 & Honeywell & Programmable & 'Hold' & Nest & Sept 12, 2014 \\
\hline 43 & Resistance & 0.03 & Honeywell & Nonprogrammable & $\mathrm{n} / \mathrm{a}$ & Lyric & Oct 28, 2014 \\
\hline 44 & Resistance & 0.07 & Honeywell & Non-programmable & $n / a$ & Lyric & Nov 19, 2014 \\
\hline
\end{tabular}

a With supplemental ductless mini-split

For the Phase II research evaluation, the thermostats were installed in PDR homes that had not received other retrofits between July 24, 2014, and December 31, 2015. The pre-retrofit evaluation periods generally ran from July 2013 through the installation date at each site, and the post-retrofit period ran from installation through December 2015. The installations were primarily in the Central Florida and South Florida areas.

These had no other retrofits that were coincident with the thermostat installation other than pool pumps, which were not expected to alter interior HVAC needs. (This eliminated Site 54 from evaluation.) No specific instruction or programming was provided to occupants, who were free to alter the thermostats as they pleased. Default Nest and Lyric settings were used. For each home, a full year of preinstallation data was available, including AC, heating, and air handling unit use as well as indoor temperatures and RH. In fact, often 2 years or more of pre-retrofit data were available, but only a full year was used, as described below. 


\subsection{Observed Time-Related Degradation in Air-Conditioning Performance}

In evaluating the various Nest sites with often 2 years of pre-data before the Nest installation, we were careful to look for changes in the air-conditioning system-specifically AC replacement because it was known that this could severely bias, in doing so with regression models tied to outdoor weather, we soon noted that performance results. However of the cooling system at most sites seemed to almost uniformly be worse in the year leading up to the Nest installation than it was the year before that. This was measureable given the regression techniques we were using with the monitored pure HVAC circuits.

Although a systematic evaluation is needed for this phenomenon, our cursory evaluation suggests that cooling-related AC performance may go down between $1 \%-4 \%$ per year on average, and therefore using a longer time period than 1 year before the Nest installation is not advisable due to the bias introduced. (The largest seeming degradation rate was shown at a recent installation.) This may be caused by many factors (indoor and outdoor coil fouling, lack of filter changing, loss of refrigerant charge, etc.), but taken in aggregate this suggests that mechanical cooling system performance degrades over time and in a measureable fashion if weather data are used to track influences. Figure 64 shows how cooling changed at Site 22 from 2013 to 2014 with very consistent interior temperatures being maintained before the Nest installation. The AC system is of a 2001 vintage (both indoor and outdoor unit).

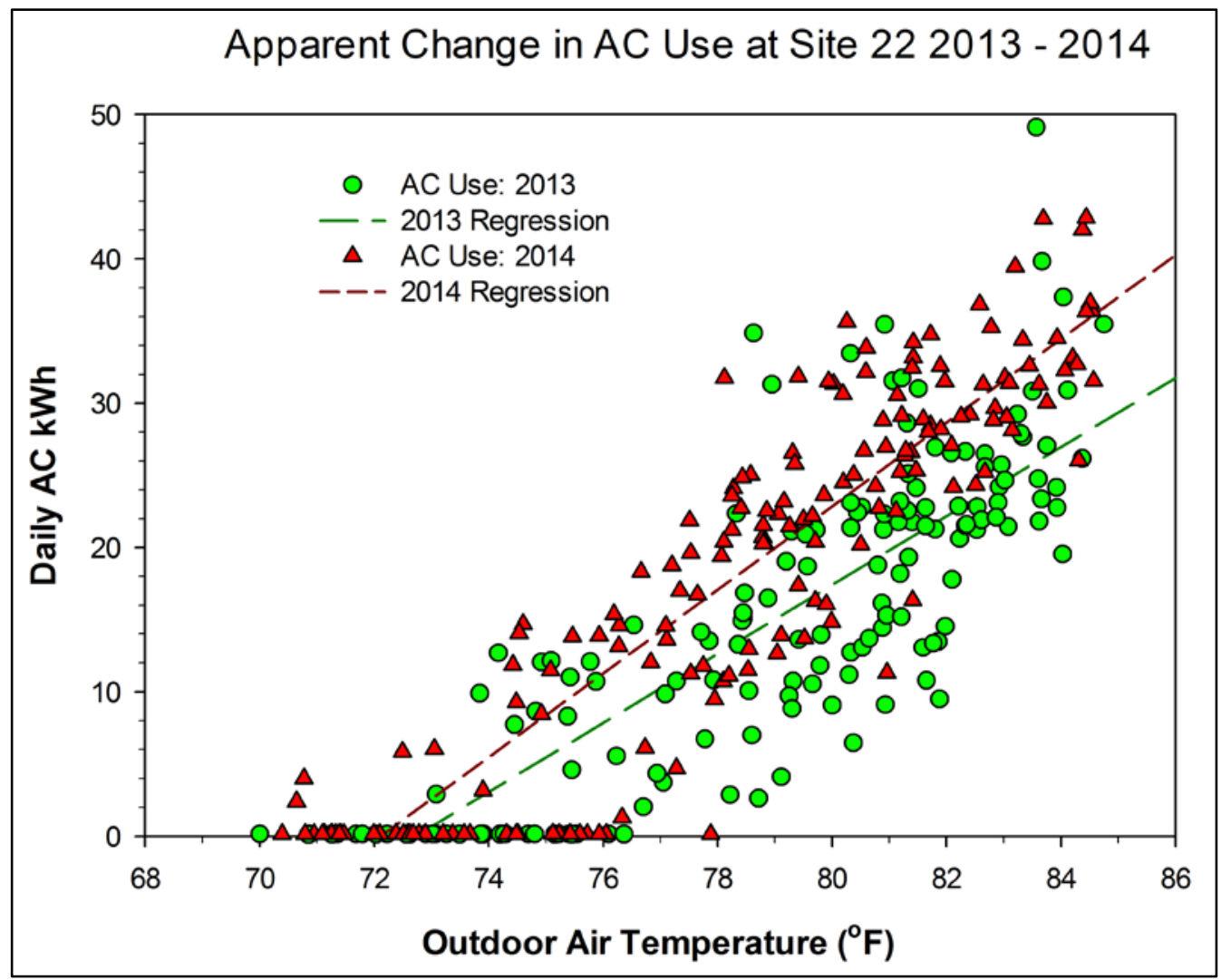

Figure 64. Observed cooling efficiency related degradation at Site 22 from 2013-2014. Note the higher trend of cooling energy regressed against outdoor temperature in 2014. 
Although it may be thought that the change between 2013 and 2014 was related to interior temperature, because this was measured we could eliminate that possibility. Figure 65 shows the same data plotted against the daily indoor to outdoor temperature. The data gives the same result: apparent degradation of the $\mathrm{AC}$ performance (or otherwise unexpected loads) in 2014 compared to 2013 .

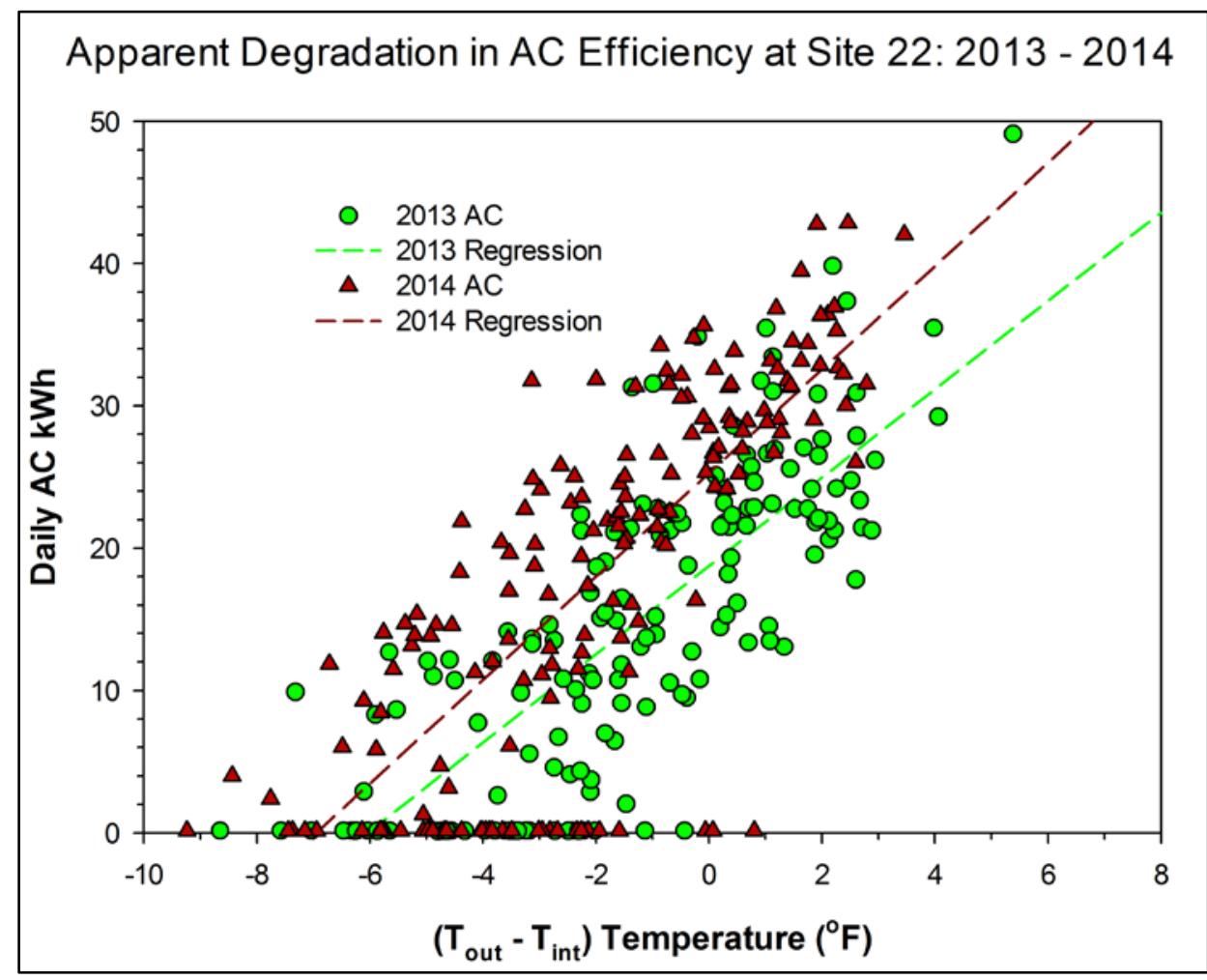

Figure 65. Cooling performance at Site 22 from 2013-2014 regressed against difference in outdoor indoor temperature

This trend was shown at Site 22 and in most of the sites where it could be examined - a trend of increasing consumption from one year to the next, even controlling for weather and interior temperature preferences. Although Site 22 represents an extreme case, we decided that it would be best to use 1 year of pre-retrofit data along with 1 year of post-retrofit data regardless of the length of the data trail available for particular sites.

\subsection{Smart Thermostat Evaluation and Example Analysis}

The analysis method used to evaluate the performance of each Nest or Lyric installation was to summarize the pre-year data and compare daily measured space-conditioning energy to outdoor temperature according to the evaluation method described in Section 4. Regressions from the analysis of the smart thermostats are provided in Appendix H.

To help understand how energy use changed before and after the smart thermostat installation, the indoor temperatures being maintained were also compared to the outdoor temperatures in an attempt to identify specific thermostat control effects. These changes were explored extensively for cases in which energy use actually increased.25.5 
Below is an example of how the analysis method was done for each site. Site 28 is a 2,622 $\mathrm{ft}^{2}$ home built in 1966 in Merritt Island, Florida, with two working adults in the household. The concrete masonry home is poorly insulated: R-16 attic insulation, no wall insulation, single-pane glass, and a blower door tested leakage of 8.9 ACH50. The heat pump system is an older 1999 vintage, 4-ton machine. The existing thermostat was a TRANE XT500C programmable thermostat (Figure 66).

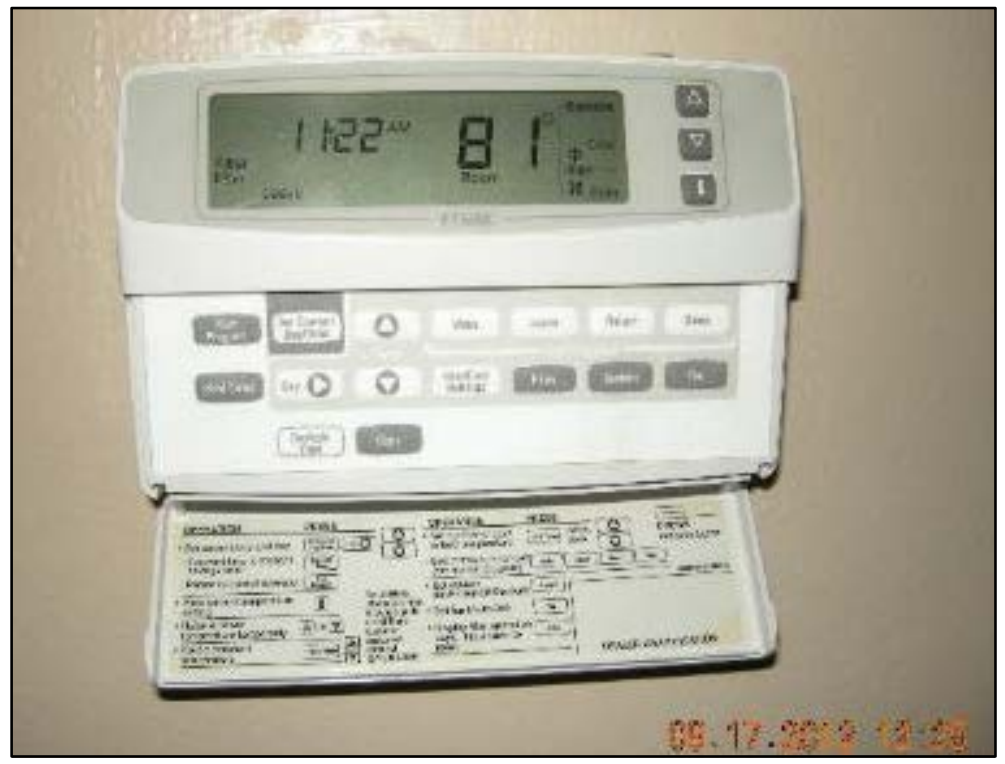

Figure 66. Existing thermostat, a Trane XT500C programmable model, at Site 28

Data from July 2013 to the present are presented in Figure 67 below for both indoor and outdoor temperature and for the HVAC time series. The Nest was installed on September 12, 2014. The interior temperature data recorded by the portable HOBO loggers (red) was continuous, showing the expected dip in response to winter outdoor conditions. Outdoor ambient temperature is light blue. 


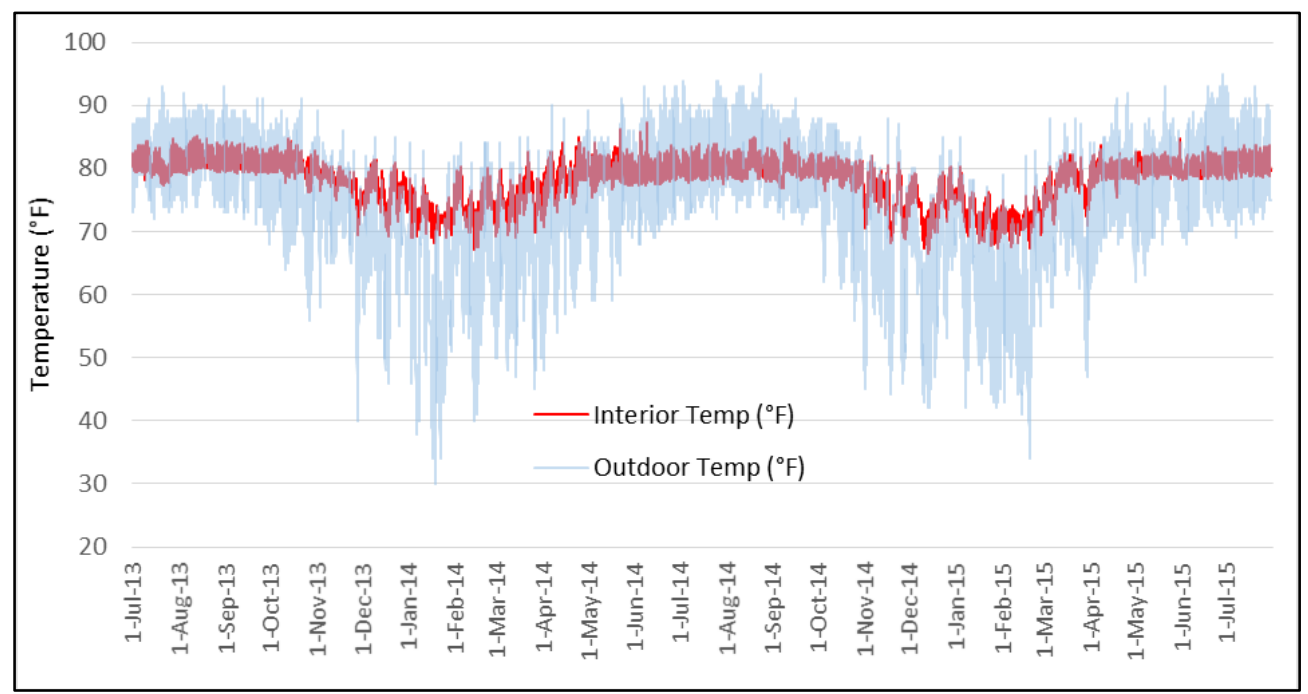

Figure 67. Interior temperature and local National Weather Service outdoor temperature from July 2013-July 2015 at Site 28

Daily HVAC data during this same period are plotted in Figure 68 below. Orange represents the compressor power, and green is the air handling unit.

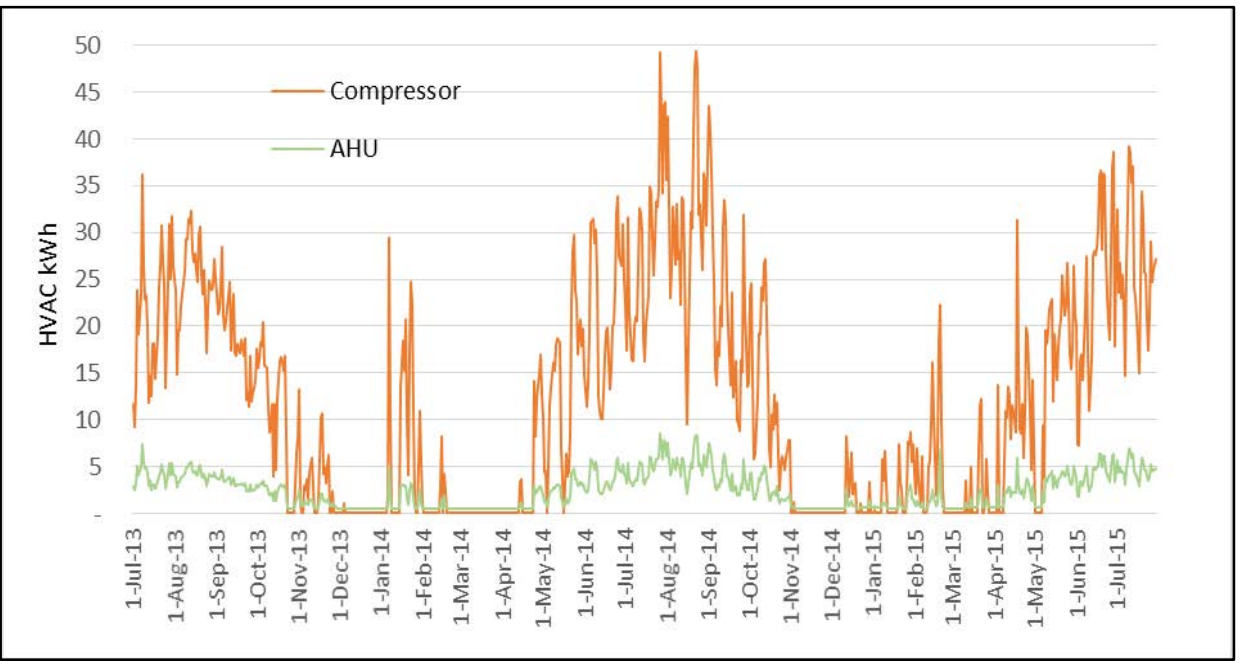

Figure 68. Compressor and air handling unit power from July 2013-July 2015 for Site 28

Because this household maintains a temperature of approximately $78^{\circ}-80^{\circ} \mathrm{F}$ during the hottest days, the data for the HVAC suggest a poorly functioning 4-ton air conditioner or a very large cooling load.

\subsubsection{Visual Plot of Cooling and Heating Against Outdoor Temperature During the Length of the Pre- and Post-Retrofit Periods and Regression Results}

A visual examination of plotted daily HVAC during a year-long period regressed against outdoor temperature (see Figure 69) suggests both winter and summer savings. Zeros are prior to the retrofit, and $1 \mathrm{~s}$ indicates post-retrofit observations. Air handling unit power is plotted at the 
bottom of the chart in brown triangles. The data also indicate an approximate $67^{\circ} \mathrm{F}$ balance point for the building.

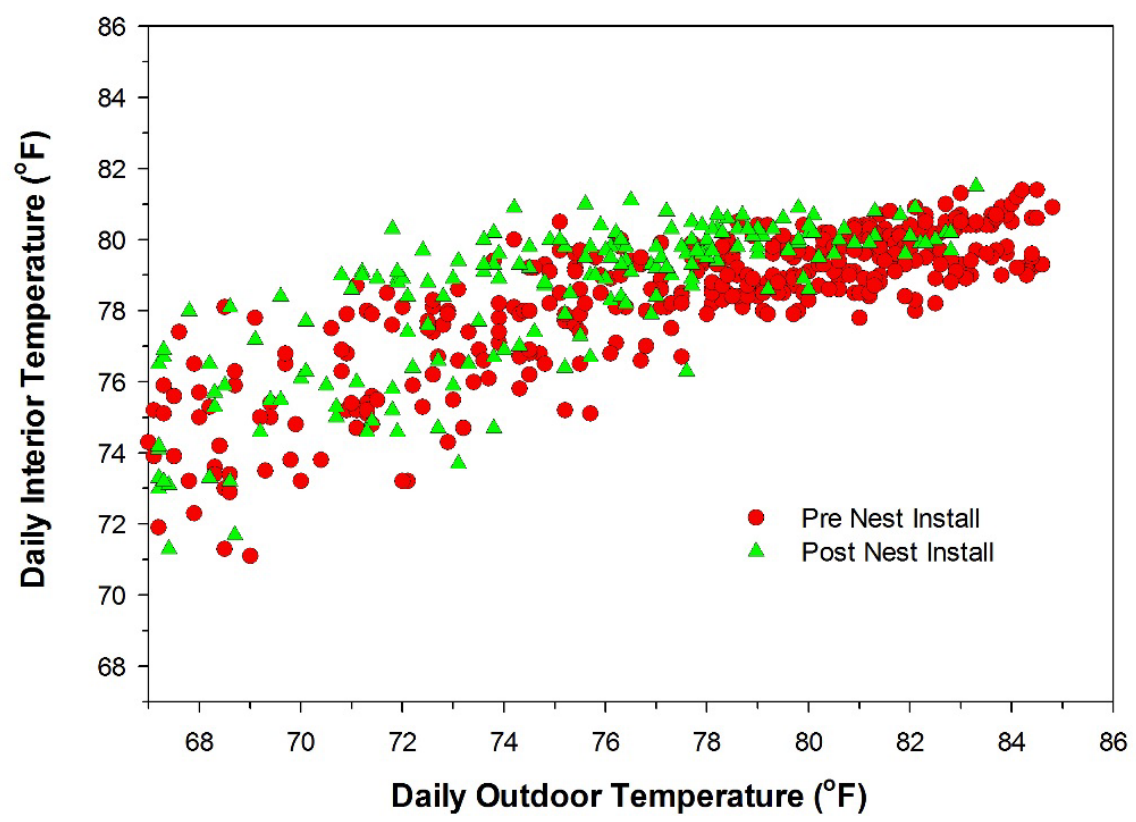

Figure 69. Daily HVAC kWh during the year-long period regressed against outdoor temperature at Site 28. Zeros are pre-retrofit period; 1s are post. Brown triangles show air handling unit power.

Site 28 cooling and heating regression results are provided in Figures 70 and 71, respectively.

\begin{tabular}{|c|c|c|c|c|c|c|}
\hline Source & SS & df & MS & \multirow{3}{*}{ 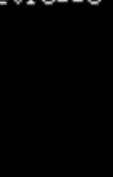 } & \multirow{3}{*}{ 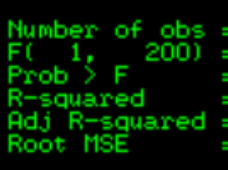 } & \multirow{3}{*}{$\begin{array}{l}=810.12 \\
=0.0000 \\
=0.8020 \\
=0.8010 \\
=7.1893\end{array}$} \\
\hline $\begin{array}{r}\text { Model } \\
\text { Resi dual }\end{array}$ & $\begin{array}{l}41871.7244 \\
10337.1927\end{array}$ & $\begin{array}{rr}1 & 418 \\
200 & 51.6\end{array}$ & $\begin{array}{l}41871.7244 \\
51.6859635\end{array}$ & & & \\
\hline Total & 52208.9171 & 201 & 259.745856 & & & \\
\hline huac & Coef. & Std. Err. & t & $P>$ it i & [95\% Conf. & Interval ] \\
\hline $\begin{array}{r}\operatorname{tamb} \\
\text { _cons }\end{array}$ & $\begin{array}{r}2.922017 \\
-206.5407\end{array}$ & $\begin{array}{r}1026617 \\
7.942728\end{array}$ & $\begin{array}{r}28.46 \\
-26.00\end{array}$ & $\begin{array}{l}0.000 \\
0.000\end{array}$ & $\begin{array}{l}2.719579 \\
-222.203\end{array}$ & $\begin{array}{r}3.124455 \\
-190.8785 \\
\end{array}$ \\
\hline \multicolumn{5}{|c|}{ reg huac tamb if tamb $>67$ \& jdate $\langle 2015196$ \& retro==1 } & \multirow{4}{*}{$\begin{array}{l}\text { Number of obs } \\
\text { F( 1; } 220) \\
\text { Prob } F \text { F } \\
\text { R-squared } \\
\text { Adj R-squared } \\
\text { Root MSE }\end{array}$} & \multirow{4}{*}{$\begin{array}{l}=502.50 \\
=0.0000 \\
=0.6955 \\
=0.6941 \\
=6.8802\end{array}$} \\
\hline Source & SS & df & MS & & & \\
\hline $\begin{array}{l}\text { Model } \\
\text { Resi dual }\end{array}$ & $\begin{array}{l}23786.8589 \\
10414.2032\end{array}$ & $\begin{array}{rr}1 & 2378 \\
220 & 47 .\end{array}$ & $\begin{array}{l}6.8589 \\
372874\end{array}$ & & & \\
\hline Total & 34201.0621 & 221 & 755937 & & & \\
\hline huac & Coef. & Std. Err. & $\mathrm{t}$ & $P>i t:$ & [95\% Conf. & Interval ] \\
\hline $\begin{array}{r}\text { tamb } \\
\text { _cons }\end{array}$ & $\begin{array}{r}2.366833 \\
-166.7016\end{array}$ & $\dot{8.055846}$ & $\begin{array}{r}22.42 \\
-20.72\end{array}$ & $\begin{array}{l}0.000 \\
0.000\end{array}$ & $\begin{array}{r}2.158746 \\
-182.5613\end{array}$ & $\begin{array}{r}2.57492 \\
-150.8418\end{array}$ \\
\hline
\end{tabular}

Figure 70. Cooling regression analysis for Site 28

Cooling for an $80^{\circ} \mathrm{F}$ summer day with the $67^{\circ} \mathrm{F}$ balance point was $27.2 \mathrm{kWh}$ /day pre-Nest installation and $22.6 \mathrm{kWh}$ post-Nest installation, for a $17 \%$ savings. 


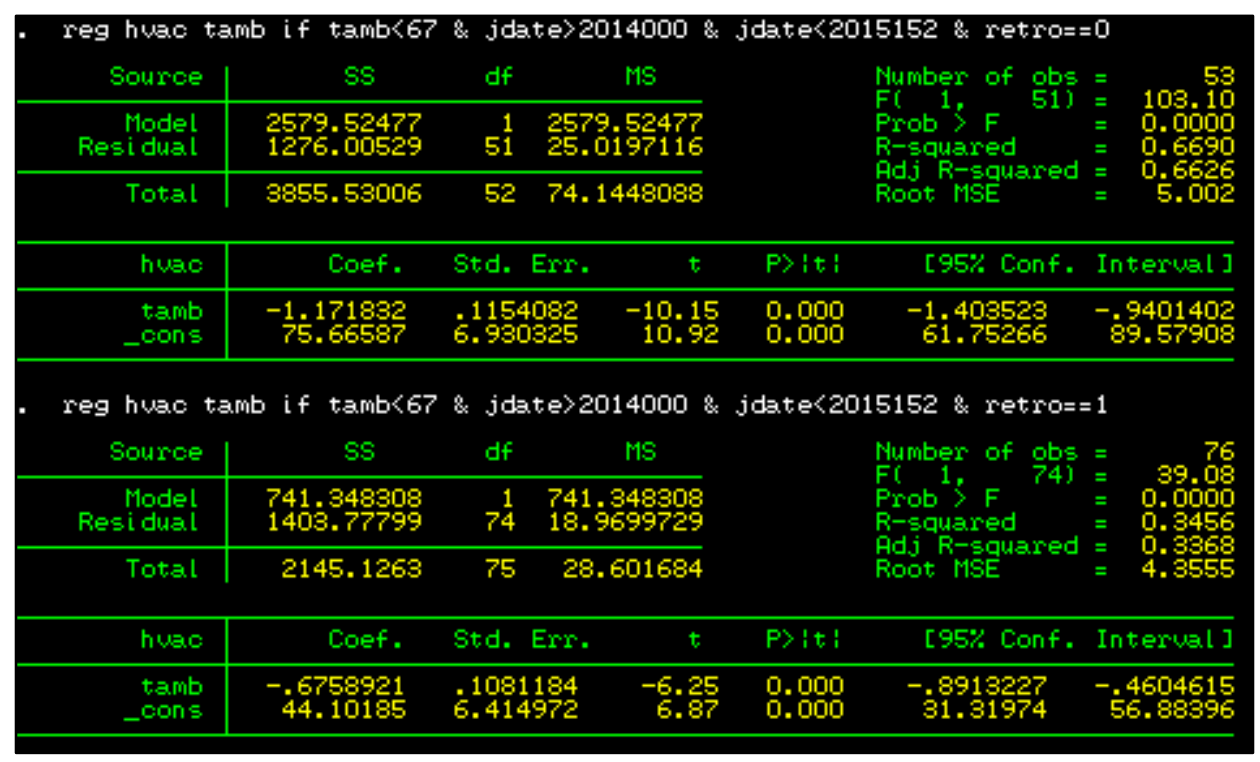

Figure 71. Heating regression analysis for Site 28

For the heat pump (which shows only modest strip heat use on cold days), the regression analysis indicated the following savings: pre-Nest installation: $17.1 \mathrm{kWh} @ 50^{\circ} \mathrm{F}$; post-Nest installation: $10.3 \mathrm{kWh}$, for $6.8 \mathrm{kWh}$ or $40 \%$ savings due to many days with no heating with the Nest, likely due to vacancy.

\subsubsection{Evaluation of Changes to Indoor Temperatures}

Figure 72 shows pre-retrofit (green circles) and post-retrofit (brown triangles) cooling interior temperatures regressed against outdoor ambient temperature. 


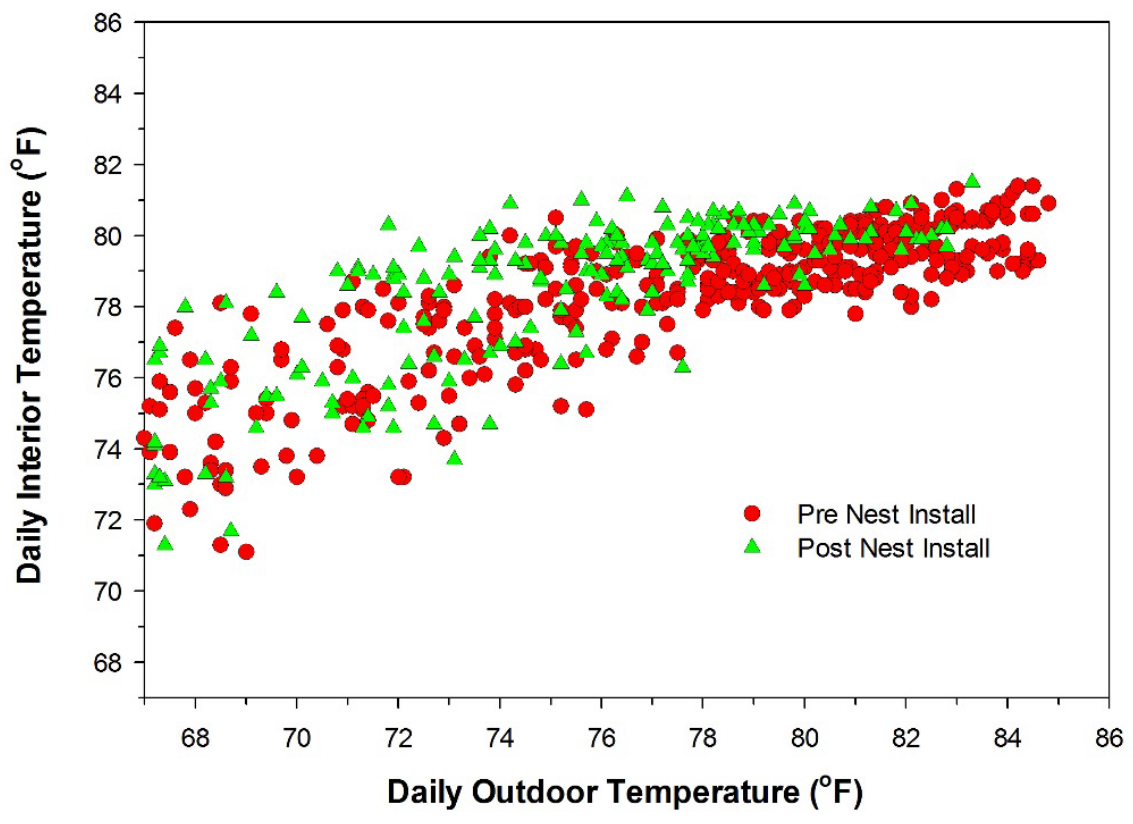

Figure 72. Pre- and post-retrofit cooling season interior temperatures regressed against outdoor temperatures for Site 28

A similar presentation of the data for heating in Figure 73 shows the Nest typically maintaining a lower interior daily temperature compared to the interior temperature in the pre-retrofit condition, which accounts for the savings. 
Site 28: Heating Season Temperatures: Pre and Post Nest Thermostat

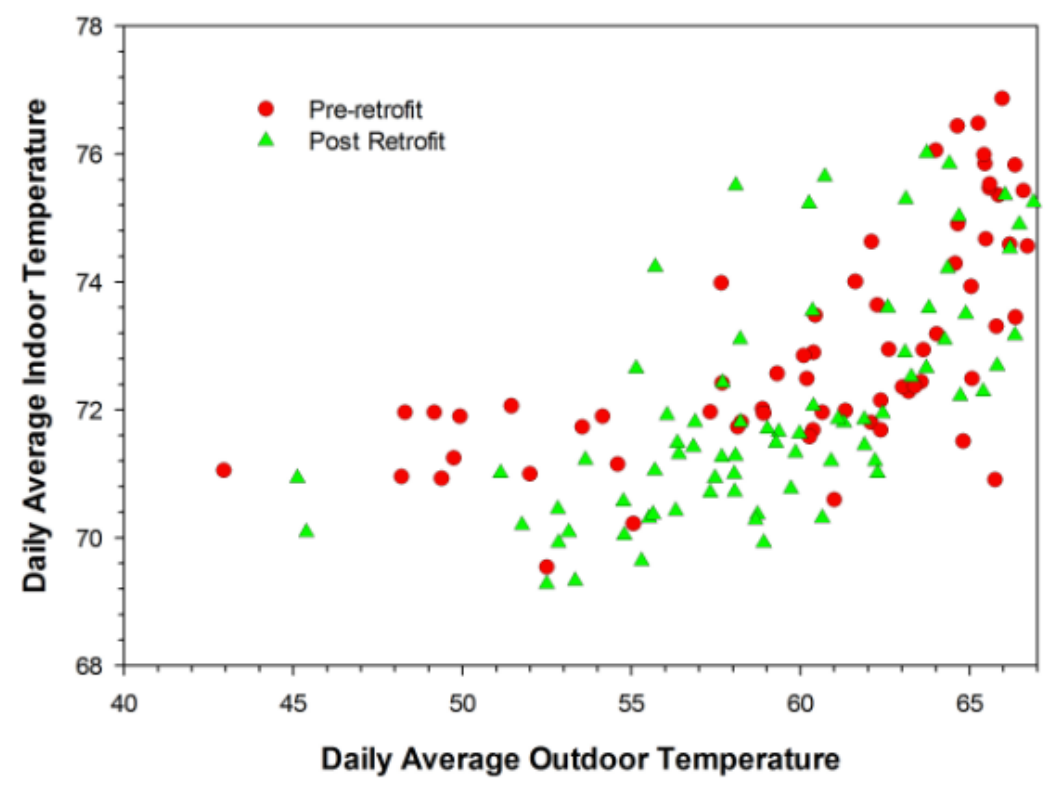

Figure 73. Pre- and post-retrofit heating season interior temperatures regressed against outdoor temperatures for Site 28

Although a complete analysis was not possible due to the need to retrieve portable humidity loggers from all of the sites, the pre- and post-retrofit measured $\mathrm{RH}$ in the Nest sites showed slightly lower humidity, as described below. Although this may seem surprising because the Nest is suspending AC run time when people are away, keep in mind that people themselves are the primary source of household internal humidity, and when homeowners return after being absent, long cooling system run times often take place.

\subsubsection{Evaluation of Influence on Interior Relative Humidity}

Interior RH impacts are always considered in Florida where cooling system operation is manipulated. In evaluating the impact of the Nest installations, 14 of the sites possessed complete measurements of RH by the thermostat both pre- and post-retrofit Nest installation for the entire year-long summer analysis periods. The average RH was 54.2\% (standard deviation $5.1 \%$ ) during the entire cooling season before the installation of the Nest and $53.9 \% \mathrm{RH}$ postinstallation ( standard deviation $=4.2 \%$ ). The medians pre- and post-retrofit were $55.0 \%$ and $54.1 \%$, respectively. Although slightly lower in the post-retrofit condition, we found no statistically meaningful difference in $\mathrm{RH}$ before or after the Nest installation either by t-test of means or by nonparametric Wilcoxon matched-pairs signed-ranks tests. This is not altogether surprising because although the Nest my reduce the time an $\mathrm{AC}$ is running when people are away, the breath and activities of the occupants form a major source of interior moisture that is not present in their absence; thus, emphasis of AC operation and run time when people are present is likely to slightly improve interior moisture control. Figure 74 shows the broadband temperature and RH measurement by a Nest thermostat. 


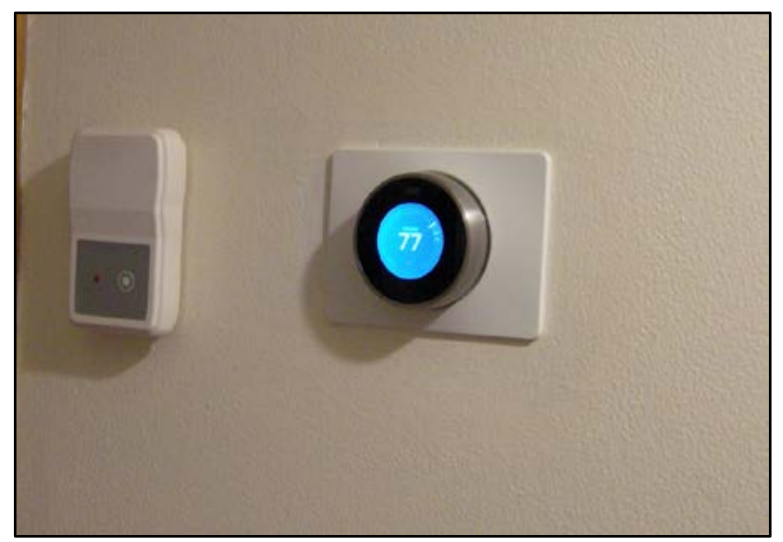

Figure 74. Installed Nest and broadband temperature and RH measurement by thermostat at Site 16

\subsection{Summary of Home-by-Home Analysis}

After completing the analysis for all 25 homes with the Nest and 2 homes with the Lyric, the results were summarized and combined into Table 35 . The data for the Lyric - two cases studies as well as the 3 Nests installed after supplemental MSHPs — cannot be evaluated in any meaningful fashion, which was anticipated within the experimental sequence involved.

However, the 22 Nest sites lend themselves to summary. Here, the average savings for cooling $\left(2.1 \mathrm{kWh} /\right.$ day at an outdoor daily temperature of $\left.80^{\circ} \mathrm{F}\right)$ was $9.3 \%$ but with a very high degree of variation. The median savings were $4.7 \%$. The standard deviation of the savings was 3.5 $\mathrm{kWh} /$ day - higher than the savings themselves. Indeed, the analysis showed that 7 out of 22 sites experienced negative savings, which appeared largely an artifact of pre-retrofit thermostat habits. In an aggregate distribution, for the sites that had positive savings, those savings were larger in magnitude than those experiencing negative savings. Not surprisingly, pre- and post-retrofit interior to outdoor temperature analysis revealed that sites without savings often maintained lower indoor temperatures in the post-Nest installation period. 
Table 35. Nest Thermostat Evaluations: Florida PDR Project 2013-2016

\begin{tabular}{|c|c|c|c|c|c|c|c|c|c|c|}
\hline $\begin{array}{l}\text { Site } \\
\text { No. }\end{array}$ & Install & $\begin{array}{l}\text { Balance } \\
\left.\text { Point ( }{ }^{\circ} \mathrm{F}\right)\end{array}$ & $\begin{array}{c}\text { Pre } \\
\text { (kWh/ } \\
\text { day) }\end{array}$ & $\begin{array}{c}\text { Post } \\
\text { (kWh/ } \\
\text { day) }\end{array}$ & $\begin{array}{c}\text { Delta } \\
\text { (kWh/ } \\
\text { day) }\end{array}$ & $\begin{array}{c}\text { Cool } \\
\text { Reduction } \\
(\%)\end{array}$ & $\begin{array}{c}\text { Pre } \\
\text { (kWh/ } \\
\text { day) }\end{array}$ & $\begin{array}{c}\text { Post } \\
\text { (kWh/ } \\
\text { day) }\end{array}$ & $\begin{array}{c}\text { Delta } \\
\text { (kWh/ } \\
\text { day) }\end{array}$ & $\begin{array}{c}\text { Heat } \\
\text { Reduction } \\
(\%)\end{array}$ \\
\hline & & & \multicolumn{4}{|c|}{ Cooling @ 80F } & \multicolumn{4}{|c|}{ Heating @ 50F } \\
\hline \multicolumn{11}{|c|}{ Nest Thermostat Evalautions } \\
\hline 4 & Sept. 3, 2014 & $65 / 65$ & 16.0 & 16.8 & -0.8 & $-5.0 \%$ & 9.0 & 8.2 & 0.8 & $8.9 \%$ \\
\hline 6 & Aug. 27, 2014 & $70 / 70$ & 8.3 & 7.7 & 0.6 & $7.2 \%$ & 12.3 & 9.1 & 3.2 & $26.0 \%$ \\
\hline 11 & Sept. 5, 2014 & $68 / 68$ & 25.0 & 24.0 & 1.0 & $4.0 \%$ & 22.0 & 19.1 & 2.9 & $13.2 \%$ \\
\hline 12 & July 10, 2015 & $65 / 65$ & 29.7 & 25.2 & 4.5 & $15.2 \%$ & & & & \\
\hline 15 & Oct. 10, 2014 & $70 / 70$ & 16.7 & 16.0 & 0.7 & $4.2 \%$ & 14.2 & 8.9 & 5.3 & $37.3 \%$ \\
\hline 17 & Sept. 10, 2014 & $70 / 65$ & 15.8 & 17.6 & -1.8 & $-11.4 \%$ & 7.7 & 6.9 & 0.8 & $10.4 \%$ \\
\hline 18 & Sept. 11, 2014 & $\mathrm{n} / \mathrm{a} / 67$ & 24.2 & 15.8 & 8.4 & $34.7 \%$ & & & & \\
\hline 21 & July 24, 2014 & $66 / 66$ & 29.0 & 20.4 & 8.6 & $29.7 \%$ & 19.9 & 33.2 & -13.3 & $-66.8 \%$ \\
\hline 22 & Sept. 6, 2014 & $69 / 69$ & 22.9 & 18.2 & 4.7 & $20.5 \%$ & & & & \\
\hline 28 & Sept. 12, 2014 & $67 / 67$ & 27.2 & 22.6 & 4.6 & $16.8 \%$ & 17.1 & 10.3 & 6.8 & $39.6 \%$ \\
\hline 29 & Aug. 20, 2014 & $68 / 68$ & 27.1 & 28.7 & -1.6 & $-5.9 \%$ & 16.9 & 10.6 & 6.3 & $37.3 \%$ \\
\hline 34 & Nov. 20, 2014 & $65 / 65$ & 16.1 & 14.2 & 1.9 & $11.8 \%$ & & & & \\
\hline 35 & Nov. 22, 2014 & $67 / 67$ & 35.1 & 36.1 & -1.0 & $-2.8 \%$ & 25.2 & 27.9 & -2.7 & $-10.7 \%$ \\
\hline 42 & Oct. 29, 2014 & $65 / 65$ & 17.3 & 19.9 & -2.6 & $-15.0 \%$ & 25.2 & 14.0 & 11.2 & $44.4 \%$ \\
\hline 45 & Nov. 20, 2014 & $68 / 68$ & 17.0 & 16.4 & 0.6 & $3.5 \%$ & & & & \\
\hline 47 & Oct. 30, 2014 & $66 / 66$ & 17.3 & 18.9 & -1.6 & $-9.2 \%$ & & & & \\
\hline 48 & Oct. 29, 2014 & $67 / 67$ & 24.7 & 25.2 & -0.5 & $-2.0 \%$ & 14.7 & 11.5 & 3.2 & $21.8 \%$ \\
\hline 50 & July 17, 2015 & $61 / 61$ & 30.4 & 24.5 & 5.9 & $19.4 \%$ & & & & \\
\hline 52 & Aug. 27, 2014 & $69 / 69$ & 18.0 & 17.1 & 0.9 & $5.0 \%$ & 5.4 & 18.1 & -12.7 & $-235.2 \%$ \\
\hline 56 & July 22, 2015 & $70 / 70$ & 25.9 & 21.0 & 4.9 & $18.9 \%$ & 42.7 & 45.7 & -3.0 & $-7.0 \%$ \\
\hline 58 & Aug. 25, 2014 & $63 / 69$ & 25.8 & 24.7 & 1.1 & $4.3 \%$ & 23.1 & 11.6 & 11.5 & $49.8 \%$ \\
\hline 59 & Sept. 12, 2014 & $63 / 67$ & 29.4 & 21.5 & 7.9 & $26.9 \%$ & 22.2 & 24.1 & -1.9 & $-8.6 \%$ \\
\hline 16 & July 29, 2015 & $60 / 65$ & 23.5 & 27.1 & -3.6 & $-15.3 \%$ & & & & \\
\hline 24 & July 20, 2015 & $60 / 60$ & 30.0 & 27.8 & 2.2 & $7.3 \%$ & & & & \\
\hline 27 & July 17, 2015 & $67 / 67$ & 35.3 & 39.8 & -4.5 & $-12.7 \%$ & & & & \\
\hline & Average & & 22.7 & 20.6 & 2.1 & $9.3 \%$ & 18.5 & 17.3 & 1.2 & $6.6 \%$ \\
\hline & Standard Devia & tion & 6.6 & & 3.5 & & 9.2 & & 7.3 & \\
\hline & Median & & 24.5 & 20.2 & 1.0 & $4.7 \%$ & 17.1 & 11.6 & 2.9 & $13.2 \%$ \\
\hline \multicolumn{11}{|c|}{ Lyric Thermostat Evaluations } \\
\hline 43 & Oct. 28, 2014 & $67 / 67$ & 20.6 & 24.0 & -3.4 & $-16.5 \%$ & 0.0 & 0.0 & 0.0 & $0.0 \%$ \\
\hline 44 & Nov. 19, 2014 & $67 / 67$ & 21.2 & 17.1 & 4.1 & $19.3 \%$ & 43.6 & 33.0 & 10.6 & $24.3 \%$ \\
\hline
\end{tabular}

Two of the group of three Nests that were installed with supplemental MSHPs in place (green text) showed negative savings, although these are novel HVAC configurations and cannot be considered as typical in the evaluation. 
On a site-by-site basis, the study found that preinstallation thermostat behavior and willingness to use available Nest features made a difference. For example, a site with a programmable thermostat that was not used cannot be expected to show savings, and those with low levels of vacancy cannot be expected to achieve much savings from the occupancy-sensing "away" function.

Heating savings from the Nest were also highly variable, particularly given the very short winter heating season in Florida. Average savings were $6.6 \%\left(1.2 \mathrm{kWh} /\right.$ day at $\left.50^{\circ} \mathrm{F}\right)$, although savings were even more variable than for cooling because some homes had heat pumps and others had electric resistance heating.

Although there was a great range in predicted savings among the Nest sites analyzed (-2.6-8.6 $\mathrm{kWh}$ /day for cooling energy and $-13.3-11.5 \mathrm{kWh} /$ day for heating energy), the average predicted savings for the Nests may provide insight into the economics of smart thermostat installation. Given its easy installation, the study assumed the Nest's retail cost of $\$ 250$ and no labor cost.

\subsubsection{Weather Normalization and Extension to Utility Service Territory}

To compute the Nest savings, the regressions developed in the foregoing analysis for each site were then applied to the weather data from the TMY observations for the identified representative Florida locations. The results were then weighted by utility customer weights for those regions to estimate a final savings for Nest-related cooling and heating in the overall PDR sample. Table 36 summarizes the evaluation.

Table 36. Weather-Normalized Nest Thermostat Projections: Florida PDR Project 2013-2016

\begin{tabular}{|c|c|c|c|c|c|c|c|c|c|c|}
\hline $\begin{array}{l}\text { Site } \\
\text { No. }\end{array}$ & Install & $\begin{array}{c}\text { Balance } \\
\text { Point } \\
\left({ }^{\circ} \mathrm{F}\right)\end{array}$ & $\begin{array}{c}\text { Pre- } \\
\text { (kWh/ } \\
\text { year) }\end{array}$ & $\begin{array}{l}\text { Post- } \\
\text { (kWh/ } \\
\text { year) }\end{array}$ & $\begin{array}{l}\text { Delta } \\
\text { (kWh/ } \\
\text { year) }\end{array}$ & $\begin{array}{c}\text { Cool } \\
\text { Reduction } \\
(\%)\end{array}$ & $\begin{array}{c}\text { Pre- } \\
\text { (kWh/ } \\
\text { year) }\end{array}$ & $\begin{array}{c}\text { Post- } \\
\text { (kWh/ } \\
\text { year) }\end{array}$ & $\begin{array}{c}\text { Delta } \\
\text { (kWh/ } \\
\text { year) }\end{array}$ & $\begin{array}{c}\text { Heat } \\
\text { Reduction } \\
(\%)\end{array}$ \\
\hline & & & \multicolumn{4}{|c|}{ Cooling } & \multicolumn{4}{|c|}{ Heating } \\
\hline \multicolumn{11}{|c|}{ Nest Thermostat Evalautions } \\
\hline 4 & Sept. 3, 2014 & $65 / 65$ & 3,975 & 4,048 & (73) & $-1.8 \%$ & 174 & 139 & 35 & $20.4 \%$ \\
\hline 6 & Aug. 27, 2014 & $70 / 70$ & 1,751 & 1,639 & 112 & $6.4 \%$ & 282 & 202 & 80 & $28.3 \%$ \\
\hline 11 & Sept. 5, 2014 & $68 / 68$ & 5,668 & 5,442 & 227 & $4.0 \%$ & 489 & 464 & 25 & $5.1 \%$ \\
\hline 12 & July 10, 2015 & $65 / 65$ & 8,340 & 7,097 & 1,243 & $14.9 \%$ & & & & \\
\hline 15 & Oct. 10, 2014 & $70 / 70$ & 3,682 & 3,474 & 208 & $5.7 \%$ & 383 & 226 & 157 & $41.1 \%$ \\
\hline 17 & $\begin{array}{c}\text { Sept. 10, } \\
2014\end{array}$ & $70 / 65$ & 3,611 & 4,075 & $(463)$ & $-12.8 \%$ & 221 & 193 & 28 & $12.5 \%$ \\
\hline 18 & $\begin{array}{c}\text { Sept. 11, } \\
2014\end{array}$ & NA/67 & 5,507 & 3,592 & 1,915 & $34.8 \%$ & & & & \\
\hline 21 & July 24, 2014 & $66 / 66$ & 6,868 & 4,999 & 1,869 & $27.2 \%$ & 377 & 536 & (159) & $-42.1 \%$ \\
\hline 22 & Sept. 6, 2014 & $69 / 69$ & 5,055 & 4,003 & 1,052 & $20.8 \%$ & & & & \\
\hline 28 & $\begin{array}{c}\text { Sept. 12, } \\
2014\end{array}$ & $67 / 67$ & 6,155 & 5,149 & 1,006 & $16.3 \%$ & 312 & 202 & 110 & $35.4 \%$ \\
\hline 29 & Aug. 20, 2014 & $68 / 68$ & 6,106 & 6,463 & (357) & $-5.8 \%$ & 353 & 222 & 131 & $37.1 \%$ \\
\hline 34 & Nov. 20, 2014 & $65 / 65$ & 3,727 & 3,263 & 464 & $12.4 \%$ & & & & \\
\hline 35 & Nov. 22, 2014 & $67 / 67$ & 8,435 & 8,422 & 13 & $0.1 \%$ & 600 & 656 & (56) & $-9.3 \%$ \\
\hline 42 & Oct. 29, 2014 & $65 / 65$ & 4,331 & 5,207 & $(876)$ & $-20.2 \%$ & 719 & 428 & 291 & $40.5 \%$ \\
\hline 45 & Nov. 20, 2014 & $68 / 68$ & 3,956 & 3,687 & 268 & $6.8 \%$ & & & & \\
\hline
\end{tabular}




\begin{tabular}{|c|c|c|c|c|c|c|c|c|c|c|}
\hline 47 & Oct. 30, 2014 & $66 / 66$ & 3,950 & 4,439 & (489) & $-12.4 \%$ & & & & \\
\hline 48 & Oct. 29, 2014 & $67 / 67$ & 5,736 & 5,972 & (236) & $-4.1 \%$ & 392 & 320 & 72 & $18.5 \%$ \\
\hline 50 & July 17, 2015 & $61 / 61$ & 8,000 & 6,253 & 1,747 & $21.8 \%$ & & & & \\
\hline 52 & Aug. 27, 2014 & $69 / 69$ & 753 & 706 & 47 & $6.2 \%$ & 142 & 386 & (244) & $-171.4 \%$ \\
\hline 56 & July 22, 2015 & 70/70 & 5,811 & 4,628 & 1,183 & $20.4 \%$ & 1,112 & 1,160 & (48) & $-4.3 \%$ \\
\hline 58 & Aug. 25, 2014 & $63 / 69$ & 5,716 & 5,505 & 212 & $3.7 \%$ & 292 & 146 & 146 & $50.1 \%$ \\
\hline 59 & $\begin{array}{c}\text { Sept. 12, } \\
2014\end{array}$ & $63 / 67$ & 6,834 & 4,952 & 1,882 & $27.5 \%$ & 307 & 290 & 17 & $5.6 \%$ \\
\hline 16 & July 29, 2015 & $60 / 65$ & 5,358 & 6,281 & (923) & $-17 \%$ & & & & \\
\hline 24 & July 20, 2015 & $60 / 60$ & 8,220 & 7,444 & 776 & $9 \%$ & & & & \\
\hline 27 & July 17, 2015 & $67 / 67$ & 9,035 & 10,447 & $(1,412)$ & $-16 \%$ & & & & \\
\hline \multicolumn{3}{|c|}{ Average } & 5,180 & 4,683 & 498 & $9.6 \%$ & 410 & 371 & 39 & $9.5 \%$ \\
\hline \multicolumn{3}{|c|}{ Standard Deviation } & 1,960 & & 851 & & 246 & & 131 & \\
\hline \multicolumn{3}{|c|}{ Median } & 5,588 & 4,790 & 219 & $6.3 \%$ & 353 & 290 & 35 & $18.5 \%$ \\
\hline
\end{tabular}

The results indicate an average $9.6 \%$ or $498 \mathrm{kWh} /$ year savings on cooling and $9.5 \%$ or 39 $\mathrm{kWh} /$ year with Florida's limited heating season, for total annual savings of $537 \mathrm{kWh}$ or $9.6 \%$. The median results for cooling were lower due to the log-normal shape of annual consumption (lots of homes with low to moderate energy use but with a long tail of high users) $6.3 \%$ (219 $\mathrm{kWh} /$ year). Median results for space heating were $18.5 \%$. Although there was a large difference between the mean and median for heating, the absolute savings numbers are quite small given Florida's limited heating needs $(35 \mathrm{kWh} /$ year $)$.

As described in the Phase I report (see Phased-Retrofits in Existing Homes in Florida Phase I: Shallow and Deep Retrofits by Parker et al. [2016]), the average annual cooling consumption in the untreated PDR sample was $5,880 \mathrm{kWh} .{ }^{18}$ The average estimated annual heating was 274 $\mathrm{kWh}$. The total HVAC consumption in the sample was estimated at 5,460 kWh compared to the total Nest estimated savings of $525 \mathrm{kWh}$.

Thus, a quick estimate for a total annual savings would indicate that $525 \mathrm{kWh}$ is approximately $\$ 60$ at $\$ 0.12 / \mathrm{kWh}$. Simple payback for the Nest installation in this example would be approximately 4 years with an annual rate of return 24\% - excellent for a low-cost retrofit measure. It is also attractive enough that future projects should consider installing smart thermostats as part of the simple utility shallow retrofit measures.

Although Nest evaluations in other U.S. regions showed annual savings of approximately $11 \%$ $15 \%$ (Nest 2015), the PDR-indicated savings level was somewhat lower in this study of Florida single-family homes. This is likely because of three reasons:

- Florida homes tend to have high thermal capacitance, with slab-on-grade floors and concrete masonry walls that respond slowly to thermostat changes.

\footnotetext{
${ }^{18} \mathrm{http} / / /$ fsec.ucf.edu/en/publications/pdf/fsec-cr-1991-14.pdf
} 
- Seasonal residents (approximately $4 \%$ of the state's population) were specifically excluded from the PDR sample. Because of long vacancy periods, such residents would likely experience higher savings rates.

- Florida single-family homeowners are older than average (many retirees) and have higher occupancy rates (spend more time at home). These circumstances result in less savings from thermostat changes compared to other demographic groups in other parts of the United States.

With that said, attached homes and rental homes in Florida have vacancy rates much higher $(13.2 \%)$ than other single-family homes (3.8\%) in this study (Mazur and Wilson 2011). This is at least partly due to older Florida residents who migrate seasonally - so-called snowbirds - and inflate the winter population by nearly 800,000 people, but they are largely gone during the ACintensive summer season (Smith and House 2006). These snowbirds may experience higher savings levels from smart thermostats even though they were not part of the evaluation. These higher savings levels could be expected because during the single-family analysis it was clear from a visual examination of the data that the Nest thermostat achieved significant savings during vacation or longer periods of vacancy, as shown in Figure 75.

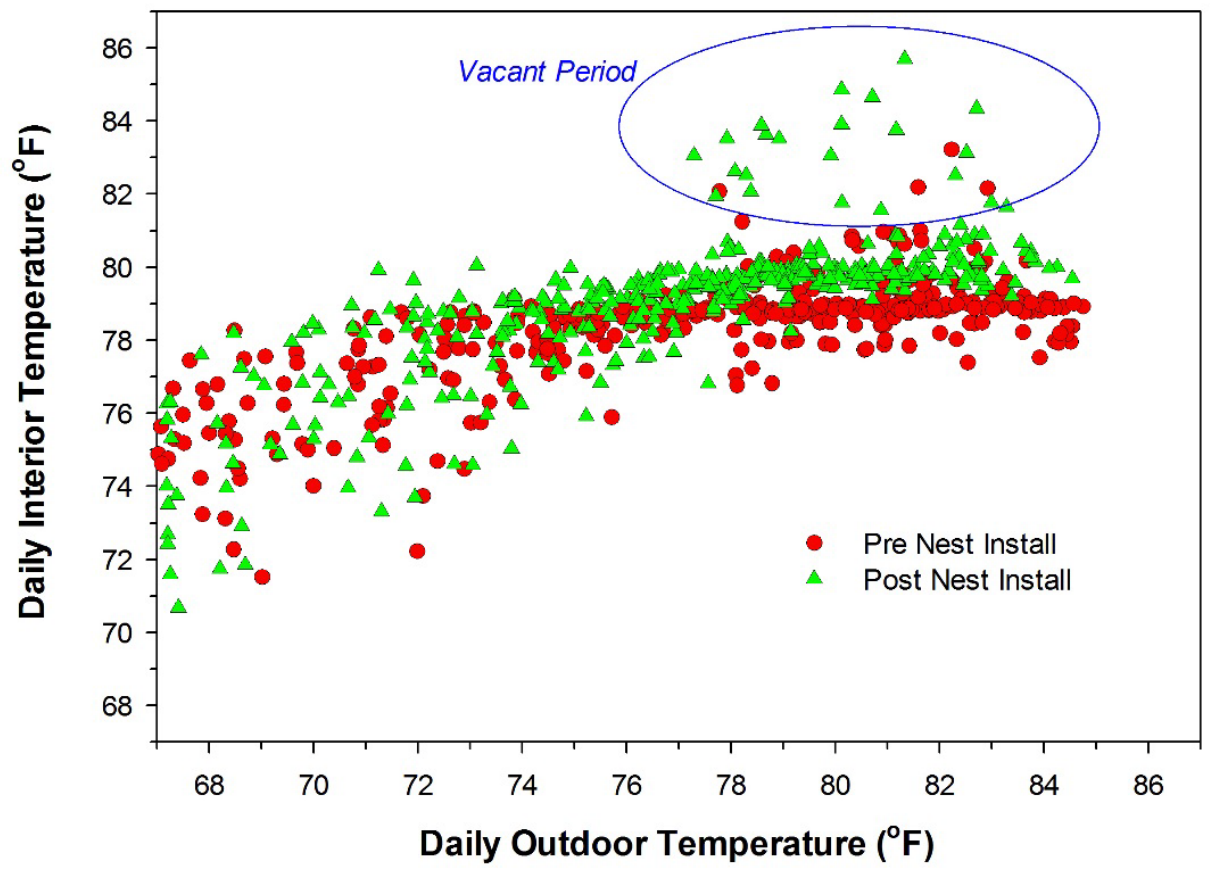

Figure 75. Pre- (green) and post-retrofit (brown) temperatures at Site 59 regressed against the daily outdoor temperature. Note the two-week period with higher set points with the Nest in the upper right.

Finally, it is important to note that FPL reported in its "Ask the Expert Energy Blog" by Patrick Agnew on January 26, 2016, its own internal monitoring evaluation of the smart thermostats, which showed very similar results with estimated annual cooling energy savings of 450 $\mathrm{kWh} / \mathrm{year}$. This is statistically indistinguishable from the results shown here. 


\subsubsection{Smart Thermostat Peak Reductions}

In an investigation of the impact of the Nest thermostats on peak summer and winter hours, HVAC power demand at the seasonal peak hours in 2014 were compared to those of $2015 .^{19}$ Modest reductions to utility coincident peak electrical demand were shown. ${ }^{20}$

Figure 76 compares the average demand during peak summer days for the 16 sites that received their Nest installation between the summer peak of July 28, 2014, (pre-retrofit) and the surrogate peak day on August 20, 2015, (post-retrofit), which shows an energy demand reduction of 0.18 $\mathrm{kWh}$ or $7 \% .^{21}$ The HVAC energy use reduction for the day was 7\%: $35.4 \mathrm{kWh}$ pre-retrofit and $28.3 \mathrm{kWh}$ post-retrofit.

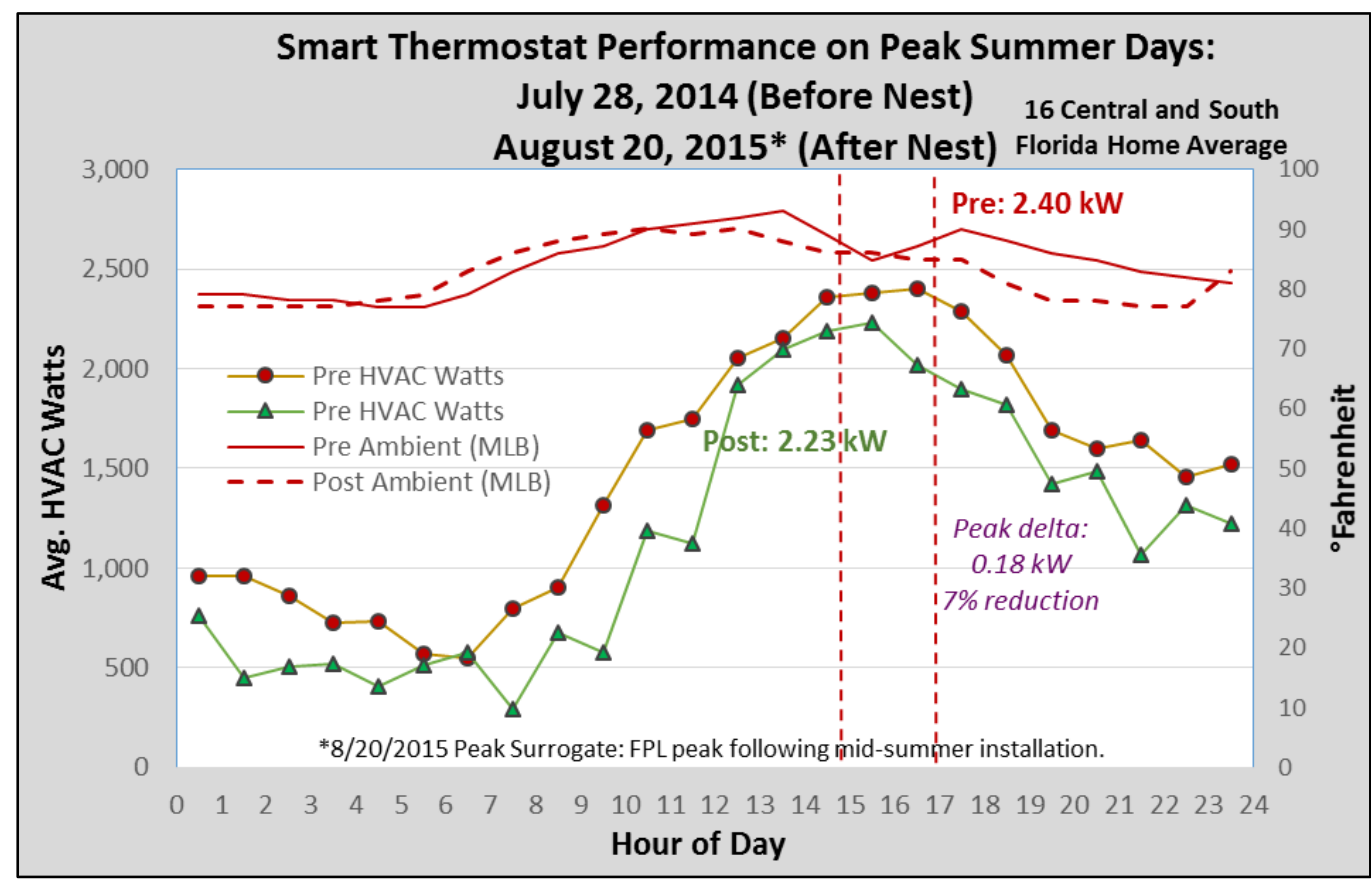

Figure 76. Summer peak: comparative analysis between pre- and post-retrofit demand on FPL's system peak summer days of 2014 and 2015

A similar analysis was performed for system peak winter days for 17 homes. Figure 77 compares the pre-retrofit peak winter day (January 23, 2014) to the post-retrofit peak winter day (February $20,2015)$, showing a reduction of $0.25 \mathrm{~kW}$ or $14 \%$ savings. Although the energy use for the day was much higher post-retrofit, up $40 \%-19.7 \mathrm{kWh}$ pre-retrofit and $27.6 \mathrm{kWh}$ post-retrofit - note that the post-retrofit day had much cooler temperatures midday: a full $6^{\circ} \mathrm{F}-7^{\circ} \mathrm{F}$ cooler than preretrofit.

\footnotetext{
${ }^{19}$ Given the date of the Nest installation, FPL's second highest summertime peak was necessary because not all 10 installations were complete before the summer 2015 peak of June 22. The slightly less hot day of August 20 was used instead.

${ }^{20}$ Note that these comparisons emphasize the changes shown from the retrofit that are coincident with the utility system peak demand rather than a comparison to the site-specific weather.

${ }^{21}$ Demand reduction is $0.39 \mathrm{~kW}$ or $16 \%$ between the typical peak hour of 4 p.m. to 5 p.m.
} 


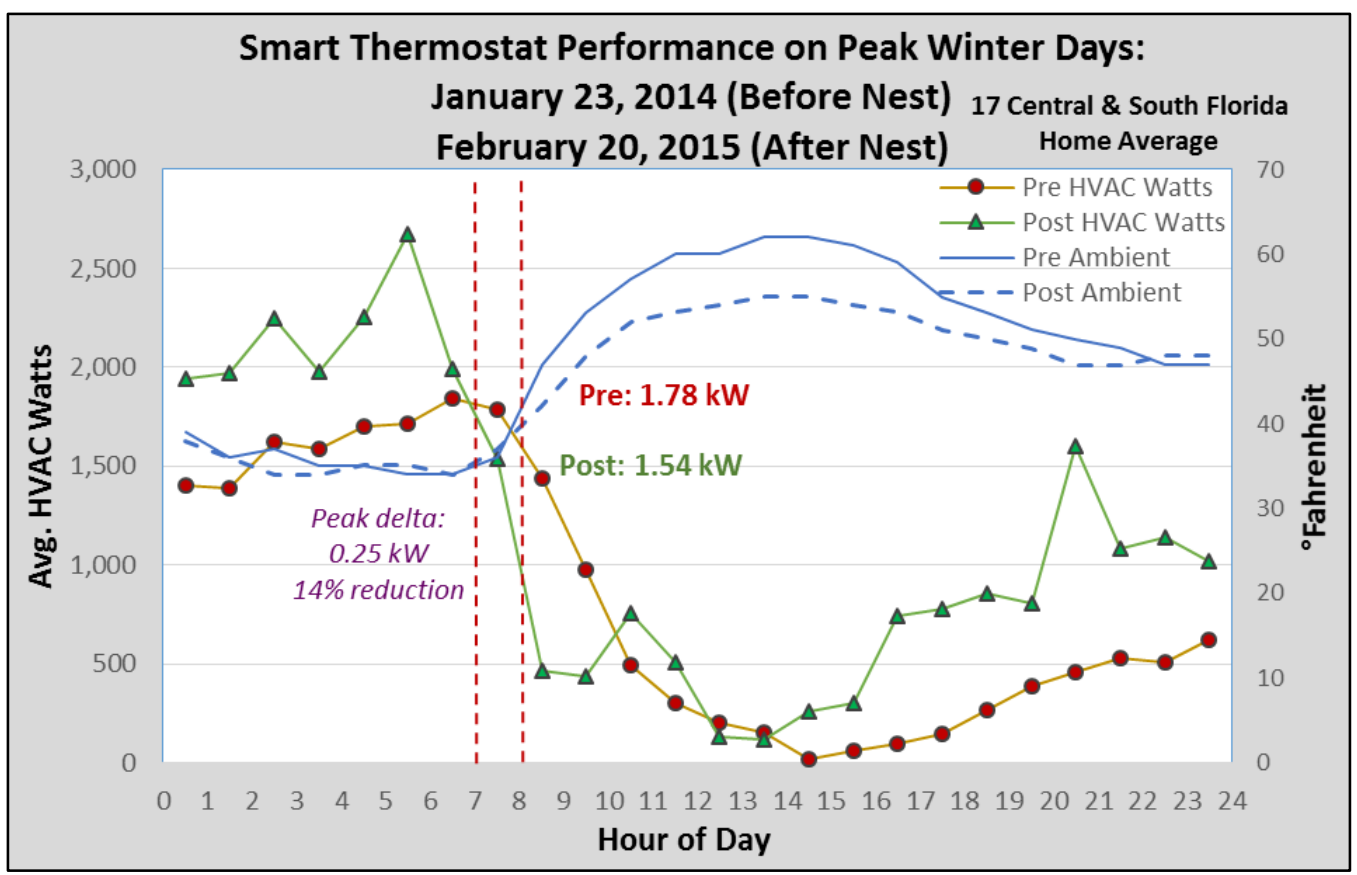

Figure 77. Winter peak: comparative analysis between pre- and post-retrofit demand on FPL's system peak winder day of 2014 and peak summer day in 2015 


\section{Evaluation of Heat Pump Clothes Dryers}

The electric resistance clothes dryers in eight homes were replaced with new Whirlpool HPCDs. The dryer model (WED99HED) is designed to be approximately 40\% more efficient than standard units and received an ENERGY STAR ${ }^{\circledR} 2014$ Emerging Technology Award. ${ }^{22}$ Table 37 provides occupancy information for the study homes and their existing washer and dryer makes and models.

Table 37. HPCD Site Characteristics

\begin{tabular}{|c|c|c|c|c|c|c|c|}
\hline $\begin{array}{l}\text { Site } \\
\text { ID }\end{array}$ & City & $\begin{array}{c}\text { No. of } \\
\text { Occupants }\end{array}$ & $\begin{array}{c}\text { Existing } \\
\text { Washer } \\
\text { Make }\end{array}$ & $\begin{array}{c}\text { Existing } \\
\text { Washer Model }\end{array}$ & $\begin{array}{c}\text { Existing } \\
\text { Dryer Make }\end{array}$ & $\begin{array}{c}\text { Existing } \\
\text { Dryer Model }\end{array}$ & $\begin{array}{c}\text { Appliance } \\
\text { Location }\end{array}$ \\
\hline 19 & Melbourne & 3 & $\begin{array}{c}\text { Whirlpool } \\
\text { Cabrio }\end{array}$ & WTW6200SW2 & Samsung & DV457 & Interior \\
\hline 22 & Cocoa Beach & 2 & Kenmore & 11020712990 & Whirlpool & 4WED5790SQ & Interior \\
\hline 25 & Melbourne & 2 & GE & S2100G2WW & $\begin{array}{c}\text { Alliance Speed } \\
\text { Queen }\end{array}$ & $\begin{array}{c}\text { ADE30RGS171 } \\
\text { TW01 }\end{array}$ & Interior \\
\hline 28 & Merritt Island & 2 & $\begin{array}{c}\text { Whirlpool } \\
\text { Duet }\end{array}$ & WFW9470WR01 & Whirlpool Duet & WED9750WRO & Exterior \\
\hline 52 & Cocoa & 2 & GE & WHRE5550K2WW & Kenmore & 96284100 & Interior \\
\hline 53 & Melbourne & 1 & GE & WWSR3090T2WW & GE & $\begin{array}{c}\text { DWXR473ET2 } \\
\text { WW }\end{array}$ & Interior \\
\hline 58 & Rockledge & 2 & GE & $\begin{array}{l}\text { HW, low water, } \\
5600 \mathrm{~W} 24 \mathrm{~A}\end{array}$ & GE & $\begin{array}{c}\text { GTDN500EM0 } \\
\text { WS }\end{array}$ & Interior \\
\hline 61 & Cocoa Beach & 2 & LG & WM2016CW & Whirlpool & WED9200SQ & Exterior \\
\hline
\end{tabular}

In a subsample of 45 PDR sites that did not receive a dryer retrofit during 2013, existing electric resistance clothes dryers were found to account for $3 \%$ or $741 \mathrm{kWh} /$ year $(2.03 \mathrm{kWh} /$ day $)$ of annual energy consumption. Table 38 shows the average monthly clothes dryer consumption with little variation from the annual average.

Table 38. Average Daily Baseline Dryer Energy by Month for 45-Home Sample for 2013

\begin{tabular}{lllllllllllll}
\hline & Jan. & Feb. & Mar. & Apr. & May & Jun. & Jul. & Aug. & Sept. & Oct. & Nov. & Dec. \\
\hline $\begin{array}{l}\text { Energy } \\
\text { (kWh/day) }\end{array}$ & 2.1 & 2.1 & 2.1 & 2.1 & 1.9 & 2.1 & 2.0 & 2.0 & 2.0 & 1.8 & 2.0 & 2.2 \\
\hline
\end{tabular}

The dryers were matched with a Whirlpool 4.5-cubic foot $\left(\mathrm{ft}^{3}\right)$ clothes washer (WFW95HED) that had an Energy Guide estimated annual electricity use of $109 \mathrm{kWh} /$ year (shown below in Figure 78) and a modified energy factor of 3.2.

\footnotetext{
${ }^{22}$ www.startribune.com/energy-guzzling-clothes-dryers-finally-get-more-eco-friendly/292379401/, https://www.energystar.gov/about/awards/energy-star-emerging-technology-award/2014-emerging-technologyaward-advanced-clothes-dryers
} 


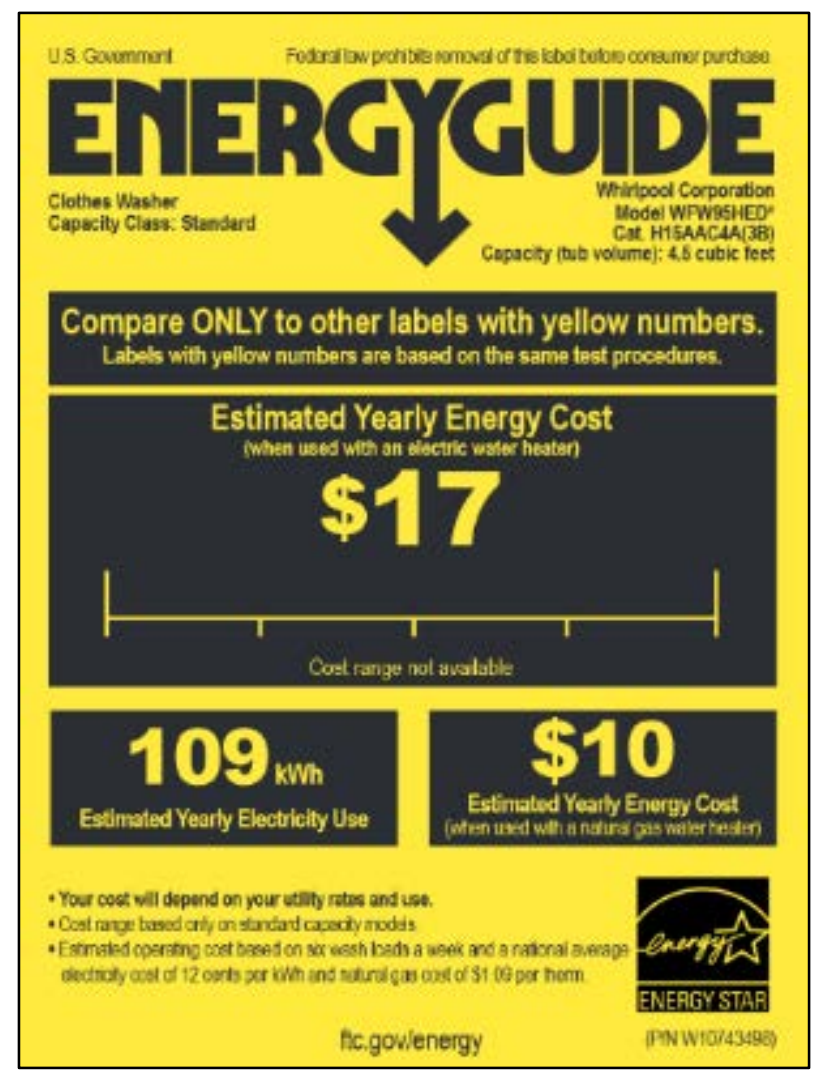

Figure 78. Energy Guide label for WFW95HED washer

The HPCD is a 7.3- $\mathrm{ft}^{3}$ condensing clothes dryer and is unvented, similar to high-efficiency European models. It has both a heat pump section and a supplemental electric heating element. There are three primary modes of dryer operation: eco mode, which mainly uses the heat pump but with longer drying times; balanced, which uses both the heat pump and electric resistance element operation to achieve faster drying times; and speed mode, which uses both the heat pump and electric resistance elements to dry in the fastest possible time.

The new clothes dryers and washers were installed in late May and early June 2015 in cooperation with the homeowners. Instructions were provided on efficient appliance operation. Seven of the PDR homes had conventional clothes washers and dryers that were then replaced by the efficient Whirlpool models (Figure 79). Site 19 had started in the PDR project with a standard washer and dryer and participated in the Phase I retrofits, including testing of the Samsung DV457 clothes dryer, which was shown to reduce consumption by $37 \%$ at this home. Significantly, the occupants of Site 19 do a very large volume of laundry, with baseline dryer energy use of approximately $8 \mathrm{kWh}$ /day (approximately 3,000 kWh/year). Replacing the Samsung unit with the new Whirlpool HPCD dryer was expected to further reduce their clothes drying energy. 


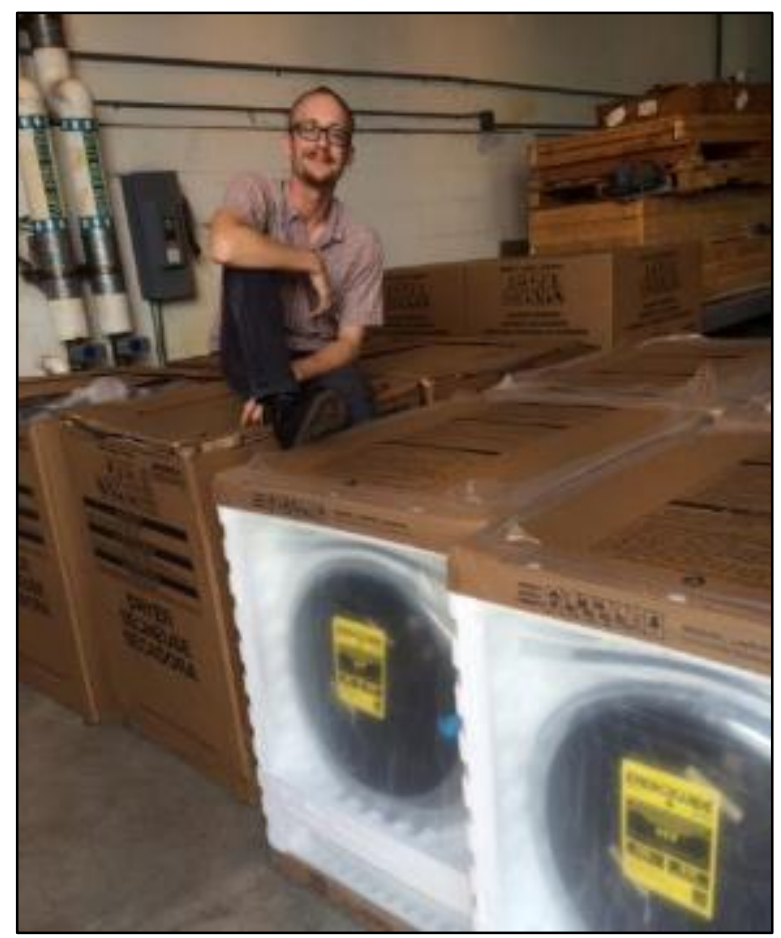

Figure 79. Building America Partnership for Improved Residential Construction team member Bryan Amos awaits shipment to one of the HPCD retrofit homes in the PDR project in May 2015

Measured baseline data began at the onset of dryer energy monitoring, generally from AugustSeptember $2014^{23}$ through the installation date for each washer/ HPCD pair, which occurred during May-June 2015. The post-installation period data were from the installation date through early February 2016. ${ }^{24}$ Although it was less than 1 full year, the 8-9-month baseline and study periods were deemed acceptable because evaluations of plotted clothes dryer data at each site revealed little in the way of time-of-year seasonality (there was a strong time-of-day element for clothes drying at each site), and each household also showed periodicity relative to the preferred time to do laundry: once every other day, each weekend, or even every day. Figure 80 shows the time-series data for Site 25 from January 2014-December 2015 with the daily clothes dryer demand plotted as well as the monthly summed clothes dryer energy. The timing and effect of the HPCD retrofit is clear in the data, with measured clothes dryer electricity falling by more than half.

\footnotetext{
${ }^{23}$ One site's data did not start collection until early December 2014.

${ }^{24}$ One site's homeowners moved out 30 days after HPCD installation. Although data was collected with the new homeowners, analysis for this site is based on the 1 month the original owners spent with the HPCD.
} 


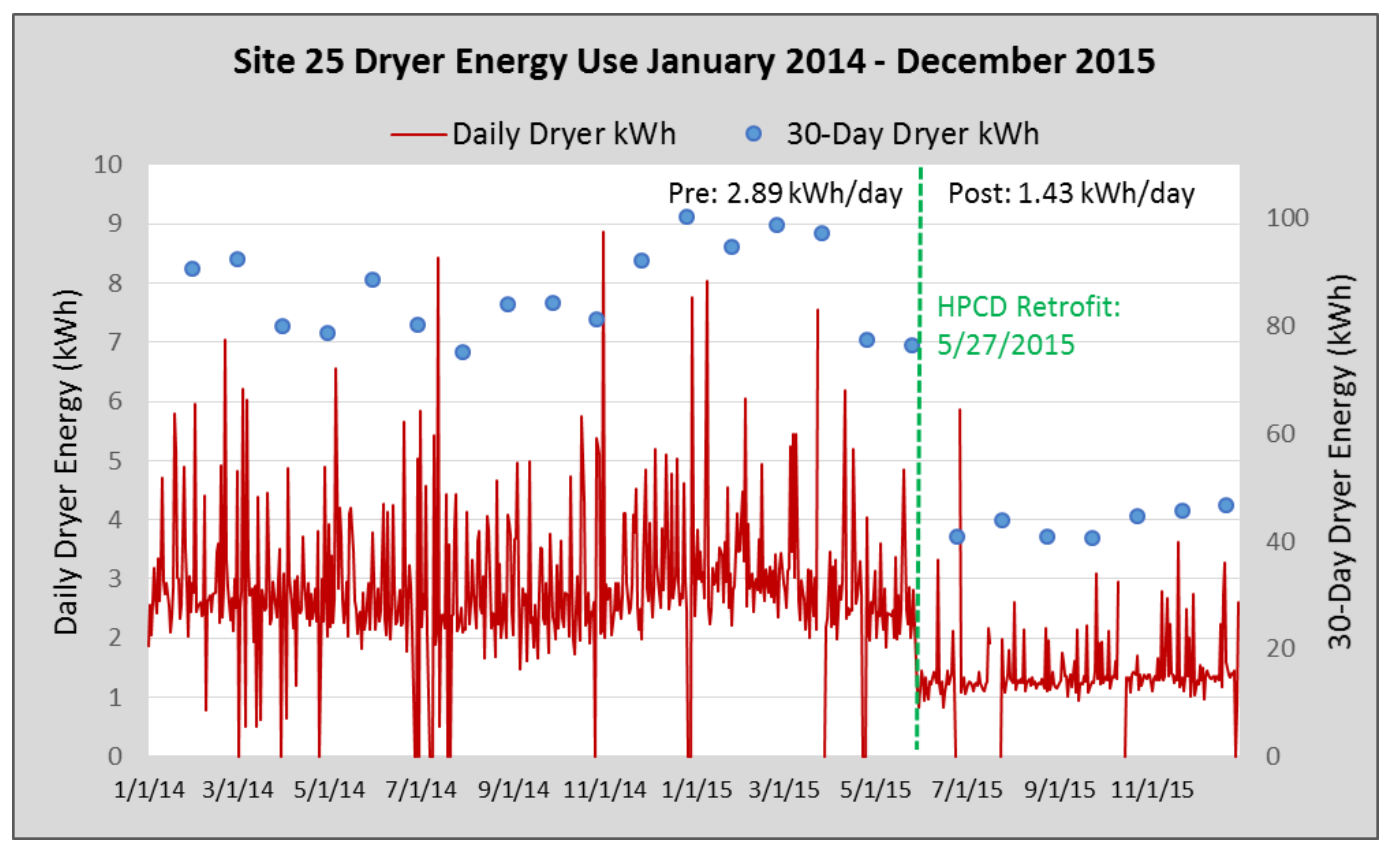

Figure 80. Time series for clothes dryer energy at Site 25

Table 39 shows the measured data in the pre- and post-installation periods for each site. Washer energy (which is typically quite modest) was not collected in the baseline period and therefore not evaluated. Note, too, that the savings level for clothes drying may reflect not only the efficiency of the clothes dryer but also of the clothes washer in reducing the amount of moisture left in the clothes to be dried.

Table 39. Summary HPCD Retrofits

\begin{tabular}{|c|c|c|c|c|c|c|c|c|c|}
\hline \multirow[b]{2}{*}{ Interior } & \multirow[b]{2}{*}{$\begin{array}{l}\text { Site } \\
\text { No. }\end{array}$} & \multirow[b]{2}{*}{$\begin{array}{c}\text { Install } \\
\text { Date }\end{array}$} & \multicolumn{2}{|c|}{ Pre- (2014-2015) } & \multicolumn{2}{|c|}{ Post- (2015-2016) } & \multicolumn{2}{|c|}{ Savings } & \multirow[b]{2}{*}{ People } \\
\hline & & & $\begin{array}{l}\text { Daily } \\
\text { (kWh) }\end{array}$ & $\begin{array}{l}\text { Annual } \\
\text { (kWh) }\end{array}$ & $\begin{array}{l}\text { Daily } \\
\text { (kWh) }\end{array}$ & $\begin{array}{l}\text { Annual } \\
\text { (kWh) }\end{array}$ & $\begin{array}{l}\text { Annual } \\
\text { (kWh) }\end{array}$ & (\%) & \\
\hline$Y$ & 58 & May 14 & 1.41 & 513 & 1.24 & 453 & 60 & $11.7 \%$ & 2 \\
\hline$Y$ & 52 & May 26 & 1.44 & 527 & 0.84 & 308 & 219 & $41.6 \%$ & 2 \\
\hline$Y$ & 25 & May 27 & 2.94 & 1,073 & 1.42 & 518 & 555 & $51.7 \%$ & 2 \\
\hline $\mathrm{N}$ & 61 & May 28 & 1.32 & 483 & 0.98 & 359 & 124 & $25.6 \%$ & 2 \\
\hline $\mathrm{N}$ & 28 & June 1 & 2.44 & 890 & 1.86 & 679 & 211 & $23.8 \%$ & 2 \\
\hline$Y$ & 53 & June 1 & 2.41 & 878 & 0.67 & 245 & 633 & $72.1 \%$ & 2 \\
\hline$Y$ & $19^{a}$ & June 3 & 7.06 & 2,577 & 6.09 & 2,222 & 355 & $13.8 \%$ & 3 \\
\hline$Y$ & 22 & June 5 & 1.66 & 606 & 0.81 & 297 & 309 & $51.0 \%$ & 2 \\
\hline Average & & & 2.59 & 944 & 1.74 & 635 & 308 & $36.4 \%$ & 2.3 \\
\hline Median & & & 2.03 & 742 & 1.11 & 406 & 264 & $33.6 \%$ & 2 \\
\hline
\end{tabular}

a January 1, 2013-November 17, 2013: standard dryer used $8.30 \mathrm{kWh} /$ day. Occupancy increased from two to three people toward the end of the pre-retrofit, and the three-person occupancy was maintained for the post-retrofit period; thus, savings results are conservative. 
Median energy savings in the pilot demonstration were estimated at $33.6 \%(264 \mathrm{kWh} /$ year or $0.72 \mathrm{kWh} /$ day) of median baseline consumption and average savings at $36.4 \%$ (308 $\mathrm{kWh} /$ year or $0.85 \mathrm{kWh} /$ day). Savings results at two sites are noteworthy. The savings for Site 19 would be $27 \%$ if based on the baseline unit rather than the more efficient Samsung DV457 unit in operation in 2014, and the owners at Site 58 reported that they were not interested in using the eco mode and preferred the speed mode, which resulted in lower savings.

With predicted median annual savings of $264 \mathrm{kWh}(\$ 32$ at $0.12 / \mathrm{kWh})$, the Whirlpool HPCD is not a cost-effective measure at its full cost of $\$ 948^{25}$ - a current advertised price for the appliance including delivery and installation. However, based on the assumption that consumers will purchase the HPCD only if they are in the market for a new dryer, an economic evaluation should consider the incremental cost for the HPCD over the consumer's standard choice (Dryer 2). If Dryer 2 costs approximately $\$ 700,{ }^{26}$ the incremental cost of $\$ 148$ will be paid back in approximately 4.5 years with a $22 \%$ annual rate of return. The economics appear less attractive, however, if the cost of the paired low-residual moisture washer is included. It is noteworthy, however, that matched washer-dryer pairs are most often installed in modern homes.

\subsection{Heat Pump Clothes Dryer Peak Reductions}

The HPCD impact on utility peak demand was also investigated. Figure 81 shows the average daily profile for seven of the eight HPCD sites pre-retrofit (2013) compared to post-retrofit (May/June 2015-February 2016). ${ }^{27}$ Although this plot consists of annual or nearly annual data, as previously mentioned the seasonal variation is limited, thus this plot provides a good indication of the large potential demand reduction coincident with utility summer peak - which typically falls between the hours of $4 \mathrm{p} . \mathrm{m}$. and $5 \mathrm{pm}$. For the homes in this study, there was a post-retrofit demand reduction of $0.09 \mathrm{~kW} /$ day or $48 \%$ among these hours.

\footnotetext{
${ }^{25}$ The manufacturer's suggested retail price is $\$ 1,799$.

${ }^{26}$ The cost of the hypothetical Dryer 2 can vary greatly from one consumer to another. The payback and rate of return for the HPCD option improves with a more costly Dryer 2.

${ }^{27}$ Site 61 was not instrumented until mid-2014, and therefore it was excluded from the evaluation comparing 2013 to $2015-2016$.
} 


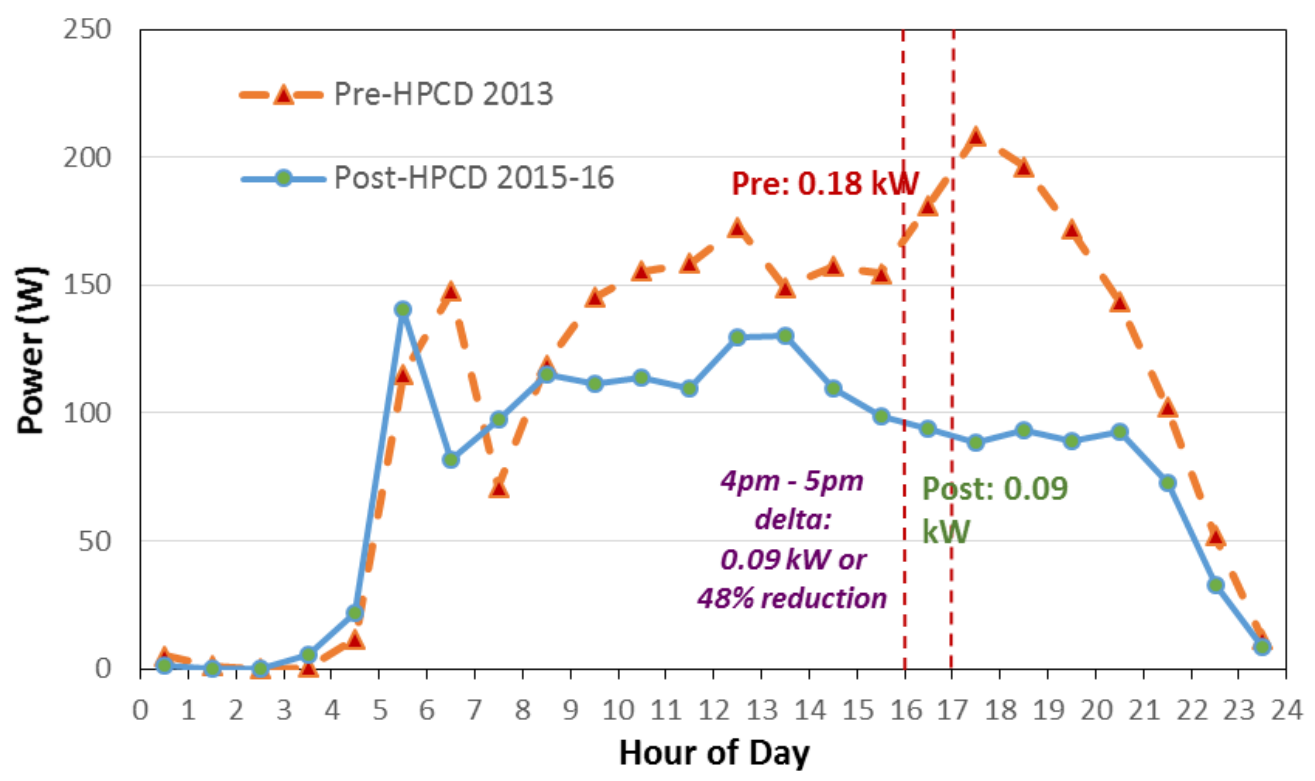

Figure 81. Comparative analysis between pre- and post-HPCD clothes drying demand

\subsection{Homeowner Complaints and Acceptability Issues}

Within the operation of the unvented HPCD, the condensed moisture from clothes is passed down a drain, and the waste heat from the heat pump and electric resistance elements of the system operation is released into the space. Although the amount of sensible heat released into the space from the nonventing HPCD was expected to be modest given the increased efficiency of the unit, the actual experience showed that a very significant quantity of sensible heat was released - more than the comparable amount of heat released to the interior from the conventional electric resistance vented clothes dryer. Figure 82 plots the temperature measured inside the laundry room at Site 25 a few weeks before and after the installation of the new unvented HPCD installed on May 27, 2015. Site 25 provides a particularly telling illustration of the issue given their regular, daily clothes washing. Pre-retrofit, the temperature during appliance operation rose from approximately $80^{\circ} \mathrm{F}$ to $83^{\circ} \mathrm{F}-84^{\circ} \mathrm{F}$; however, post-HPCD dryer installation, the utility room temperature frequently exceeded $95^{\circ} \mathrm{F}$ and nearly approached $100^{\circ} \mathrm{F}$. This is exceedingly uncomfortable, particularly because many clothes dryers in Florida are located in utility rooms in an effort to make the laundry operation a less onerous duty. Ambient moisture levels also varied somewhat, with slightly elevated room dew point temperatures coincidental with the room dry bulb temperature spikes associated with dryer operation. 


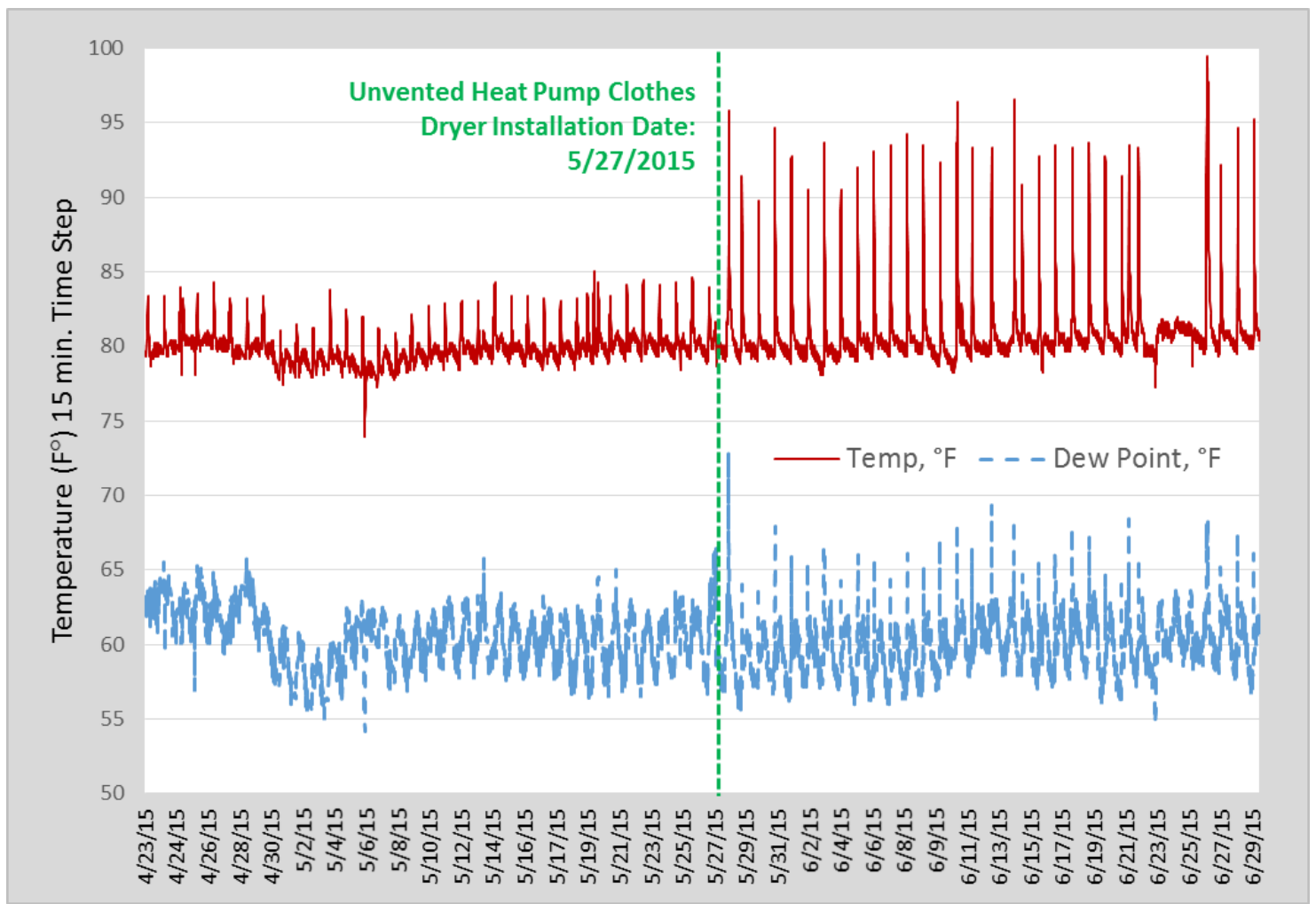

Figure 82. Laundry room dry bulb and dew point temperatures pre- and post-unvented heat pump clothes dryer installation for Site 25

Among the full sample of PDR project homes, approximately $70 \%$ had clothes dryers inside the conditioned space when audited - a value that likely reflects conditions in Florida for existing homes. In lieu of additional data, there would be no reason not to believe that this number does not reflect statewide conditions. In particular, the PDR sample excludes homes built after 2006, where almost all are located inside the conditioned space, so the number of homes with clothes dryers in the conditioned space could be higher. Among the eight HPCD retrofit sites, six have their clothes dryers located in interior utility rooms. It is also likely that operation of the interior HPCD may have led to increased space-cooling energy at the homes, but time did not allow for this analysis.

Notably, four other sites complained of both noise and excessive heat during system operation (sites 19, 53, 58, and 61). Such issues, particularly excess heat release, could limit the adoption of the technology in hot-humid Florida where homeowners are very much heat-averse. An HPCD vented to the outside is much more likely to be popular in this climate. Meanwhile, the researchers shared the findings with Whirlpool, and the manufacturer is reportedly looking into several modifications to mitigate the excessive heat issue. 


\section{Evaluation of Variable-Speed Pool Pump}

Existing pool pumps were replaced with VSPPs in five retrofit homes (Table 40). Energy and demand savings were calculated using 6 months of post-retrofit data and are evaluated for each site below.

Table 40. VSPP Site Characteristics

\begin{tabular}{ccccc}
\hline $\begin{array}{c}\text { Site } \\
\text { No. }\end{array}$ & City & $\begin{array}{c}\text { No. of } \\
\text { Occupants }\end{array}$ & $\begin{array}{c}\text { Pool Size } \\
\text { (gal.) }\end{array}$ & $\begin{array}{c}\text { Original Pump } \\
\text { (hp) }\end{array}$ \\
\hline $\mathbf{1 3}$ & Merritt Island & 2 & 15,000 & 1 \\
\hline $\mathbf{2 8}$ & Merritt Island & 2 & 18,000 & 1 \\
\hline $\mathbf{4 1}$ & Bonita Springs & 2 & 12,000 & 2 \\
\hline $\mathbf{4 4}$ & Naples & 2 & 14,000 & 1.5 \\
\hline $\mathbf{5 0}$ & Melbourne & 4 & 14,000 & $0.25 / 1.5$ (two-speed) \\
\hline
\end{tabular}

The tables and figures for each site include all measured energy data during the entire pre- and post-retrofit periods. Plots represent an average daily energy profile during the entire measurement period rather than an actual day. Run-time hours/day are averages calculated during each period to provide a comparison of equivalent run time at the average peak power draw-essentially the actual run times for single-speed pumps and a representation of equivalent run time (at peak) for the VSPPs. Actual run times of the VSPPs (at all speeds) are noted in the narrative.

\subsection{Evaluation for Site 13}

Pre-retrofit monitoring of the 1-horsepower (hp) single-speed pump was conducted for 275 days (August 22, 2012-May 23, 2013). Run time during this period averaged 5.6 hours/day with an average draw of $1.66 \mathrm{~kW}$ for an average daily energy use of $9.3 \mathrm{kWh}$, as shown in Table 41 . Run time of the single-speed pump was reduced to 5.5 hours/day during the shallow retrofit, resulting in a $5 \%$ measured savings, with average daily energy use reduced to $8.8 \mathrm{kWh}$ during a period of 598 days (May 25, 2013-January 12, 2015).

Table 41. Measured Pool Pump Energy for Site 13

\begin{tabular}{lcccccc}
\hline & $\begin{array}{c}\text { Monitored } \\
\text { (days) }\end{array}$ & $\begin{array}{c}\text { Run Time } \\
\text { (hours/day) }\end{array}$ & $\begin{array}{c}\text { Average } \\
\text { (kWh/day) }\end{array}$ & $\begin{array}{c}\text { Energy } \\
\text { Savings }\end{array}$ & $\begin{array}{c}\text { Average } \\
\text { kW Draw }\end{array}$ & $\begin{array}{c}\text { Demand } \\
\text { Savings }\end{array}$ \\
\hline 1-hp, one-speed pump & 275 & 5.6 & 9.3 & & 1.66 \\
Adjusted schedule & 598 & 5.5 & 8.8 & $5 \%$ & 1.60 & $3 \%$ \\
$\begin{array}{l}\text { New variable-speed } \\
\text { pump }\end{array}$ & 175 & 5.9 & 3.0 & $68 \%$ & 0.51 & $69 \%$ \\
\hline
\end{tabular}

Note: Electric demand ( $\mathrm{kW}$ draw) values are based on hourly energy use measurements and determined here by dividing average $\mathrm{kWh} /$ day by run-time hours.

A VSPP and new filter were installed on January 13, 2015. The post-retrofit evaluation period ending July 7, 2015, showed a $68 \%$ reduction in measured energy use and average hourly demand during the pre-retrofit scenario, as shown in Figure 83. The 3-hp Pentair VSPP ran an equivalent of 5.9 hours/day at the average peak draw of $0.51 \mathrm{~kW}$ with an average energy use of 
$3.0 \mathrm{kWh}$ /day during the 6-month post-retrofit period. When all hours of run time are included, the pump was active at various speeds for approximately 9 hours/day.

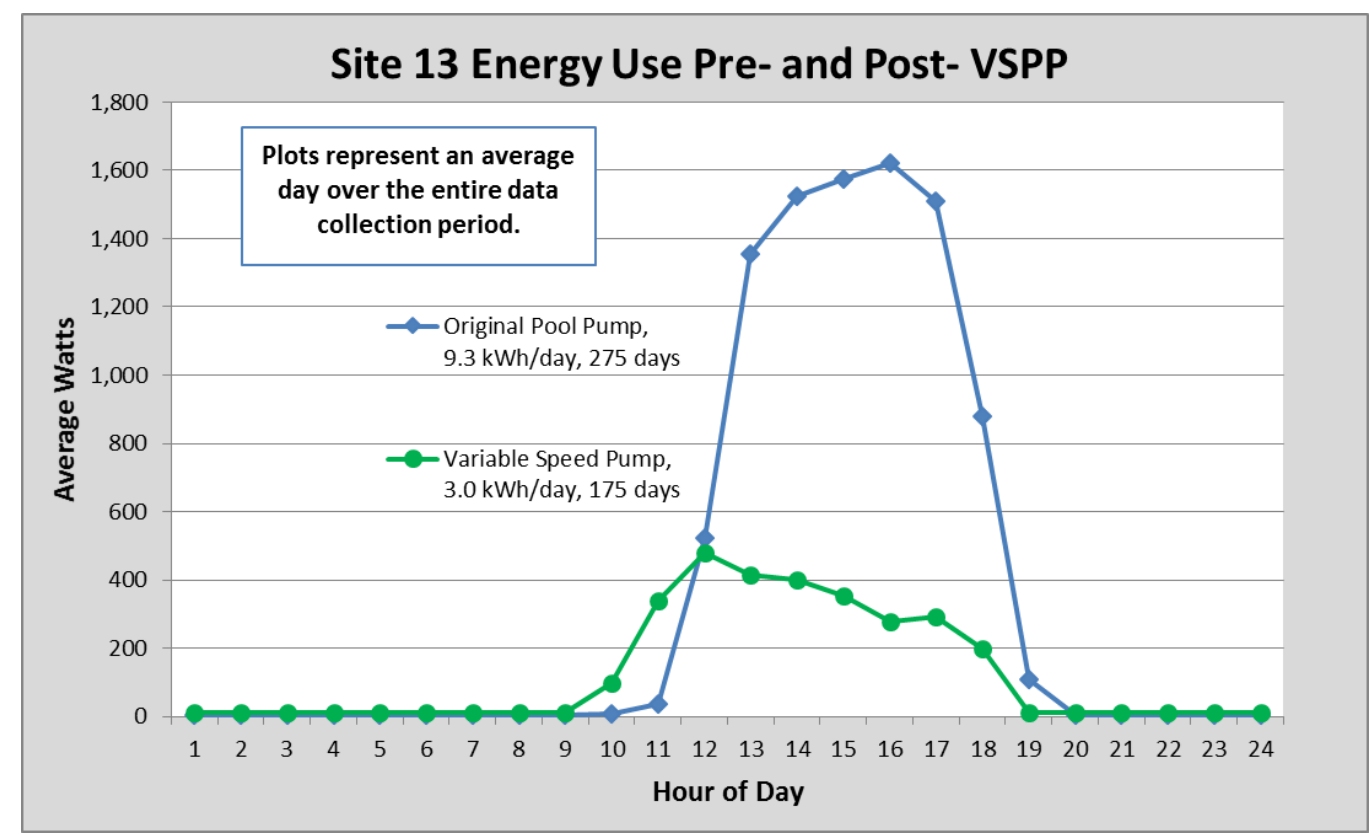

Figure 83. Average time-of-day pool pump demand at Site 13 as originally found (blue) and after VSPP retrofit (green)

\subsection{Evaluation of Site 28}

Energy savings at Site 28 were significantly less than those at the four other retrofit sites. This site had a different electrical configuration, with the pump powered by a single-phase $120-\mathrm{V}$ circuit rather than the typical 240-V circuit. Pre-retrofit monitoring of the 1-hp single-speed pump was conducted for 255 days (September 18, 2012-May 30, 2013). Run time during this period averaged 6.6 hours/ day with an average draw of $1.52 \mathrm{~kW}$ for an average daily energy use of $10.0 \mathrm{kWh}$ (Table 42). Run time of the single-speed pump was reduced to 5.8 hours/day during the shallow retrofit, resulting in a $9 \%$ measured savings with average daily energy use reduced to $9.1 \mathrm{kWh}$ during a period of 591 days (June 1, 2013-January 12, 2015).

Table 42. Measured Pool Pump Energy for Site 28

\begin{tabular}{lcccccc}
\hline & $\begin{array}{c}\text { Monitored } \\
\text { (days) }\end{array}$ & $\begin{array}{c}\text { Run Time } \\
\text { (hours/day) }\end{array}$ & $\begin{array}{c}\text { Average } \\
\text { (kWh/day) }\end{array}$ & $\begin{array}{c}\text { Energy } \\
\text { Savings }\end{array}$ & $\begin{array}{c}\text { Average } \\
\text { kW Draw }\end{array}$ & $\begin{array}{c}\text { Demand } \\
\text { Savings }\end{array}$ \\
\hline 1 hp, one-speed pump & 255 & 6.6 & 10.0 & & 1.52 & \\
Adjusted schedule & 591 & 5.8 & 9.1 & $9 \%$ & 1.56 & $-3 \%$ \\
$\begin{array}{l}\text { New variable-speed } \\
\text { pump }\end{array}$ & 165 & 4.0 & 5.1 & $49 \%$ & 1.30 & $14 \%$ \\
\hline
\end{tabular}

Note: Electric demand values are based on hourly energy use measurements and determined here by dividing average $\mathrm{kWh} /$ day by run-time hours.

A VSPP and new filter were installed on January 23, 2015. Six months of data collection ending July 7, 2015, show a 49\% average reduction in measured energy use compared to the pre-retrofit condition (Figure 84 ). The 1.5 -hp Pentair VSPP ran the equivalent of 4.0 hours/day at the 
average peak draw of $1.30 \mathrm{~kW}$ with an average energy use of $5.1 \mathrm{kWh} /$ day during the 6-month post-retrofit period. When all hours of run time are included, the pump was active at various speeds for approximately 9 hours/day.

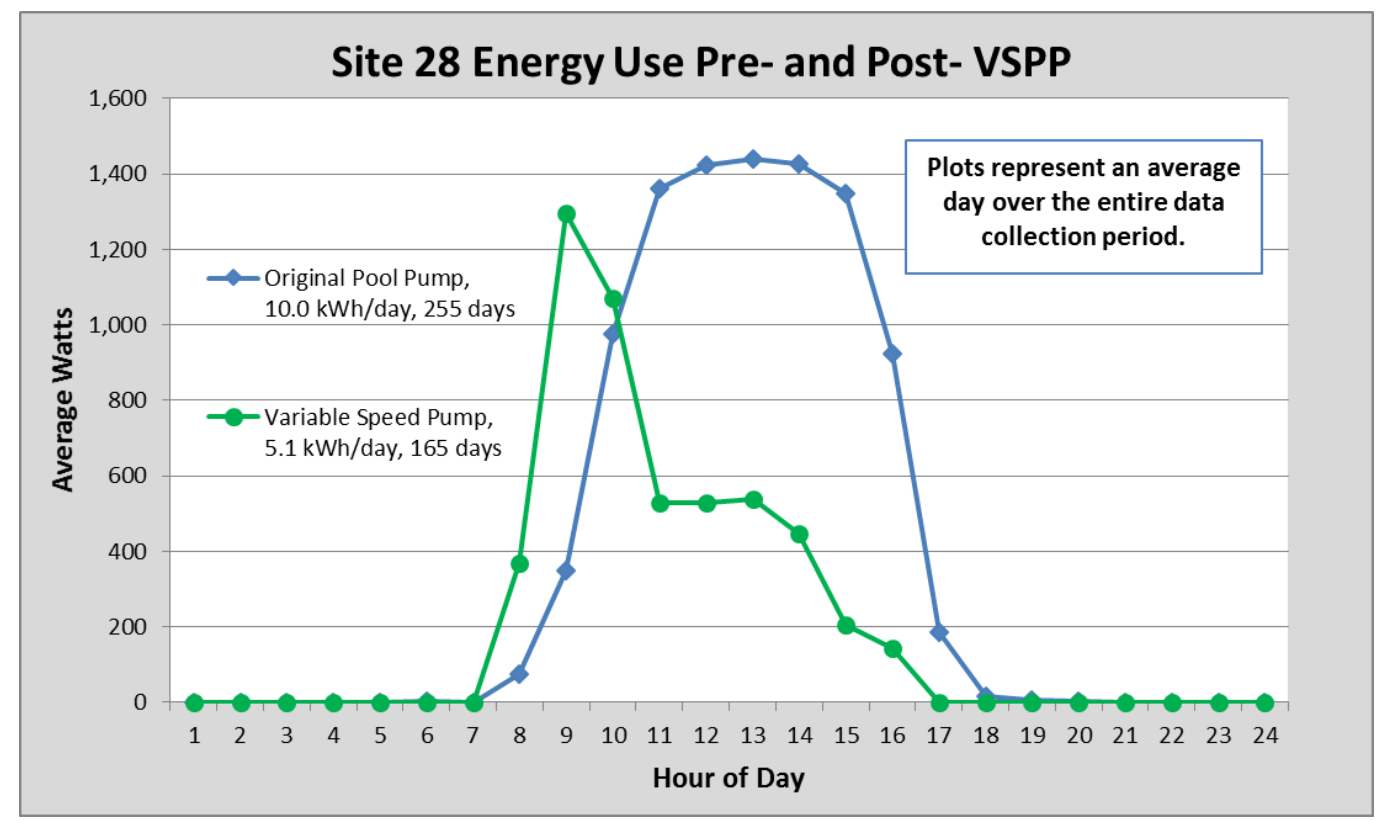

Figure 84. Average time-of-day pool pump demand at Site 28 as originally found (blue) and after VSPP retrofit (green)

\subsection{Evaluation of Site 50}

Pre-retrofit equipment at this site was a two-speed pump running at either 0.25 or $1.5 \mathrm{hp}$. This pump was monitored for 161 days from December 13, 2012-May 22, 2013, with an average run time of 7.3 hours/day primarily in high-speed mode and an average peak draw of $1.82 \mathrm{~kW}$ (Table 43). Average daily energy use was $13.3 \mathrm{kWh}$. Average run time of the two-speed pump was reduced to 7.2 hours/day during the shallow retrofit period, resulting in a $16 \%$ measured savings, with average daily energy use reduced to $11.1 \mathrm{kWh}$ during a period of 599 days (May 24, 2013January 12, 2015).

Table 43. Measured Pool Pump Energy for Site 50

\begin{tabular}{lcccccc}
\hline & $\begin{array}{c}\text { Monitored } \\
\text { (days) }\end{array}$ & $\begin{array}{c}\text { Run Time } \\
\text { (hours/day) }\end{array}$ & $\begin{array}{c}\text { Average } \\
\text { (kWh/day) }\end{array}$ & $\begin{array}{c}\text { Energy } \\
\text { Savings }\end{array}$ & $\begin{array}{c}\text { Average } \\
\text { kW Draw }\end{array}$ & $\begin{array}{c}\text { Demand } \\
\text { Savings }\end{array}$ \\
\hline $\begin{array}{l}\text { 0.25-1.5-hp two-speed } \\
\text { original pump }\end{array}$ & 161 & 7.3 & 13.3 & & 1.82 & \\
$\begin{array}{l}\text { Adjusted schedule } \\
\text { New variable-speed }\end{array}$ & 599 & 7.2 & 11.1 & $16 \%$ & 1.54 & $15 \%$ \\
pump & 175 & 5.9 & 3.1 & $77 \%$ & 0.52 & $71 \%$ \\
\hline
\end{tabular}

Note: Electric demand ( $\mathrm{kW}$ draw) values are based on hourly energy use measurements and are determined here by dividing average $\mathrm{kWh} /$ day by run-time hours.

A VSPP and new filter were installed on January 13, 2015. Data collected during the post-retrofit period ending July 7,2015 , showed a $77 \%$ reduction in measured energy use and $71 \%$ less 
average hourly demand compared to the pre-retrofit scenario, as shown in Figure 85. The 3-hp Pentair VSPP ran the equivalent of 5.9 hours/day at the average peak draw of $0.52 \mathrm{~kW}$ with an average energy use of $3.1 \mathrm{kWh} /$ day during the 6 -month post-retrofit period. When including all hours of run time, the pump was active at various speeds for approximately 12 hours/day.

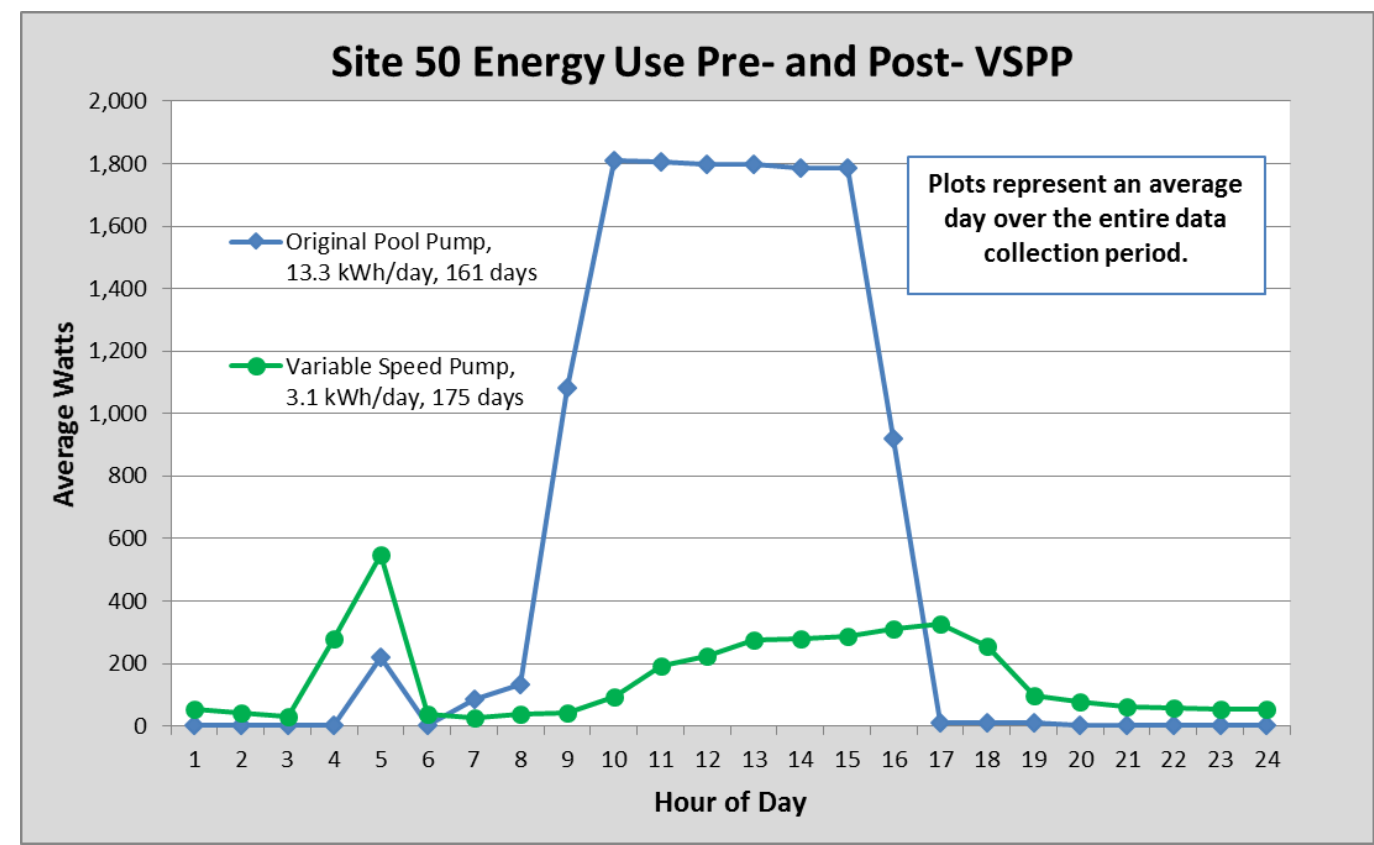

Figure 85. Average time-of-day pool pump demand at Site $\mathbf{5 0}$ as originally found (blue) and after VSPP retrofit (green)

\subsection{Evaluation of Site 41}

Pre-retrofit monitoring of the 2-hp single-speed pump was conducted for 219 days (November 11, 2012-June 17, 2013). Run time during this period averaged 4.5 hours/day with an average peak draw of $2.35 \mathrm{~kW}$, resulting in an average daily energy use of $10.7 \mathrm{kWh}$ (Table 44 ).

Measurements show a slight increase in run time during the 574-day shallow retrofit period (June 18, 2013-January 13, 2015) and almost identical energy use resulting in no ( $0 \%)$ measured savings.

Table 44. Measured Pool Pump Energy for Site 41

\begin{tabular}{lcccccc}
\hline & $\begin{array}{c}\text { Monitored } \\
\text { (days) }\end{array}$ & $\begin{array}{c}\text { Run Time } \\
\text { (hours/day) }\end{array}$ & $\begin{array}{c}\text { Average } \\
\text { (kWh/day) }\end{array}$ & $\begin{array}{c}\text { Energy } \\
\text { Savings }\end{array}$ & $\begin{array}{c}\text { Average } \\
\text { kW Draw }\end{array}$ & $\begin{array}{c}\text { Demand } \\
\text { Savings }\end{array}$ \\
\hline 2-hp, one-speed pump & 219 & 4.5 & 10.7 & & 2.35 & \\
Adjusted schedule & 574 & 4.7 & 10.6 & $0 \%$ & 2.24 & $5 \%$ \\
$\begin{array}{l}\text { New variable-speed } \\
\text { pump }\end{array}$ & 174 & 4.7 & 3.4 & $68 \%$ & 0.72 & $70 \%$ \\
\hline $\begin{array}{l}\text { Note: Electric demand (kW draw) values are based on hourly energy use measurements and determined here by } \\
\text { dividing average kWh/day by run-time hours. }\end{array}$
\end{tabular}

A VSPP and new filter were installed on January 14, 2015. The post-retrofit evaluation period, ending July 7,2015 , resulted in a $68 \%$ reduction in measured energy use and average hourly 
demand compared to the pre-retrofit scenario, as shown in Figure 86. The 3-hp Pentair VSPP ran the equivalent of 4.7 hours/day at the average peak draw of $0.72 \mathrm{~kW}$ with an average energy use of $3.4 \mathrm{kWh}$ /day during the 6-month post-retrofit period. When hours of run time are included, the pump was active at various speeds for approximately 7 hours/day.

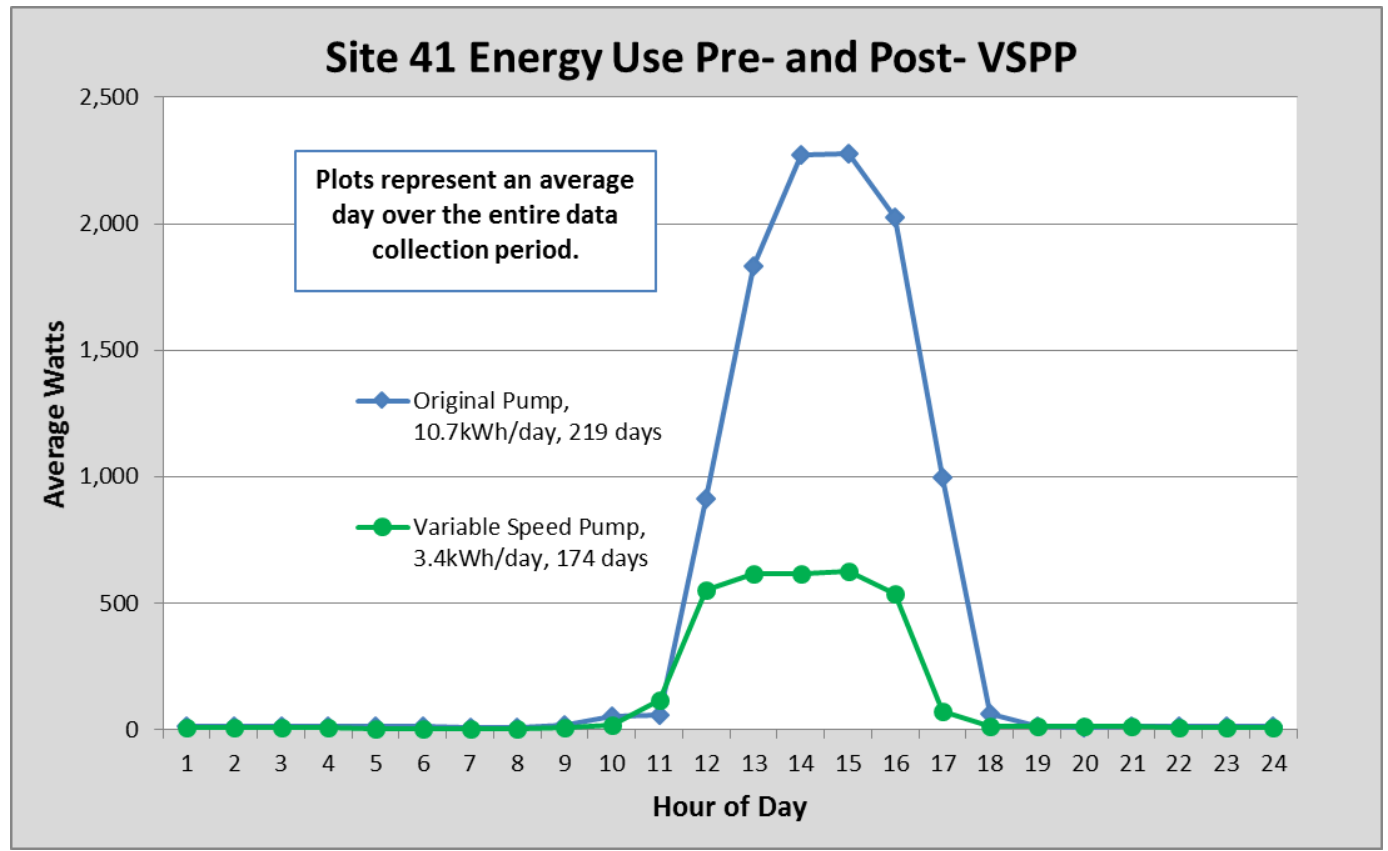

Figure 86. Average time-of-day pool pump demand at Site 41 as originally found (blue) and after VSPP retrofit (green)

\subsection{Evaluation of Site 44}

Pre-retrofit monitoring of the 1.5-hp single-speed pump was conducted for 214 days (November 15, 2012-June 16, 2013). Run time during this period averaged 7.3 hours/day with an average peak draw of $1.78 \mathrm{~kW}$, resulting in an average daily energy use of $12.9 \mathrm{kWh}$ (Table 45). Run time of the single-speed pump was reduced to 5.6 hours/day during the shallow retrofit period, resulting in a $24 \%$ measured savings with average daily energy use reduced to $9.9 \mathrm{kWh}$ during a period of 575 days (June 18, 2013-January 13, 2015).

Table 45. Measured Pool Pump Energy for Site 44

\begin{tabular}{lcccccc}
\hline & $\begin{array}{c}\text { Monitored } \\
\text { (days) }\end{array}$ & $\begin{array}{c}\text { Run Time } \\
\text { (hours/day }\end{array}$ & $\begin{array}{c}\text { Average } \\
\text { (kWh/day) }\end{array}$ & $\begin{array}{c}\text { Energy } \\
\text { Savings }\end{array}$ & $\begin{array}{c}\text { Average } \\
\text { kW Draw }\end{array}$ & $\begin{array}{c}\text { Demand } \\
\text { Savings }\end{array}$ \\
\hline $\begin{array}{l}\text { 1.5-hp one-speed } \\
\text { pump }\end{array}$ & 214 & 7.3 & 12.9 & & 1.78 \\
$\begin{array}{l}\text { Adjusted schedule } \\
\text { New variable-speed }\end{array}$ & 575 & 5.6 & 9.9 & $24 \%$ & 1.77 & $-1 \%$ \\
pump & 174 & 6.2 & 2.6 & $80 \%$ & 0.42 & $76 \%$ \\
\hline
\end{tabular}

Note: Electric demand (kW draw) values are based on hourly energy use measurements and determined here by dividing average $\mathrm{kWh} /$ day by run-time hours.

A VSPP and new filter were installed on January 14, 2015. The post-retrofit evaluation period, ending July 7, 2015, resulted in an 80\% reduction in measured energy use and $76 \%$ lower 
average hourly demand compared to the pre-retrofit scenario, as shown in Figure 87. The 3-hp Pentair VSPP ran the equivalent of 6.2 hours/day at the average peak draw of $0.42 \mathrm{~kW}$ with an average energy use of $2.6 \mathrm{kWh} /$ day during the 6-month post-retrofit period. When all hours of run time are included, the pump was active at various speeds for approximately 8 hours/day.

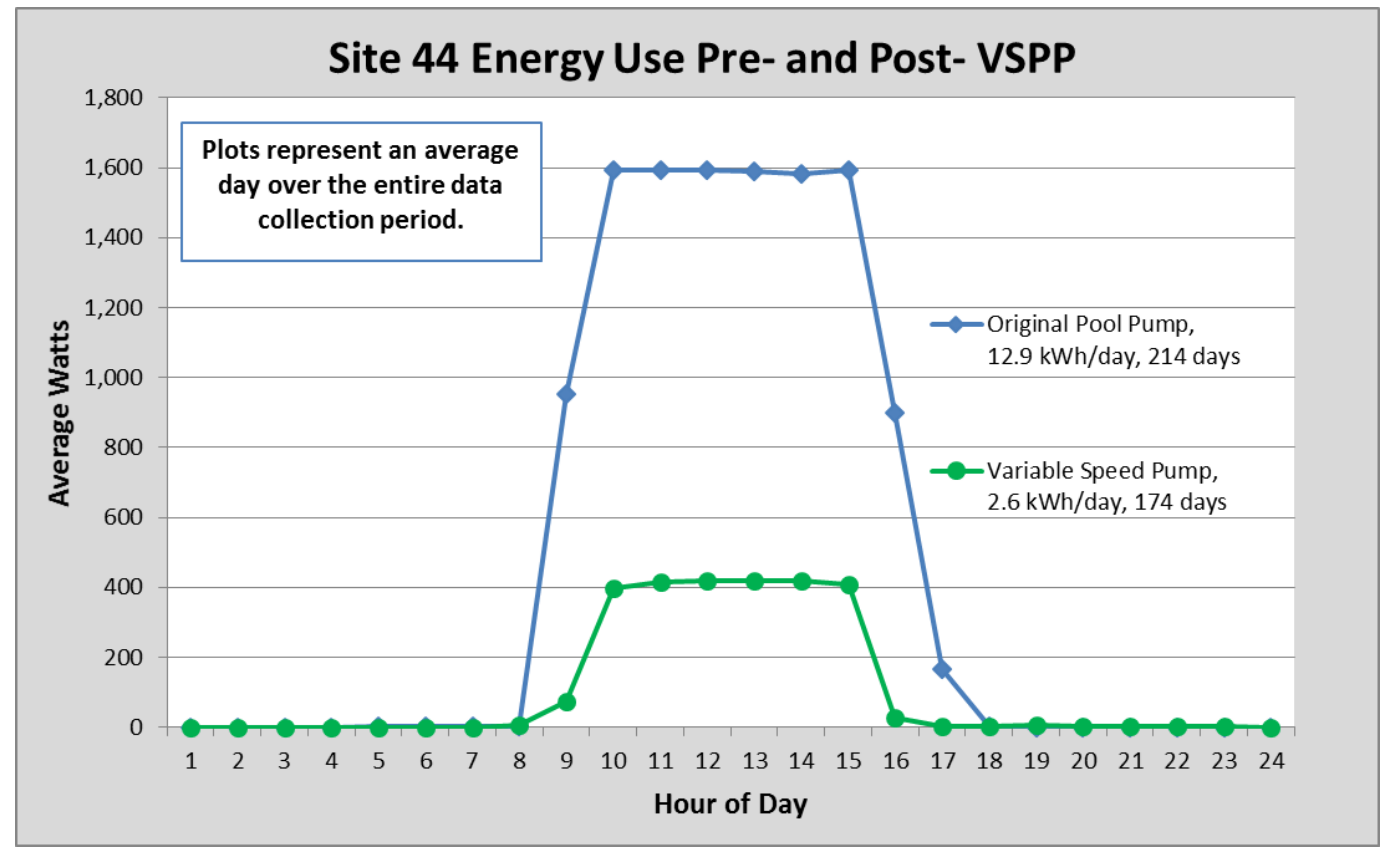

Figure 87. Average time-of-day pool pump demand at Site 44 as originally found (blue) and after VSPP retrofit (green)

\subsection{Summary Savings and Cost Analysis}

The energy use savings among the five VSPP installations were large, averaging 69\% and 2,846 $\mathrm{kWh}$ /annually or $7.8 \mathrm{kWh} /$ day. Savings at the individual sites ranged from $49 \%-80 \%$ and $4.9-$ $10.3 \mathrm{kWh} /$ day. Average hourly demand was typically reduced by approximately $70 \%$, except for one home with a $120-\mathrm{V}$ (rather than typical $240-\mathrm{V}$ ) pump where demand was reduced by only $14 \%$.

Total costs of equipment and installation of each VSPP in Central Florida was $\$ 1,500$. The installer quoted a standard single-speed pool pump replacement at $\$ 650$ for a 1-hp unit. With a median savings from the five homes of $7.3 \mathrm{kWh} /$ day $(68 \%)$, annual cost savings at $\$ 0.12 / \mathrm{kWh}$ amounts to $\$ 320$. Assuming the incremental cost above the single-speed unit, this results in a rapid simple payback of 2.7 years and an annual rate of return of $38 \%$. Although the worst-case payback was 4 years at Site 28, sites 50 and 44 exhibited payback periods of less than 2 years.

\subsection{Variable-Speed Pool Pump Peak Reductions}

In an investigation of the VSPP's impact on peak summer and winter hours, HVAC power demand at the seasonal peak hours in 2014 were compared to those of 2015. Large reductions to utility coincident peak electrical demand were shown during summertime peak. Figure 88 compares the average demand during peak summer days for four of the retrofit sites ${ }^{28}$ for the

\footnotetext{
${ }^{28}$ Missing post-retrofit data for Site 44 prevented its inclusion in the peak summertime evaluation.
} 
pre-retrofit peak of July 28, 2014, and the post-retrofit peak of June 22, 2015, which shows a reduction of $1.08 \mathrm{~kW}$ or $86 \%$ between the peak hour from 4 p.m. to 5 p.m. The HVAC energy demand reduction for the day was $65 \%: 10.25 \mathrm{kWh}$ pre-retrofit and $3.54 \mathrm{kWh}$ post-retrofit.

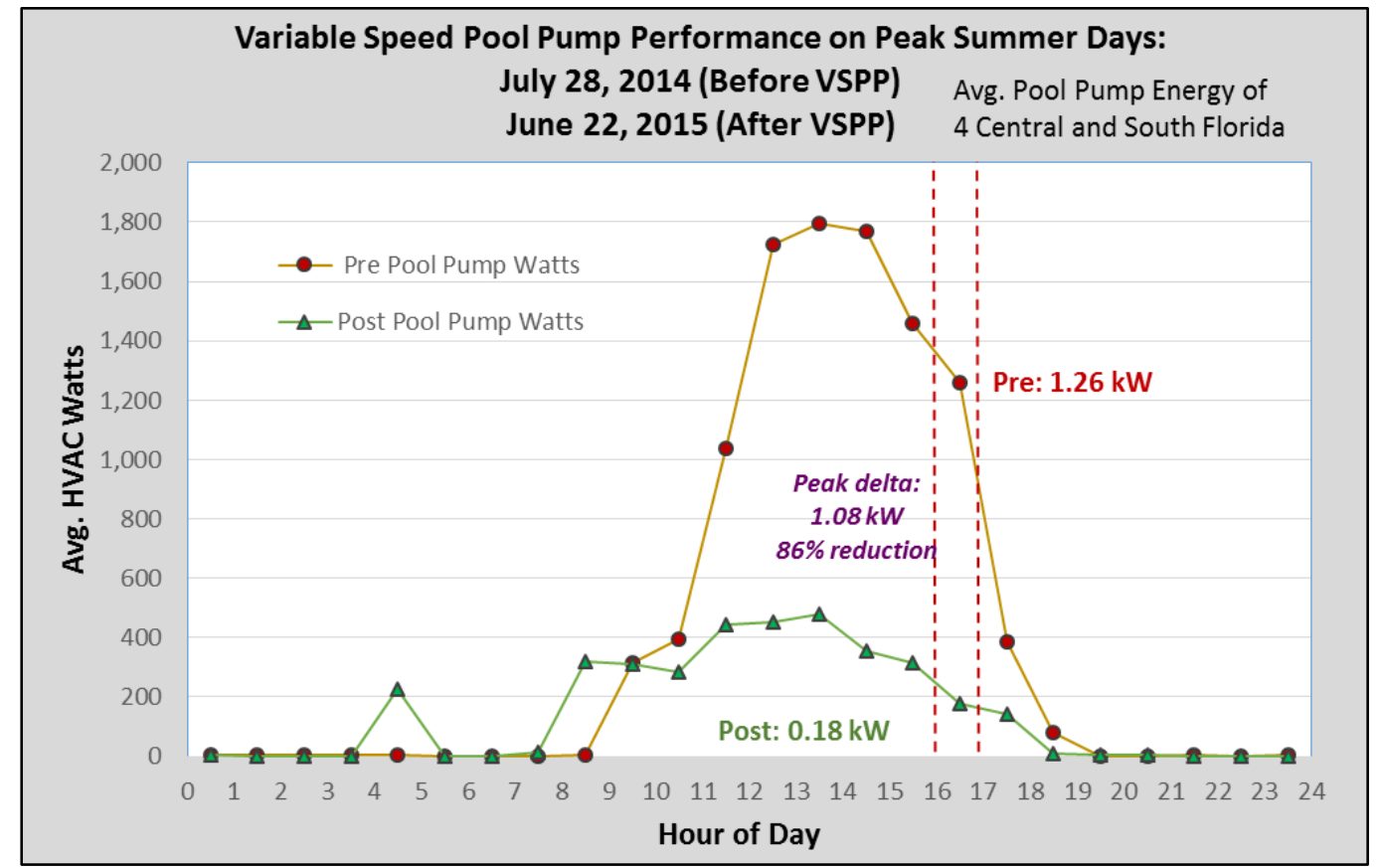

Figure 88. Summer peak: comparative analysis between pre- and post-retrofit demand on FPL's system peak summer day of 2014 and 2015

Electrical demand coincident to utility wintertime peak increased. Figure 89 compares the average pool pump demand during peak winter days for the five retrofit sites for the pre-retrofit peak of January 23, 2014 to the post-retrofit peak of February 20, 2015, which shows an increase of $0.27 \mathrm{~kW}$ between the peak hour from 7 p.m. to 8 p.m., a result of slightly longer pump run time post-retrofit. Still, the pool pump energy demand reduction for the day was large, at $63 \%$ : $8.81 \mathrm{kWh}$ pre-retrofit and $3.22 \mathrm{kWh}$ post-retrofit. 


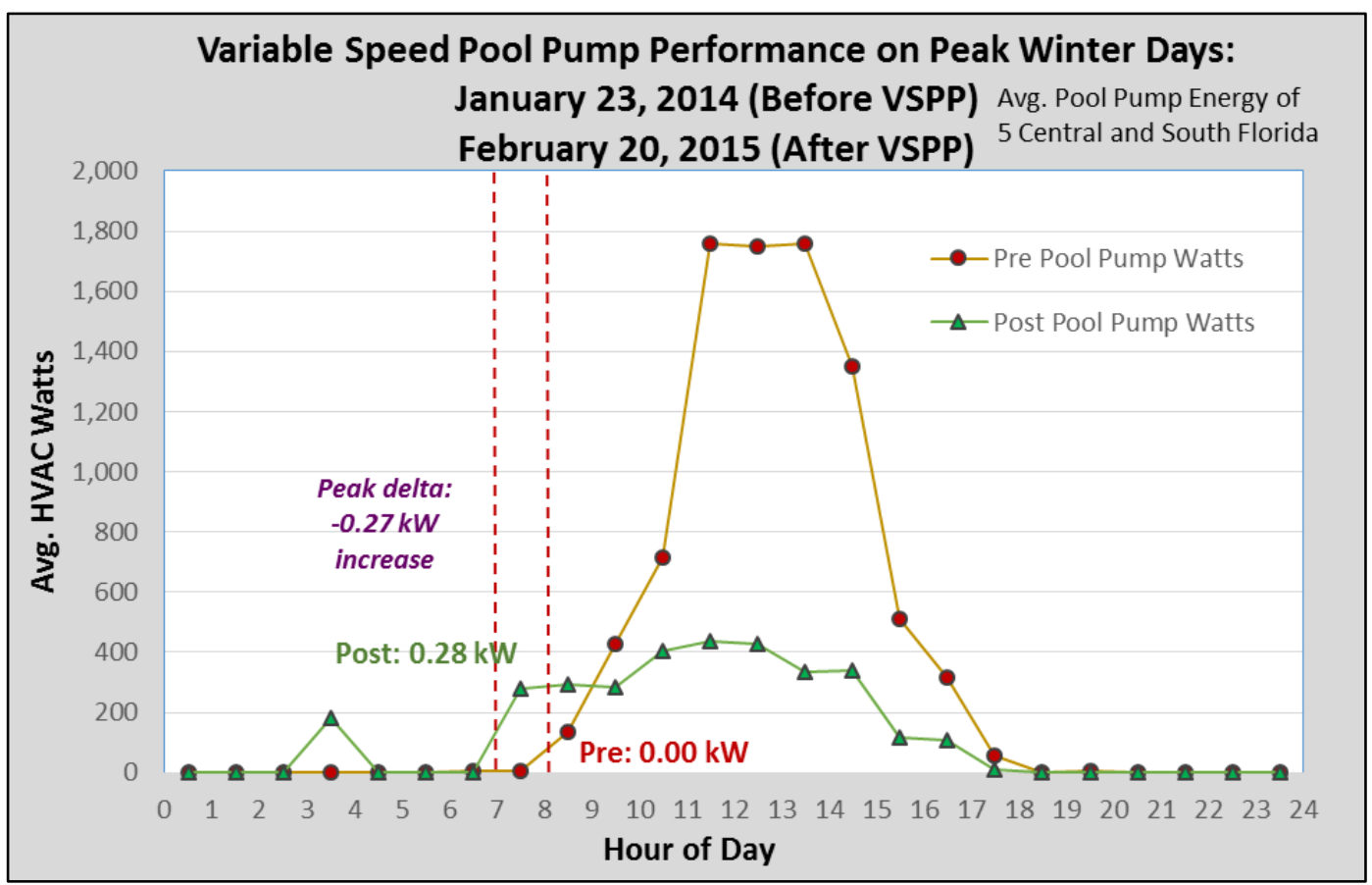

Figure 89. Winter peak: comparative analysis between pre- and post-retrofit demand on FPL's system peak summer day of 2014 and 2015 


\section{Conclusions}

Eight innovative technology energy-efficiency measures were installed in a subsample of the PDR project test sites under Phase II of the project. End-use savings and economics revealed several promising measures for inclusion into a refined deep-retrofit package; however, other measures, such as the EIFS and window retrofit, may be justifiable only based on increased comfort, acoustical advantages, or aesthetics. Findings for each energy-efficiency measure are summarized below.

\section{Supplemental Mini-Split Heat Pump}

The project involved the evaluation of ductless, 1-ton, variable-speed MSHPs with ratings of 25.5 SEER and 12 HSPF installed in the main living areas of 10 study homes as a supplemental system to the main central cooling air conditioner or heat pump. Results suggest cooling energy use savings of $32.7 \%(2,007 \mathrm{kWh} /$ year or $7.0 \mathrm{kWh} /$ day $)$, and heating energy use savings of $58.8 \%(390 \mathrm{kWh} /$ year or $6.8 \mathrm{kWh} /$ day $)$. The average percent heating energy reductions were significantly greater than cooling savings in the six homes with electric resistance central heating. Electrical demand reductions during peak system hour were $0.50 \mathrm{~kW}(16 \%)$ for summer and $2.06 \mathrm{~kW}(56 \%)$ for winter.

Measure economics, assuming a current installation price of approximately $\$ 3,900$, are potentially attractive, with a suggested payback of approximately 14 years and $7.3 \%$ annual rate of return. As the MSHP market continues to mature and installation costs fall, it is likely that the economics will further improve. A large added benefit to the consumer is a redundant heating and cooling system - highly desirable given the approximate $10 \%$ annual failure rate of central AC systems.

\section{Complete Central System Replacement with Inverter-Driven Heat Pump}

The project involved the evaluation of two different replacement schemes using (1) a ducted multi-split design and (2) a ducted mini-split design for complete replacements of a home's existing central system to allow insight into contrasting solutions. The multi-split installation involved one condenser and two fan coils: a ductless unit to condition the main living area and a ducted component to condition the rooms isolated from the main living space. Cooling energy use savings were impressive at $37.4 \%(2,250 \mathrm{kWh} /$ year or $7.8 \mathrm{kWh} /$ day $)$. Heating energy use showed negative savings of $1.0 \%(5 \mathrm{kWh}$ /year); however, large take-back was observed on interior temperature. HVAC electric demand reductions in the single case study during peak summer system hour were $0.24 \mathrm{~kW}(11 \%)$. Nevertheless, this installation highlighted unresolved comfort issues that need to be considered for widespread installation in the hot-humid climate.

The design for the second site consisted of one MSHP ducted to condition the whole house. Space-conditioning energy use savings were large, totaling $38.3 \%$ (1,548 $\mathrm{kWh} /$ year), comprising $29.2 \%(948 \mathrm{kWh} /$ year or $3.5 \mathrm{kWh} /$ day $)$ for cooling and $76.0 \%(601 \mathrm{kWh} /$ year or $6.7 \mathrm{kWh} /$ day $)$ for heating. Most significant are the improvements to the interior conditions - with take-back during both heating and cooling seasons and large reductions in $\mathrm{RH}$ (5.3\% drop) during the cooling season amid slightly higher ambient dew point conditions. Observed electrical demand reductions during peak summer system hour for the single ducted mini-split case study were 0.70 $\mathrm{kW}(41 \%)$. With an installation price of approximately $\$ 9,100$, measure economics are attractive if installed upon old system expiration. 


\section{Space-Coupled Heat Pump Water Heater}

The results from evaluations of eight homes retrofitted with an HPWH coupled to the conditioned living space show a median of $8.2 \%(1.1 \mathrm{kWh} /$ day $)$ space-cooling energy savings. Meanwhile, space-heating energy use showed negative savings of $8.9 \%(0.8 \mathrm{kWh} /$ day $)$, with considerable variation among homes.

The effect of space-coupled HPWH retrofits on DHW energy use was also evaluated. Among the six homes in which an electric resistance-type tank was replaced with an HPWH coupled to the conditioned space, average DHW energy savings were large: $53.3 \%$ (3.2 kWh/day). Two of the sites had HPWHs operating for a substantial amount of time prior to ducting, enabling the effect of the coupling on DHW energy use to be isolated. As expected, due to changing the HPWH heat source from warmer garage air to room temperature air and somewhat reducing system airflow, the coupling slightly reduced potential DHW energy savings from an uncoupled, garage-located HPWH by $0.4 \mathrm{kWh} /$ day. Electrical demand reductions during peak system hour were $0.23 \mathrm{~kW}$ (7\%) for summer and $0.18 \mathrm{~kW}(5 \%)$ for winter.

The cost to install the ducting to couple the HPWH to the conditioned space, inclusive of materials and labor, was $\$ 620$. Median annual cooling savings for the ducted sites was $412 \mathrm{kWh}$ or $\$ 49 /$ year, yielding a simple payback of approximately 13 years. An average heating energy penalty of $79 \mathrm{kWh}$ or $\$ 16$ cut these savings by one-third, yielding a simple payback in approximately the length of the expected 20 -year life span of the ducting. This penalty could be reduced or eliminated with a damper system enabling cold HPWH exhaust air to be diverted from the conditioned space during winter. Aside from the premium for the HPWH itself, there is no cost associated with locating an HPWH inside the conditioned space such as a utility room. In this case, net savings on space-conditioning and water heating are immediately realized. DHW energy savings for an interior-coupled HPWH in Florida is slightly less than for a garage-located HPWH due to a lower temperature heat source, but the space-conditioning energy savings outweighs the slight DHW energy loss.

\section{Exterior Insulation Finish System}

Space-cooling evaluation results for the single home receiving R-7.7 hr- $\mathrm{ft}^{2}-{ }^{\circ} \mathrm{F} / \mathrm{Btu}$ exterior wall insulation show cooling energy use reductions of $18.2 \%\left(5.0 \mathrm{kWh} /\right.$ day at $\left.80^{\circ} \mathrm{F}\right)$. Heating energy use was projected to increase by $12.3 \%\left(-1.0 \mathrm{kWh} /\right.$ day at $\left.50^{\circ} \mathrm{F}\right)$. However little significance can be attached to the results given the poor statistical models resulting from Florida's short and highly variable heating season. Given the variations in occupancy behavior and internal gains, the savings from EIFS in Florida will differ considerably for individual homes. With considerable variance from the regression analysis, a simulation evaluation was conducted to see how these varying factors might influence results and found:

- Annual savings from EIFS vary substantially depending on the interior thermostat setting.

- Preexisting exterior wall color has a very large impact on potential EIFS cooling energy savings.

- Preexisting shading from adjacent buildings, porches, blinds, and insect screens impacts EIFS savings, but these impacts are modest with light-colored walls. 
- Greater internal heat gains from appliance and plug loads reduce the savings from better wall insulation, particularly for cooling.

- At a cost approaching $\$ 20,000$, based either on measurement or simulation, the EIFS retrofit is not cost-effective for Florida homes; however, the measure may be justified by other benefits such as better interior comfort and a more stable interior temperature.

\section{Advanced Windows}

Advanced solar-control windows were installed in three homes (SHGC: 0.19-0.24; U-values $\left.0.27-0.30 \mathrm{Btu} / \mathrm{ft}^{2}-{ }^{\circ} \mathrm{F}\right)$. Analysis showed that cooling season energy savings ranged from $-4.8 \%$ to $27 \%\left(-0.7\right.$ to $6.9 \mathrm{kWh} /$ day at $\left.80^{\circ} \mathrm{F}\right)$ and heating energy savings of $6.8 \%\left(4.2 \mathrm{kWh}\right.$ at $\left.50^{\circ} \mathrm{F}\right)$ for the one home with heating season data available. A range in results is not unexpected given that the buildings varied in their degree of internal and external window shading, internal set points, and internal heat gains. A simulation evaluation was conducted to see how various factors such as occupancy behavior might be influencing results, and the findings include:

- Preexisting shading from adjacent buildings, porches, blinds, and insect screens has a very large impact on potential savings, reducing them by more than $50 \%$ relative to standard assumptions (which also includes interior shading).

- Greater internal gains from appliance and plug loads reduce the cooling energy savings from advanced windows because interior temperatures tend to be higher during nighttime hours when ambient temperatures are lower and heat loss is beneficial.

- The annual savings of advanced windows varies very significantly by the interior thermostat setting. Low cooling temperatures produce savings; temperatures higher than $78^{\circ} \mathrm{F}$ yield very low savings levels.

- Either based on the monitoring or the measurement, the cost, $\$ 8,000-\$ 10,000$, means that window retrofits are not cost-effective energy-efficiency strategies for Florida homes. This evaluation, however, did demonstrate the potential for a window retrofit to improve comfort with more stable indoor temperatures. Moreover, consumers overwhelmingly favor the measure based on improvements to house appearance, thermal comfort, and acoustic qualities.

\section{Smart Thermostat}

Evaluations of the 22 Nest thermostats installed as part of Phase II show average cooling energy savings of $9.6 \%(498 \mathrm{kWh} /$ year or $2.1 \mathrm{kWh} /$ day $)$ but with a very high degree of variation. The median savings were $6.3 \%(219 \mathrm{kWh} /$ year or $1.0 \mathrm{kWh} /$ day $)$. The analysis showed that 6 of 22 sites experienced negative savings, which was largely an artifact of pre-retrofit thermostat habits. On average, the positive savings were larger in magnitude than the absolute difference at sites that experienced negative savings. Space-heating savings from the Nest were also highly variable, particularly given the very short Florida winter heating season. Average savings were $9.5 \%(39 \mathrm{kWh} /$ year or $1.1 \mathrm{kWh} /$ day $)$, although the median was higher, at $18.5 \%(35 \mathrm{kWh} /$ year or $1.9 \mathrm{kWh} /$ day). Electrical demand reductions during peak system hour were $0.18 \mathrm{~kW}(7 \%)$ for summer and $0.25 \mathrm{~kW}(14 \%)$ for winter.

The economics reveal the Nest thermostat to be a promising low-cost retrofit measure. Simple payback for the installation of the $\$ 250$ Nest is estimated to be approximately 4 years with an 
annual rate of return of $24 \%$. The evaluations of two Lyric installations had highly disparate findings with no conclusive results, although consumer acceptance of the technology appeared more limited.

On a site-by-site basis, preinstallation thermostat behavior and willingness to use available Nest features made a difference for individual homes. For example, a site with a programmable thermostat that was effectively used prior to the retrofit cannot be expected to experience much savings. On the other hand, those with low levels of vacancy cannot be expected to achieve much energy reduction, and, in particular, defeating the "away" function appeared to affect savings adversely.

\section{Heat Pump Clothes Dryer}

Energy use savings were achieved among all eight homes that received an unvented condensing HPCD. The estimated median energy savings are $33.6 \%$ (264 kWh/year or $0.72 \mathrm{kWh} /$ day $)$, and average annual savings are $36.4 \%(308 \mathrm{kWh} /$ year or $0.85 \mathrm{kWh} /$ day $)$. ENERGY STAR ${ }^{\circledR}$ washing machines were installed along with the clothes dryer. The energy-efficient washing machines are likely removing more moisture from the laundry loads than the replaced washers, thus also contributing to these savings. Estimated utility coincident electrical demand reductions during peak summer system hour were $0.09 \mathrm{kWh}(48 \%)$.

With a current retail cost of $\$ 948$ for the dryer, there is only a minor premium on the HPCD compared to standard resistance models. With replacement at the end of dryer life and incremental cost the HPCD choice appears economically appealing, although it varies somewhat depending on the cost of the standard model. The incremental cost premium is falling as the market matures with increased competition, thus improving the economics of the HPCD measure.

Although the HPCD use less electricity than a standard resistance dryer, they still release a significant amount of heat from their operation. The unvented units that were located inside the home led to very high utility room temperatures and increases in cooling that may compromise identified savings. Thus, these unvented clothes dryers appear appropriate in Florida only if they will be installed outside of the conditioned space, typically in the garage. (Approximately onethird of dryers in the PDR project were located outside of the conditioned space.)

\section{Variable-Speed Pool Pump}

As a measure, the substitution of a VSPP for a standard constant-speed variety towered over the other measures in terms of both percentage and annual savings. Economics were also very compelling. An evaluation of the VSPPs installed in five homes showed $68 \%$ median savings ( $7.3 \mathrm{kWh} /$ day), ranging from $49 \%$ to $80 \%$ (4.9-10.3 kWh/day). Average hourly demand often occurring at or near the utility peak period was typically reduced by approximately $70 \%$. Annual cost savings amounted to $\$ 320$ assuming the $2,665 \mathrm{kWh} /$ year median savings of the five homes. Even given the high VSPP cost (\$1,500 installed), this made for an exceedingly rapid simple payback of 2.7 years and a $38 \%$ annual rate of return. Three similar retrofits analyzed under Phase I of the study showed even greater savings $(85 \%, 12.6 \mathrm{kWh} /$ day $)$, so the Phase II result is likely conservative. Electrical demand reductions during peak system hour were $1.08 \mathrm{~kW}(86 \%)$ for summer, but with a rise in winter demand of $0.27 \mathrm{~kW}$ due, at least in part, to a small sample 
size magnifying a schedule change. This appears to be a particularly important measure given Florida's 33\% saturation of homes with swimming pools with millions in operation.

\section{Phase I and Phase II Savings Summary}

The PDR project consisted of two phases. Under Phase I, a total of 56 homes received simple, pass-through retrofit measures including those for lighting (compact fluorescent and lightemitting diode lamps), domestic hot water (water heater tank wraps and low-flow showerheads), refrigeration (cleaning coils), pool pumps (reduction of operating hours), and the use of smart plugs for home entertainment centers. Ten of these homes received a deeper package with measures that included replacing air-source heat pumps, repairing ducts, and substituting conventional thermostats with learning thermostats. HPWHs were installed to reduce waterheating energy. Pool pumps were changed to variable-speed units, and ceiling insulation was augmented where deficient. Old and inefficient major appliances such as refrigerators and dishwashers were replaced with more efficient units. Table 46 summarizes the energy- and demand-savings results from the shallow and deep measures as well as the shallow-plus measures described in this report.

Table 46. Phase I and Phase II PDR Measures Evaluation Savings Summary

\begin{tabular}{|c|c|c|c|c|c|c|c|}
\hline \multirow[t]{2}{*}{ Option } & \multirow[b]{2}{*}{$n$} & \multicolumn{2}{|c|}{ Annual Energy Savings } & \multicolumn{2}{|c|}{$\begin{array}{c}\text { Summer Peak Demand } \\
\text { Savings }^{\mathrm{a}}\end{array}$} & \multicolumn{2}{|c|}{$\begin{array}{c}\text { Winter Peak } \\
\text { Demand Savings }\end{array}$} \\
\hline & & kWh & $\%$ & kWh & $\%$ & kWh & $\%$ \\
\hline Shallow Retrofit & 56 & & & & & & \\
\hline Space cooling & & 1,353 & $16 \%$ & 0.42 & $24 \%$ & $\mathrm{n} / \mathrm{a}$ & $\mathrm{n} / \mathrm{a}$ \\
\hline Space heating & & (629) & $-78 \%$ & $\mathrm{n} / \mathrm{a}$ & $\mathrm{n} / \mathrm{a}$ & $(0.11)$ & $-6 \%$ \\
\hline Lighting and other & & 664 & $22 \%$ & 0.24 & $42 \%$ & $(0.02)$ & $-6 \%$ \\
\hline Water heating & & 180 & $11 \%$ & 0.11 & $26 \%$ & 0.36 & $56 \%$ \\
\hline Pool pump & & 175 & $14 \%$ & 0.05 & $28 \%$ & 0.00 & $7 \%$ \\
\hline Whole-house & & 1,356 & $9 \%$ & 0.67 & $20 \%$ & 0.25 & $7 \%$ \\
\hline \multicolumn{8}{|c|}{ Deep Retrofit (Shallow and deep retrofit impacts are presented unless otherwise noted.) } \\
\hline Space cooling & 10 & 4,336 & $46 \%$ & 1.92 & $52 \%$ & $\mathrm{n} / \mathrm{a}$ & $\mathrm{n} / \mathrm{a}$ \\
\hline Space heating & 10 & 854 & $33 \%$ & $\mathrm{n} / \mathrm{a}$ & $\mathrm{n} / \mathrm{a}$ & 2.26 & $80 \%$ \\
\hline Water heating ${ }^{\mathrm{b}}$ & 8 & 1,924 & $69 \%$ & 0.26 & $100 \%$ & 0.32 & $34 \%$ \\
\hline Refrigerator & 3 & 471 & $42 \%$ & 0.06 & $48 \%$ & 0.02 & $19 \%$ \\
\hline Clothes dryer & 8 & 267 & $22 \%$ & 0.04 & $26 \%$ & 0.08 & $39 \%$ \\
\hline Dishwasher & 1 & 175 & $32 \%$ & $(0.27)$ & $\mathrm{n} / \mathrm{a}$ & - & $\mathrm{n} / \mathrm{a}$ \\
\hline Pool pump & 3 & 4,599 & $86 \%$ & 0.89 & $91 \%$ & $(0.09)$ & $\mathrm{n} / \mathrm{a}$ \\
\hline Whole-house & 10 & 7,067 & $38 \%$ & 1.96 & $39 \%$ & 2.71 & $60 \%$ \\
\hline \multicolumn{8}{|c|}{ Shallow-Plus (Percent savings are of HVAC energy unless otherwise noted.) } \\
\hline Supplemental MSHP & 10 & 2,397 & $34 \%$ & 0.50 & $16 \%$ & 2.06 & $56 \%$ \\
\hline Ducted MSHP & 2 & $2245 \& 1548$ & $35 \& 38 \%$ & $0.24 \& 0.70$ & $11 \% \& 41 \%$ & $\mathrm{n} / \mathrm{a}$ & $\mathrm{n} / \mathrm{a}$ \\
\hline Space-coupled HPWH ${ }^{\mathrm{C}}$ & 8 & 95 & $2 \%$ & 0.23 & $7 \%$ & 0.18 & $5 \%$ \\
\hline
\end{tabular}




\begin{tabular}{llcccccc}
\hline \multicolumn{1}{c}{ Option } & & Annual Energy Savings & $\begin{array}{c}\text { Summer Peak Demand } \\
\text { Savings }^{\mathrm{a}}\end{array}$ & \multicolumn{2}{c}{$\begin{array}{c}\text { Winter Peak } \\
\text { Demand Savings }\end{array}$} \\
\hline EIFSC $^{\mathrm{d}}$ & 1 & 913 & $17 \%$ & $\mathrm{n} / \mathrm{a}$ & $\mathrm{n} / \mathrm{a}$ & $\mathrm{n} / \mathrm{a}$ & $\mathrm{n} / \mathrm{a}$ \\
Advanced windows $^{\mathrm{d}, \mathrm{e}}$ & 3 & -231 & $-4 \%$ & $\mathrm{n} / \mathrm{a}$ & $\mathrm{n} / \mathrm{a}$ & $\mathrm{n} / \mathrm{a}$ & $\mathrm{n} / \mathrm{a}$ \\
Nest thermostat & 22 & 537 & $10 \%$ & 0.18 & $7 \%$ & 0.25 & $14 \%$ \\
HPCD $^{f}$ & 8 & 264 & $34 \%$ & 0.09 & $48 \%$ & $\mathrm{n} / \mathrm{a}$ & $\mathrm{n} / \mathrm{a}$ \\
VSPPg & 5 & 2,846 & $69 \%$ & 1.08 & $86 \%$ & $(0.27)$ & $\mathrm{n} / \mathrm{a}$ \\
\hline
\end{tabular}

${ }^{a}$ The shallow retrofit summer peak are surrogate Octobers dates, pre- and post-; the deep retrofit summer peak is for the deep retrofit only (excluding shallow), so results are conservative. Within the shallow-plus measures, a post-retrofit summer peak surrogate August date is used for the MSHP and Nest thermostat demand results. The HPCD is a 9-month pre-/post-comparison rather than of peak system hours.

${ }^{b}$ The water-heating energy-saving baseline includes partial post-retrofit (shallow), so results are conservative. Water heating had no post-retrofit peak summer hour demand in the HPWH segment.

${ }^{\mathrm{c}}$ Reported results are the HVAC savings (including negative space-heating savings) as well as the negative waterheating savings. HPWH savings are excluded. Negative space-heating savings could have been somewhat avoided had occupants used the installed damper to divert cold air during space heating.

${ }^{d}$ Percent HVAC savings are based on PDR average annual pre-retrofit space heating and space cooling, presented in Appendix A.

${ }^{\text {e }}$ Predicted space-cooling savings for the window retrofits ranged from (0.7) to $6.9 \mathrm{kWh} /$ day, depending on assumptions, and the median was $(0.5) \mathrm{kWh} /$ day.

${ }^{f}$ Dryer measure savings are as a percentage of dryer energy use. The potential impact from the washer's reduction in residual moisture content is ignored.

${ }^{\mathrm{g}}$ Pool pump measure savings are as a percentage of pool pump energy use. There was no pre-retrofit peak summer hour pool pump demand in the VSPP segment.

\section{Looking Forward}

Future research on the supplemental MSHP proposition is warranted. In addition to generating large energy savings, the supplemental MSHP showed an ability to improve interior conditions, albeit inconsistently from one site to the next. For the ducted multi- and mini-split concepts where the central system is displaced, the ducted mini-split concept appeared the more robust of the two strategies, with greater energy savings potential, based on available system SEER, and improved interior humidity control, albeit with the requirement for two or more such systems in a home.

Although the ducted multi-split concept has the attractiveness of lower cost, we found challenges for temperature and humidity control that must be addressed. In particular, refinement of these systems should be an objective for future research.

Additional research is also needed to investigate the optimum designs and the ideal set points for the competing mini-split systems (either supplemental or ducted) for different house designs as well as to track evolving economics for replacement scenarios at the end of the central system's life. Given the potential of this measure, such research is strongly encouraged.

An examination of the very favorable energy savings achieved by the HPCD remains incomplete. The unvented appliances release a significant amount of heat from their operation. Given the prevalence of dryers located inside homes, further research for the hot-humid climate should include an examination of the vented HPCDs. Based on findings here, we expect that such vented HPCD systems could provide significant benefits in Florida homes. 


\section{References}

Agnew, Patrick. FPL: “Ask the Expert,” Accessed February 10, 2016.

http://www.fplblog.com/ask-the-expert/can-smart-thermostats-save-me-money/?cid=ren0216AE.

Anello, Michael T., Danny S. Parker, John R. Sherwin, and Katie Richards. 2000. "Measured Impact of Advanced Windows on Cooling Energy Use." Paper presented at the 2000 ACEEE Summer Study on Energy Efficiency in Buildings, Pacific Grove, CA, August 20-25. http://aceee.org/files/proceedings/2000/data/papers/SS00_Panel1_Paper03.pdf.

American Society of Heating, Refrigeration and Air Conditioning Engineers. 2002. ASHRAE Guideline 14-2002 for Measurement of Energy and Demand Savings. Atlanta, GA. www.techstreet.com/ashrae/products/1645226.

Asfour et al. 2010. "Field Monitoring of Pool Pump Technologies." Ph.D. diss. University of Miami.

Barkaszi, Stephen, Jr., and Danny S. Parker. 1995. Florida Exterior Wall Insulation Field Test: Final Report (Technical Report, Florida Solar Energy Center, FSEC-CR-868-95). Oak Ridge, TN: Oak Ridge National Laboratory. www.fsec.ucf.edu/en/publications/html/FSEC-CR-868-95.

Brand, Larry. 1987. "Critical Needs Weatherization Research Project Final Report," Contract No. 5086-245-1352. Prepared for Governor's Energy Council, Harrisburg, PA (US) by the Gas Research Institute.

Colon, Carlos, and Danny S. Parker. 2013. Side-by-Side Testing of Water Heating Systems: Results from the 2010-2011 Evaluation (Technical Report, Florida Solar Energy Center, FSECRR-386-12). Golden, CO: National Renewable Energy Laboratory. www.fsec.ucf.edu/en/publications/pdf/FSEC-RR-386-12.pdf.

Colon, Carlos. Forthcoming. Side-by-Side Testing of Water Heating Systems: Results from the 2013-2014 Evaluation. Golden, CO: National Renewable Energy Laboratory.

Colon, Carlos, Eric Martin, and Danny S. Parker. Forthcoming. Effect of Ducted HPWH on Space Conditioning and Water Heating Energy Use-Central Florida Lab Home. Golden, CO: National Renewable Energy Laboratory.

Farrar-Nagy, Sara, Ren Anderson, C.E. Hancock, and Paul Reeves. 2000. "Impacts of Shading and Glazing Combinations on Residential Energy Use in a Hot Dry Climate." Paper presented at the 2000 ACEEE Summer Study on Energy Efficiency in Buildings, Pacific Grove, CA, August 20-25. www.nrel.gov/docs/fy00osti/28203.pdf.

Haberl, Jeff S., Charles Culp, and David E. Claridge. 2005. “ASHRAE's Guidelines 14-2002 for Measurement of Energy and Demand Savings: How to Determine What Was Really Saved by the Retrofit." Paper presented at the Fifth International Conference for Enhanced Building Operations, Pittsburgh, PA, October 11-13. http://esl.tamu.edu/docs/terp/2005/esl-ic-05-1050.pdf. 
Kotey, Nathan A., John L. Wright, Charles S. Barnaby, and Michael R. Collins. 2009. "Solar Gain through Windows with Shading Devices: Simulations versus Measurement." ASHRAE Transactions 115(2):18-30.

www.researchgate.net/publication/275212154_Solar_Gain_Through_Windows_with_Shading Devices Simulations Versus Measurements.

Levins, William P. 1988. Experimental Measurements of Heating Season Energy Savings from Various Retrofit Techniques in Three Occupied Houses (Technical Report, ORNL/CON-227). Oak Ridge, TN: Oak Ridge National Laboratory.

Lopes, Joseph S., and Patrick Agnew. 2010. "FPL Residential Thermostat Load Control Pilot Project Evaluation." Paper presented at the 2010 ACEEE Summer Study on Energy Efficiency in Buildings, Pacific Grove, CA, August 15-20. Proceedings of the 2010 ACEEE Summer Study on Energy Efficiency in Buildings 2:184-192.

http://aceee.org/files/proceedings/2010/data/papers/1953.pdf.

Manning, Marianne M., Mike C. Swinton, Frank Szadkowski, John Gusdorf, and Ken Ruest. 2007. The Effects of Thermostat Set-Back and Set-Up on Seasonal Energy Consumption, Surface Temperatures and Recovery Times at the CCHT Twin House Facility (Technical Report, NRCC48361). Ottawa, Ontario, Canada: Institute for Research in Construction, National Research Council Canada. www.healthyheating.com/downloads/Thermostats/nrcc48361.pdf.

Mazur, Christopher, and Ellen Wilson. 2011. "Housing Characteristics: 2010." (State Tables, p. 3-4). Washington, D.C.: U.S. Census Bureau.

https:/www.census.gov/prod/cen2010/briefs/c2010br-07.pdf.

Meier, Alan, Cecilia Aragon, Therese Peffer, Daniel Perry and Marco Pritoni. 2011. "Usability of Residential Thermostats: Preliminary Investigations.” Building and Environment. 46(10):1,891-1,898. www.sciencedirect.com/science/article/pii/S0360132311000874.

Nest. 2014. Energy Savings from Nest: The Impact of Having a Nest Learning Thermostat. (White Paper Summary). Palo Alto, CA: Nest Labs, Inc.

https://nest.com/downloads/press/documents/efficiency-simulation-white-paper.pdf.

Nest. 2015. Energy Savings from the Nest Learning Thermostat: Energy Bill Analysis Results. (White Paper Summary). Palo Alto, CA: Nest Labs, Inc.

https://nest.com/downloads/press/documents/energy-savings-white-paper.pdf.

Nevius, Monica J., and Scott Pigg. 2000. "Programmable Thermostats that Go Berserk? Taking a Social Perspective on Space Heating in Wisconsin." Paper presented at the 2000 ACEEE Summer Study on Energy Efficiency in Buildings, Pacific Grove, California, August 20-25. http://aceee.org/files/proceedings/2000/data/papers/SS00 Panel8 Paper19.pdf.

Nevius, Monica. 2000. “An Unexpected Setback for Programmable Thermostats.” Energy Design Update 20 (November):1-4. 
National Weather Service. 2014. "Requirements and Standards for Climate Observation." National Weather Service Instruction 10-1302, National Oceanic \& Atmospheric Administration, November 14. www.nws.noaa.gov/directives/sym/pd01013002curr.pdf.

Parker, D., K. Sutherland, D. Chasar, J. Montemurno, B. Amos, and J. Kono. 2016. Phased Retrofits in Existing Homes in Florida Phase I: Shallow and Deep Retrofits (Technical Report, DOE/GO-102016-4810). Washington, D.C.: U.S. Department of Energy, Energy Efficiency and Renewable Energy.

http://apps1.eere.energy.gov/buildings/publications/pdfs/building america/65327.pdf.

Parker, Danny S. 2002. "Research Highlights from a Large Scale Residential Monitoring Study in a Hot Climate." Proceedings of the International Symposium on Highly Efficient Use of Energy and Reduction of its Environmental Impact, Japan Society for the Promotion of Science, JPS-RFTF97P01002, Osaka, Japan, January 2002. (Also published as FSEC-PF369-02, Florida Solar Energy Center, Cocoa, FL: fsec.ucf.edu/en/publications/html/FSEC-PF-369-02/index.htm.)

Roberts, David, and Kerylyn Lay. 2013. Variability in Measured Space Temperatures in 60 Homes (Technical Report, NREL/TP-5500-58059). Golden, CO: National Renewable Energy Laboratory. www.nrel.gov/docs/fy13osti/58059.pdf.

Smith, Stanley K., and Mark House. 2006. "Snowbirds, Sunbirds and Stayers: Seasonal Migration of Elderly Adults in Florida." Journal of Gerontology 61B(5):S232-S239. http://econpapers.repec.org/scripts/search.pl? $\mathrm{adv}=\mathrm{true} ; \mathrm{wp}=\mathrm{on} ; \mathrm{art}=\mathrm{on} ; \mathrm{soft}=\mathrm{on} ; \mathrm{mh}=100 ; \mathrm{ph}=10 ; \mathrm{sor}$ $\mathrm{t}=$ rank; $\mathrm{kwp}=$ true; $\mathrm{kw}=$ Snowbirds, + Sunbirds, + and + Stayers $:+$ Seasonal + Migration + of + Elderly $+\mathrm{Ad}$ $\underline{\text { ults }+ \text { in }+ \text { Florida }}$

Vastamaki, Raino, Irmeli Sinkkonen, and Cecelia Leinonen. 2005. "A Behavioural Model of Temperature Controller Usage and Energy Saving." Personal and Ubiquitous Computing 9(4):250-259. http://dl.acm.org/citation.cfm?id=1081778. 


\section{Appendix A: Estimating Florida Residential End Uses in the PDR Sample}

An important objective in the second year of project monitoring was to evaluate average end-use loads in the phased deep retrofit (PDR) sample as a method to evaluate residential end-use loads within the Florida Power \& Light Company (FPL) service territory. To make the estimates, the entire year of 2013 was used to evaluate loads in the PDR sample. Although 60 homes were included in the original sample, 5 homes were lost before the end of 2013, and the 10 deep retrofit homes had to be eliminated from the sample because it was important to estimate heating and cooling at each home to determine how to split them into the respective heating, ventilating, and air-conditioning end-use loads. The average measured consumption for 2013 was 41.7 $\mathrm{kWh}$ /day, but consumption would have been an estimated $43.7 \mathrm{kWh} /$ day if the shallow retrofit program had not taken place.

Respective heating and cooling loads were separated by obtaining the hourly heating, cooling and air handling unit loads for each of the 8,760 hours; regressing the heating and cooling loads against the outdoor temperature in that location; and then finding the best balance temperature yielding the most reliable estimate of the split. ${ }^{29}$

\section{Averaged End-Use Consumption}

\section{Heating and Cooling}

The measured heating and cooling for each site was examined against the outdoor temperature in that location to determine the balanced point for each home. The averaged measured heating was $275 \mathrm{kWh}$ year (range: 0-1812 kWh); whereas cooling in the same sample averaged 5,205 $\mathrm{kWh}$ (range: 2,475-10,692 kWh). The key adjustment was to cooling from the influence of the lighting retrofit. As shown in our analysis within the shallow retrofits, the lighting retrofit reduced average space cooling by approximately $16 \%$ due to the reduction in released heat and also a measured $0.6^{\circ} \mathrm{F}-8^{\circ} \mathrm{F}$ increase in the thermostat set temperature. This had to then be reduced by the portion of the cooling occurring after the shallow retrofits took place. This was done by estimating the cooling degree days for 2013 and then estimating the fraction after the shallow retrofits were installed. This evaluation showed $83 \%$ of the cooling in that year; thus, the final adjustment to the raw cooling numbers was to increase them by $13 \%$ based on what was measured.

The interaction of the lighting retrofit did not have to be applied to the heating numbers because the shallow retrofits were installed after the heating season was over and the lack of cold weather the following autumn (checked with heating degree days) made adjustments unnecessary.

The estimates for many of the end uses were taken directly from the averages of the 45 shallow homes in the monitored sample with complete data. Values for some end uses, however, had to be adjusted given influences observed on space conditioning from the shallow retrofits, which were in place for an average of $65 \%$ of the year during the year. These are reproduced below showing the averages, standard deviation, minimum, and maximums.

\footnotetext{
${ }^{29}$ For the regression analysis, sites were matched to weather data for Daytona (Site 12), Ft. Lauderdale (33, 34, 35, 45), and Melbourne (all others).
} 
Table A-1. Average Raw kWh/day for Sites by End Uses in PDR Sample for 2013

\begin{tabular}{|c|c|c|c|c|c|}
\hline Uariable & Obs & Mean & Std. Dev. & Mi n & Max \\
\hline whol se & 45 & 32.04444 & .26317 & & \\
\hline $\begin{array}{r}\text { whol ehouse } \\
\text { hpoomp }\end{array}$ & $\begin{array}{l}45 \\
45\end{array}$ & $\begin{array}{l}41.70889 \\
12.95111\end{array}$ & $\begin{array}{r}12.69737 \\
6.30435\end{array}$ & $\begin{array}{r}15.7 \\
2.7\end{array}$ & \\
\hline ahu & 45 & 2.255556 & 1.484091 & & \\
\hline $\begin{array}{r}\text { waterheater } \\
\text { druer }\end{array}$ & 45 & $\begin{array}{l}4.531111 \\
2.013333\end{array}$ & $\begin{array}{l}1.888821 \\
1.360748\end{array}$ & 1.4 & 8. \\
\hline range & 45 & .7533338 & .4020402 & .2 & \\
\hline & 43 & :2906977 & .22553 & & \\
\hline $\begin{array}{l}\text { fridge1 } \\
\text { fri dge? }\end{array}$ & 45 & $\begin{array}{l}2.373333 \\
1.602222\end{array}$ & $\begin{array}{r}.7764722 \\
2.0115\end{array}$ & 1.3 & \\
\hline spare 1 & 45 & 1.382222 & 2.668613 & 0 & \\
\hline spare? & 45 & .6577778 & 1.324505 & 0 & \\
\hline spares & 45 & . 6777778 & 1.453818 & 0 & \\
\hline spare4 & 45 & 6177778 & 2.614756 & 0 & 16 \\
\hline pool pump & 45 & 04444 & 4.527289 & 0 & \\
\hline mai nhomeent & 43 & $\frac{1.713953}{7.25333}$ & 1. 074727 & $1 \cdot 3$ & \\
\hline temp & 45 & 74.86889 & 1.930123 & 67.4 & 78 \\
\hline rh & 45 & 58.98889 & 4.487874 & 47.6 & \\
\hline i ncompl ete & 45 & & & O & \\
\hline pool & 45 & & 4840903 & 0 & \\
\hline $\begin{array}{l}\text { huac } \\
\text { mi soel }\end{array}$ & $\begin{array}{l}45 \\
45\end{array}$ & & $\begin{array}{l}6.791586 \\
.4170362\end{array}$ & 3.9 & \\
\hline & & & & & \\
\hline
\end{tabular}

To estimate the end uses for typical FPL customers, we had to make adjustments to the data to reflect differing saturation levels as well as the fact that shallow retrofits were in place for the homes more than $65 \%$ of the year. (Some end uses - notably, lighting, water heating, swimming pool pumps, and refrigerators, were affected by the shallow retrofits.)

\section{Water Heating}

Water heating averaged $4.53 \mathrm{kWh} /$ day in the overall sample of 45 homes (range: $1.4-8.7$ $\mathrm{kWh} /$ day), although it was estimated that the average water-heating loads were reduced by 0.29 $\mathrm{kWh} /$ day $^{30}$ (due to the hot water tank wraps and the smaller portion that had showerhead changeouts), resulting in a corrected average of $4.82 \mathrm{kWh} /$ day or approximately $1,760 \mathrm{kWh} /$ year. Note that one of the shallow homes (Site 39) already had a heat pump water heater (HPWH) installed on audit, and this was not removed in the sample because it could easily represent the saturation of these appliances in the field.

\section{Clothes Dryer}

The standard electric-resistance clothes dryer was a major appliance energy end use in the PDR study, averaging $2.01 \mathrm{kWh}$ day (range: $0.3-7.6 \mathrm{kWh} /$ day) or $734 \mathrm{kWh} /$ year. Previous monitoring studies in Florida have found an average consumption closer to $890 \mathrm{kWh} / \mathrm{year}$, so it may be that dryer energy use has fallen by approximately $20 \%$ because modern clothes washers remove more residual water from laundry (Parker 2002).

\section{Lighting}

Lighting was strongly influenced by the lighting retrofit largely done in March 2013. A total of 3,597 lamps were changed, and $66 \%$ of the lamps were found to be incandescent of halogen bulbs (30\% were compact fluorescent lamp (CFL), and 4\% were light-emitting diode (LED) types). As shown in the report on the shallow retrofits, the lighting retrofit saved an average of

\footnotetext{
${ }^{30}$ Estimate is the mean of the 30 -day pre- and post- estimates $(0.5 \mathrm{kWh} /$ day $)$ and the October estimate $(0.4$ $\mathrm{kWh} /$ day) evaluated throughout $65 \%$ of the year.
} 
$1.9 \mathrm{kWh} /$ day per household with $56 \%$ of the lighting fixtures changed out. The average connected lighting load changed from $2.7 \mathrm{~kW}$ to $1.3 \mathrm{~kW}$ within the study so that each $\mathrm{kW}$ change in the connected lighting load saved $1.36 \mathrm{kWh} /$ day. These ratios can then be used to estimate the initial lighting consumption before the lamps were changed.

The unchanged lighting consumption is then $2.7 \mathrm{~kW} * 1.36=3.67 \mathrm{kWh} /$ day, which intrinsically includes the fact that $34 \%$ of lighting fixtures were already of the more efficient CFL and LED types.

\section{Ceiling Fan and Plug Loads}

Ceiling fans, computers, plugs loads, and many home electronic loads are captured in the "lightsother" category in the statistical summary above; thus, their consumption level would be $7.25 \mathrm{kWh}-3.67 \mathrm{kWh}=3.58 \mathrm{kWh} /$ day. The range of plug loads was tremendous, however: 0.8 $23 \mathrm{kWh} /$ day.

\section{Spares}

So-called spare loads are major submetered electrical loads that defy conventional classification. These include home offices, large computer systems, second and third televisions, window or wall air conditioners, well pumps, home yard ponds and fountains, portable and indoor spas, home aquariums, wine coolers, gaming consoles, and a plugged-in recreational vehicle. Most houses had at least two spare loads, which averaged $3.30 \mathrm{kWh} /$ day, but with very large variability $(0-18.2 \mathrm{kWh} /$ day $)$.

\section{Home Entertainment}

The main home entertainment center or main television was monitored at each house. These often included peripherals such as cable boxes, digital video disc players, and stereo systems. These averaged $1.71 \mathrm{kWh}$ per day (range: $0.3-5.7 \mathrm{kWh} /$ day).

\section{Swimming Pools}

Swimming pool pump energy averaged $8.73 \mathrm{kWh} /$ day $(4.5-14.3 \mathrm{kWh} /$ day) in the 16 homes in the PDR shallow retrofit sample. Swimming pools were strongly influenced by the retrofits as operating hours were cut, but the savings quickly eroded as operating hours were set back close to previous schedules; thus, the 30 -day pre-/post-reduction was $2.68 \mathrm{kWh} /$ day, but this dropped to $0.23 \mathrm{kWh} /$ day by October. With the pool retrofits in place for an average of $75 \%$ of the year, this means that the pool pump load should be approximately $0.95 \mathrm{kWh} /$ day higher if the retrofit had not taken place, or $9.68 \mathrm{kWh} /$ day. FPL estimates that the saturation of pools in the FPL service territory to be $33 \%$, which was used to estimate the influence in the mixed sample. Note that one of the pool pumps in the study was the variable-speed type, which the deep retrofits showed would cut pool pumping energy by $70 \%$ or more (Asfour et al. 2010).

\section{Refrigerators}

All homes had a primary refrigerator, which was measured to use $2.37 \mathrm{kWh} /$ day (range: $1.3-4.3$ $\mathrm{kWh} /$ day), representing $865 \mathrm{kWh}$ of annual loads. As shown in a later, more detailed analysis, we found that the measured refrigerator energy use in Florida's warmer homes averaged approximately $25 \%$ more than indicated by the energy-use label —at least for the older units 
examined in our study. Even more importantly, many homes had a second refrigerator or freezer that was often older and located in the garage or utility room.

To estimate the end uses for the typical FPL customer, we had to make adjustments to the differing saturation levels for second refrigerators in the PDR vs. FPL samples. After the saturation issue with the second refrigerator/freezer was addressed, the Florida Solar Energy Center did another systematic reevaluation of the Refrigerator 2 circuit, which resulted in some small changes (two home offices, a wine cooler, and attic fan were behaving as second refrigerators). These end uses were then rightfully placed in the spares category.

After critical examination, the PDR sample showed that $60 \%$ of the homes had a second refrigerator or separate freezer. We compared this to Itron's 2010 Home Energy Survey (HES) for FPL, showing a total saturation of refrigerators and freezers of 39\% (16\% second refrigerators, $23 \%$ separate freezers). The lower saturation in the FPL service territory was then used to lower the end-use load estimates to be in line with the FL-HES survey data. ${ }^{31}$

Once corrected for FPL's lower saturation, the average addition to the average FPL customer profile of the second refrigerator or freezer was $1.07 \mathrm{kWh} /$ day; however, our data showed that if a customer has a second refrigerator or separate freezer, that unit will use considerably more power $(3.13 \mathrm{kWh} /$ day) than the main refrigerator $(2.37 \mathrm{kWh}$ /day). Consumption was also highly variable. In our year-long evaluation, we measured that separate freezers tend to use a lot more electricity.

\section{Final End-Use Characterization}

Based on the detailed calculations above, we created three pie charts showing the energy end-use breakout by pool ownership_-which makes a large difference in measured consumption:

- Average end-use energy use for FPL single-family residential customers

- Average electricity end uses for FPL single-family customers without pools

- Average electricity end uses for FPL single-family customers with pools.

\footnotetext{
${ }^{31}$ Corina Jump to Craig Muccio, "Saturation of Freezers in 2010 Home Energy Survey," Itron, March 24, 2015.
} 


$\begin{array}{lrr}\text { End-Use } & \mathrm{kWh} \text { /day } & \mathrm{kWh} / \mathrm{yr} \\ \text { Heating } & 0.75 & 274 \\ \text { Cooling } & 16.11 & 5,880 \\ \text { DHW } & 4.82 & 1,759 \\ \text { Dryer } & 2.01 & 734 \\ \text { Range } & 0.75 & 274 \\ \text { Dishwasher } & 0.29 & 106 \\ \text { Refrig } & 2.37 & 865 \\ \text { Refrig2 } & 1.07 & 391 \\ \text { MainTV } & 1.71 & 624 \\ \text { Pool_pump } & 3.19 & 1,164 \\ \text { Spares } & 3.34 & 1,219 \\ \text { Lighting } & 3.67 & 1,340 \\ \text { Plugs \& Fans } & 3.58 & 1,307 \\ & & \\ & 43.66 & 15,936\end{array}$

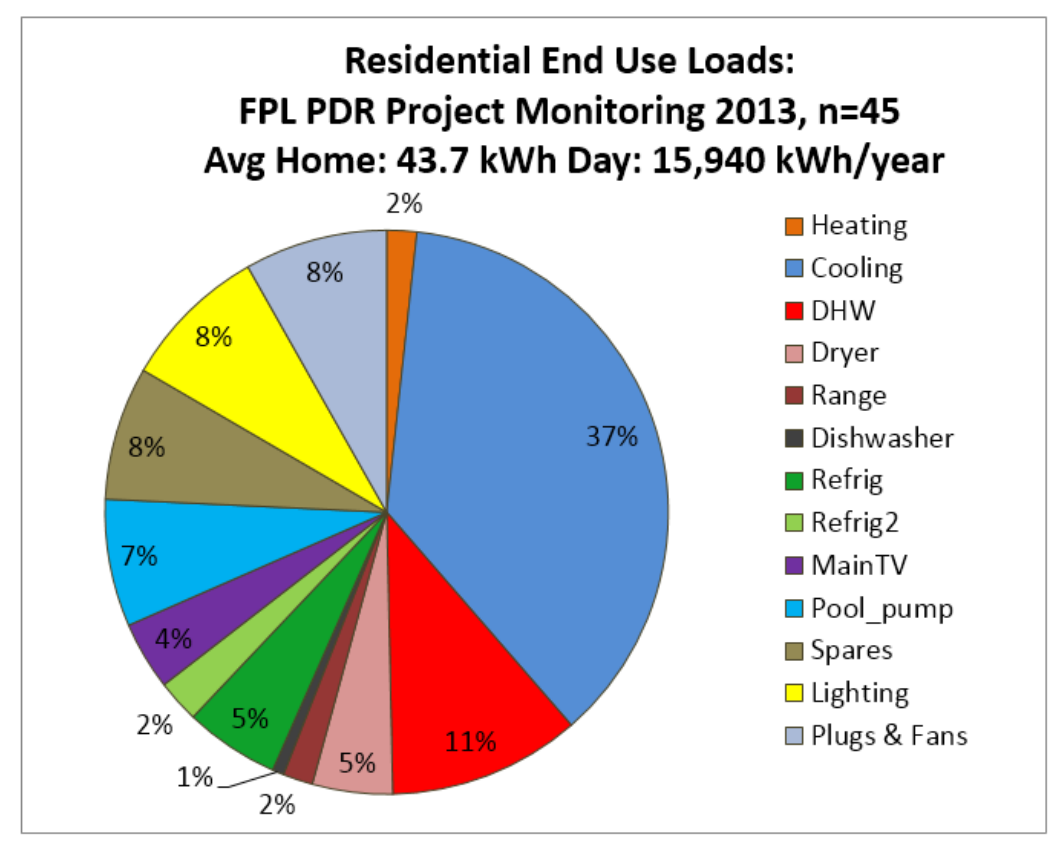

Figure A-1. Estimated end uses of FPL residential homes (mixed): 2013

$\begin{array}{lrr}\text { End-Use } & \mathrm{kWh} / \text { day } & \mathrm{kWh} / \mathrm{yr} \\ \text { Heating } & 0.75 & 274 \\ \text { Cooling } & 16.11 & 5,880 \\ \text { DHW } & 4.82 & 1,759 \\ \text { Dryer } & 2.01 & 734 \\ \text { Range } & 0.75 & 274 \\ \text { Dishwasher } & 0.29 & 106 \\ \text { Refrig } & 2.37 & 865 \\ \text { Refrig2 } & 1.07 & 391 \\ \text { MainTV } & 1.71 & 624 \\ \text { Pool_pump } & 0 & - \\ \text { Spares } & 3.34 & 1,219 \\ \text { Lighting } & 3.67 & 1,340 \\ \text { Plugs \& Fans } & 3.58 & 1,307 \\ & & \\ & 40.47 & 14,772\end{array}$

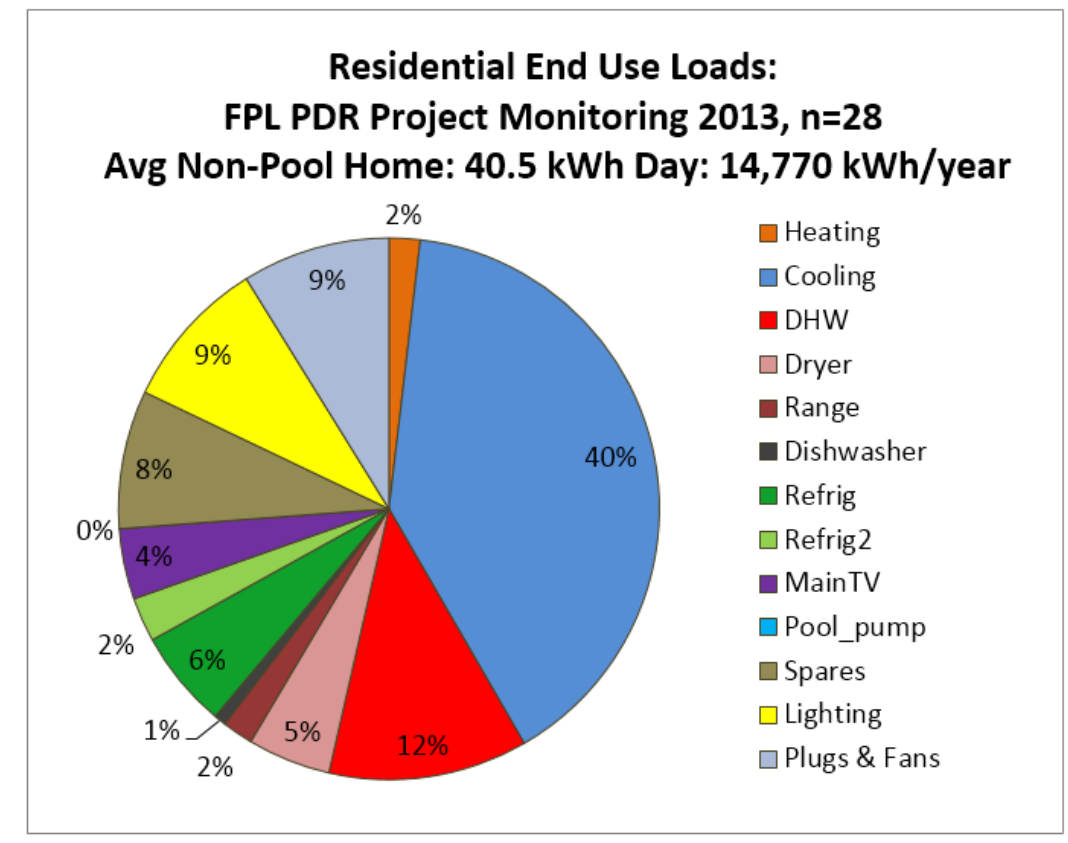

Figure A-2. Estimated end uses of FPL residential homes (non-pool homes): 2013 


$\begin{array}{lrr}\text { End-Use } & \mathrm{kWh} / \text { day } & \mathrm{kWh} / \mathrm{yr} \\ \text { Heating } & 0.75 & 274 \\ \text { Cooling } & 16.11 & 5,880 \\ \text { DHW } & 4.82 & 1,759 \\ \text { Dryer } & 2.01 & 734 \\ \text { Range } & 0.75 & 274 \\ \text { Dishwasher } & 0.29 & 106 \\ \text { Refrig } & 2.37 & 865 \\ \text { Refrig2 } & 1.07 & 391 \\ \text { MainTV } & 1.71 & 624 \\ \text { Pool_pump } & 9.68 & 3,533 \\ \text { Spares } & 3.34 & 1,219 \\ \text { Lighting } & 3.67 & 1,340 \\ \text { Plugs \& Fans } & 3.58 & 1,307 \\ & & \\ & 50.15 & 18,305\end{array}$

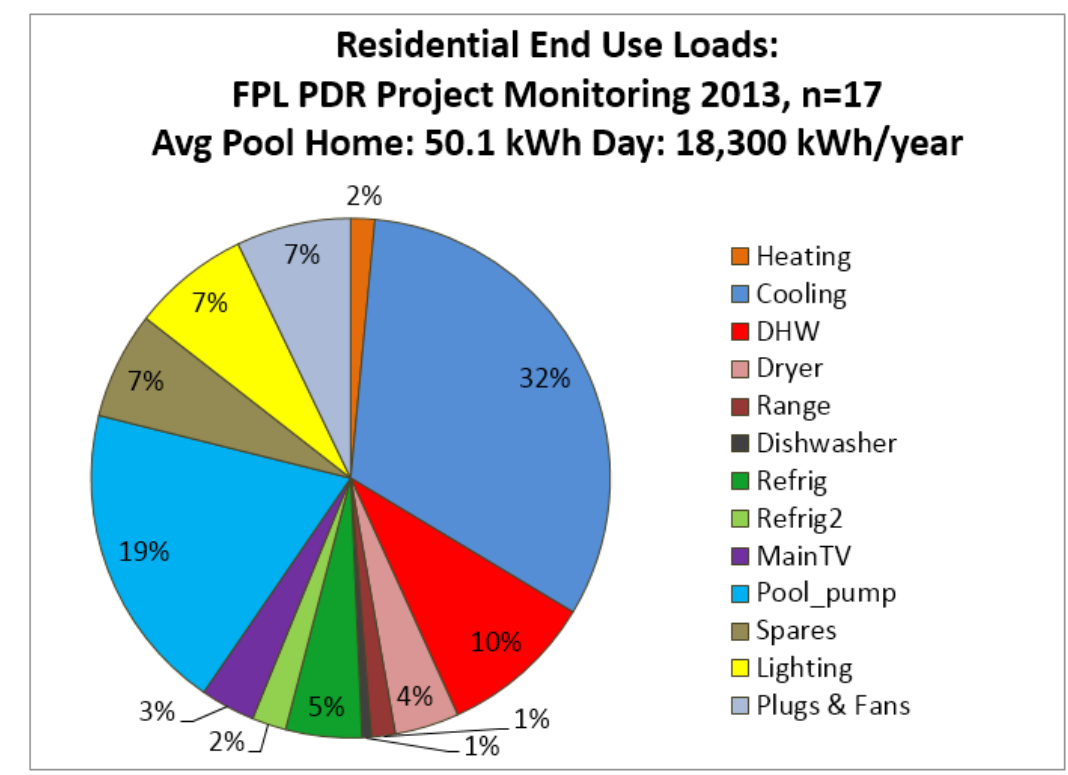

Figure A-3. Estimated end uses of FPL residential homes (pools): 2013

\section{Implications for Future Residential Loads in the FPL Service Territory}

There are implications from what we observed in the PDR project for the changing utility electrical loads in Florida. The evaluated data indicates that lower future residential electrical loads are likely in residences in the FPL service territory. We summarize the evidence and trends below:

- Saturation of CFL and LED lighting was approximately 34\% in the audits of the PDR homes, but this is changing rapidly in Florida homes. For instance, the 2006 HES showed only $6 \%$ CFL lamps in single-family homes in the FPL service territory, but this had grown to $20 \%$ in only 4 years for the 2010 survey. As incandescent fixtures are replaced with LED light sources, the lighting energy end use is certain to fall and will tend to reduce space cooling at the same time. In the PDR project, we saw that changing out all available lighting fixtures reduced space cooling by approximately $13 \%$ - both coming from reduced heat released indoors but also from slightly relaxed interior thermostat settings. At the same time, space-heating loads are increased; but because they are fairly low to begin with, this is a small influence. The net effect will be that not only will lighting energy use in Florida homes be reduced by approximately $2 \mathrm{kWh} /$ day, cooling energy will also be reduced by a similar amount.

- Swimming pool pump energy will also fall with the increased saturation of more efficient pool pumps that are now required by state code. ${ }^{32}$ For homes that have swimming pools, pool pumping represents the second largest electrical load $(\sim 10 \mathrm{kWh} /$ day $)$, and variablespeed pool pumps (VSPPs) will often cut this end use by $70 \%$ or more. Market saturation of the more efficient pumps may play a large role in load changes for Florida homes. The

\footnotetext{
32 "FS 553.909 (4) Residential swimming pool filtration pumps and pump motors manufactured and sold on or after December 31, 2011, for installation in the state must comply with the requirements of the Florida Energy Efficiency Code for Building Construction." This essentially requires either two-speed pool pumps or VSPPs.
} 
new regulations for pool pumps larger than 1 horsepower will play a role in the changing saturation of these technologies.

- Any increase in the saturation of HPWH will serve to cut water-heating loads by 2-3 $\mathrm{kWh}$ /day per household adopting these systems. This technology is likely to be appealing in Florida given that a byproduct of their operation is cooling the space wherein they are located - often a garage or utility room. However, given the size constraints and incremental cost, the saturation of HPWH in Florida homes may be slow during the near term. A reasonable guess is a $20 \%$ saturation achieved during the next decade.

- As average air-conditioner efficiency changes with federal regulations from 13 to 14 $\mathrm{Btu} / \mathrm{Wh}$, it can be expected that cooling energy use will drop by approximately $10 \%$ during the next decade - or $1.5 \mathrm{kWh} /$ day. Because of air-conditioner replacement rates, much of the cooling equipment stock will change during that period.

- Against these reductions to energy use, there is little reason to believe that plug loads will fall; on the contrary, despite increases to appliance efficiency, they will likely increase with the greater saturation of home electronics, computers, gaming stations, etc., of all types. A reasonable expectation is a $2-\mathrm{kWh}$ /day increase during the decade. This may, however, be somewhat ameliorated by new standards for cable and satellite set-top boxes, which are now major loads in Florida homes. (In the $2010 \mathrm{HES}, 86 \%$ of homes had a digital video recorder, set-top box, or satellite box at home. These typically draw 15-30 Watts year-round).

- On balance, unless electric vehicles become popular in Florida (a distinct possibility), it can be expected from the above that combined impacts will lead average household electricity use to fall from $44 \mathrm{kWh} /$ day to $\sim 38 \mathrm{kWh} /$ day by 2025 . As shown in trends during the last few years, the expectation is that conventional loads such as cooling, water heating, and pool pumping will continue to fall while nonconventional loads (home electronics) grow. 


\section{Appendix B: Regressions from Analysis of Supplemental Mini- Split Heat Pump Installations}

Coefficients are in $\mathrm{kWh} /$ day.

Site 3: Balance point: $65^{\circ} \mathrm{F}$ cooling and heating

Cooling: pre-: $-178.1+2.64$ (Tamb); post-: $-140.8+2.05$ (Tamb)

Heating: pre-: 16.3-0.23 (Tamb); post-: 18.0-0.27(Tamb)

Site 5: Balance point: $64^{\circ} \mathrm{F}$ cooling and heating

Cooling: pre-: $-337.1+5.02$ (Tamb); post-: $-266.9+3.87$ (Tamb)

Heating: pre-: 192.8-3.01 (Tamb); post-: 82.2-1.29(Tamb)

Site 12: Balance point: $65^{\circ} \mathrm{F}$ cooling and heating

Cooling: pre-: $-174.5+2.57$ (Tamb); post-: $-155.4+12.26$ (Tamb)

Heating: pre-: 68.6-1.08(Tamb); post-: 61.7-0.97 (Tamb)

Site 16: Balance point: $70^{\circ} \mathrm{F}$ cooling; $63^{\circ} \mathrm{F}$ heating

Cooling: pre-: $-279.1+3.89$ (Tamb); post-: $-217.1+3.02$ (Tamb)

Heating: pre-: 81.8-1.19(Tamb); post-: 48.6-0.82(Tamb)

Site 21: Balance point: $69^{\circ} \mathrm{F}$ for cooling and heating

Cooling: pre-: $-111.0+1.65$ (Tamb); post-: -91.3+1.29(Tamb)

Heating: pre-: 124.0-1.90 (Tamb); post-: 9.2-0.12 (Tamb)

Site 23: Balance point: $69^{\circ} \mathrm{F}$ for cooling and heating Cooling: pre-: $-311.5+4.43$ (Tamb); post-: $-179.9+2.59$ (Tamb) Heating: pre-: 196.4-2.85 (Tamb); post-: 65.7-0.94 (Tamb)

Site 24: Balance point: $64^{\circ} \mathrm{F}$ for cooling and heating Cooling: pre-: $-144.1+2.17$ (Tamb); post-: $-130.9+2.00$ (Tamb) Heating: pre-: 111.8-1.78 (Tamb); post-: 41.4-0.63 (Tamb)

Site 27: Balance point: $69^{\circ} \mathrm{F}$ cooling and heating

Cooling: pre-: $-295.8+4.38$ (Tamb); post-: $-185.1+2.73$ (Tamb)

Heating: pre-: 214.1-2.91 (Tamb); post-: 98.0-1.35(Tamb)

Site 54: Balance point: $65^{\circ} \mathrm{F}$ for cooling - no heating evaluation possible Cooling: pre-: $-172.1+2.57$ (Tamb); post-: -79.6 + 1.30 (Tamb)

Site 60: Balance point: $64^{\circ} \mathrm{F}$ for cooling and heating Cooling: pre-: $-105.3+1.59$ (Tamb); post-: $-91.1+1.33$ (Tamb) Heating: pre-: 110.8-1.73 (Tamb): post-: 33.6-0.53 (Tamb) 


\section{Appendix C: Regressions from Ducted Multi-MSHPs and Single- Ducted MSHPs}

Coefficients are in $\mathrm{kWh} / \mathrm{day}$.

\section{MSHP}

Site 11: Balance point: $67^{\circ} \mathrm{F}$ for cooling and heating

Cooling: pre-: $-171.8+2.47$ (Tamb); post-: $-96.5+1.41$ (Tamb)

Heating: pre-: 93.2 - 1.42(Tamb); post-: $107.7-1.66$ (Tamb)

\section{Ducted MSHP}

Site 61: Balance point: $70^{\circ} \mathrm{F}$ for cooling and heating

Cooling: pre-: $-142.1+1.96$ (Tamb); post-: $-72.8+1.04$ (Tamb)

Heating: pre-: $99.6-1.44(\mathrm{Tamb})$; post-: $16.0-0.22$ (Tamb) 


\section{Appendix D: Regressions from Analysis of Coupled Heat Pump Water Heaters}

Coefficients are in $\mathrm{kWh} /$ day.

Site 1: Balance point: $68^{\circ} \mathrm{F}$ for cooling

Cooling: pre-: $17.1+2.39$ (Tamb-Tint); post-: $15.2+2.23$ (Tamb-Tint)

Heating: $\mathrm{n} / \mathrm{a}$

Site 5: Balance point: $65^{\circ} \mathrm{F}$ for cooling; $65^{\circ} \mathrm{F}$ for heating

Cooling: pre-: 45.6 + 5.93(Tamb-Tint); post-: $44+6.13$ (Tamb-Tint)

Heating: pre-: 49.3-0.74(Tamb); post-: 194.8-3.05(Tamb)

Site 9: Balance point: $68^{\circ} \mathrm{F}$ for cooling; $64^{\circ} \mathrm{F}$ for heating

Cooling: pre-: $12.1+1.46$ (Tamb-Tint); post-: $10.6+1.37$ (Tamb-Tint)

Heating: pre-: 48.5-0.76(Tamb); post-: 99.3-1.56(Tamb)

Site 13: Balance point: $70^{\circ} \mathrm{F}$ cooling

Cooling: pre-: $7.4+1.42$ (Tamb-Tint); post-: $6.6+1.32$ (Tamb-Tint)

Heating: $\mathrm{n} / \mathrm{a}$

Site 26: Balance point: $62^{\circ} \mathrm{F}$ for cooling; $60^{\circ} \mathrm{F}$ for heating

Cooling: pre-: $10.5+1.20$ (Tamb-Tint); post-: $9.1+1.16$ (Tamb-Tint)

Heating: pre-: 37.8-0.62(Tamb); post-: 32.6-0.52(Tamb)

Site 50: Balance point: $65^{\circ} \mathrm{F}$ for cooling; $64^{\circ} \mathrm{F}$ for heating

Cooling: pre-: $21.4+2.47$ (Tamb-Tint); post-: $20.8+2.65$ (Tamb-Tint)

Heating: pre-: 153.89-2.42(Tamb); post-: 164.97-2.65(Tamb)

Site 51: Balance point: $70^{\circ} \mathrm{F}$ for cooling

Cooling: pre-: $15.8+2.35$ (Tamb-Tint); post-: $15+2.57$ (Tamb-Tint)

Heating: $\mathrm{n} / \mathrm{a}$

Site 56: Balance point: $69^{\circ} \mathrm{F}$ for cooling; $69^{\circ} \mathrm{F}$ for heating

Cooling: pre-: $21.8+3.06$ (Tamb-Tint); post-: $21.7+3.50$ (Tamb-Tint)

Heating: pre-: 159-2.35(Tamb); post-: 164.02-2.42(Tamb) 


\section{Appendix E: Regressions from Analysis of Exterior Insulation Finish Systems}

Coefficients are in $\mathrm{kWh} /$ day.

Balance point: $63^{\circ} \mathrm{F}$ for cooling; $62^{\circ} \mathrm{F}$ for heating

Cooling: pre-: $10.9+1.8$ (Tamb-Tint) +0.5 (Qint) +1.3 (Solar)

post-: $2.6+1.4($ Tamb-Tint $)+0.8($ Qint $)+1.6($ Solar $)$

Heating: pre-: 37.9-0.6(Tamb); post-: 40.2-0.6(Tamb) 


\section{Appendix F: Regressions from Analysis of Advanced Windows}

Coefficients are in $\mathrm{kWh} /$ day.

Site 23: Balance point: $69^{\circ} \mathrm{F}$ for cooling; $65^{\circ} \mathrm{F}$ for heating

Cooling: pre-: $-108.6+1.7$ (Tamb); post-: $-84.8+1.3$ (Tamb)

Heating: pre-: 263.5 - 4.0(Tamb); post-: 235.1 - 3.6(Tamb)

Site 25: Balance point: Evaluation period low temperature $=73^{\circ} \mathrm{F}$

Cooling: pre-: $-98.0+1.3$ (Tamb) +0.3 (Qint) +0.6 (Solar)

Cooling: post-: $-56.4+0.8(\mathrm{Tamb})+0.3(\mathrm{Qint})+0.8$ (Solar)

Site 54 (advanced windows only): Balance point: $63^{\circ} \mathrm{F}$ for cooling

Cooling: pre-: $-118.9+1.7$ (Tamb) +0.7 (Qint) +0.7 (Solar)

Cooling: post-: $-142.7+1.9$ (Tamb) $+0.6($ Qint $)+2.0($ Solar $)$

Site 54 (EIFS and advanced windows): Balance point: $63^{\circ} \mathrm{F}$ for cooling

Cooling: pre-: $16.6+2.4$ (Tamb-Tint) +0.6 (Qint) +0.6 (Solar)

Cooling: post-: $7.7+2.4$ (Tamb-Tint $)+01.0($ Qint $)+0.9$ (Solar) 


\section{Appendix G: Installed Nest Serial and Base Numbers}

\begin{tabular}{crr}
\hline $\begin{array}{c}\text { Site } \\
\text { No. }\end{array}$ & Seral Number & \multicolumn{1}{c}{ Base Number } \\
\hline 4 & 02AA01AC011406UJ & 02BA03AC021400NB \\
\hline 6 & 02AA01AC011405S9 & 02BA03AC521306DQ \\
\hline 11 & 02AA01AC251405SG & 02BA03AC251401UN \\
\hline 15 & 02AA01AC251407HO & 02BA03AC2514021D \\
\hline 17 & 02AA01AC251405NV & 02BA03AC231405F6 \\
\hline 18 & 02AA01AC25140A9A & 02BA03AC23140A1L \\
\hline 21 & 02AA01AC0114077S & 02BA03AC521304TX \\
\hline 22 & 02AA01AC251407L3 & 02BA03AC231409ZL \\
\hline 28 & 02AA01AC251408NU & 02BA03AC2414031D \\
\hline 29 & 02AA01AC011406X1 & 02BA03AC511308Q2 \\
\hline 34 & 02AA01AC231406E2 & 02BA03AC221401JY \\
\hline 35 & 02AA01AC281404R1 & 02BA03AC271400MC \\
\hline 42 & 02AA01AC22140C37 & 02BA03AC01140569 \\
\hline 45 & 02AA01AC2814022N & 02BA03AC281401E5 \\
\hline 47 & Not recorded & Not recorded \\
\hline 48 & 02AA01AC221409U4 & Not recorded \\
\hline 52 & 02AA01AC011404NC & 02BA03AC5213060R \\
\hline 58 & 02AA01AC0114034J & 02BA03AC011400PS \\
\hline 59 & 02SS01AC25140A8Z & 02BA03AC25140500 \\
\hline
\end{tabular}




\section{Appendix H: Regressions from Analysis of Smart Thermostats}

Nest

Coefficients are in $\mathrm{kWh} /$ day.

Site 4: Balance point: $65^{\circ} \mathrm{F}$ cooling and heating

Cooling: pre-:-75.8+1.15(Tamb); post-: $-89.8+1.33$ (Tamb)

Heating: pre-:38.6-0.59(Tamb); post-: 38.1-0.6(Tamb)

Site 6: Balance point: $70^{\circ} \mathrm{F}$ cooling and heating

Cooling: pre-:-91.7+1.25(Tamb); post-: $-82.7+1.13$ (Tamb)

Heating: pre-:49.8-0.75(Tamb); post-: 36.8-0.55(Tamb)

Site 11: Balance point: $68^{\circ} \mathrm{F}$ cooling and heating

Cooling: pre-:-181.4+2.58(Tamb); post-: $-184+2.6$ (Tamb)

Heating: pre-:88-1.32(Tamb); post-: 73.6-1.09(Tamb)

Site 12: Balance point: $65^{\circ} \mathrm{F}$ cooling; no heating regression

Cooling: pre-:-165.5+2.44(Tamb); post-: $-165.5+2.44(\mathrm{Tamb})$

Site 15: Balance point: $70^{\circ} \mathrm{F}$ cooling and heating

Cooling: pre-:-146.3+2.04(Tamb); post-: $-158+2.17$ (Tamb)

Heating: pre-:55.2-0.81(Tamb); post-: 33.5-0.49(Tamb)

Site 16: Balance point: $67^{\circ} \mathrm{F}$ cooling; no heating regression

Cooling: pre-:-176.5+2.5(Tamb); post-: $-186.5+2.67$ (Tamb)

Site 17: Balance point: $70^{\circ} \mathrm{F}$ cooling and $65^{\circ} \mathrm{F}$ heating

Cooling: pre-:-100.2+1.45(Tamb); post-: $-124+1.77$ (Tamb)

Heating: pre-:25.2-0.35(Tamb); post-: 23.1-0.32(Tamb)

Site 18: Balance point: $67^{\circ} \mathrm{F}$ cooling; no heating regression

Cooling: pre-:-174.3+2.48(Tamb); post-: $-118.7+1.68(\mathrm{Tamb})$

Site 21: Balance point: $66^{\circ} \mathrm{F}$ cooling and heating

Cooling: pre-:-178.2+2.59(Tamb); post-: -103.4+1.55(Tamb)

Heating: pre-:86.9-1.34(Tamb); post-: 156.7-2.47(Tamb)

Site 22: Balance point: $69^{\circ} \mathrm{F}$ cooling; no heating regression

Cooling: pre-:-198.1+2.76(Tamb); post-: $-160.6+2.24(\mathrm{Tamb})$

Site 24: Balance point: $60^{\circ} \mathrm{F}$ cooling; no heating regression

Cooling: pre-:-93.1+1.54(Tamb); post-: -92.2+1.5(Tamb)

Site 27: Balance point: $67^{\circ} \mathrm{F}$ cooling; no heating regression 
Cooling: pre-:-143.9+2.24(Tamb); post-: $-122.6+2.03$ (Tamb)

Site 28: Balance point: $67^{\circ} \mathrm{F}$ cooling and heating

Cooling: pre-:-206.5+2.92(Tamb); post-: $-166.7+2.37$ (Tamb)

Heating: pre-:75.7-1.17(Tamb); post-: 44.1-0.68(Tamb)

Site 29: Balance point: $68^{\circ} \mathrm{F}$ cooling and heating

Cooling: pre-:-219.3+3.08(Tamb); post-: -236.9+3.32(Tamb)

Heating: pre-:69.4-1.05(Tamb); post-: 44-0.67(Tamb)

Site 34: Balance point: $65^{\circ} \mathrm{F}$ cooling; no heating regression Cooling: pre-:-103.9+1.5(Tamb); post-: $-99.8+1.43$ (Tamb)

Heating: pre-:9.8-0.15(Tamb); post-: 58.3-0.93(Tamb)

Site 35: Balance point: $67^{\circ} \mathrm{F}$ cooling and heating

Cooling: pre-:-197.7+2.91(Tamb); post-: -227.5+3.29(Tamb)

Heating: pre-:97.8-1.45(Tamb); post-: 109.6-1.63(Tamb)

Site 42: Balance point: $65^{\circ} \mathrm{F}$ cooling and heating

Cooling: pre-:-77.4+1.18(Tamb); post-: $-70.8+1.13$ (Tamb)

Heating: pre-:163.2-2.51(Tamb); post-: 77.8-1.17(Tamb)

Site 45: Balance point: $68^{\circ} \mathrm{F}$ cooling; no heating regression

Cooling: pre-:-119.8+1.71(Tamb); post-: $-131.6+1.85$ (Tamb)

Site 47: Balance point: $66^{\circ} \mathrm{F}$ cooling; no heating regression

Cooling: pre-:-123.9+1.76(Tamb); post-: $-122.7+1.77$ (Tamb)

Site 48: Balance point: $66^{\circ} \mathrm{F}$ cooling and $64^{\circ} \mathrm{F}$ heating

Cooling: pre-:-165.2+2.37(Tamb); post-: $-147.7+2.16$ (Tamb)

Heating: pre-:110.4-1.74(Tamb); post-: 80.3-1.25(Tamb)

Site 50: Balance point: $61^{\circ} \mathrm{F}$ cooling; no heating regression

Cooling: pre-:-108.6+1.74(Tamb); post-: $-100+1.56$ (Tamb)

Site 52: Balance point: $69^{\circ} \mathrm{F}$ cooling and heating

Cooling: pre-:-21.6+0.31(Tamb); post-: $-20+0.29$ (Tamb)

Heating: pre-:19.9-0.29(Tamb); post-: 74.3-1.12(Tamb)

Site 56: Balance point: $70^{\circ} \mathrm{F}$ cooling and heating

Cooling: pre-:-210.9+2.96(Tamb); post-: $-180.4+2.52$ (Tamb)

Heating: pre-:160-2.35(Tamb); post-: 172.7-2.54(Tamb)

Site 58: Balance point: $69^{\circ} \mathrm{F}$ cooling and $63^{\circ} \mathrm{F}$ heating

Cooling: pre-:-222.7+3.11(Tamb); post-: -206.5+2.89(Tamb)

Heating: pre-:130.6-2.15(Tamb); post-: 65.1-1.07(Tamb) 
Site 59: Balance point: $67^{\circ} \mathrm{F}$ cooling and $63^{\circ} \mathrm{F}$ heating

Cooling: pre-:-210.6+3.01(Tamb); post-: $-157.7+2.24(\mathrm{Tamb})$

Heating: pre-:117.7-1.91(Tamb); post-: 145.6-2.43(Tamb)

\section{Lyric}

Site 43: Balance point: $62^{\circ} \mathrm{F}$ cooling; no heating regression

Cooling: pre-:-112.2+1.66(Tamb); post-: -107.2+1.64(Tamb)

Site 44: Balance point: $67^{\circ} \mathrm{F}$ cooling and heating

Cooling: pre-:-154+2.19(Tamb); post-: $-103.7+1.51$ (Tamb)

Heating: pre-:259.2-3.92(Tamb); post-: 204.9-3.13(Tamb) 


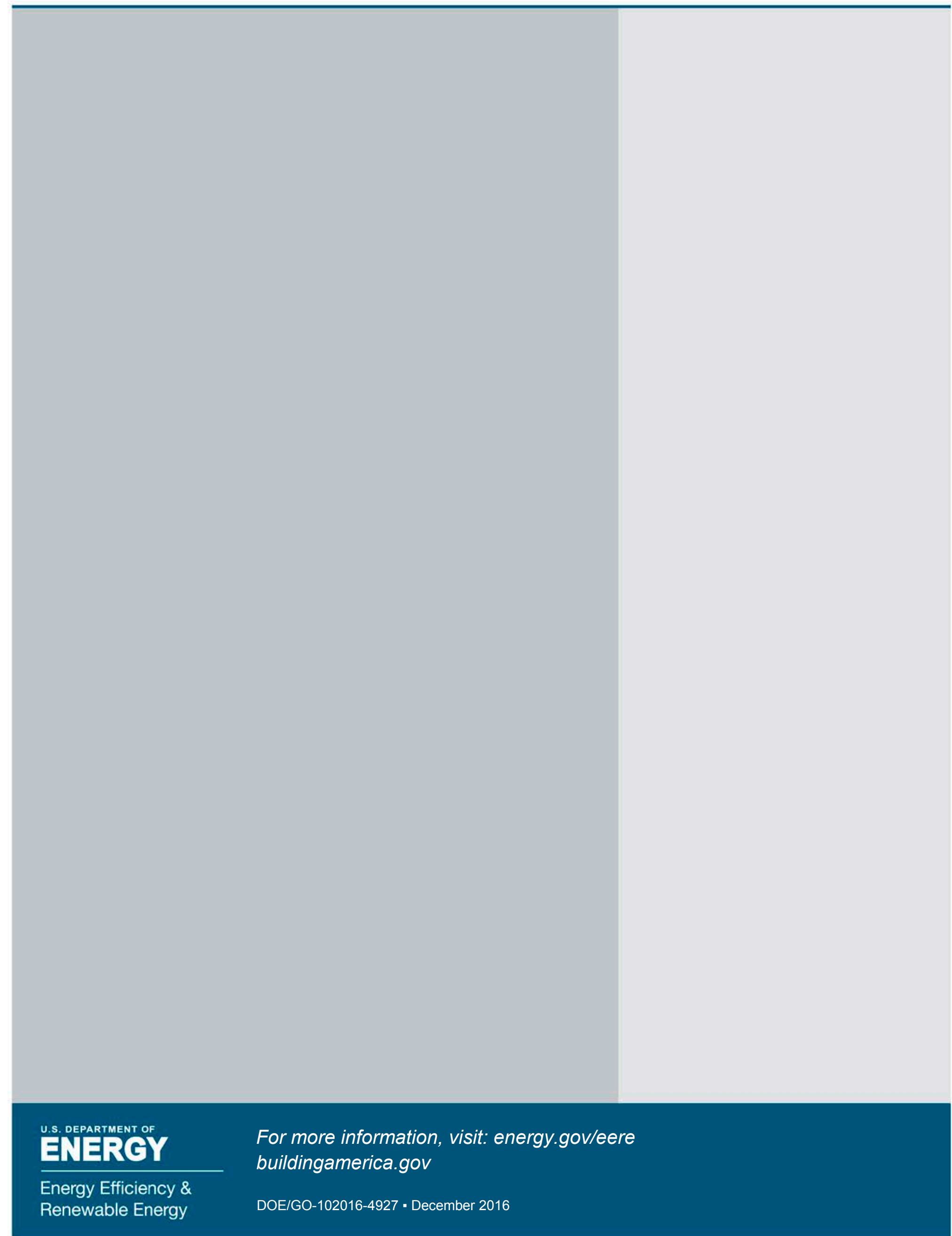

